"Direct threats require decisive action": An investigation on how levels of political conservatism change in the face of economic, natural and social threats.

\author{
By \\ Clara Brasiliana Ribeiro Cantal
}

\begin{abstract}
A thesis
Submitted to the Victoria University of Wellington in fulfilment of the requirements for the degree of

Doctor of Philosophy in Psychology
\end{abstract}

Victoria University of Wellington

2015 


\section{Abstract}

The extant literature has suggested that threatening time periods and situations can enhance people's political conservatism levels. This thesis provides a systematic examination of the impact of societal threat on political conservatism, and whether distinct types of threat (economic, natural, and social) differentially impact political conservatism. In particular, the present research examines two main competing hypotheses. The conservative shift hypothesis (Jost, Glaser, Kruglanski, \& Sulloway, 2003b) postulates that people become more politically conservative during/after threatening periods. The cultural worldview enhancement hypothesis (Pyszczynski, Solomon, \& Greenberg, 2003) postulates that people tend to cling more strongly to what they believe when their death is made salient, be it a more conservative or liberal political belief - we assume that societal threat could also make mortality salient, enhancing a held political worldview. Additionally, the present research also examines in more depth how societal threat impacts political conservatism. The dual-process mediation hypothesis suggests that the impact of societal threat on political conservatism happens via variables in the dual-process motivational (DPM; Duckitt, 2001) model, being differentially mediated by world beliefs (dangerous and competitive) and socio-political attitudes (rightwing authoritarianism and social dominance orientation). Finally and because the direct impact of threat on authoritarianism has been questioned (Feldman \& Stenner, 1997), the activation of authoritarianism by social threat hypothesis suggests an interaction between social threat and previous levels of right-wing authoritarianism in predicting political conservatism and variables in the DPM model. Seven empirical studies were carried out to test these hypotheses using different methodological designs. The correlational findings of Study 1 showed that the DPM model was useful in predicting political conservatism. The mix-method findings of Study 2A showed that economic, natural, and social threats have distinct psychological meanings. Based on these initial findings, two mix-method studies were conducted to develop textual (Study 2B) and pictorial (Study 2C) experimental stimuli depicting economic, natural and social threat scenarios plus a control scenario. Three experiments were then conducted to test the complete set of hypotheses: Study 3A was completed online with textual stimuli, Study 3B was completed in a lab with textual stimuli, and Study $3 \mathrm{C}$ was completed in a lab with pictorial stimuli. Overall, the experimental findings provided more support for the conservative shift hypothesis with participants showing greater conservative political orientation after the threat manipulation (compared to the control 
condition) in Study 3C. However, this effect did not generalise to other measures of political conservatism (right-wing political orientation, conservative voting intention and preference for political discourses of conservative parties). Additionally, some distinctions between threat types were observed. The dual-process mediation hypothesis was partially supported in Studies 3A and 3C. The threat manipulation impacted political conservatism indirectly via an increase in competitive world beliefs and an increase in RWA in Study 3A, while it impacted political conservatism via an increase in dangerous world beliefs and increases in right-wing authoritarianism and/or social dominance orientation in Study 3C. No empirical support was observed for both the cultural worldview enhancement and the activation of authoritarianism by social threat hypotheses. Overall, the present research suggests that it is possible to experimentally modify people's political conservatism using threat manipulation, that threat enhances (at least to some extent) political conservatism, and that this impact may be differentially mediated by variables in the DPM model. These conclusions are discussed in more depth along with limitations and future directions in the general discussion of the thesis. 


\section{Acknowledgements}

In the mystery of the endless

balances a planet.

And on the planet, a garden, and on the garden, a flowerbed;

on the flowerbed, a violet

and upon her, the whole day,

between the planet and the endless,

the wing of a butterfly...

During my undergraduate and masters degrees I was lucky enough to work with some amazing lecturers and professors who made me fall in love with research. Thank you Isolda Günther, Hartmut Günther and Luiz Pasquali for making me feel a bit of what you feel about research, teaching me to be curious about the world we are in, and showing me that research does matter. These lessons shall not be forgotten!

I would not have been capable of completing the $\mathrm{PhD}$ without the scholarship and support system provided by Victoria University of Wellington. I would like to thank Dr. Taciano Milfont for the support provided, knowledge shared, and for being patient when I was not. I would also like to thank Dr. Marc Wilson for guiding me through some of the studies and being my secondary supervisor. A big thank you also to Dr. Paul Jose for being so helpful with my data analysis questions - Your love for research is contagious! Thanks Al Benoja, Alana Hamill, Doug Drysdale, Jebi Jayapalan, Laura Dimock, Michael France, Nicola Panapa, Sam Akhir, Susan Cayless, and Wendy Ward for being so helpful all the time!

The making of this thesis was not an easy process, but some people inside and outside academia made my life brighter and my days more colourful. I would like to thank the CACR crowd for all the experience shared. Thank you Adrienne Girling, Ágnes Szabó, Carmen Leong, Claudia Recker, Laina Isler, Maree Kibblewhite, Miriam Schwarzenthal, Mohsen Joshanloo, Pollyane Diniz, Reneeta Mogan, Rochelle Stewart-Allen, Samantha Rae, and Tamara Qumseya - you provided warmth, support, and guidance on daily basis! A big thank you also to Paula Realman - Thanks for spending time with us querida!

I also had two fantastic office mates during this endeavour - Thank you Adrienne Girling and Sarah Goddard for being more than only office mates, being people to share and celebrate the day with! 
I would also like to thank my family, specially my mother (Bia), my siblings (Dri, Flávia, and Guila), my nieces/nephews (Hugo, Igor, Lelê, and Mamá), and my brother/sister in law (Naka and Dréia) for their unconditional support throughout the PhD course - My life with you is happier and more meaningful! Thanks Marina for coming over and reminding me of how great it is to be with family.

During my PhD course, I had two of the best flatmates ever. Thanks Christoph Hasenöhrl and Adriana Orsoni for being my flatmates and friends during one of the most maddening periods of my life - You are awesome (for bearing me)! My friends back home were also a big part of this accomplishment - our chats via Skype, Facebook and email were always plentiful and brightened my day! A special thanks to Tatiana Moreira, Zenith Delabrida, and Jamila Zgiet who happened to be where my conference was - during that conference leave I had the ultimate proof that space and distance can be warped! A special thanks also to Luh Barroncas for making the time to meet me in Auckland - You make me proud!

During my $\mathrm{PhD}$ course, a meaningful person walked away from my life. Dad, thank you for being there when I was not at my best and for loving me unconditionally. You will always be part of who I am and my accomplishments!

During my $\mathrm{PhD}$ course, a meaningful person walked into my life. Thank you Dan for being my partner in everything - I carry your heart in mine!

Now, onto the mystery of the endless! 


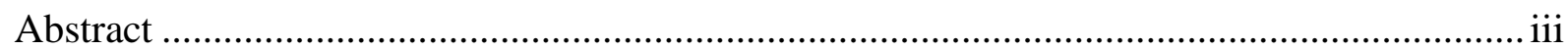

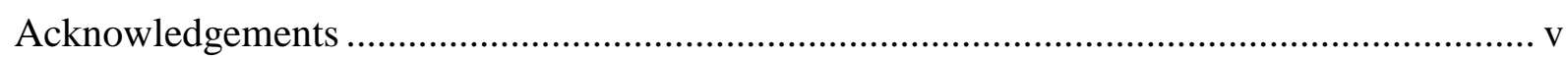

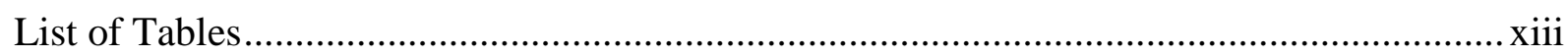

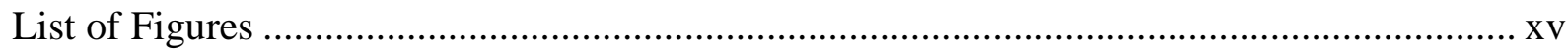

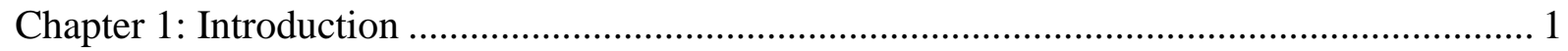

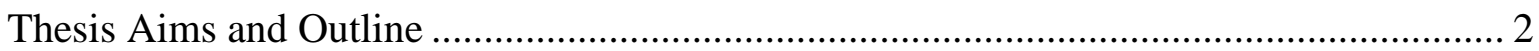

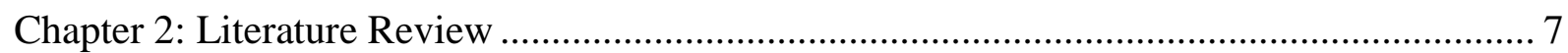

Models Including Threat as Part of the Understanding of Intergroup Behaviour................. 7

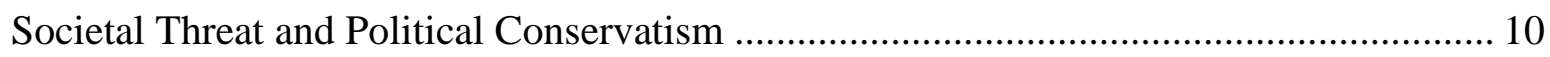

Mediators of the Impact of Societal Threat on Political Conservatism .............................. 13

Duckitt's (2001) Dual-Process Motivational Model ..................................................... 14

Threat Research Including Variables Described in the DPM Model ............................ 16

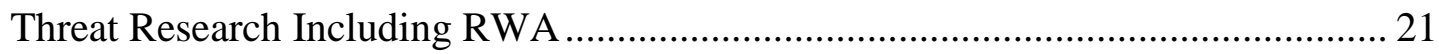

Societal Dimensions of Threat and the Prediction of Political Conservatism..................... 22

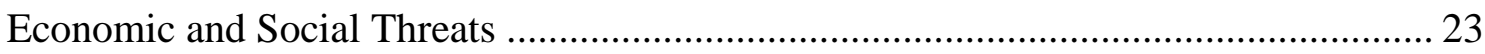

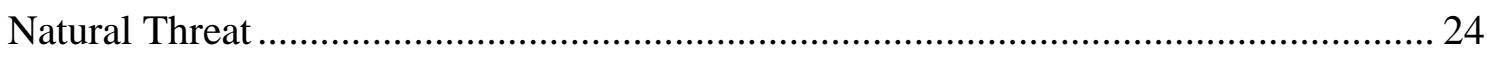

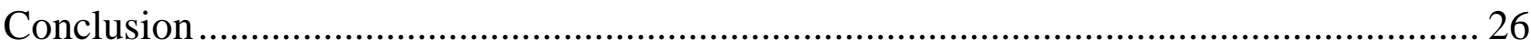

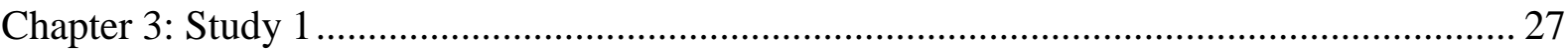

Duckitt's DPM Model and the Prediction of Political Conservatism ................................ 27

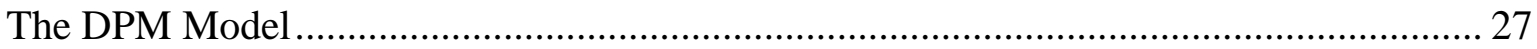

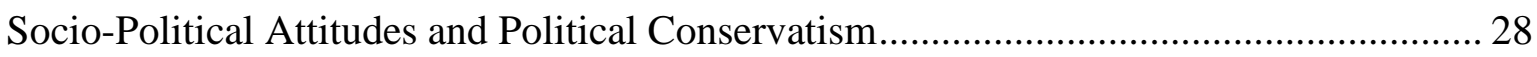

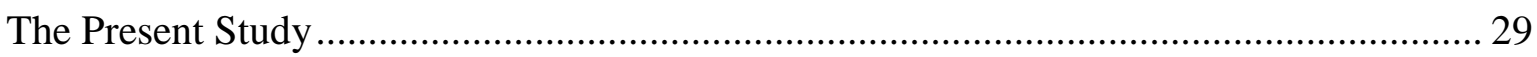

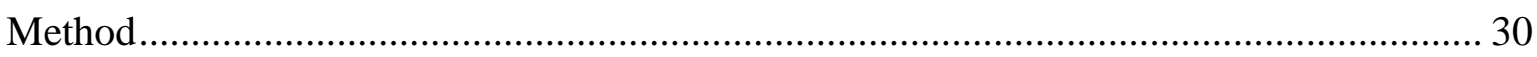

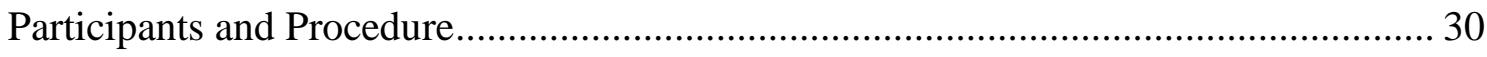

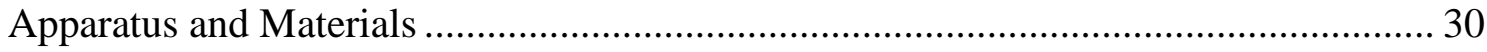

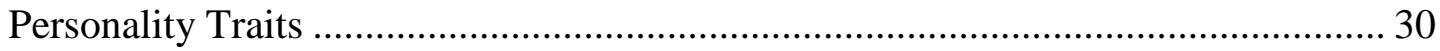

Competitive and Dangerous Worldviews .............................................................. 30

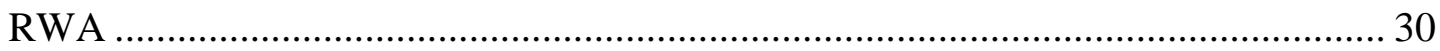

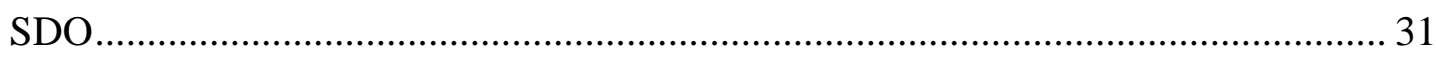

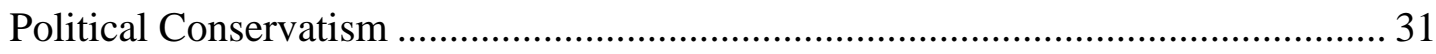

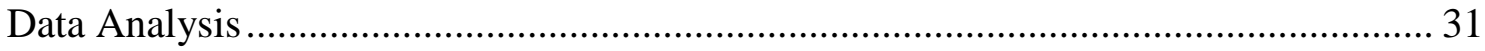


Results 32

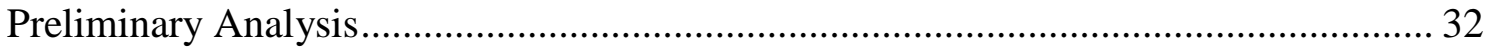

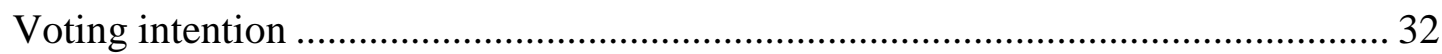

Testing the Big-Five Personality Model under the DPM Model Frame......................... 33

The Association between the DPM Model and Political Conservatism ......................... 35

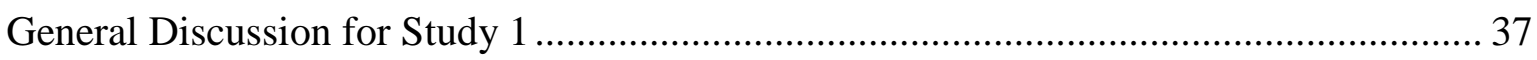

The DPM and the Big-Five Personality Models ....................................................... 38

The DPM Model and Political Conservatism .................................................................. 39

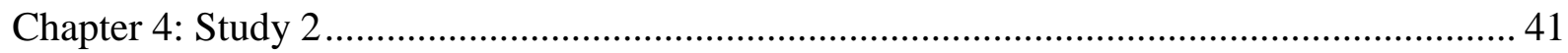

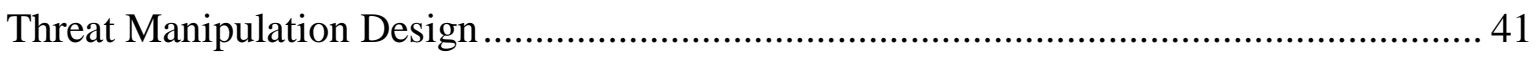

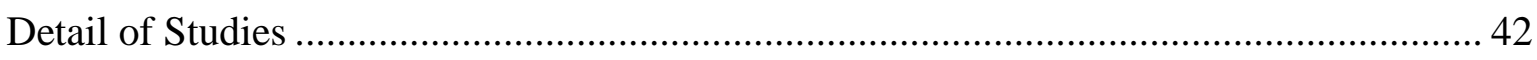

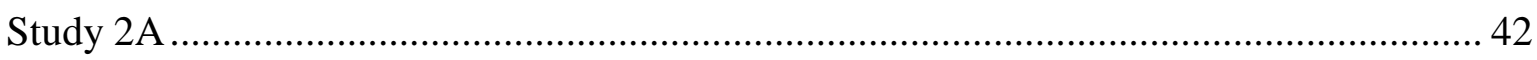

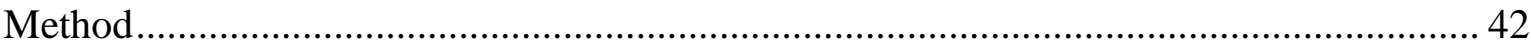

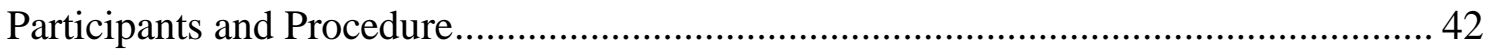

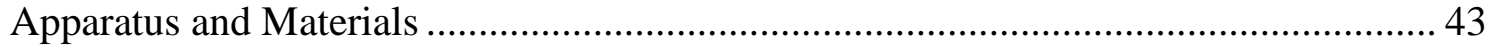

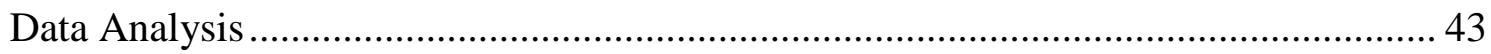

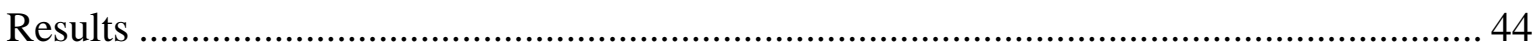

Number of Words/Expressions Evoked by Each Societal Threat ................................ 44

Meaningful Words/Expressions for Each Societal Threat.......................................... 44

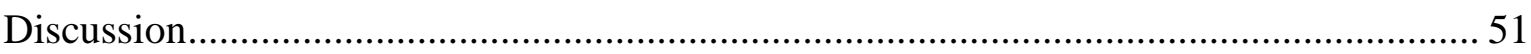

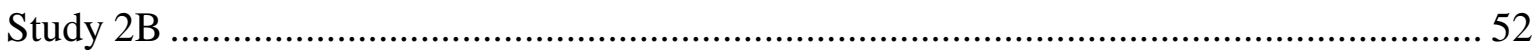

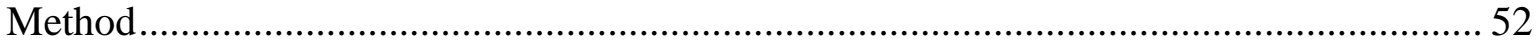

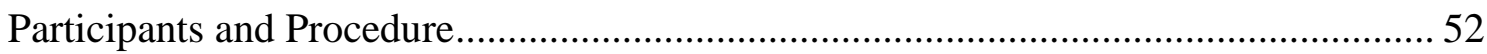

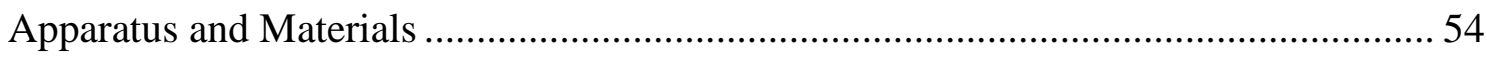

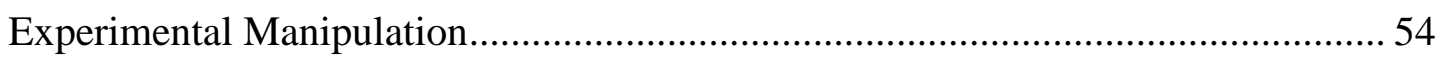

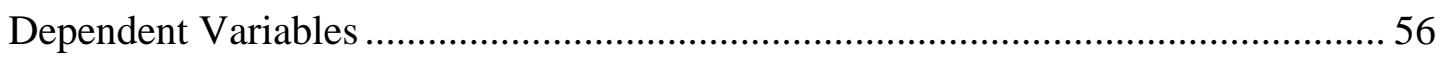

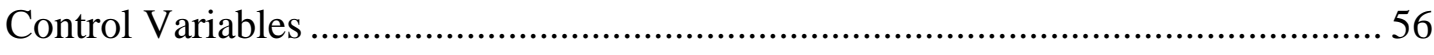

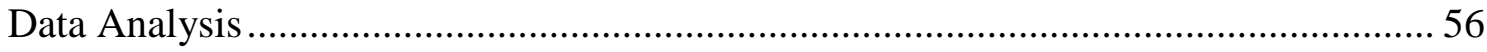

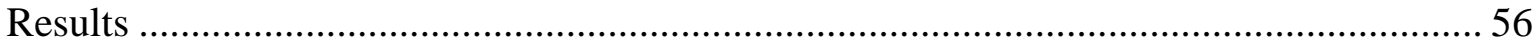

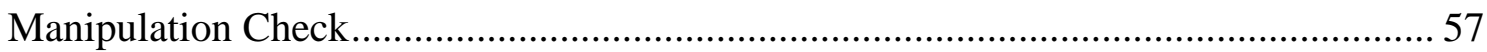

Differential Effect of Societal Threat on Political Conservatism ................................. 57

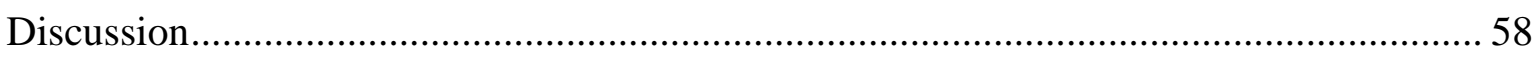

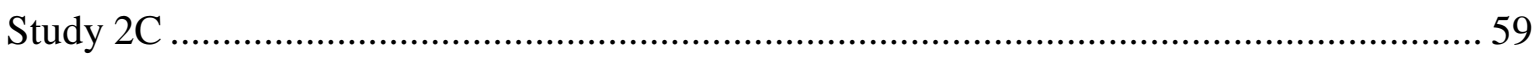

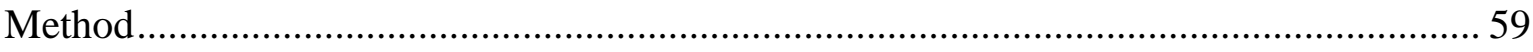




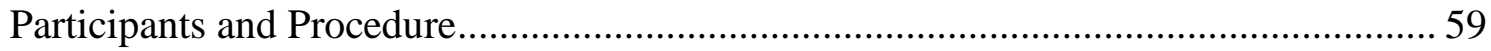

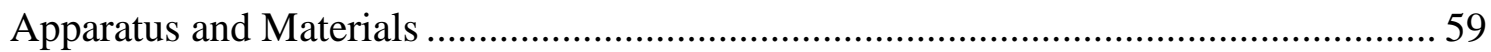

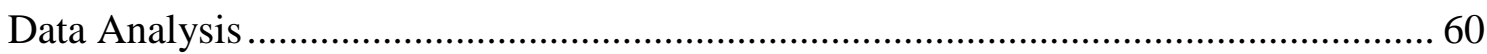

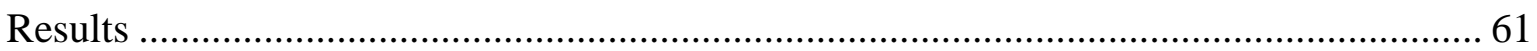

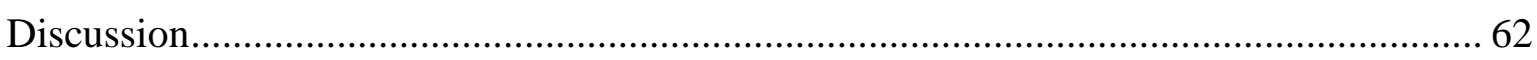

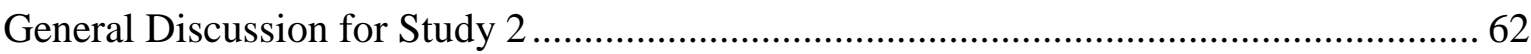

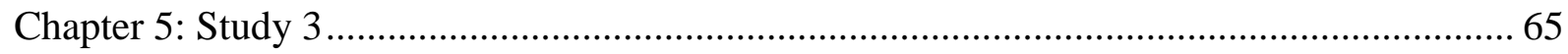

The Impact of Threatening Scenarios on Political Conservatism ........................................6 65

Societal Threat and the Prediction of Political Conservatism ............................................. 65

Understanding How Societal Threat Impacts Political Conservatism ................................ 66

The Impact of Different Types of Societal Threat on Political Conservatism .................... 69

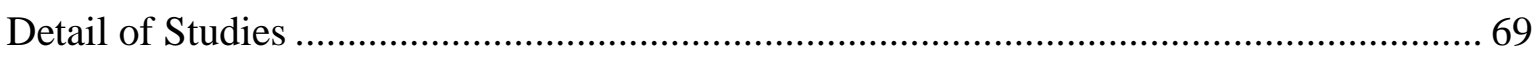

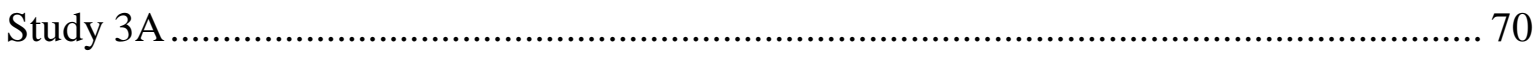

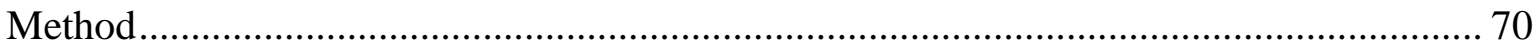

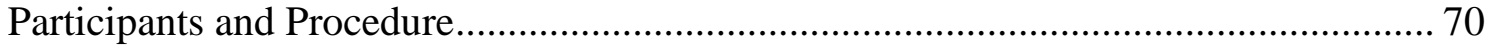

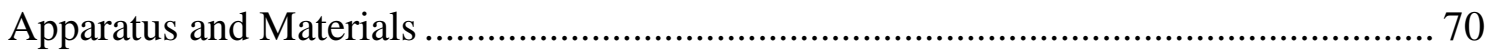

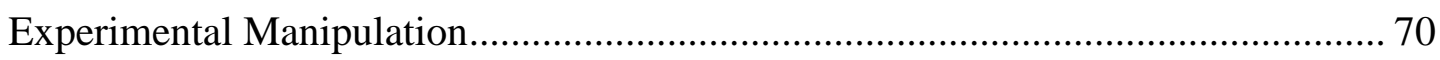

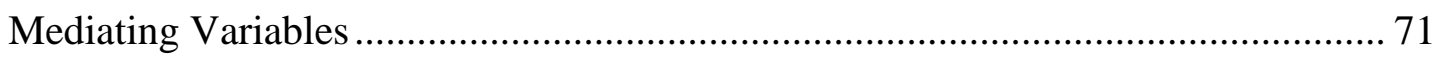

Competitive and Dangerous Worldviews ..................................................... 71

RWA

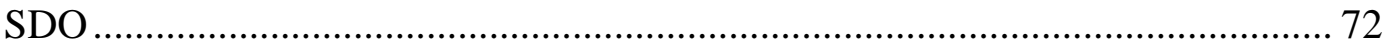

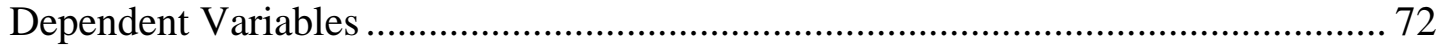

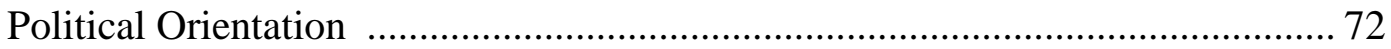

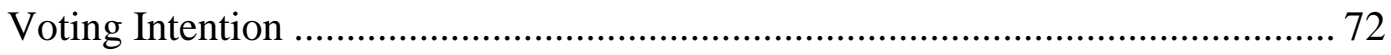

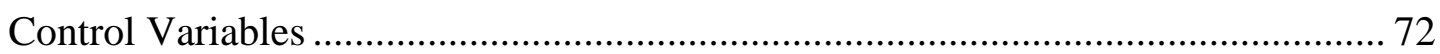

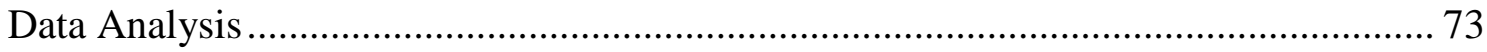

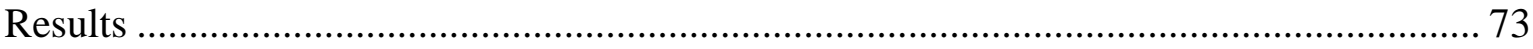

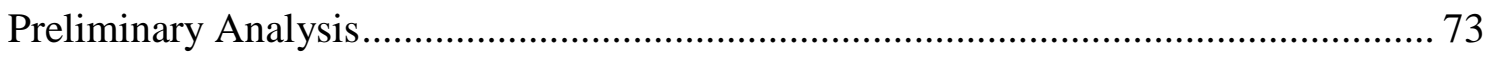

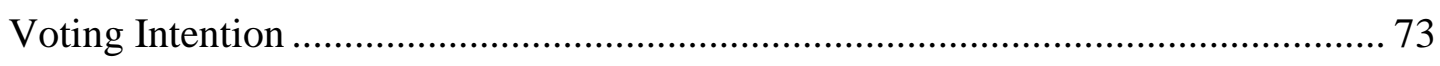

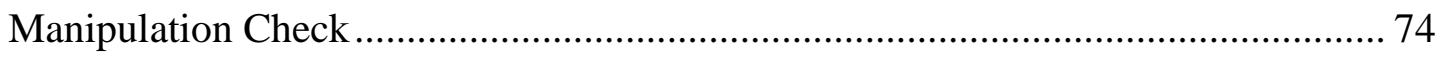

Conservative Shift versus Cultural Worldview Enhancement ..................................... 75

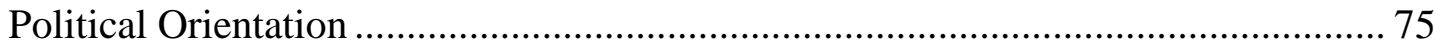

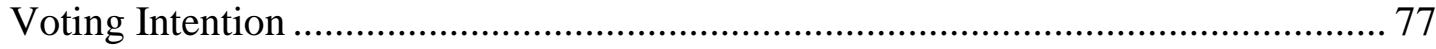

Dual-Process Mediation of the Impact of Societal Threat on Political Conservatism .. 78 
Differences in World Beliefs and Socio-Political Attitudes across Scenarios. .78

Indirect Effects of the Scenarios on Political Conservatism: Mediational Path Model 79

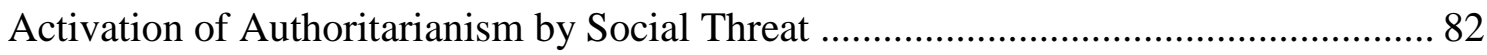

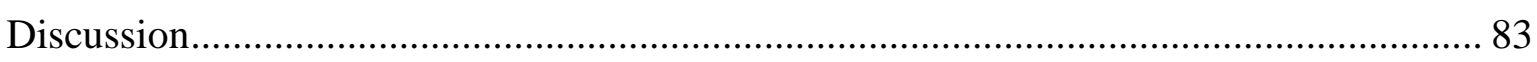

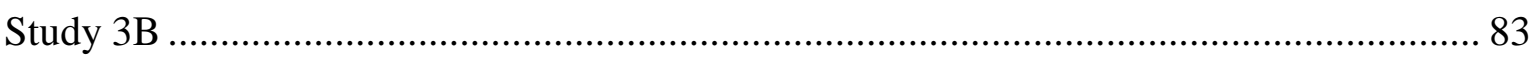

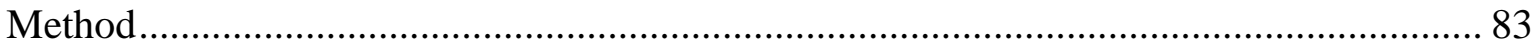

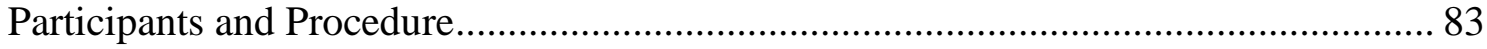

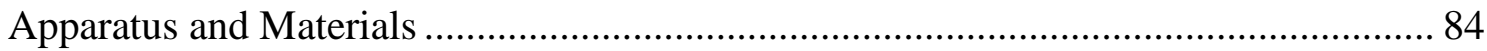

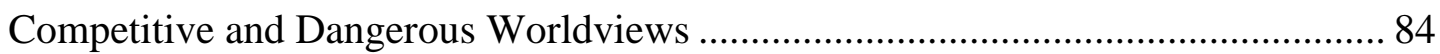

SDO

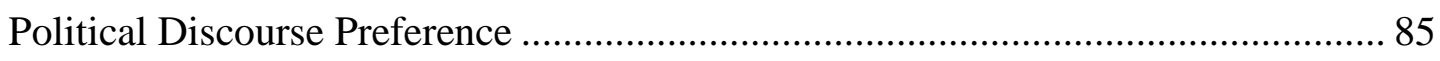

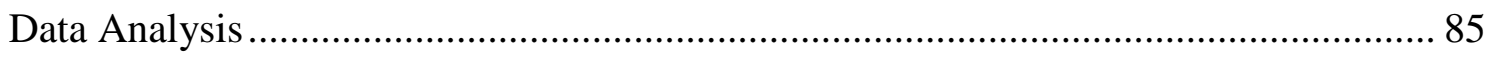

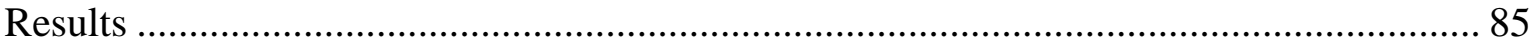

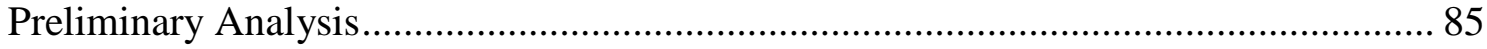

Voting Intention and Political Discourse Preference .................................................. 86

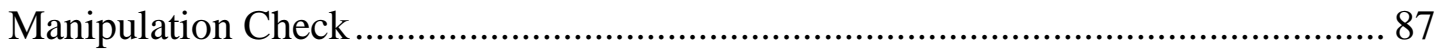

Conservative Shift versus Cultural Worldview Enhancement .................................... 87

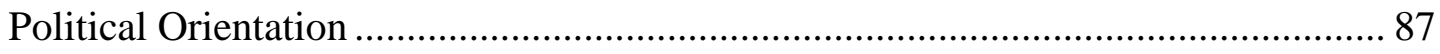

Voting Intention and Political Discourse Preference ............................................... 90

Dual-Process Mediation of the Impact of Societal Threat on Political Conservatism ... 90

Differences in World Beliefs and Socio-Political Attitudes across Scenarios........... 90

Indirect Effects of the Scenarios on Political Conservatism: Mediational Path Model

Activation of Authoritarianism by Social Threat .................................................. 93

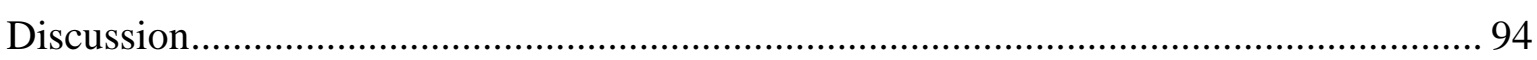

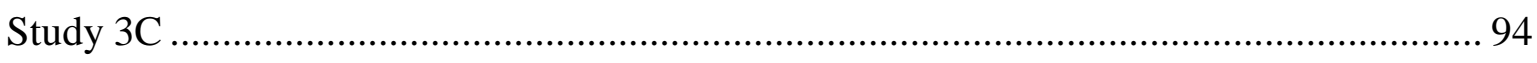

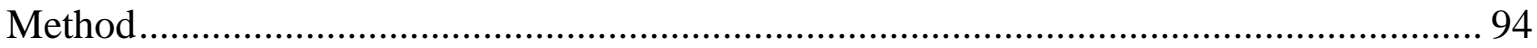

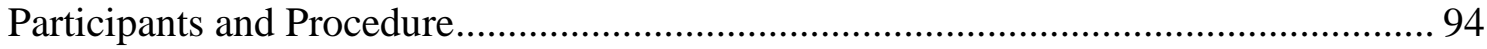

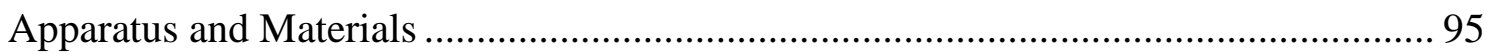

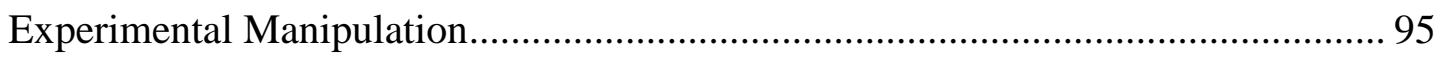

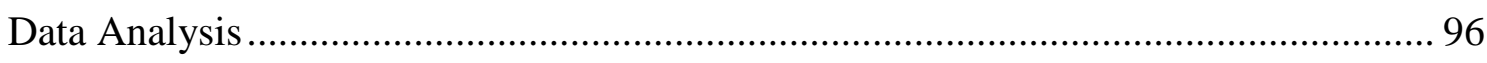

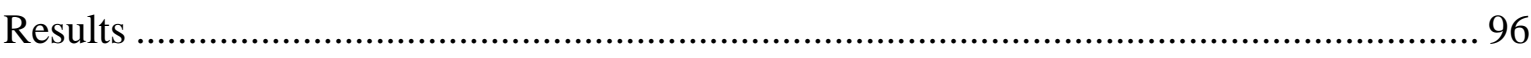

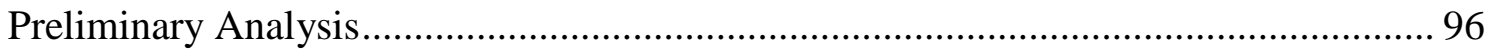


Voting Intention and Political Discourse Preference ................................................ 96

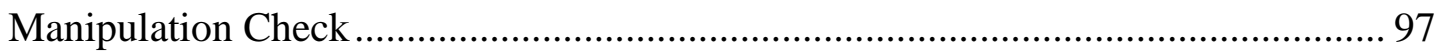

Conservative Shift versus Cultural Worldview Enhancement ...................................... 98

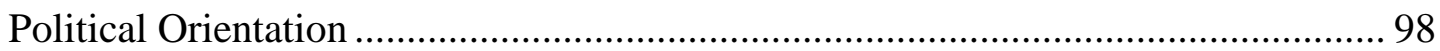

Voting Intention and Political Discourse Preference ............................................ 101

Dual-Process Mediation of the Impact of Societal Threat on Political Conservatism . 101

Differences in World Beliefs and Socio-Political Attitudes across Scenarios......... 101

Indirect Effects of the Scenarios on Political Conservatism: Mediational Path Model 102

Activation of Authoritarianism by Social Threat ....................................................... 105

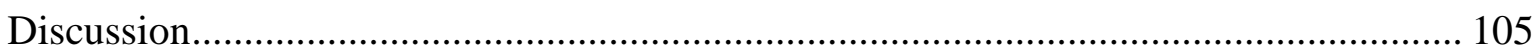

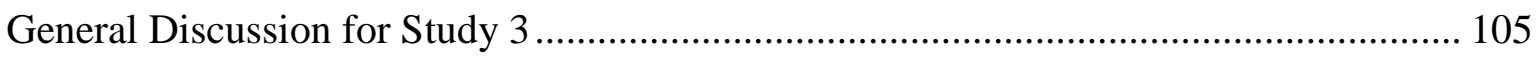

Conservative Shift versus Cultural Worldview Enhancement ..................................... 106

Dual-Process Mediation of the Impact of Societal Threat on Political Conservatism . 108

Activation of Authoritarianism by Social Threat ......................................................... 111

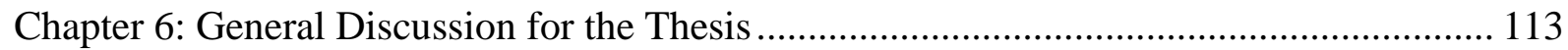

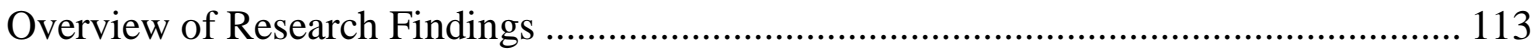

Duckitt's DPM Model and the Prediction of Voting Intention and Political Orientation

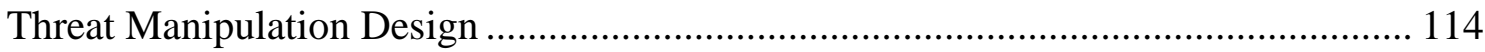

The Impact of Threatening Scenarios on Political Conservatism............................... 115

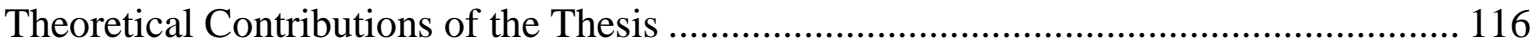

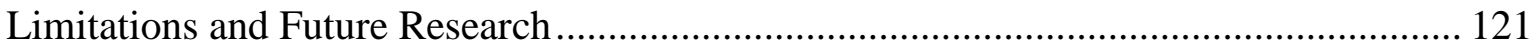

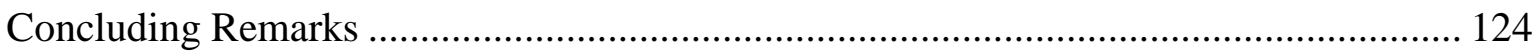

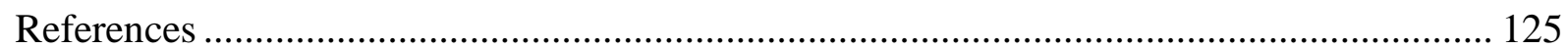

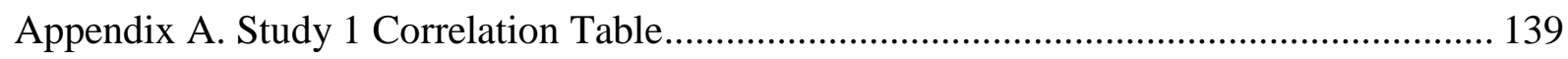

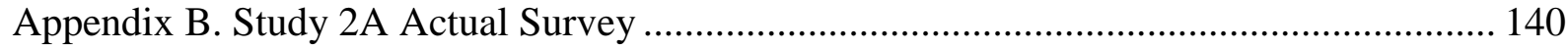

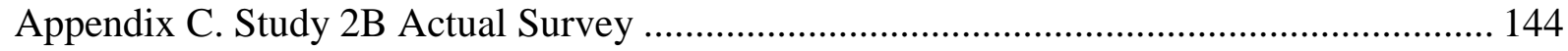

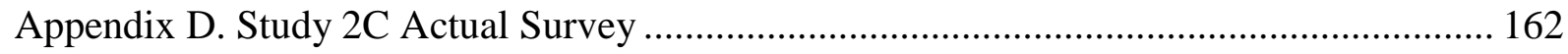

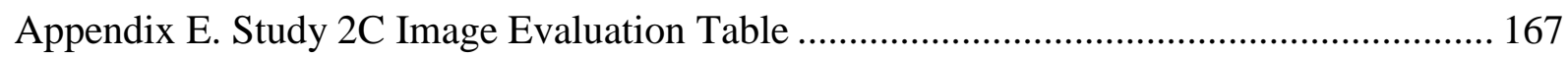

Appendix F. Examples of Images Selected for Study 3C per Type of Condition ................. 180

Appendix G. Description of the Control Measures Initially Included in Study 3................ 181

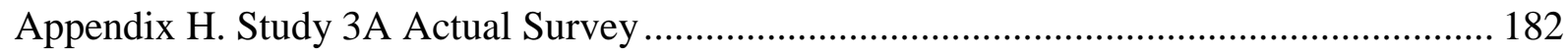

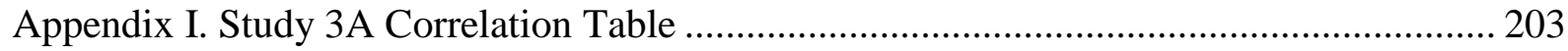


Appendix J. Study 3A Correlations between Sentiments toward Political Parties 205

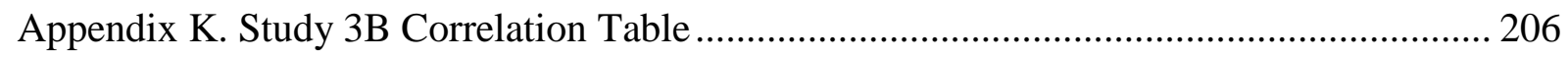

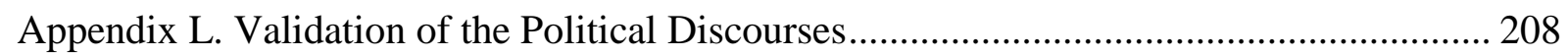

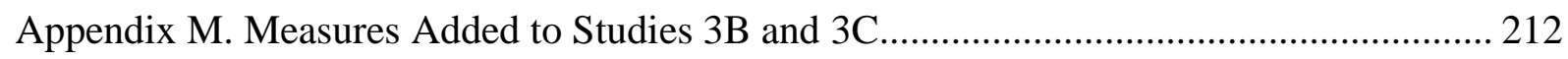

Appendix N. Study 3B Correlations between Sentiments toward Political Parties ............... 215

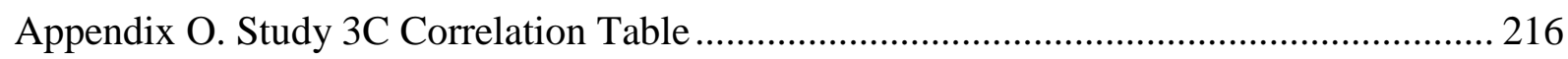

Appendix P. Study 3C Correlations between Sentiments toward Political Parties................ 218 


\section{List of Tables}

Table 1.1 Overview of the empirical studies in the thesis

Table 3.1 Correlations between sentiments toward five of New Zealand's political parties in Study 1

Table 4.1 Meaningful words/expressions with semantic weight and semantic distance for social, economic and natural threats

Table 4.2 Frequency and semantic weight for the words/expressions included in the social, economic, and natural threat scenarios

Table 4.3 Means and standard deviations for the perception of social, economic and natural threats in Study $2 B$

Table 5.1 Means and standard deviations for the perception of economic, natural and social threats in Study $3 A$

Table 5.2 Means, standard deviations and frequencies for political conservatism across experimental conditions in Study $3 A$

Table 5.3 Means and standard deviations per experimental condition for variables included in Duckitt's DPM model (2001) in Study 3A.

Table 5.4 Model fit indices for the path analysis models including societal threat, world beliefs, socio-political attitudes and political conservatism in Study 3 A.

Table 5.5 Means and standard deviations for the perception of economic, natural and social threats in Study $3 B$

Table 5.6 Means, standard deviations and frequencies for political conservatism across experimental conditions in Study $3 B$.

Table 5.7 Means and standard deviations per experimental condition for variables included in Duckitt's DPM model (2001) in Study 3B.

Table 5.8 Model fit indices for the path analysis models including societal threat, world beliefs, socio-political attitudes and political conservatism in Study $3 B$.

Table 5.9 Means and standard deviations for the perception of economic, natural and social threats in Study $3 C$. .98 
Table 5.10 Means, standard deviations and frequencies for political conservatism across experimental conditions in Study $3 C$

Table 5.11 Means and standard deviations per experimental condition for variables included in Duckitt's DPM model (2001) in Study 3C 102

Table 5.12 Model fit indices for the path analysis models including societal threat, world beliefs, socio-political attitudes and political conservatism in Study $3 C$ 


\section{List of Figures}

Figure 2.1 Duckitt's (2001) dual-process motivational model

Figure 2.2 Duckitt and Fisher's (2003) path model of the associations between societal threat, dangerous world beliefs, RWA dimensions and SDO

Figure 2.3 Sibley and Duckitt's (2010) dual-process motivational model including context and three of the big-five personality traits

Figure 3.1 Structural equation model of the associations between personality traits, world beliefs and socio-political attitudes

Figure 3.2 Structural equation model of the associations between personality traits, world beliefs, socio-political attitudes and voting intention 36

Figure 4.1 Scree plot for social threat 46

Figure 4.2 Scree plot for economic threat

Figure 4.3 Scree plot for natural threat

Figure 5.1 Causal model of the impact of economic and social threats based on Duckitt and Fisher's (2003) and Sibley and Duckitt's (2009) models 68

Figure 5.2 Causal model of the impact of the interaction between RWA measured before the experiment and social threat on dangerous world beliefs

Figure 5.3 Path analysis models of the associations between societal threat, world beliefs, socio-political attitudes and political conservatism in Study $3 A$

Figure 5.4 Path analysis models of the associations between societal threat, world beliefs, socio-political attitudes and political conservatism in Study $3 B$.....

Figure 5.5 Path analysis models of the associations between societal threat, world beliefs, socio-political attitudes and political conservatism in Study $3 C$. 
Archival data and anecdotal evidence suggest that threatening situations lead to change in individual responses (Perrin, 2005; Sales, 1973). In particular, when exposed to threatening situations, individuals tend to preserve the in-group and denigrate and discriminate out-group members (Fritsche, Jonas, \& Kessler, 2011). Although functional for the short-term survival of the in-group, this process can lead to significant crises and intergroup conflicts (Hsiang, Burke, Miguel, 2013; Kessler \& Cohrs, 2008; Pratto, Sidanius, \& Levin, 2006).

Some theories and models have tried to explain (to a greater or lesser extent) the interplay between feeling personally threatened, in-group processes triggering and out-group reactions. For example, Fritsche et al. (2011) considered in their review how personal and group factors interplayed and led to ethnocentric tendencies. In their model, group membership was a factor that granted the threatened individual some sense of reassurance. More specifically, they hypothesized that threat to one's sense of global control led to ethnocentric tendencies and that this relationship was moderated by salience and relevance of the group membership and by perceived in-group agency. As a result, the boundaries between the in-group and the out-group became more defined and fixed.

Besides influencing intergroup behaviour, threatening situations have also been shown to influence individual behaviours such as support for conservative candidates (Doty, Peterson, \& Winter, 1991). The impact of threatening situations on political party support and voting might perhaps be a result of the activated psychological processes of higher conservatism, authoritarianism and support for hierarchical group relations (Wilson \& Sibley, 2013). This hypothesis is, however, not unanimously accepted. Research has suggested that this apparent conservative shift might only be a result of people's reinforcement of their cultural worldviews or a result of other external variables such as the leadership style of conservative politicians (Anson, Pyszczynski, Solomon, \& Greenberg, 2009).

Despite the recognition that threat might lead to individuals behaving in more protective ways toward the in-group, as well as influencing voting behaviour, so far no previous research has provided a systematic examination of the impact of different societal threats (but see Duckitt \& Fisher, 2003). Moreover, past research on threat has mainly focused on the difference between the impact of collective, social and national threats versus the impact of personal threat on people's attitudes and behaviours (Fritsche et al., 2011; 
Harvey \& Belt, 1995; Huddy, Feldman, Capelos, \& Provost, 2002). This distinction has been empirically supported more recently in the study by Onraet, Van Hiel, Dhont and Pattyn (2013). These authors also found that external threat (originating from society; e.g. ideological danger) was more strongly associated with authoritarianism than internal threat (originating from one's private life; e.g. mental distress). Based on this empirical distinction, the present research focuses on external threat, both in terms of situational change or societal threat (e.g. period of economic instability in New Zealand) and in terms of subjective perceptions of external threat (e.g. individuals' perception that this economic instability might change New Zealand society).

Obviously, people do not stop voting or making decisions about whom to vote for during or after threatening periods. Citizens remain part of the political process and opt for the best political option available at a specific historical moment according to their worldviews and needs (Jost, Glaser, Kruglanski, \& Sulloway, 2003b). As pointed out by Jonathan Haidt (2012) in his recent book Righteous mind: Why good people are divided by politics and religion, people who vote for conservative political parties vote based on their beliefs about the country they want just as liberals do. According to the author, people in general and researchers studying conservative politics should stop attributing conservative voting to "bad childhoods" or "ugly personality traits".

At the same time, in a world where change is commonplace and uncertainty is a common experience, feeling threatened and having logical and affective reactions toward threat which might impact one's political behaviour is not so unusual (Pyszczynski, Solomon, \& Greenberg, 2003; Slovic \& Peters, 2006). Systematic research investigating the impact of economic, natural and social threats on political orientation and behaviour would clarify the direct (and indirect) consequences of feeling threatened on these variables. More importantly, the study of the impact of different types of threat on voting, an important feature of democratic political systems, would help to determine which policy changes to expect after threatening periods.

\section{Thesis Aims and Outline}

The main purpose of this thesis was therefore to evaluate the impact of societal threat on political conservatism. Along with this main goal, the thesis also had the peripheral goal of verifying whether economic, natural and social threats impact differentially political conservatism.

In order to outline the research area, Chapter 2 presents a literature review of theoretical and empirical work examining the impact of threat on political conservatism. This 
chapter presents the main theories which enclose threat, how societal threat and political conservatism have been studied, and possible mediators of the impact of societal threat on political conservatism. It also discusses further the controversial relationship between threat and authoritarianism and delimits the types of societal threat we will focus on.

Chapter 3 then presents the first empirical study which includes secondary quantitative data collected just before New Zealand's 2011 general election. This study tested the predictive power of Duckitt's (2001) dual-process motivational (DPM) model in explaining political conservatism, determining whether or not it was plausible to adopt its variables as mediators of the impact of societal threat on political conservatism.

Chapter 4 then presents three empirical studies which had the general goal of designing stimuli for subsequent experimental studies. The first study evaluated the psychological meanings attributed to social, economic, and natural threats. Following results from the first study, the second and third studies sought to validate textual and pictorial stimuli, respectively.

Based on findings from previous chapters, Chapter 5 then describes three experimental studies which had the overall goal of verifying how societal threat impacts political conservatism. More specifically, these studies sought to investigate whether economic, natural and social threats impact directly political conservatism, and whether this predicted impact could also be differentially mediated by variables included in the DPM model. The first experiment was completed online at any time during the data collection period. Building on results from the first experiment and trying to address possible methodological issues, the second and third experiments were completed at labs during scheduled time slots and included extra measures evaluating dangerous and competitive world beliefs and political conservatism. While the first and second studies included experimental textual stimuli, the third included pictorial experimental stimuli.

Finally, Chapter 6 presents the overall discussion for the seven empirical studies, merging experimental findings with previous empirical and theoretical work. It also addresses limitations and further directions for this research area. An overview of the empirical studies is depicted in Table 1.1. 


\section{Table 1.1}

Overview of the empirical studies in the thesis

\begin{tabular}{|c|c|c|c|}
\hline Study & Main Goal & $\begin{array}{c}\text { Methodology } \\
\text { (main analyses) }\end{array}$ & Sample \\
\hline Study 1 & $\begin{array}{l}\text { Test the predictive power of } \\
\text { Duckitt's (2001) DPM } \\
\text { model in explaining political } \\
\text { conservatism }\end{array}$ & $\begin{array}{l}\text { Quantitative survey-based study } \\
\text { with secondary data } \\
\text { (Structural Equation Modeling) }\end{array}$ & $\begin{array}{l}\text { New Zealand-born members of } \\
\text { the general population } \\
(N=2,884)\end{array}$ \\
\hline Study $2 \mathrm{~A}$ & $\begin{array}{l}\text { Examine the psychological } \\
\text { meanings attributed to } \\
\text { economic, natural and social } \\
\text { threats }\end{array}$ & $\begin{array}{l}\text { Mix-method study with an open- } \\
\text { ended questionnaire } \\
\text { (Pearson's chi-square test and } \\
\text { Semantic Network Technique) }\end{array}$ & $\begin{array}{l}\text { New Zealand-born Pākehā } \\
\text { (European) members of the } \\
\text { general population } \\
\quad(N=78)\end{array}$ \\
\hline Study 2B & $\begin{array}{l}\text { Validate textual } \\
\text { experimental stimulus for } \\
\text { further studies }\end{array}$ & $\begin{array}{l}\text { Quantitative survey-based study } \\
\text { with textual scenarios } \\
\text { (MANOVA and MANCOVA) }\end{array}$ & $\begin{array}{l}\text { New Zealand-born Pākehā } \\
\text { members of the general } \\
\text { population } \\
(N=181)\end{array}$ \\
\hline Study $2 \mathrm{C}$ & $\begin{array}{l}\text { Validate pictorial } \\
\text { experimental stimulus for } \\
\text { further studies }\end{array}$ & $\begin{array}{l}\text { Quantitative survey-based study } \\
\text { with images } \\
\text { (\% of agreement and means) }\end{array}$ & $\begin{array}{l}\text { New Zealand-born Pākehā } \\
\text { undergraduate students } \\
\qquad(N=40)\end{array}$ \\
\hline
\end{tabular}




\begin{tabular}{|c|c|c|c|}
\hline Study & Main Goal & $\begin{array}{l}\text { Methodology } \\
\text { (main analyses) }\end{array}$ & Sample \\
\hline Study $3 \mathrm{~A}$ & & & $\begin{array}{l}\text { New Zealand-born Pākehā } \\
\text { undergraduate students } \\
\qquad(N=142)\end{array}$ \\
\hline Study 3B & $\begin{array}{l}\text { Verify how societal threat impacts } \\
\text { political conservatism and } \\
\text { whether or not different types of } \\
\text { societal threat impact } \\
\text { differentially political } \\
\text { conservatism }\end{array}$ & $\begin{array}{c}\text { with textual and pictorial } \\
\text { scenarios } \\
\text { (MANOVAs, ANOVAs, } \\
\text { Pearson's chi-square tests and } \\
\text { Structural Equation Modeling) }\end{array}$ & $\begin{array}{l}\text { New Zealand-born Pākehā } \\
\text { undergraduate students } \\
\qquad(N=121)\end{array}$ \\
\hline Study 3C & & & $\begin{array}{l}\text { New Zealand-born Pākehā } \\
\text { undergraduate students } \\
\qquad(N=99)\end{array}$ \\
\hline
\end{tabular}




\section{Chapter 2: Literature Review}

Threat: 1. A statement of an intention to inflict pain, injury, damage, or other hostile action on someone in retribution for something done or not done; 2. A menace of bodily harm, such as may restrain a person's freedom of action; 3. A person or thing likely to cause damage or danger; and 4. The possibility of trouble, danger, or ruin.

Oxford dictionary, 2014

It is sometimes unfortunate that social science research depends on natural language definitions of key concepts. "Threat" is a perfect example of this problem. In normal speech it wouldn't be uncommon to say that a person is "threatened" by the sight of a large spider; or by the loss of their job; or by the thought of an airplane crashing; or by the prospect of being killed in a terrorist attack; or by increasing cultural diversity in their country. All of these things and more could be negative outcomes that people fear might occur.

Feldman, 2013

The definition and quote reported above show that the most used definition of threat arises from natural language and could enclose hundreds, thousands, or even millions of occurrences that could be threatening depending on people's context. Indeed, the extant literature has defined threat mostly as the perception or feeling of imminent aversive outcomes, consequences, and/or situations. Although this conceptualisation of threat has been widely used, Fritsche et al. (2011) highlight the importance of other definitions that also consider the perception of control over situations that otherwise would be perceived as threatening (see also Blascovich \& Tomaka, 1996). Below, we present some of the models that have, to a greater or lesser extent, focused on how threat to people's integrity (in the broad sense) affects attitudes and behaviours relating to the group level.

\section{Models Including Threat as Part of the Understanding of Intergroup Behaviour}

In their model of group-based control restoration, Fritsche et al. (2011) assigned a central role to the perception of control over situations when conceptualising threat. More specifically, these authors posited that threat to people's sense of global control - and not threat per se - impacted ethnocentric attitudes. Similarly to Fritsche and colleagues, some other researchers and theories have tried to explain the impact of threat on ethnocentric tendencies, focusing to a greater or lesser extent on the group level.

The integrated threat theory, for example, posits that when groups interact, threat in the form of intergroup anxiety, realistic threat, symbolic threat and negative stereotypes result in extreme and negative responses toward out-group members (Stephan, Stephan, \& Gudykunst, 1999). This theory has been supported by previous empirical work suggesting that 
these four variables are related and lead to negative attitudes toward immigrants (Gonzalez, Verkuyten, Weesie, \& Poppe, 2008; Stephan, 2014; Stephan, Ybarra, Martnez, Schwarzwald, \& Tur-Kaspa, 1998; Ward \& Masgoret, 2008). According to this theory, if, for instance, members from a nationality that had not previously immigrated to New Zealand started coming to this country and dominating the available jobs in the labour market, New Zealanders could perceive realistic threat or, more specifically, threat to New Zealanders' economic integrity. This perception could in turn generate negative attitudes, behaviours, and regulations toward the new nationality group such as nationality targeting in selection processes.

Another theoretical model that has focused on threat and considers the group level to some extent is the terror management theory (Rosenblatt, Greenberg, Solomon, Pyszczynski, \& Lyon, 1989). This theory posits that people, different from other animals, are continuously conscious of the imminence of death and, as a way to dissipate or control the fear (and threat) related to death, attain to and defend their own cultural worldviews, derogate different cultural worldviews, and seek self-esteem (Anson et al., 2009; Harmon-Jones, Simon, Solomon, Pyszczynski, \& McGregor, 1997; Rosenblatt, et al., 1989). In derogating other worldviews, people also tend to present ethnocentric tendencies.

Empirical work has confirmed the role of people's cultural worldview defence and high self-esteem as buffers of the anxiety provoked by the imminence of death. Burke, Martens and Faucher (2010), for instance, investigated the relationship between mortality salience with cultural worldview enhancement and self-esteem. The authors found in their meta-analysis, which included 164 articles, that the effect of mortality salience on cultural worldview and self-esteem was significant and moderate, varying in size depending on the nature of the particular worldview/self-esteem factor $[r(276)=.35, p<.001$. $]$. Additionally, threatening events such as the 2001's 9/11 terrorist attacks in the United States have also been explained in a new light using terror management theory (Pyszczynski et al., 2003). More specifically related to the content of this thesis, political speeches that sustained the view of American culture as "good" have been interpreted as a way to reinforce Americans' set of beliefs in the face of death salience (triggered by the terrorist attack) and gain astonishing rates of approval in return.

Another relevant theory that includes threat in the explanation of intergroup behaviour is system justification theory. According to this theory, individuals sustain external ideologies that confirm the existing social system when threatened as a way to seek for certainty and consistence (Anson et al., 2009). More specifically, system justification theory considers 
threat as a booster of the social system defence and justification, recognizing it more as a prior enhancer of the way groups relate to each other than as a consequence of groups' interaction (Jost, Banaji, \& Nosek, 2004). According to this theory, there are three justification tendencies that pervade individuals: the ego justification tendency, the group justification tendency, and the system justification tendency (Jost \& Banaji, 1994). The ego justification tendency relates to one's need to keep a positive self-image and feel as a valuable individual actor. The group justification tendency relates to the desire to keep a positive image of the in-group, defending and explaining in-group members' behaviours. Finally, system justification tendency relates to the need to provide meaning to the status quo, seeing it as natural, good, desirable, inevitable and fair. This need is motivated by epistemic and cognitive demands for certainty and consistence.

In particular, and according to system justification theory, the three justification tendencies can be either in consonance or in dissonance. The theory argues that the defence and justification of the status quo along with increasing the legitimacy of the existing social order is a general tendency as strong as the ego and group justification tendencies, which, many times, may even overshadow both. In their review of ten years of research connected to system justification theory, Jost et al. (2004) noted that substantial evidence has been found for the theory in empirical studies. Overall, the review showed empirical evidence for 20 hypotheses derived from system justification theory. Among those hypotheses, evidence was reported for people's defence and justification of the existing social system and greater group differentiation when threatened.

When comparing terror management theory to system justification theory in relation to the explanation of stability and change in ideology, Anson and colleagues (2009) focused on the internal versus external location of the ideologies that were sustained versus those that were defended. In contrast to system justification theory, terror management theory posits that individuals defend internal ideologies (i.e. their own cultural worldviews) based on external aspects of the world when confronted with death anxiety as a way to protect themselves against the fear of death. Anson and colleagues (2009) further argued that while the need for consistence and certainty is an assumption of system justification theory, terror management theory seeks to explain why people have these needs. It posits that people need consistency and certainty in order to protect themselves from death anxiety, which is reached through defence of one's cultural worldview and increased self-esteem.

Another important distinction between both theories is that the importance of selfesteem seems restricted to the concept of ego justification tendency in system justification 
theory, which can be easily overshadowed by one's system justification tendency (Jost et al., 2004). By contrast, in terror management theory the concept of self-esteem boost is central, serving as a way to reduce death anxiety.

Terror management theory has also been compared to uncertainty management theories in the literature, and has been argued as fitting within this broader context of theories (Van Den Bos, 2009). Uncertainty management theories emphasize the role of uncertainty, and not death, as an undesirable state that should be managed by adherence to one's worldviews and by derogation of opposing worldviews. Trying to verify this hypothesis, Van Den Bos (2009) conducted five experiments contrasting a mortality salience condition with an uncertainty salience condition, and having as dependent variables participants' reactions to worldviews which threatened or confirmed their own.

Van Den Bos found that both experimental conditions enhanced participants' reactions to worldviews different and similar from theirs. Further, the effect of uncertainty salience was larger than the effect of mortality salience, and the effects for support or derogation of worldviews were larger in four of the studies when participants in the mortality salience condition reported words related to uncertainty after the manipulation. According to Van Den Bos (2009), the results suggested that at least to some extent uncertainty and terror management theories address the same issues.

Overall, the models and theories presented above reaffirm the importance assigned to threat (also in the form of uncertainty and death salience) on the explanation of intergroup behaviour and, more specifically, ethnocentric behaviour. Putting their differences in theoretical focus and argumentation aside, these theoretical models propose an impact of threatening situations on intergroup behaviour. Furthermore, these theories also enable the explanation of the association between threat and political conservatism. Given that people categorize themselves in political groups according to their level of political conservatism, the impact of threat on political conservatism could be, for instance, either understood in terms of previous levels of political conservatism (terror management theory) or in terms of a political option that would maintain society's order (system justification theory).

\section{Societal Threat and Political Conservatism}

In trying to elaborate specifically on the different theories and aspects related to political conservatism in the literature, Jost et al. (2003b) introduced the idea of political conservatism as motivated social cognition. Through several meta-analyses enclosing the empirical production between 1958 and 2002, the authors confirmed the relationship between political conservatism and a number of important psychological constructs, including 
dogmatism/intolerance to ambiguity, integrative complexity, openness to experience, uncertainty tolerance, need for order/structure/closure, self-esteem, fear of threat/loss (perceived threat), mortality salience and system instability (societal threat). Supporting the motivated social cognition account, the results suggested that variables of personality, epistemic and existential needs, and ideological rationalisation do explain political conservatism understood in terms of higher resistance to change and support for inequality (see Jost, 2006; Jost, Federico, \& Napier, 2009).

More particularly related to the present thesis, this review and subsequent studies enclosing societal threat have shown that societal threat (and not calmer periods of time) increases political conservatism, leading to a conservative shift. However, a major limitation of the studies included in this review and produced after it appears to be that the relationship between societal threat and political conservatism has been mainly studied using proxy measures of political conservatism such as city budget for police departments versus fire departments instead of direct measures such as voting or political orientation (Perrin, 2005; Peterson \& Gerstein, 2005). Even so, two studies reviewed by Jost and colleagues (Doty et al., 1991; McCann, 1997) have shown that greater societal threat increased a more direct measure of political conservatism understood in terms of voting for a right-wing party.

Although Jost and colleagues managed to synthesize the relationship between variables investigated in different niches of the political conservatism literature, there have still been criticisms made of their model. The most important criticisms related to their model and relevant to the present thesis revolve around two main points (Anson et al., 2009; Burke, Kosloff, \& Landau, 2013; Greenberg \& Jonas, 2003): (1) their definition of the core components of conservatism (defined as resistance to change and tolerance for inequality); and (2) their findings implying a conservative shift.

Regarding the first criticism, some researchers have argued that the structure of political conservatism varies across countries. Greenberg and Jonas (2003), for instance, pointed out in their reply to Jost and colleagues' article that while resistance to change and support for inequality characterize conservative political regimes in the West, they characterize liberal regimes in countries with a history of communist regimes. Discussing the topic further, Jost, Glaser, Kruglanski and Sulloway (2003a) argued that there are two options when communist regimes are mature (older). The first one includes resistance to change and the desire to keep the power and ruling to those in power, maintaining the status-quo. The second one connects to the desire for change in the system, moving the system toward characteristics connected to conservative regimes in the West (e.g. free market). Going 
further, in their review about political ideology, Jost et al. (2009) even acknowledged the importance of studying the relationship between resistance to change and support for inequality in countries with a history of communist or socialist regimes. Still, the authors pointed out that research has shown that one should expect political conservatism to be characterized in most countries by higher resistance to change and higher support for inequality.

Regarding the second criticism, Anson et al. (2009) observed that a long tradition in the literature has described conservative ideologies as reassuring and based on a desire to reduce uncertainty. In that sense, people would be stimulated to adopt conservative ideologies when threatened, shifting their beliefs toward conservatism. The understanding of conservatism as reassuring and as based on the desire to solve uncertainty has even granted to it the character of a system justifying ideology in system justification theory.

However, this idea is not unanimously agreed on. It is possible that when faced with societal threat, people could be reminded of their own mortality, defending their own political worldviews as a way to dissipate or control the fear (and threat) related to it. In this sense, some have defended the idea of cultural worldview enhancement when people are faced with mortality saliency instead of the idea of conservative shift proposed by Jost et al. (2003b).

Adding to this understanding, Burke et al. (2013) evaluated both the hypothesis of conservative shift and the hypothesis of cultural worldview enhancement as a result of mortality salience in two different meta-analyses. The authors found that the weighted effect size for the effect of mortality salience on political conservatism for studies confirming the conservative shift hypothesis was small $[r(25)=.22, p<.02]$, while the weighted effect size for the effect of mortality salience on political conservatism for studies confirming the cultural worldview hypothesis was moderate $[r(13)=.35, p<.01]$. However and despite the apparent difference in effect sizes, this difference was not statistically significant.

These results add more mixed evidence for the impact of threat on political conservatism given the intrinsic relationship between threat and harm to one's integrity. More specifically, they show that there are two contrasting views in the literature regarding mortality salience - one that stands for the direct impact of mortality salience on political conservatism (conservative shift hypothesis) and another that stands for the moderated impact of mortality salience on political conservatism depending on people's previous political worldviews (cultural worldview enhancement hypothesis).

Overall, the assumptions and results suggest that there are different ways of thinking about the impact of societal threat or system instability on political conservatism. One way of 
examining the threat-conservatism link refers to the conservative shift hypothesis, suggesting that people become more conservative when faced with threat or mortality salience triggered by threat. A second way of examining the threat-conservatism link refers to the cultural worldview enhancement hypothesis, suggesting that people may or may not become more conservative when faced with threat (and reminded about their own deaths) depending on their previous political beliefs. Thus, two competing hypotheses will be evaluated in this research:

Hypothesis 1 (conservative shift). The hypothesis of conservative shift in the face of societal threat (Jost et al., 2003b) postulates that individuals will become more politically conservative during/after threatening periods

Hypothesis 2 (cultural worldview enhancement). The hypothesis of cultural worldview enhancement elicited by societal threat (Burke et al., 2013) postulates that threat will enhance individuals' held political worldview during/after threatening periods

\section{Mediators of the Impact of Societal Threat on Political Conservatism}

The extant literature, and in particular the conservative shift (Jost et al., 2003b) hypothesis, suggests a direct influence of societal threat on political conservatism. But it is also possible that the societal threat-conservatism link might be mediated by important psychological constructs. In particular, authoritarianism and social dominance orientation could be possible mediators as both constructs have been widely recognized as variables that tackle the political conservatism dimensions of resistance to change and acceptance of inequality (Jost et al., 2009). Authoritarianism and social dominance orientation have been already shown to explain additively and interactively political conservatism (Wilson \& Sibley, 2013).

Studies examining the relationship of threat with authoritarianism and social dominance orientation have to a large extent focused on the prediction of prejudice (Matthews \& Levin, 2012; Thomsen, Green, \& Sidanius, 2008), with both authoritarianism and social dominance orientation predicting higher levels of prejudice. However, some studies have also focused on the relationship between threat and both authoritarianism and social dominance orientation in the prediction of attitudes toward political issues such as support for military attack and restriction of human rights (Kossowska et al., 2011; McFarland, 2005). 
A model described in more detail below provides a framework for understanding the theoretical relations between authoritarianism and social dominance orientation and why their association with threat and political conservatism should be considered jointly.

Duckitt's (2001) dual-process motivational model. The study of conservative orientation goes back to the 1950s with the publication of The Authoritarian Personality (Adorno, Frenkel-Bruswick, Levinson, \& Sanford, 1950). At that time, conservative orientation was conceived as a single dimension construct ranging from a liberal orientation at the low end to a conservative orientation at the high end (Duckitt \& Sibley, 2010). Only years after, with the publication of the right-wing authoritarianism (RWA; Altemeyer, 1981) and the social dominance orientation (SDO; Pratto, Sidanius, Stallworth, \& Malle, 1994) scales, the unidimensionality of political conservatism was questioned.

The RWA scale was created in 1981 to measure authoritarianism, considering three different components: authoritarian submission, authoritarian aggression, and conventionalism (Altemeyer, 1981). An authoritarian individual would thus be submissive to authorities, aggressive when authorities approved aggression, and conventional (Altemeyer, 2004). The SDO scale was created in 1994 to measure to what extent individuals desired and supported hierarchy, inequality between social groups and domination of "inferior" groups by "superior" groups (Pratto, et al., 1994; Sidanius \& Pratto, 1999). Nowadays, RWA and SDO are recognized to index resistance to change and support for inequality, the underlying dimensions of political conservatism (Jost et al., 2009).

In this sense, comprehensive empirical evidence has shown that high levels of RWA and SDO express complementarily prejudice (Altemeyer, 1998; McFarland \& Adelson, 1996) and also conservative political beliefs (Van Hiel \& Mervielde, 2002; Wilson \& Sibley, 2013). Additionally, Wilson and Sibley (2013) have shown an interactive effect between these variables on explaining political conservatism, but this effect was only small.

Trying to explain prejudice, Duckitt (2001) proposed a dual-process motivational (DPM) model that accounted for the roles of RWA and SDO. According to the DPM model, and as depicted in Figure 2.1, RWA and SDO result from distinct socialisation practices, personality traits and worldviews. RWA reflects a punitive socialisation, social conformity and the perception of the world as a dangerous place. In contrast, SDO reflects an unaffectionate socialisation, tough-mindedness and the perception of the world as competitive. The DPM model thus proposes a dual mediational model with socialisation practices influencing the development of RWA and SDO via particular personality traits and worldviews. 


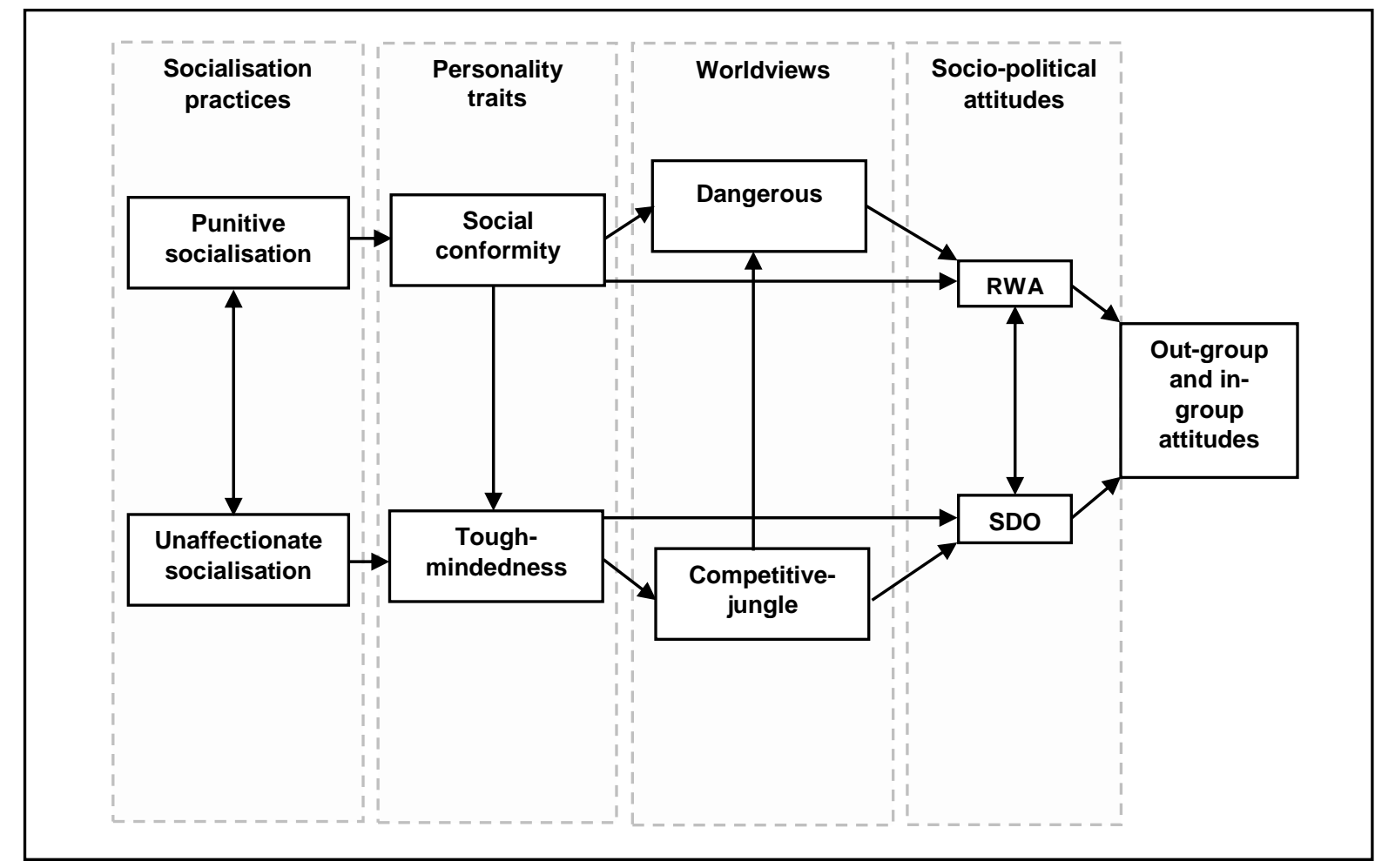

Figure 2.1. Duckitt's (2001) dual-process motivational model (adapted from Duckitt, 2001).

Overall, support for the whole model or particular portions of it has been shown in a number of studies (for reviews and meta-analyses see Duckitt \& Sibley, 2010; Perry, Sibley, \& Duckitt, 2013; Sibley \& Duckitt, 2008). Under the DPM model framework, RWA and SDO have been heavily used to explain prejudice (Cohrs \& Asbrock, 2009; Cohrs \& Stelzl, 2010; Thomsen e al., 2008).

In considering the relationship between political issues and RWA and SDO, a wide range of topics have been studied. For example, RWA has been shown to be positively related to support for military aggression (Crowson, 2009; Henderson-King, Henderson-King, Bolea, Koches, \& Kauffman, 2004), tough government actions (Duckitt, Bizumic, Krauss, \& Heled, 2010), and harsh and punitive political positions (Peterson, Doty, \& Winter, 1993). Similarly, SDO has been shown to be positively related to support for greater violence in war (Henry, Sidanius, Levin \& Pratto, 2005), lack of support for environmental/pro-egalitarian policies (Milfont, Richter, Sibley, Wilson, \& Fischer, 2013; Milfont \& Sibley, 2014; Pratto et al., 1994), and conservative social policy (Jost \& Thompson, 2000). Other studies have also shown that both RWA and SDO are positively related to restriction of human rights (Cohrs, Maes, Moschner, \& Kielmann, 2007; Crowson, 2007) and conservative voting (Duckitt et al., 2010; Ho, et al., 2012). 
To our knowledge, only two articles have focused on the impact of both RWA and SDO on the orientation toward different political parties. Examining preference for political parties as measured through ratings given by participants to the program of the six major parties in Flanders (Belgium), Van Hiel and Mervielde (2002) found that RWA was more positively correlated to the preference for a more religious and traditional party, while SDO was more positively correlated to the preference for a more anti-immigration party (an extreme right-wing party). The researchers also observed that RWA and SDO independently explained conservative beliefs.

Wilson and Sibley (2013) evaluated how RWA and SDO explained political conservatism across 14 samples from New Zealand. The way conservatism was measured across the samples varied from attitudes toward political issues to support for political parties and answers in response to a version of the Wilson-Patterson Conservatism scale. Overall, the authors found that RWA and SDO explained additively and interactively political conservatism, and both the additive and interactive effects were only small. More specifically, they found that RWA and SDO complementarily increased political conservatism, but that in order for participants to be extremely liberal, they had to show low scores in both RWA and SDO. This interactive effect was not observed for participants who were extremely conservative. When considering only support for political parties as the dependent variable, just the additive effect of RWA and SDO was observed and the interactive effect did not significantly explain unique variance in support for political parties. Together, these findings support the widespread influence of RWA and SDO on political issues, and also lend support for their differential influence as proposed by the DPM model.

Threat research including variables described in the DPM model. Duckitt and Fisher (2003) were perhaps the first to test a model which included threat under the DPM model frame. The authors hypothesised that threatening social situations and the personality trait of social conformity would lead to dangerous world beliefs and to RWA. On the other hand, the authors hypothesised that competitive-jungle social situations and the personality trait of tough-mindedness would lead to competitive-jungle world beliefs and to SDO. The authors tested part of this model experimentally in a between-subjects design with introductory psychology students. Participants were presented with one of three scenarios describing the situation in their country ten years into the future as threatening, safe or unchanged. After reading one of the scenarios, the participants answered measures of dangerous world beliefs, RWA and SDO. The authors found that societal threat (when 
compared to the control condition) led to dangerous world beliefs which in turn led to two of the RWA measure factors - conservative attitudes and authoritarian attitudes (Figure 2.2).

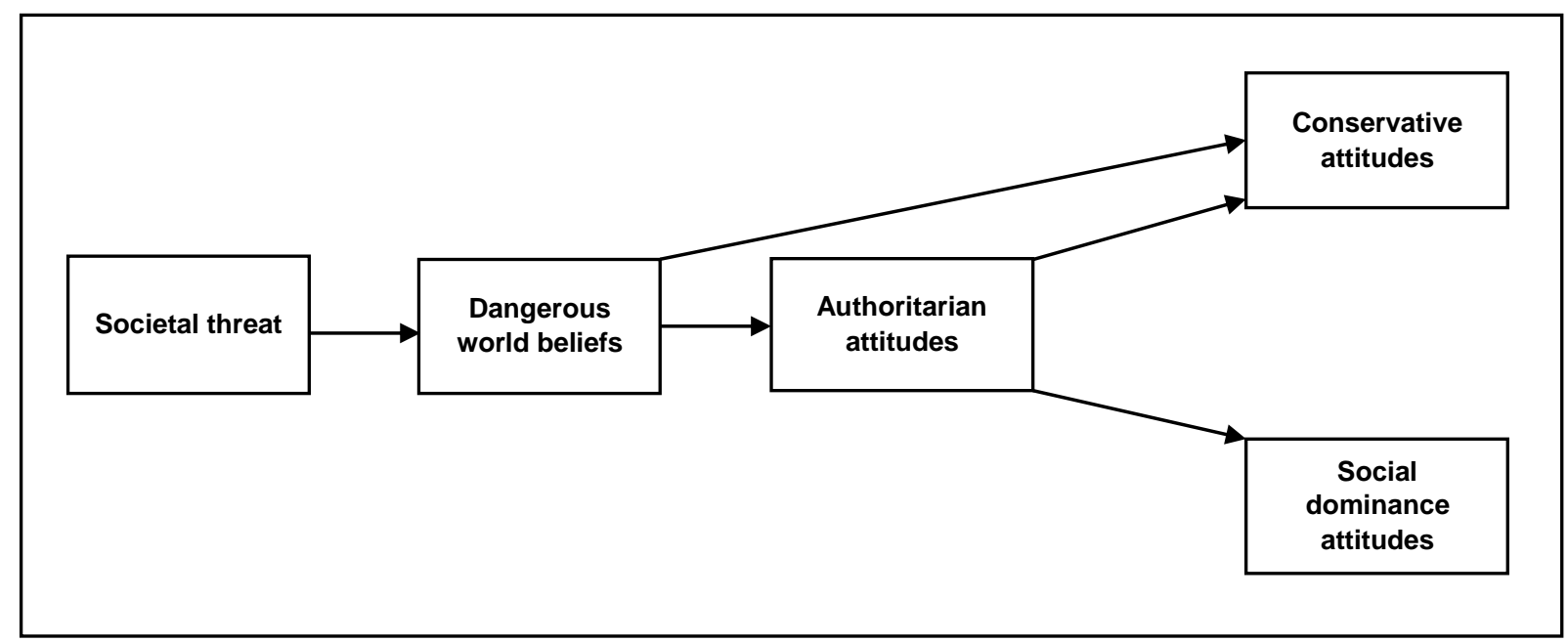

Figure 2.2. Duckitt and Fisher's (2003) path model of the associations between societal threat, dangerous world beliefs, RWA dimensions and SDO (adapted from Duckitt \& Fisher, 2003).

In addition, authoritarian attitudes impacted conservative attitudes and SDO, which was only marginally and indirectly impacted by societal threat. Overall, the empirical findings supported the hypothesized paths. This model was further supported in another New Zealand study conducted by Jugert and Duckitt (2009).

Reviewing the literature around the DPM model, Duckitt and Sibley (2010) endorsed the model proposed by Duckitt and Fisher (2003) by highlighting that enduring and drastic changes in the social environment could impact DPM model variables (also see Duckitt, 2006; Duckitt \& Sibley, 2009). The new version of the model focused on social or group context instead of socialisation practices and substituted the personality traits of social conformity and tough-mindedness for three (agreeableness, conscientiousness and openness) of the big-five personality traits (Figure 2.3). 


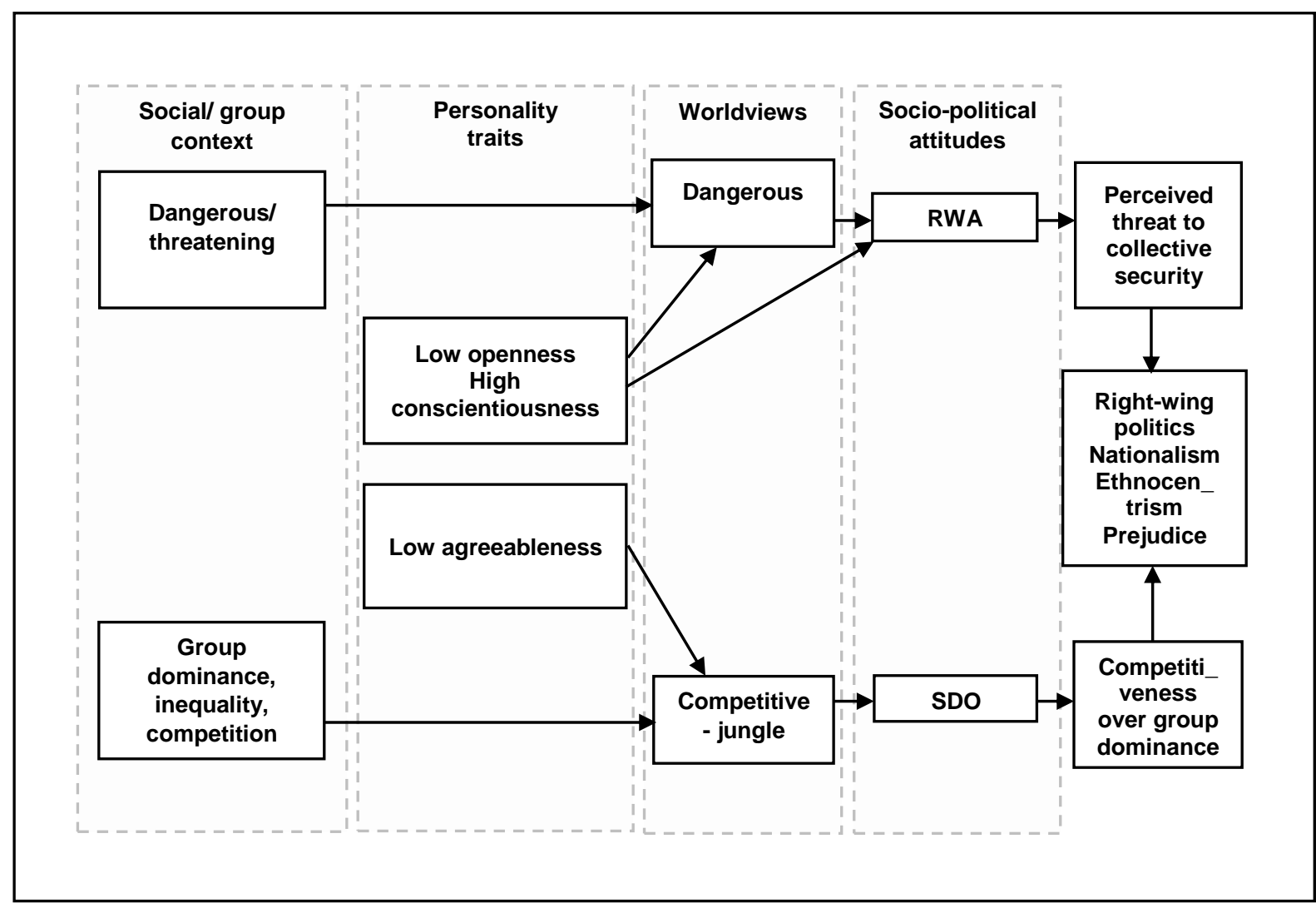

Figure 2.3. Duckitt and Sibley's (2010) dual-process motivational model including context and three of the big-five personality traits (adapted from Duckitt \& Sibley, 2010).

Differently from the original model, RWA and SDO were hypothesized to impact right-wing politics, nationalism, ethnocentrism and prejudice only indirectly via perceived threat to collective security (for RWA) and competitiveness over group dominance (for SDO). According to this model, worldviews could change in accordance with changes in the social environment, especially if the change in the social environment was enduring and considerable.

Overall, Duckitt and Sibley's (2010) new version of the model made it reasonable to assume that enduring and considerable threat could impact worldviews, RWA, SDO and the resulting political and ethnocentric behaviours. Moreover, the model also made it possible to assume that social contexts characterized by danger and threat would impact world beliefs differently when compared to social contexts characterized by merciless competition for resources.

Although to our knowledge no study has tested the full model presented by Duckitt and Sibley (2010), some studies have tested the stability of the DPM model or parts of the model in relation to systemic threat. In a recent study, Sibley and Duckitt (2013) evaluated the 
relationship between the big-five personality traits, competitive and dangerous worldviews, and both RWA and SDO using a cross-lagged design. In this study, data were collected before (time 1) and during (time 2) a global financial crisis. Confirming the DPM model, the authors found that low openness in time 1 predicted dangerous worldview in time 2 , and that dangerous worldview in time 1 predicted RWA in time 2 (i.e. low openness $\rightarrow$ dangerous worldview $\rightarrow$ RWA). On the other hand, low agreeableness and low openness to experience in time 1 predicted competitive worldview in time 2 , and competitive worldview in time 1 predicted SDO in time 2 (i.e. low agreeableness/openness $\rightarrow$ competitive worldview $\rightarrow$ SDO), only partially supporting the model.

Unexpectedly, RWA and SDO in time 1 predicted dangerous and competitive worldviews, respectively, in time 2. Also unexpectedly, competitive worldview and SDO in time 1 predicted agreeableness in time 2. Overall, the empirical model obtained in this study provided evidence of the causal links hypothesized by Duckitt (2001) even when considering a time of global financial crisis in comparison to a relatively safer time period. Importantly for the context of the present research, Sibley and Duckitt (2013) also pointed out that the connection between the variables in the DPM model was more readily observed in times of systemic instability or societal threat.

Also contributing to the literature on threat and the DPM model, Sibley et al. (2013) studied how characteristics of the social context interacted with world beliefs on explaining prejudice using a dataset with 6,489 members of the general population. The authors confirmed that competitive and dangerous worldviews interacted with characteristics of the residential area - the proportion of immigrants in the area and economic deprivation of the area - in the prediction of attitudes toward immigrants. More specifically, those high in dangerous worldview who lived in areas with a higher proportion of immigrants presented more negative attitudes toward immigrants, while those high in competitive worldview who lived in non-economically deprived areas presented more negative attitudes toward immigrants.

Also adding to the literature on threat and variables included in the DPM model, but also associating these with political conservatism, Sibley, Osborne and Duckitt (2012) focused on the moderation of the impact of personality on political conservatism by systemic threat (societal threat). More specifically, the studies considered in their meta-analysis focused on the impact of the big-five personality traits on political orientation measured on a selfplacement single-item measure (liberal versus conservative). The indices of systemic threat considered by the authors were the national-level measures of intentional homicides per 
100,000 people (systemic danger) and of unemployment percentage on the labour force (systemic instability). The authors found that the strength of the relationship between openness to experience and political orientation decreased when systemic danger was higher. For systemic instability the authors found that as systemic instability increased, the impact of openness to experience on political orientation became slightly less negative. The prediction of political orientation by the other big-five factors was not moderated by systemic threat.

Together, the literature reviewed above concerning the association of threat and variables in the DPM model shows that different types of social contexts including external danger or competition for resources can differently impact political conservatism and related variables. Moreover, the limited empirical literature suggests that the relationship between variables in the DPM model is more readily observable during threatening situations or periods of systemic instability, and also that the association between types of social context (dangerous versus competitive) and some of the DPM model variables impact differentially prejudice and political conservatism.

Drawing upon the literature reviewed above, we will also evaluate the following hypothesis in this research:

Hypothesis 3 (dual-process mediation). The hypothesis of dual-process mediation (Duckitt \& Fisher, 2003) postulates that world beliefs (competitive and dangerous) and socio-political attitudes (RWA and SDO) will differentially mediate the impact of societal threat on political conservatism

More specifically, this hypothesis will evaluate whether or not economic and social threats (in comparison to a control condition) will impact differentially political conservatism via different DPM model pathways. In order to evaluate this differential mediation hypothesis, we will evaluate first whether or not there are differences in world beliefs and socio-political attitudes across conditions. In order to test this dual-process mediation hypothesis accurately, we hypothesize that:

Hypothesis 3A. Individuals facing social threat will perceive the world as more dangerous and will be more authoritarian than individuals facing economic threat or the absence of threat 
Hypothesis 3B. Individuals facing economic threat will perceive the world as more competitive and will be more social dominance oriented than individuals facing social threat or the absence of threat

Below, we explore further how threat has been studied along with RWA outside the DPM model, describing an alternative hypothesis for this association. The relationship between threat and authoritarianism has been questioned in the literature, deserving even a special issue in the International Journal of Psychology (Duckitt, 2013).

Threat research including $\boldsymbol{R} W \boldsymbol{A}$. Considering the variables included in the DPM model, right-wing authoritarianism has been the most studied along with threat. However, the nature of the relationship between these two variables has been questioned. Overall and outside the DPM model, the relationship between threat and RWA in the prediction of political conservatism has been mainly conducted considering perceived (internal/psychological) and not societal threat. Among these studies, perceived threat has been studied either as the mediator of the impact of RWA on political conservatism (McFarland, 2005) or as a moderator of the impact of RWA on political conservatism (Kossowska et al., 2011).

Among the studies which have considered perceived threat as a mediator of the impact of RWA on political conservatism, McFarland (2005) examined the different ways in which RWA and SDO led to support for military attacks on Iraq. He found that only RWA led to the perception of Iraq as a threat which in turn led to support for military attacks (i.e. RWA $\rightarrow$ Iraq as a threat $\rightarrow$ military support).

Among the studies which have considered threat as a moderator of the impact of RWA on political conservatism, Kossowska et al. (2011) investigated in four different countries how RWA, support for limitation of civil liberties and perceived terrorism threat related to each other. The authors hypothesized that in a country in which threat was situational (and not chronic), threat would enhance the relationship between RWA and support for limitation of civil rights. The authors confirmed their hypothesis, finding that only high-RWAs were impacted by terrorism threat in this country (i.e. high-RWA $\times$ terrorism threat $\rightarrow$ limitation of civil rights). Importantly, this article included predictions per country context, considering to some extent the interplay between societal context of the country, RWA and perceived threat.

Also focusing on the role of threat as a moderator, Hastings and Shaffer (2005) investigated how RWA predicted support for military aggression and support for democratic values. Participants in this study answered the RWA scale and then were assigned to a 
condition in which they read a threatening scenario about the war on terrorism or a safe scenario enclosing the same topic. After reading the scenario, the participants answered the other attitudinal measures. The authors found that the extent to which RWA impacted the support for democratic values depended on the condition the participant was allocated. More specifically, the authors found support for the RWA activation by threat hypothesis which posits that only high authoritarians are affected by threat (Feldman \& Stenner, 1997; Feldman, 2013). However, they did not find support for the same relationship between threat and RWA when support for military aggression was considered.

Additionally, some literature has already been focusing on the nature of the relationship between RWA and threat. Onraet, Dhont, and Van Hiel (2014), for instance, used a cross-lagged design to test the relationship between RWA with internal threat (conceptualized as the perception of threat in the personal life of oneself) and external threat (conceptualized as the perception of threat to the society) in a tree-wave longitudinal study. The authors found that external threat was impacted by previous levels of RWA but also impacted posterior levels of RWA.

Given that the nature of the relationship between threat and RWA is uncertain and that the interaction between authoritarianism and perceived threat has been acknowledged in the literature (Feldman, 2013), we will also test the effect of the interaction between previous levels of RWA and social threat on variables included in the DPM model. More specifically, and based on the DPM model, we will also evaluate the following fourth and final hypothesis:

Hypothesis 4 (activation of authoritarianism by social threat). The hypothesis of activation of authoritarianism by social threat (Feldman \& Stenner, 1997) postulates that authoritarians will be more sensitive to social threat, and this interaction will increase dangerous world beliefs (i.e. authoritarianism $\times$ social threat $\rightarrow$ dangerous world beliefs).

Along with these main predictions, it also will be investigated whether or not different types of societal threat differentially impact political conservatism. Below, the literature examining the association between economic, social, and natural threats with political conservatism is presented.

\section{Societal Dimensions of Threat and the Prediction of Political Conservatism}

The studies presented in this thesis will also try to evaluate the differential impact of economic, natural and social threats on political conservatism throughout the four hypotheses 
presented previously. While the relationship of economic and social threats with political conservatism has at least been considered in the literature (but often without clear distinction between these types of threat), the relationship between natural threat and political conservatism has been conducted entirely based on specific types of natural threat and not on natural threat as an umbrella term. Below, the literature enclosing the relationship between political conservatism and economic and social threats is introduced, followed by the literature enclosing the relationship between political conservatism and natural threat.

Economic and social threats. Studies examining the influence of threat on social behaviour, and in particular on socio-political attitudes and voting, have to some extent examined the impact of economic and social threats on political conservatism. In their metaanalytical review of the relationship between societal threat and political conservatism, Jost et al. (2003b) found only four articles focusing on economic and social threats along with political threat. The studies were based on archival data and their authors mainly categorized periods as high or low in threat. The impact of these periods on several indices connected to political conservatism was then evaluated. Supporting the conservative shift hypothesis, these studies indicated that threatening economic, social and political periods are associated with an increase in political conservatism. Some of the articles based their threatening period definition on the evaluation of experts, but none verified within samples of the population what was specifically perceived as economic, social and political threats (McCann \& Stewin, 1990).

Overall, the articles evaluated in Jost et al.'s (2003b) meta-analysis had the limitation of not basing their threatening period categorisation on what the population perceived as threatening, a matter of fundamental importance (Slovic, 1987). They also did not differentiate the impact of economic and social threats on political conservatism. These limitations were mostly due to the type of studies enclosed in the meta-analysis - archival data studies.

After the 9/11 terrorist attacks, various studies have investigated the impact of threat on political conservatism using terrorist attacks as markers or antecedent variables. These events have been connected to higher prejudice, authoritarianism, conservative values, conservative shift and support for harsher policies regarding terrorism in the literature (Bonanno \& Jost, 2006; Echebarria-Echabe \& Fernandez-Guede, 2006; Huddy \& Feldman, 2011; Henderson-King et al. 2004). Some authors have also used the framework of terror management theory to try to explain why people reacted the way they did after the $9 / 11$ attacks (Pyszczynski et al., 2003). The use of a theory that includes death salience to explain 
the effects of a threatening event on people's behaviours shows how death salience and threat can be intrinsically related concepts.

To our knowledge, no previous study has examined systematically the impact of social and economic threats, as perceived by the population, on political conservatism. These types of threat are clearly related, but we argue that they can be conceptually distinguished with possible independent influence on behaviour. Also to our knowledge, no study has considered the relationship between these types of threat and voting using New Zealand samples, although some studies have considered the relationship between variables in Duckitt's (2001) DPM model, threat, and/or political orientation (Sibley \& Duckitt, 2013; Sibley et al., 2012).

Natural threat. Dunlap, Gallup and Gallup (1993) using samples from 12 industrializing and 12 developing countries found with open-ended questions that at least $21.0 \%$ of the respondents in each country perceived environmental problems as very serious. In the same report the authors described that with the exception of three countries, more than $50.0 \%$ of the respondents were "a great deal" or "a fair amount" personally concerned with environmental problems. Despite the acknowledgement of environmental problems as a source of concern and possibly threat, the impact of natural threat on political conservatism has not been systematically explored.

Threatening situations related to natural threat could include events such as floods, hurricanes, tornadoes, earthquakes, volcano eruptions, tsunamis, and sea level rise depending on the geographic circumstances of the given location and also on the meaning of these hazards to the population. Díaz, Tapia, Estrada and Leiva-Bianchi (2012), for instance, studied the psychological meaning of earthquakes and tsunamis among Chileans affected directly or indirectly by them. They found that negative sentiments, feelings and consequences were intrinsically linked to the meaning of both natural disasters, with words such as "fear", "suffering", "disaster", and "destruction" central to the meaning of these hazards. These results suggest that earthquakes and tsunamis could possibly be perceived as threat, at least in regions affected by them.

McClure, Johnston, Henrich, Milfont, and Becker (2015) illustrated this point in a study conducted in New Zealand evaluating how much participants expected that earthquakes would happen, how real the risk of an earthquake was, how much participants were prepared for an earthquake and the perception of damage after a major earthquake in cities affected and not affected by earthquakes. Overall, they found that participants expected more earthquakes in New Zealand after a major earthquake than before it and that the number of participants 
who said the earthquake was more real after the major earthquake was higher in the city affected by it than in a city where earthquakes do not usually happen.

In general, research including the consequences of these natural disasters is incipient, but has shown continuous growth, especially when considering the threat of climate change (Intergovernmental Panel on Climate Change [IPCC], 2014). Some countries, as well as some studies, have started to recognize the role of climate change in fostering internal instability and international conflict (Broder, 2012). At least one study has summarized research addressing climate variation and its impact on conflict. In the meta-analysis by Hsiang et al. (2013), the impact of climate variation on conflict was evaluated using variations in temperature, rain, flood, storm, drought and a drought severity index as independent variables, and interpersonal and intergroup conflict as dependent variables. The authors found that climate variation had a positive association with interpersonal and intergroup conflict, meaning that climate variation might lead to an increase in conflict.

Despite this meaningful relationship, to our knowledge, no study has evaluated the impact of natural threat as an umbrella term on political conservatism. Instead, studies have mainly focused on the impact of specific types of natural threat (similarly to the general literature) on variables associated to political conservatism. Fritsche, Cohrs, Kessler and Bauer (2012), for instance, evaluated the impact of climate change on authoritarianism, which has been identified in the literature as a key predictor of political conservatism (Jost et al., 2009). The authors observed that participants' authoritarian attitudes and derogation toward threatening groups increased after having been exposed to priming making salient the negative consequences of climate change.

Focusing on religious conversion, a variable that has been associated to higher authoritarianism, Sibley and Bulbulia (2012) found that the number of people who became religious between 2009 and 2011 living around the region of the destructive 2011 Christchurch earthquake in New Zealand was higher than the number of people who became religious living in other parts of the country. The rate of conversion was also higher among people directly affected by the earthquake than among people not directly affected by it. Religiosity has been related in the literature to higher traditionalism, one of the key components of authoritarianism (Duckitt et al., 2010).

Overall, the studies reviewed above suggest that specific types of natural threat might influence political conservatism. However, so far no study has examined this prediction systematically and explicitly using natural threat as an umbrella term. Adding to the literature, 
the experimental studies reported in this thesis will try to provide a systematic investigation of the differential effects of economic, social, and natural threats on political conservatism.

\section{Conclusion}

Overall the literature review suggests that (1) in the presence of societal threat, people may or may not shift their political orientation towards political conservatism; (2) the impact of societal threat on political conservatism has not been studied in a systematic way; (3) the variables included in Duckitt's (2001) DPM model could mediate the impact of societal threat on political conservatism; and (4) the relationship between threat and authoritarianism is controversial in the literature.

Based on these conclusions, the empirical studies presented in the present research test whether or not: (1) societal threat always enhances political conservatism (conservative shift hypothesis, H1); (2) societal threat enhances political conservatism only in people who were already conservative before experiencing threat (cultural worldview enhancement hypothesis, $\mathrm{H} 2$ ); (3) the impact of societal threat on political conservatism is differentially mediated by variables in the DPM model (dual-process mediation hypothesis, H3); (4) social and economic threats differentially impact specific DPM model variables (dangerous world beliefs and RWA, H3A; and competitive world beliefs and SDO, H3B); and (5) only people high in authoritarianism are impacted by social threat (activation of authoritarianism by social threat hypothesis, H4). Additionally, we also explore the differential impact of economic, social and natural threats on political conservatism. The next chapters describe the seven empirical studies conducted in order to test the set of hypotheses indicated above. 


\section{Chapter 3: Study 1}

\section{Duckitt's DPM Model and the Prediction of Political Conservatism}

Despite the recognition that societal threat might lead to more conservative political behaviour, so far only a limited number of studies have systematically focused on variables which could mediate this impact. In this sense, before turning to a formal test of the hypotheses presented in the previous chapter, it is important to establish whether or not the proposed mediators for the impact of societal threat on political conservatism (dangerous and competitive world beliefs, RWA and SDO) systematically predict political conservatism. The present study tests the prediction of voting intention and political orientation by the DPM model (Duckitt, 2001), firstly by confirming the DPM model structure observed in Sibley and Duckitt's (2009) study and secondly by verifying the prediction of voting intention and political orientation by this model.

Although the predictive and explanatory validity of variables in the DPM model has been tested in a number of studies (e.g. Perry \& Sibley, 2012; Sibley \& Duckitt, 2010), only three previous studies (Sibley \& Duckitt, 2009; Sibley \& Duckitt, 2013; Van Hiel, Cornelis, $\&$ Roets, 2007) have examined the extent to which the big-five model of personality could be used to index the specific personality traits in the development of RWA and SDO through social worldviews. Moreover, while variables of the DPM model have been extensively used in the prediction of intergroup prejudice and related prejudiced attitudes and behaviours (e.g. Cohrs \& Asbrock, 2009; McFarland, 2010), to the best of our knowledge the full model has never been used in the prediction of conservative voting intention and related conservative political orientations. The present study expands extant research by testing the DPM model with the big-five personality traits and testing its usefulness in predicting conservative political variables.

\section{The DPM Model}

The DPM model outlines two pathways underlying the development of RWA and SDO, which are the core socio-political attitudes explaining intergroup prejudice (Duckitt, 2001). According to this model, RWA and SDO result from particular socialisation practices, personality traits and worldviews. RWA reflects a punitive socialisation, social conformity and the perception of the world as a dangerous place. In contrast, SDO reflects an unaffectionate socialisation, tough-mindedness and the perception of the world as competitive. The DPM model thus proposes a dual mediational model with personality traits influencing the development of RWA and SDO via particular worldviews. Support for the 
DPM model (or portions of the model) has been shown in a number of studies (e.g. Perry \& Sibley, 2012; Sibley \& Duckitt, 2009, 2010; Sibley, Wilson, \& Duckitt, 2007) and metaanalyses (Perry et al., 2013; Sibley \& Duckitt, 2008).

Nowadays, studies focusing on the model include mostly the big-five personality traits instead of the personality traits of social conformity and tough-mindedness. Sibley and Duckitt's (2009) results, for instance, supported the inclusion of the big-five personality traits in the DPM model based on a New Zealand undergraduate sample. The authors found that overall the big-five personality traits impacted RWA and SDO indirectly through dangerous and competitive worldviews. Specifically, they found that low openness to experience led to high dangerous worldview, while low agreeableness led to high competitive worldview. Also in line with the DPM model, dangerous worldview predicted RWA and competitive worldview predicted SDO.

Most of the effect from personality to RWA/SDO was mediated by the worldviews, but some direct paths between personality and socio-political attitudes were observed. In particular, high conscientiousness and low openness to experience led to high RWA, while low agreeableness led to high SDO. These results confirm findings reported by Van Hiel et al. (2007) with student and voter samples from Belgium. These authors showed that neuroticism and openness impacted RWA directly and indirectly through dangerous worldview, and that agreeableness impacted SDO only indirectly through competitive worldview.

Supporting and extending the DPM model, the findings of these two studies (Sibley \& Duckitt, 2009; Van Hiel et al., 2007) have shown that the big-five model of personality could be used and that the relationships between the personality dimensions and RWA/SDO are by and large mediated by social worldviews. In particular, the two distinct pathways suggest the following pattern: conscientiousness/openness $\rightarrow$ dangerous worldview $\rightarrow$ RWA, and agreeableness $\rightarrow$ competitive worldview $\rightarrow$ SDO. The present study explores these associations in the context of voting intention and political orientation.

\section{Socio-Political Attitudes and Political Conservatism}

Despite its enormous popularity in explaining intergroup prejudice, the DPM model has not been widely used in the context of voting intention and political orientation. Nevertheless, a number of studies have started to show the extent to which RWA and/or SDO can also predict political conservatism. For example, RWA has been shown to be positively related to support for military aggression (Crowson, 2009; Henderson-King et al., 2004), tough government actions (Duckitt et al., 2010), and harsh and punitive political positions (Peterson et al.1993). Similarly, SDO has been shown to be positively related to support for 
greater violence in war (Henry et al., 2005), lack of support for environmental or proegalitarian policies (Pratto et al., 1994; Milfont et al., 2013) and conservative social policy (Jost \& Thompson, 2000). Other studies have also shown that both high RWA and high SDO are positively related to restriction of human rights (Cohrs et al., 2007; Crowson, 2007) and conservative voting (Duckitt et al., 2010; Ho et al., 2012).

To our knowledge, only two articles have focused on the impact of both RWA and SDO on voting and support for different parties (Van Hiel \& Mervielde, 2002; Wilson \& Sibley, 2013). The study of Van Hiel and Mervielde (2002) with members of the general population investigated the predictive validity of RWA and SDO in explaining political party preferences - measured by participants' agreements toward the program of the six major political parties in Flanders. Results showed that RWA was more positively correlated to the preference for a more religious and traditional party, while SDO was more positively correlated to the preference for a more anti-immigrant party (an extreme right-wing party).

Wilson and Sibley (2013) examined how RWA and SDO explained political conservatism across 14 samples from New Zealand. Political conservatism was operationalised in a variety of ways, including attitudes toward political issues, scores in a version of the Wilson-Patterson Conservatism scale, and support for New Zealand political parties. Overall, they observed that high levels of both RWA and SDO were associated with high levels of political conservatism, and RWA and SDO predicted political conservatism both in additive and interactive fashion. More important for the context of the present study, these authors showed that both RWA and SDO predicted support for conservative parties in New Zealand.

\section{The Present Study}

The studies reviewed above provide empirical support for using the DPM model to predict political conservatism. Building on the theoretical and empirical considerations presented previously, the goals of the present study are twofold. First, the study tries to replicate the latest model by Sibley and Duckitt (2009) proposing a causal flow based on the DPM model, with personality traits predicting RWA and SDO via worldviews. Expanding the work by Sibley and Duckitt (2009), the study also examines whether the DPM model could be used to predict political conservatism, including voting intention as well as left/right and liberal/conservative orientations.

Although RWA and SDO were linked to social conformity and tough-mindedness respectively in the original conceptualisation of the DPM model (Duckitt, 2001), most recent work has considered the big-five personality traits (e.g. Duckitt \& Sibley, 2010; Sibley \& 
Duckitt, 2009, 2013). From this perspective, social conformity would be indexed by lowopenness and high-conscientiousness in predicting RWA, while tough-mindedness would be indexed by low-agreeableness in predicting SDO. This study thus examines whether the bigfive personality traits could be used in exchange of the traits originally proposed in the model, and whether this modified model can predict voting intention and political orientation.

\section{Method}

\section{Participants and Procedure}

Data used in this study came from an online survey conducted in September of 2011 investigating New Zealanders' political and social attitudes (Wilson, 2011), solicited through the Sunday Star Times, a national New Zealand newspaper. A total of 5,744 individuals completed the online survey (via SurveyMonkey), but participants with more than $5 \%$ of their responses missing were excluded from the dataset in order to safeguard the effectiveness of the missing data imputation procedure (Tabachnick \& Fidell, 2007). Outliers and normality analyses were also undertaken but no other participant was discarded. A total of 2,884 participants who intended to vote for one of the four political parties in which participants mostly reported intention to vote for remained for use in the main analyses. All participants were New Zealand-born and $61.6 \%$ were females. The mean age was 50.90 years $(S D=$ 14.97).

\section{Apparatus and Materials}

Personality traits. The ten-item personality inventory was used to measure the bigfive personality traits (Gosling, Rentfrow, \& Swann, 2003). Each sub-scale included two items rated on a 7-point scale varying from 1 (strongly disagree) to 7 (strongly agree).

Competitive and Dangerous Worldviews. Two balanced items based on previous research (Duckitt, 2001) were used by Wilson (2011) to measure competitive (e.g. "It's a dogeat-dog world where you have to be ruthless at times") and dangerous worldviews (e.g. "There are many dangerous people in our society who will attack someone out of pure meanness, for no reason at all"). Items were rated on a 7-point scale varying from 1 (strongly disagree) to 7 (strongly agree).

RWA. Six items were randomly sampled from the original RWA scale (Altemeyer, 1996) so as to have an equal number of pro-trait (e.g. "Once our government leaders give us the "go ahead", it will be the duty of every patriotic citizen to help stomp out the rot that is poisoning our country from within") and con-trait (e.g. "Everyone should have their own lifestyle, religious beliefs, and sexuality, even if it makes them different from everyone else") 
items. Items were also carefully selected to include features of the three RWA factors found by Mavor, Louis and Sibley (2010). Items were rated on a 7-point scale varying from 1 (strongly disagree) to 7 (strongly agree).

SDO. Six items were randomly sampled from the original SDO scale (Sidanius \& Pratto, 1999) so as to have an equal number of dominance items (e.g. "To get ahead in life, it is sometimes okay to step on other groups.") and equality items (e.g. "It would be good if groups could be equal"). The items were the same as those used in the New Zealand Attitudes and Values Survey (NZAVS; Sibley \& Greaves, 2014). Items were rated on a 7-point scale varying from 1 (strongly disagree) to 7 (strongly agree).

Political conservatism. Three questions were used to measure political conservatism. Participants were asked which political party they would vote for in the upcoming general election. Besides voting intention, participants were also asked to indicate their left/right and liberal/conservative orientations on single-item scales varying from 1 (left or liberal) to 7 (right or conservative).

Extra questions also evaluated participants' sentiments toward New Zealand political parties on a 7-point scale varying from 1 (strongly negative) to 7 (strongly positive). These questions were used to investigate the viability of a dummy voting intention variable.

\section{Data analysis}

Multiple imputation technique with Expectation Maximization (Tabachnick \& Fidell, 2007) was used to substitute missing data. Structural equation modeling was performed with maximum likelihood estimation procedures in AMOS 20. Due to the mediational nature of the DPM, bootstrapping procedures were implemented (with 1000 re-samplings) to calculate the indirect effects. Before running the models, item parcels were created for the RWA and SDO scales. Each parcel included one pro-trait and one con-trait item randomly assigned to it (Little, Cunningham, Shahar, \& Widaman, 2002).

Four indicators of model fit were considered when evaluating the models: The ratio $\chi^{2} / d f$ (chi-square over degree of freedom), the comparative fit index (CFI), the standardized root mean square residual (sRMR), and the root mean square error of approximation (RMSEA). Values of $\chi^{2} / d f$ smaller than two indicate good fit and values between two and three indicate acceptable fit (Bollen \& Long, 1993). Models with CFI values close to .95 indicate an acceptable fit; while SRMR and RMSEA having values close to .08 and .06, respectively, or lower indicate an acceptable fit (Byrne, 2001; Hu \& Bentler, 1999). The consistent Akaike information criterion (CAIC), the expected cross-validation index (ECVI), and the chi-square difference test $\left(\chi^{2}\right.$ d.ff $)$ were used to evaluate improvements over competing 
models. Lower values in the first two indices reflect better fit, while a significant chi-square difference test reflects model improvement (Byrne, 2010). When initially fitting the models to the data, the error variance for one extraversion item ("I am extraverted, enthusiastic") was negative and non-significant, resulting in a non-identified model. This error variance was then fixed to a small and positive value (Gerbing \& Anderson, 1987) in all subsequent models.

\section{Results}

\section{Preliminary Analysis}

Appendix A presents descriptive statistics, reliability estimates and correlations between all variables considered in this study. Besides focusing on these basic statistics, the preliminary analysis focused on the voting intention variable detailed below.

Voting intention. The variable measuring voting intention was created by grouping intention to vote for liberal versus conservative parties. Before creating this variable, a correlational analysis was run to evaluate the relationship between sentiments toward five of the New Zealand political parties (from 1 = strongly negative to 7 = strongly positive). The dataset for this analysis included the participants described in this study $(2,884$ participants who reported intention to vote for the ACT, the Green, the Labour or the National parties) plus 62 participants who reported intention to vote for the New Zealand First party.

Sentiments toward the remaining New Zealand political parties were not considered given the limited voting intention for these parties $(2.0 \%)$.

We predicted that sentiments toward liberal parties (Green and Labour parties) should be positively correlated, sentiments toward conservative parties (ACT and National parties) should be positively correlated, and sentiments toward liberal and conservative parties should be negatively correlated in order to group intention to vote for liberal or conservative parties. The correlational analysis suggested the expected pattern (Table 3.1). As a centre-party, sentiments toward New Zealand First correlated weakly and positively with almost all the remaining political parties. 
Table 3.1

Correlations between sentiments toward five of New Zealand's political parties in Study 1

\begin{tabular}{lccccc}
\hline & 1 & 2 & 3 & 4 & 5 \\
\hline 1. ACT & - & $-.36^{* *}$ & $-.40^{* *}$ & $.48^{* *}$ & $.11^{* *}$ \\
2. Green & - & - & $.56^{* *}$ & $-.45^{* *}$ & .03 \\
3. Labour & - & - & - & $-.59^{* *}$ & $.15^{* *}$ \\
4. National & - & - & - & - & $-.06^{* *}$ \\
5. NZ First & - & - & - & - & - \\
\hline
\end{tabular}

Note. $* * p<.01$.

As expected, the newly created variable was positively correlated to left/right $(r=.68)$ and liberal/conservative $(r=.54)$ orientations, and these political orientations were also highly correlated $(r=.64)$.

\section{Testing the Big-Five Personality Model under the DPM Model Frame}

The model proposed by Sibley and Duckitt (2009) showed only marginal fit to the data: $\chi^{2}(146, N=2,884)=1507.29 ; \chi^{2} / d f=10.32 ; \mathrm{CFI}=.90 ; \mathrm{sRMR}=.045 ; \mathrm{RMSEA}=.057$; $90 \%$ CI RMSEA $=.054-.059 ;$ CAIC $=2081.178 ; \mathrm{ECVI}=.567$. Modification indices suggested the omission of three causal paths and the inclusion of three other causal paths. Figure 3.1 depicts this modified model, which was better fitting than the proposed model: $\chi^{2}(146, N=2,884)=1426.08 ; \chi^{2} / d f=9.77 ; \mathrm{CFI}=.91 ; \mathrm{sRMR}=.043 ; \mathrm{RMSEA}=.055 ; 90 \% \mathrm{CI}$ RMSEA $=.053-.058 ;$ CAIC $=1999.966 ; \mathrm{ECVI}=.539$.

As can be seen in Figure 3.1, and consistent with Sibley and Duckitt's (2009) findings, overall the big-five personality dimensions predicted dangerous and competitive worldviews, which in turn predicted RWA and SDO. In contrast to their findings, the direct paths between extraversion $\rightarrow$ dangerous worldview, agreeableness $\rightarrow$ SDO and emotional stability $\rightarrow$ RWA were not statistically significant in our sample. At the same time, both emotional stability and dangerous worldview had a direct effect on SDO, while extraversion had a direct impact on RWA. 


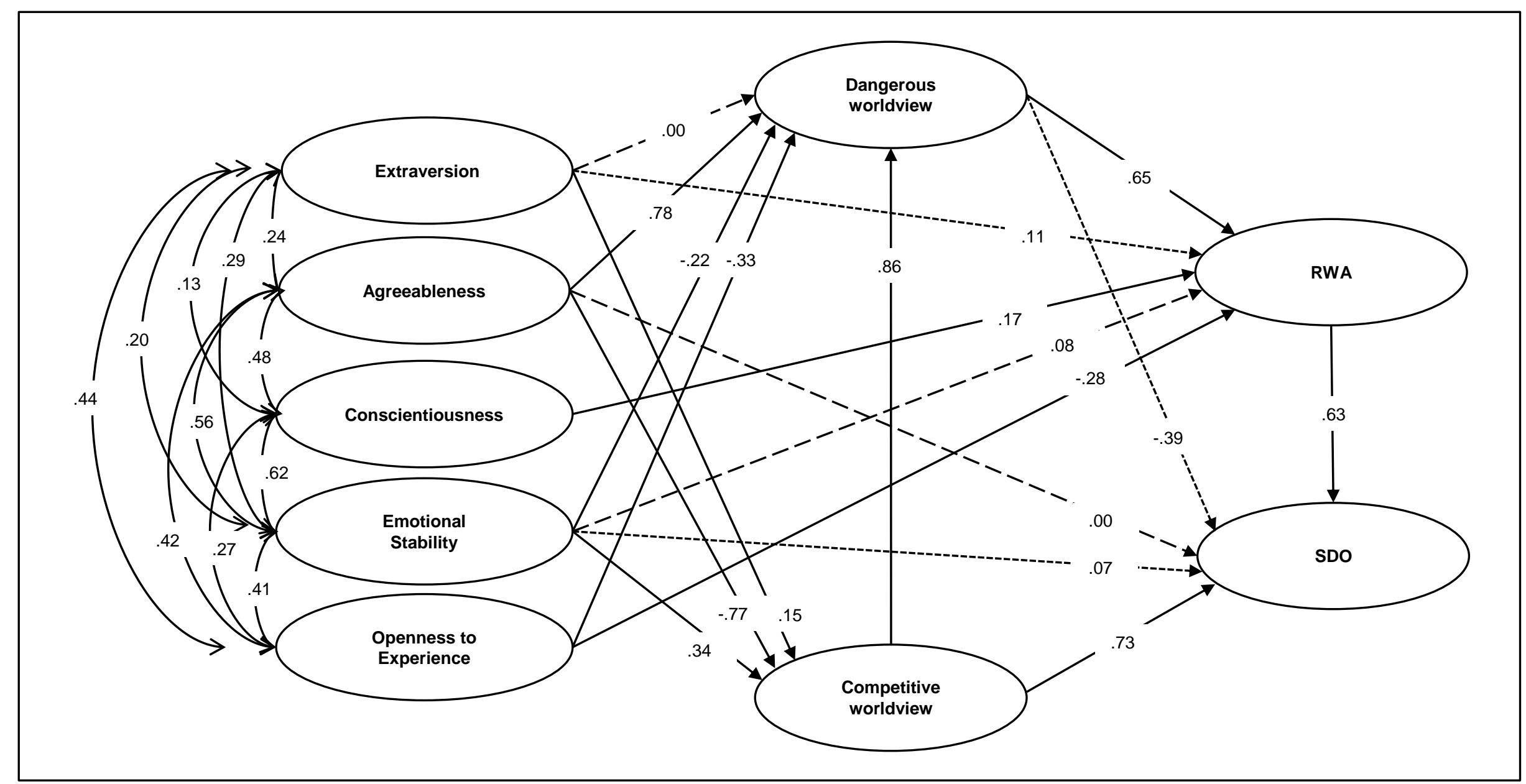

Figure 3.1. Structural equation model of the associations between personality traits, world beliefs and socio-political attitudes. Solid arrows represent significant causal paths $(p<.01)$. Long-dashed arrows represent significant causal paths $(p<.05)$ in Sibley and Duckitt $(2009)$, but not in the present study. Short-dashed arrows represent significant causal paths in this study $(p<.01)$, but not in Sibley and Duckitt (2009). For simplicity, manifest indicators and paths from latent to manifest indicators are not shown. 


\section{The Association between the DPM Model and Political Conservatism}

We expanded the model in Figure 3.1 to predict political conservatism with direct paths from RWA/SDO to the three political orientation variables. The model predicting voting intention was satisfactory: $\chi^{2}(164, N=2884)=1540.68 ; \chi^{2} / d f=9.39 ; \mathrm{CFI}=.91$; $\mathrm{sRMR}=.044 ; \mathrm{RMSEA}=.054 ; 90 \%$ CI RMSEA $=.052-.056 ; \mathrm{CAIC}=2141.462 ; \mathrm{ECVI}=$ .581 .

However, modification indices suggested the inclusion of a direct path from emotional stability to voting intention. This modified model was statistically better fitting than the initial model, $\chi_{\text {d.ff }}^{2}(1)=37.43, p<.001$, and provided an adequate fit to the observed data: $\chi^{2}(163, N=2884)=1503.25 ; \chi^{2} / d f=9.22 ; \mathrm{CFI}=.91 ; \mathrm{sRMR}=.042 ; \mathrm{RMSEA}=.053$; $90 \%$ CI RMSEA $=.051-.056 ;$ CAIC $=2113.004 ; \mathrm{ECVI}=.569$. As can be seen in Figure 3.2, the personality traits impacted voting intention mainly indirectly via worldview beliefs and socio-political attitudes. Indeed, all variables in the model that did not impact voting intention directly, impacted it indirectly. ${ }^{1}$ Importantly, SDO impacted voting intention more strongly than RWA. ${ }^{2}$

\footnotetext{
${ }^{1}$ The statistically significant $(p<.005)$ indirect effects on voting intention were as follows: openness to experience $\left(\beta_{\text {indirect effect }}=-.19\right)$, agreeableness $\left(\beta_{\text {indirect effect }}=-.19\right)$, emotional stability $\left(\beta_{\text {indirect effect }}=.13\right)$, extraversion $\left(\beta_{\text {indirect effect }}=.12\right)$, conscientiousness $\left(\beta_{\text {indirect effect }}=.08\right)$, competitive worldview $\left(\beta_{\text {indirect effect }}=.43\right)$, dangerous worldview $\left(\beta_{\text {indirect effect }}=.18\right)$ and RWA $\left(\beta_{\text {indirect effect }}=.23\right)$.

${ }^{2}$ To test whether the associations between RWA and SDO with voting intention were statistically different, a similar model was run by fixing the unstandardized relations to be equal. However, the iteration limit for this model was reached even when the limit was fixed to 1,000 iterations. Thus, a correlation difference test based on Fisher $r$ - $z$ transformation was used instead to compare the correlations between RWA and voting intention [ $r_{\mathrm{ab} . c}$ $(2,868)=.31, p<.001]$ and SDO and voting intention $\left[r_{\text {ab.c }}(2,868)=.36, p<.001\right]$. The test confirmed that SDO correlated more strongly to voting intention than $\operatorname{RWA}(z=2.314, p=.02)$.
} 


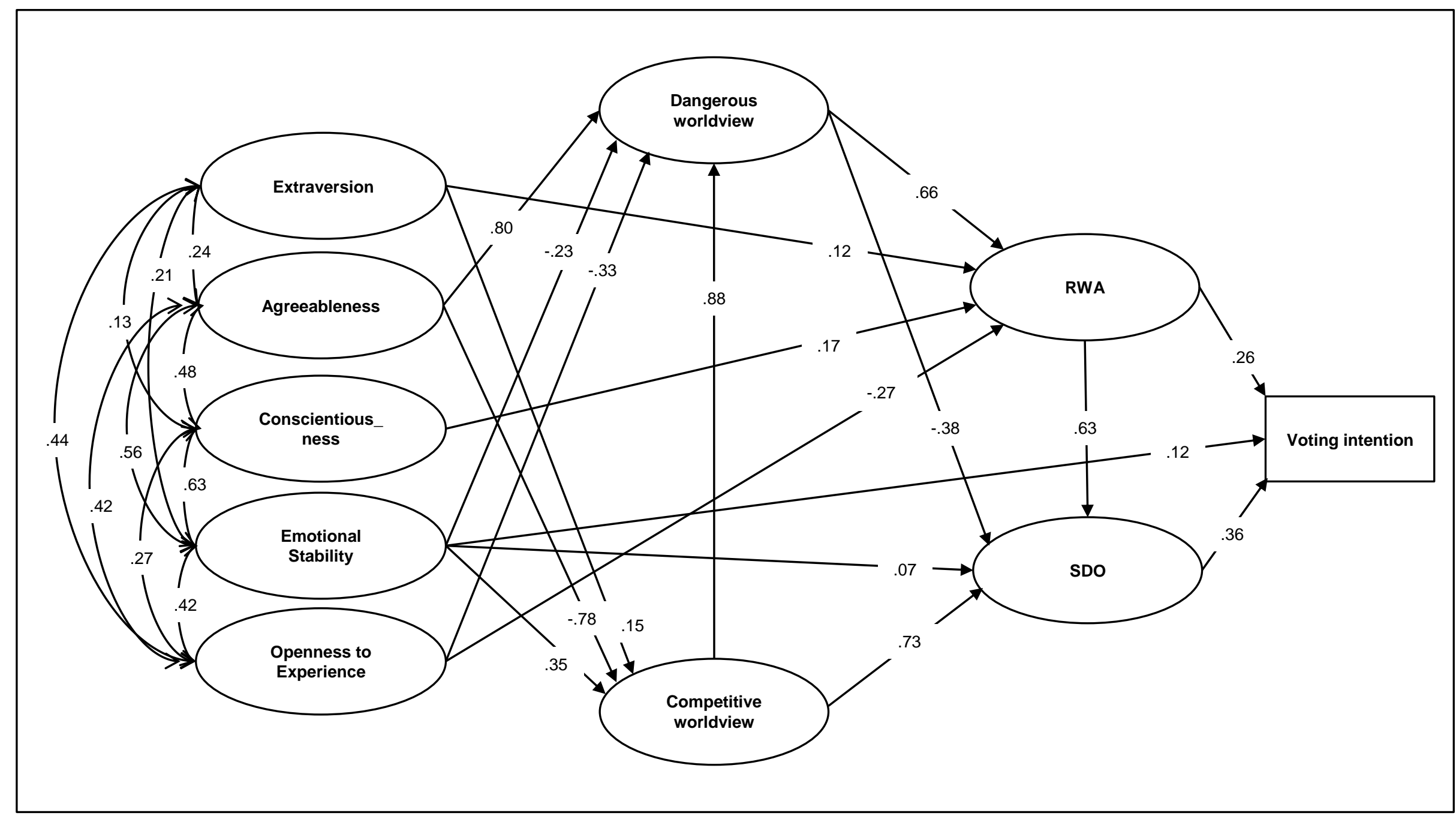

Figure 3.2. Structural equation model of the associations between personality traits, world beliefs, socio-political attitudes and voting intention. All paths were significant at $p<.01$. For simplicity, manifest indicators and paths from latent to manifest indicators are not shown. 
The same modified model was then used to predict the other two political orientation variables. The model for left/right orientation presented good fit to the data: $\chi^{2}(163, N=$ $2884)=1486.64 ; \chi^{2} / d f=9.12 ; \mathrm{CFI}=.91 ; \mathrm{sRMR}=.042 ; \mathrm{RMSEA}=.053 ; 90 \% \mathrm{CI}$ RMSEA $=$ .051-.056; $\mathrm{CAIC}=2096.396 ; \mathrm{ECVI}=.563$. Again, $\mathrm{SDO}$ was a much stronger predictor $(\beta=$ $.47)$ of right political orientation than $\operatorname{RWA}(\beta=.23), \chi_{d . f f}^{2}(2)=367.21, p<.001$. The model for liberal/conservative orientation also presented good fit to the data: $\chi^{2}(163, N=2884)=$ $1512.55 ; \chi^{2} / d f=9.28 ; \mathrm{CFI}=.91 ; \mathrm{sRMR}=.042 ; \mathrm{RMSEA}=.054 ; 90 \%$ CI RMSEA $=.051-$ $.056 ; \mathrm{CAIC}=2122.298 ; \mathrm{ECVI}=.572 .{ }^{3}$ Surprisingly, RWA was a much stronger predictor $(\beta$ $=.51)$ of being conservative than $\operatorname{SDO}(\beta=.15), \chi_{d . f f}^{2}(2)=436.43, p<.001$. In combination, these results provide strong empirical evidence for the use of the DPM model in predicting political conservatism. The results also indicate that RWA and SDO have differential predictive power, which will be elaborated below.

\section{General Discussion for Study 1}

Despite its widespread use in predicting intergroup prejudice, the DPM model proposed by Duckitt (2001) has not been extensively used for predicting political conservatism. Moreover, only a few studies (Sibley \& Duckitt, 2009, 2013; Van Hiel et al., 2007) have examined whether the big-five personality traits could replace the specific personality traits of social conformity and tough-mindedness in the DPM model. The present study contributed to the literature by examining the usefulness of the inclusion of the big-five personality traits in the DPM model, and by examining whether this model had predictive validity regarding political conservatism.

Overall, the present study replicated the findings reported by Sibley and Duckitt (2009) that the big-five personality traits impact RWA and SDO indirectly through dangerous and competitive worldviews. However, discrepancies were also observed. First, three direct paths were non-significant in the present study (i.e. extraversion $\rightarrow$ dangerous worldview,

agreeableness $\rightarrow$ SDO, and emotional stability $\rightarrow$ RWA). Additionally, three extra significant paths were observed in the present study but not in Sibley and Duckitt's (2009) study: extraversion $\rightarrow$ RWA $(\beta=.11)$, emotional stability $\rightarrow \operatorname{SDO}(\beta=.07)$, and dangerous worldview $\rightarrow$ SDO $(\beta=-.39)$. Importantly, we found that the modified predictive model appropriately explained voting intention and left/right and liberal/conservative orientations. These results will be further discussed below.

\footnotetext{
${ }^{3}$ Modification indices suggested the inclusion of a new path from extraversion to liberal/conservative orientation $(\beta=-.06)$.
} 


\section{The DPM and the Big-Five Personality Models}

One modification of the DPM model as originally proposed by Duckitt (2001) is the use of the big-five personality traits instead of social conformity and tough-mindedness (Duckitt \& Sibley, 2010). The present study provides independent support for this modification. All paths in the final model depicted in Figure 3.1 are in the same direction as the paths reported by Sibley and Duckitt (2009), and are also in consonance with other empirical findings (Perry \& Sibley, 2012; Sibley \& Duckitt, 2013). It is also worth noting that all significant paths (with the exception of extraversion $\rightarrow$ competitive worldview and openness $\rightarrow$ RWA) observed in the present study were stronger in terms of effect size than the paths reported by Sibley and Duckitt (2009). Considering that Sibley and Duckitt used student data collected farther away from elections, it is likely that the general population sample considered in the present study and the proximity of the general election may have enhanced these relationships.

The only significant path observed in Sibley and Duckitt's (2009) model that was theoretically predicted but not replicated in the present study was the direct path between agreeableness and SDO. Nevertheless, the indirect effect of agreeableness on SDO was significant and in the expected direction $\left(\beta_{\text {indirect effect }}=-.56\right)$, while the indirect effect of agreeableness on RWA was statistically non-significant $\left(\beta_{\text {indirect effect }}=.08\right)$. An indirect effect of agreeableness on SDO was also observed by Van Hiel et al. (2007). In line with empirical findings from other studies (for a review, see Sibley \& Duckitt, 2008), these findings indicate that conscientiousness and openness impact more strongly RWA than SDO, and agreeableness only impacts SDO (even if only indirectly).

A strong negative path between dangerous worldview and SDO was also observed in the present study, but not in Sibley and Duckitt's (2009) study. Perry et al. (2013) also reported in their meta-analysis a correlation between dangerous worldview and SDO, but they reported a positive association in contrast to our study $(r=.17)$. Perhaps the negative association between dangerous worldview and SDO observed in the present study could be a result of the indirect impact of competitive worldview on SDO through dangerous worldview. The impact of competitive worldview on dangerous worldview in our sample $(\beta=.86)$ was much stronger than that observed by Sibley and Duckitt $(\beta=.36)$. It is possible that this enhanced effect could lead to the observed negative impact of dangerous worldview on SDO. In fact, additional analyses focusing on the impact of competitive worldview on SDO through dangerous worldview showed that this indirect effect explained most of the impact of 
dangerous worldview on SDO $\left(\beta_{\text {indirect effect }}=-.36\right)$. The indirect prediction of SDO by competitive worldview via other DPM model variables could be explored in future studies.

\section{The DPM Model and Political Conservatism}

We also found that the modified model appropriately explained voting intention. In line with previous findings (Van Hiel \& Mervielde, 2002; Wilson \& Sibley, 2013), both RWA and SDO were able to explain conservative voting intention (see Figure 3.2). Consistent with the findings reported by Van Hiel and Mervielde (2002), SDO explained more of the variance of conservative voting intention than RWA. In their study, SDO was more related to the preference for a more anti-immigrant party, while RWA was more related to the preference for a more religious party. Among the four main political parties included in the present study to create the liberal (the Green and Labour parties) and conservative (the ACT and National parties) categories, none specifically focuses on policies clearly driven by religious beliefs. In this sense, the voting intention of the participants was probably based on the parties' economic and social policies rather than on religious standpoints. It is worth noting that one direct path from personality to voting intention was observed (from emotional stability) but was only weakly associated with voting intention.

The model explaining voting intention was also adequate in explaining right-wing and conservative orientations. SDO impacted left/right orientation more strongly than RWA, while RWA impacted liberal/conservative orientation more strongly than SDO. These contrasting results suggest that the dimensions of political conservatism enclosed by left/right and liberal/conservative orientations are not equivalent (albeit highly correlated). The Van Hiel and Mervielde (2002) findings linking SDO to the preference for a more antiimmigrant/right-wing party and RWA to the preference for a more religious/traditional party could help to explain these findings.

It is likely that participants in the present study thought about economic and social policies when indicating their left/right orientation, while thinking about tradition and social norms when indicating their liberal/conservative orientation. This would explain the stronger impact of SDO on left/right orientation and the stronger impact of RWA on liberal/conservative orientation. Further studies evaluating the meaning of these dimensions to New Zealand's general population could confirm or refute this speculation.

Taken as a whole, the final model suggests that the view of the world as a dangerous or competitive place leads to higher scores on RWA and SDO, which in turn lead to conservative voting intention and political orientation. These findings imply that conservative voting intention and political orientation might become a more common trend if inhabitants 
perceive the world as more dangerous and competitive. Clearly this has implications for the political landscape and can help to explain increases in the number of conservative governments all around the world. Future studies should consider experimentally manipulating different types of societal threat (see Duckitt \& Fisher, 2003) and evaluating their effect on conservative voting and political orientation in order to link more strongly political conservatism to reality.

Following this approach, we present next a set of three studies with the main goal of validating experimental stimuli for the last three experimental studies focusing on the impact of societal threat on political conservatism. 


\section{Chapter 4: Study 2}

\section{Threat Manipulation Design}

Despite the recognition that threat might lead to individuals behaving in more protective ways toward the in-group and influence political attitudes and behaviour, past research has not attempted to systematically distinguish types of societal threat, and to evaluate whether these different types of societal threat differentially impact political attitudes and behaviours. Moreover, past research on societal threat has focused mainly on the impact of collective, social or national threat versus personal threat on people's attitudes and behaviours (Fritsche et al., 2011; Harvey \& Belt, 1995; Huddy, et al., 2002).

To be clear, it is not that the impact of different societal threats on behaviour has not been studied; it is the impact of different types of societal threat on behaviour that has not been systematically studied. Fritsche et al. (2011), for example, presented three specific complex societal threats in order to exemplify the importance of group level variables on the explanation of collective reactions to threat in their model. In doing so, they presented studies including the societal threats of economic crisis/unemployment, terrorism and climate change. The studies described in the article provided a comprehensive summary about the impact of different societal threats on behaviour, but did not address, however, the three distinct societal treats at the same time.

Other authors, focusing on the structure of collective and personal threats, have provided empirical evidence for the distinction between different types of societal threat. Onraet and Van Hiel (2013), for instance, found four factors for their measure enclosing collective and personal threats. The four factors displayed four clusters of items enclosing perceived personal economic threat, perceived collective economic threat, perceived personal terroristic threat, and perceived collective terroristic threat. Their result suggests that societal threat, and more specifically economic and terroristic threats, can be perceived differentially according to the type of threat and unit of society they enclose.

Studies examining more particularly the influence of societal threat on political conservatism have focused mainly on economic, social and political threats (Jost et al., 2003b). Similarly to the general literature on the topic, however, the impact of these societal threats on political conservatism has not been systematically distinguished. Most research has focused on generally threatening periods of time or one specific threatening event (e.g. terrorist attack). 
The number of studies considering the impact of natural threat on political conservatism has been far more limited than the ones focusing on economic, social and political threats. Moreover, only specific types of natural threat, and not natural threat as an umbrella term including different natural disasters, have been examined (Fritsche et al., 2012). Since the shared meaning by some natural threats has already been observed in the literature (Díaz et al., 2012), the study of different natural disasters under a natural threat umbrella term seems more parsimonious than the study of different types of natural disasters.

The literature provided above and in Chapter 2 suggests that the impact of economic and social threats on political conservatism has been generally studied without distinction and that natural threat has not been used as an umbrella term for the study of the impact of different natural disasters on political conservatism. Yet, in order to provide a broad theoretical account of the influence of societal threat on political conservatism, it is important to understand the extent to which individuals in a particular society perceive particular types of societal threat.

\section{Detail of Studies}

Given the limited literature on the differential impact of different types of societal threat on political conservatism, the present chapter describes three empirical studies addressing this issue. Study $2 \mathrm{~A}$ evaluates the psychological meaning of economic, natural, and social threats among European New Zealanders (Pākehā). Studies 2B and 2C build on results from Study $2 \mathrm{~A}$ to validate experimental stimuli including economic threat, natural threat, social threat and a control scenario. While Study 2B validates textual stimuli, Study 2C validates pictorial stimuli. If successfully validated, these stimuli will be used in further experimental studies focusing on the impact of societal threat on political conservatism. In the following, method, results and discussion sections are presented for each of the studies. These sections are followed by a brief general discussion for Study 2.

\section{Study 2A}

\section{Method}

\section{Participants and Procedure}

A total of 97 participants completed the paper-based study, but only 78 who were New Zealand-born, at least 18 years old and described themselves as European (Pākehā) were included in the analyses. The mean age of the sample was $32.73(S D=17.73)$ and $55.13 \%$ of the participants were female, while $52.56 \%$ had college or university degree. Participants were randomly recruited at Victoria University's Kelburn campus and at the Central Library 
of Wellington between February and May of 2013. Individuals who were passing by or seated in a shared study space were recruited for the study at Kelburn campus, while participants who were looking for books or seated reading or studying were recruited inside the library. The Central Library of Wellington formally granted permission to collect data inside the library. The study was approved by the School of Psychology Human Ethics Committee under delegated authority of the Victoria University of Wellington Human Ethics Committee (Reference number: RM019658).

\section{Apparatus and Materials}

A questionnaire with three open-ended questions was used to gather data on types of societal threat (Appendix B). Brief descriptions of social, economic and natural threats were first presented to participants in order to elicit words or expressions associated to each type of threat. Participants were then asked to list five words or expressions associated with each of the types of societal threat (in this order: social, economic and natural), following procedure from the natural semantic network literature (Figueroa, González, \& Solís, 1976, 1981; Reyes-Lagunes, 1993). Sociodemographic data were also gathered.

The description of social and economic threats was based on the description of dangerous and competitive worldviews, respectively, as provided by Perry and Sibley (2010). This decision was based on previous theoretical and empirical studies suggesting that dangerous worldview and RWA could be associated with social threat, while competitive worldview and SDO could be associated with group dominance, competition and inequality (Duckitt, 2001; Duckitt \& Fisher, 2003; Duckitt \& Sibley, 2010).

Since worldviews can be described as "descriptive beliefs of the world as it is" (Perry \& Sibley, 2010, p. 984), the description of economic and social threats based on the description of competitive and dangerous worldviews tried to capture the societal aspects related to these two different ways to see the world. A description eliciting situations and elements perceived as environmental hazards or disasters was specially created for this study given that there is no worldview connected to natural threat in Duckitt's (2001) DPM model.

\section{Data Analysis}

A mixed method approach for data analysis was used. The mixed method approach had the goal of investigating whether different types of societal threat elicited significantly different frequencies of words/expressions (chi-square) and also to evaluate the relevance of the concepts linked to the meaning of each type of societal threat (semantic network technique). The difference in word/expression frequency per type of threat was calculated by entering in a chi-square analysis the network size or the total number of words/expressions 
elicited by participants and the number of words that could be elicited but were not per type of threat. The relevance or meaningfulness of the concepts to social, economic and natural threats was assessed using the semantic weight and distance for each word/expression per type of threat (Figueroa et al., 1981; Reyes-Lagunes, 1993). Affective loading was not calculated given that threat is a negative construct per se (see Milfont, 2010).

Semantic weight was calculated by assigning a number between five and one to each word or expression written by each of the participants. This number was based on the order the participant wrote the word or expression in response to the description of each of the types of societal threat. Words or expressions written first were granted five points, while words or expressions written last were granted one point. The scores for similar words or expressions were then summed up generating the semantic weight for each of the words or expressions. The semantic distance was calculated by attributing the value of $100 \%$ to the semantic distance of the word or expression with the highest semantic weight for a specific type of societal threat. A rule of three was then used to calculate the semantic distance for each of the semantic weights of the other words or expressions evoked by this specific type of societal threat. Greater semantic weights and semantic distances for a word or expression implied greater representation of a specific type of societal threat by the word/expression.

Scree plots with the semantic weights for the words/expressions per each type of threat were used to define the cut-off point for the relevance of the words/expressions to the meaning of social, economic and natural threats (see Reyes-Lagunes, 1993). The scree plot technique determined the most meaningful words per type of threat or the core of each of the types of societal threat. This core encloses the words/expressions with higher semantic weights and therefore the core psychological meaning of the different types of societal threat (Milfont, 2010).

\section{Results}

\section{Number of Words/Expressions Evoked by Each Societal Threat}

A total of 390 words/expressions for each type of threat could be expected based on 78 participants and five requested words/expressions. Considering the number of actual words/expressions evoked for each threat, social threat elicited 371 words, economic threat elicited 349 words and natural threat elicited 362 words. The chi-square test showed that participants wrote more words for social and natural threats than for economic threat, $\chi^{2}(2, N$ $=1170)=9.019, p=.011$, Cramér's $V=.09$.

\section{Meaningful Words/Expressions for Each Societal Threat}


Scree plots suggested 12 meaningful words/expressions for social threat, 18 for economic threat, and five for natural threat (Figures 4.1, 4.2 and 4.3, respectively). 


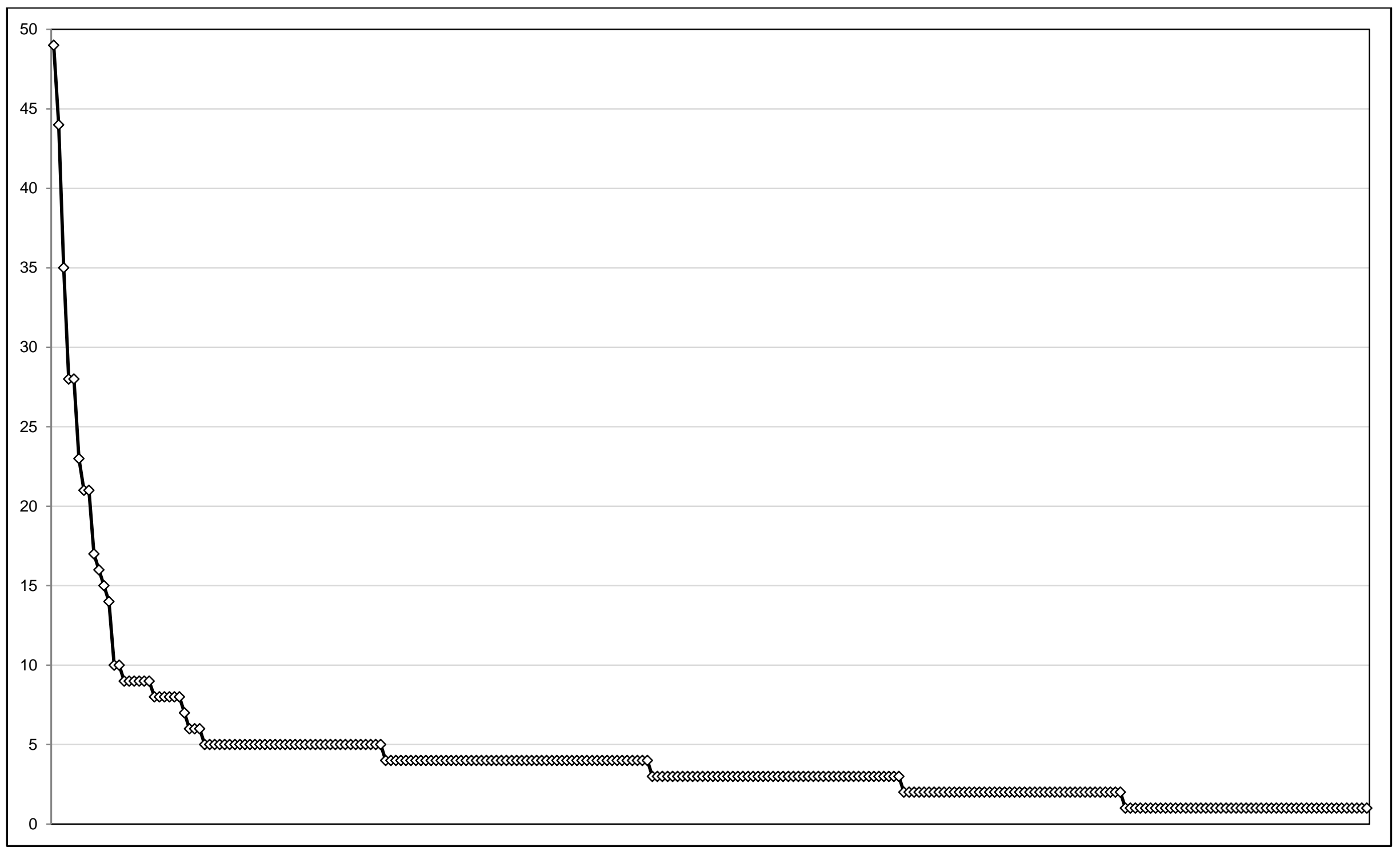

Figure 4.1. Scree plot for social threat.

46 


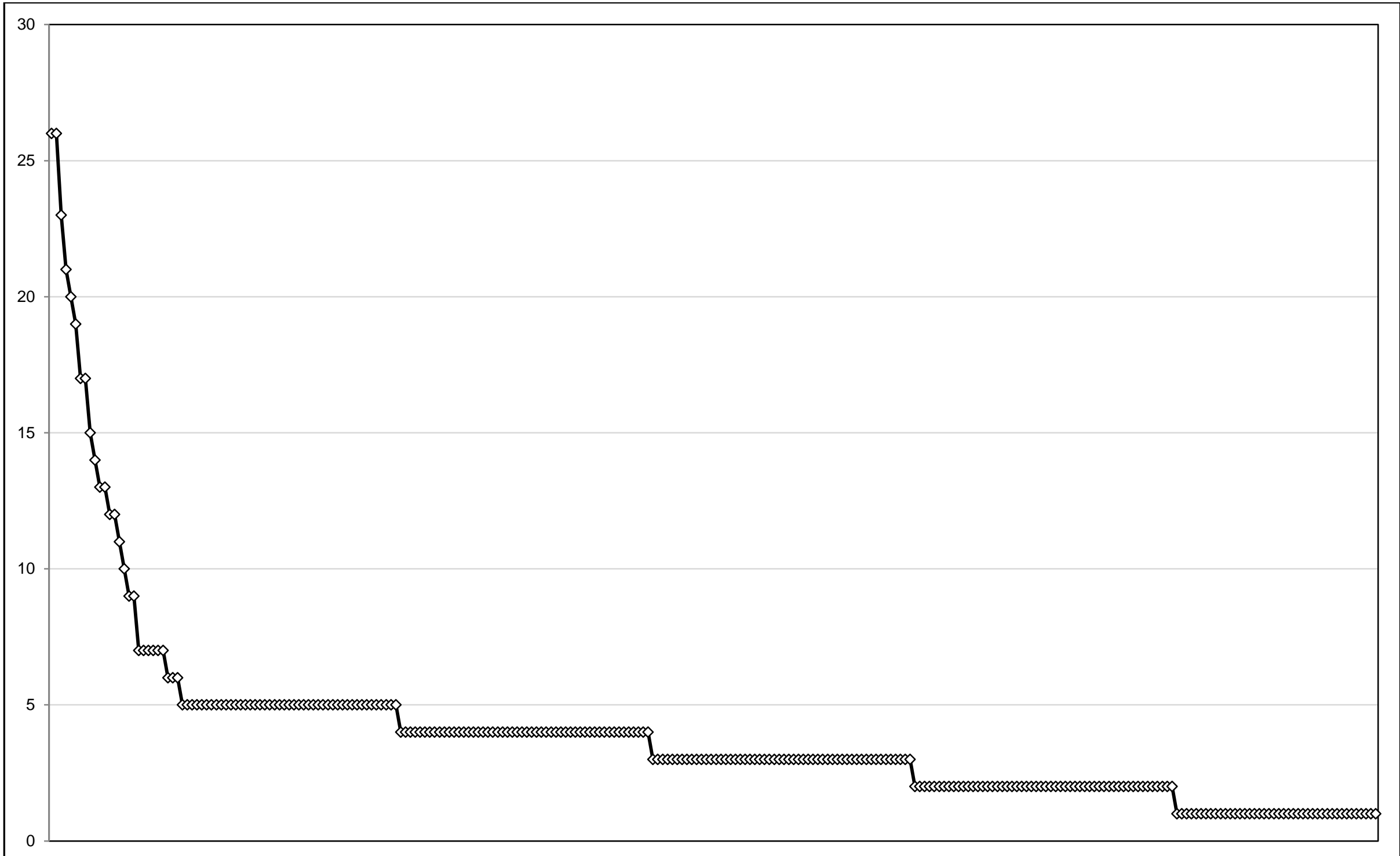

Figure 4.2. Scree plot for economic threat. 


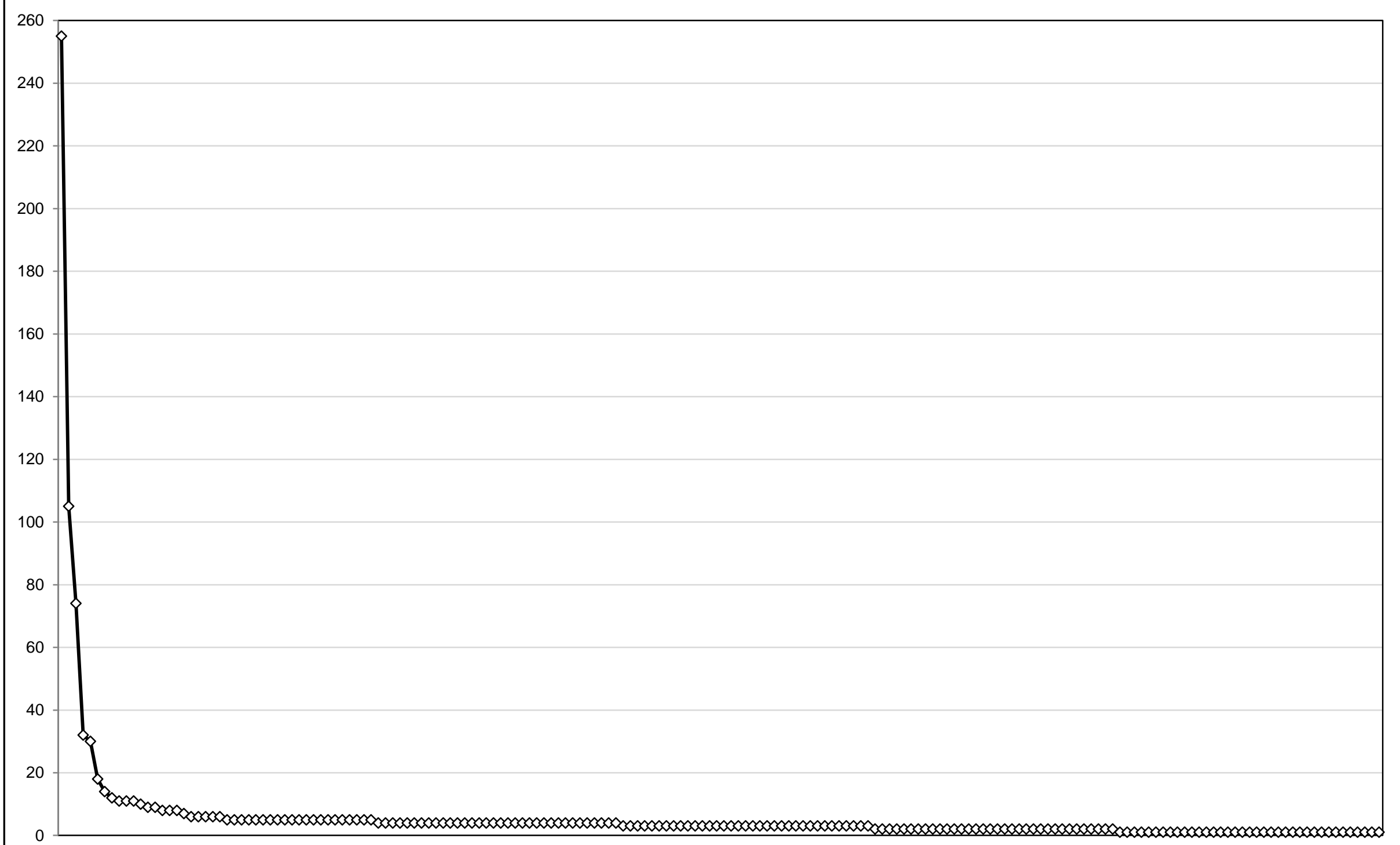

Figure 4.3. Scree plot for natural threat. 
Among these meaningful words/expressions, only "war" was evoked by more than one type of societal threat (Table 4.1). Additionally, some of the words/expressions characterizing natural threat presented far higher semantic weights than the words/expressions characterizing economic and social threats. This indicates that there are fewer meaningful words associated with natural threat because participants tend to attribute the same words to it (i.e. earthquakes and tsunamis). 
Table 4.1

Meaningful words/expressions with semantic weight and semantic distance for social, economic and natural threats

\begin{tabular}{|c|c|c|c|c|c|c|c|c|c|c|c|}
\hline \multicolumn{4}{|c|}{ Social threat } & \multicolumn{4}{|c|}{ Economic threat } & \multicolumn{4}{|c|}{ Natural threat } \\
\hline Words & $N$ & $S W$ & $S D(\%)$ & Words & $N$ & $S W$ & $S D(\%)$ & Words & $N$ & $S W$ & $S D(\%)$ \\
\hline Gangs & 12 & 49 & 100.00 & Asset sales & 6 & 26 & 100.00 & Earthquakes & 55 & 255 & 100.00 \\
\hline Racism & 12 & 44 & 89.80 & Recession & 6 & 26 & 100.00 & Tsunamis & 31 & 105 & 41.18 \\
\hline Bullying & 9 & 35 & 71.43 & Greed & 6 & 23 & 88.46 & Floods & 22 & 74 & 29.02 \\
\hline Violence & 7 & 28 & 57.14 & Inequality & 6 & 21 & 80.77 & Fires & 11 & 32 & 12.55 \\
\hline Terrorists/terrorism & 7 & 28 & 57.14 & Unemployment & 6 & 20 & 76.92 & Global warming & 8 & 30 & 11.76 \\
\hline War & 6 & 23 & 46.94 & War & 7 & 19 & 73.08 & & & & \\
\hline Rape & 7 & 21 & 42.86 & Bankruptcy & 5 & 17 & 65.38 & & & & \\
\hline Religion & 6 & 21 & 42.86 & Politics & 4 & 17 & 65.38 & & & & \\
\hline Fear & 8 & 17 & 34.69 & Job loss & 4 & 15 & 57.69 & & & & \\
\hline Intimidation & 4 & 16 & 32.65 & Debt & 5 & 14 & 53.85 & & & & \\
\hline Guns & 5 & 15 & 30.61 & Corruption & 4 & 13 & 50.00 & & & & \\
\hline \multirow[t]{7}{*}{ Looting } & 3 & 14 & 28.57 & Globalisation & 4 & 13 & 50.00 & & & & \\
\hline & & & & Depression & 3 & 12 & 46.15 & & & & \\
\hline & & & & Inflation & 3 & 12 & 46.15 & & & & \\
\hline & & & & Capitalism & 3 & 11 & 42.31 & & & & \\
\hline & & & & Economic crisis & 2 & 10 & 38.46 & & & & \\
\hline & & & & Competition & 3 & 9 & 34.62 & & & & \\
\hline & & & & Money & 2 & 9 & 34.62 & & & & \\
\hline
\end{tabular}

Note. $N=$ frequency the words/expressions were evoked; $S W=$ Semantic Weight; $S D=$ Semantic Distance. 


\section{Discussion}

The goal of Study 2A was to examine the psychological meaning of social, economic, and natural threats. The results suggest that social, economic and natural threats have different psychological meanings for European New Zealanders (Pākehā) living in New Zealand. In fact, only one meaningful word (i.e. war) was part of the meaning of both social and economic threats.

Considering the number of words/expressions evoked by each type of threat, participants evoked less elements connected to economic threat than elements connected to natural and social threats. In addition, the number of meaningful words for economic threat was larger than the number of meaningful words for social and natural threats. In conjunction, these results suggest that the strength of the association between economic threat and its definers is weaker than the strength of the association between natural threat and social threat with their definers. In other words, it seems that participants had more difficulty on attributing meaning to economic threat and that this threat type includes a broad range of concepts not so tightly related to its meaning.

Additionally, some of the words/expressions connected to natural threat presented far higher semantic weights than the words/expressions connected to economic and social threats. New Zealand is a country highly affected by earthquakes and constantly under threat of tsunamis (GeoNet, 2015).This probably explains the relevance of the words "earthquakes" and "tsunamis" for the participants and their high semantic weights. Earthquakes and tsunamis have been known to be highly characterized by negative sentiments, feelings and consequences in a country also affected by earthquakes and under the threat of tsunamis (Díaz et al., 2012).

A limitation of this study is that participants were always asked to provide words/expressions for social, economic and natural threats in this order. Additionally, the definitions for economic and social threats used to facilitate participants responding were based on theoretical considerations (Perry \& Sibley, 2010). However, both of these issues seem to have not adversely impacted the main results of the study. It is clear through the results that different types of threat elicited distinct words/expressions (only 'war' overlapped for social and economic threats) and that the number of words/expressions clearly varied across threats (see Table 4.1).

Overall, this study succeeded in establishing that social, economic and natural threats enclose different meaningful words/expressions, and that these types of threat can be empirically distinguished. In Studies $2 \mathrm{~B}$ and 2C, these meaningful words/expressions are used 
to design and select stimuli for experiments focusing on the impact of societal threat on political conservatism. Study 2B validates experimental textual scenarios, while Study 2C validates images to be included in experimental pictorial scenarios.

\section{Study 2B}

\section{Method}

\section{Participants and Procedure}

Written experimental stimuli based on Duckitt and Fisher's (2003) textual scenarios were designed. These stimuli included the meaningful words described in Study 2A for each type of societal threat (social, economic, and natural). Differently from Duckitt and Fisher's (2003) study, the control stimulus was modified to include a brief description of New Zealand's geography (and not a description of New Zealand as it was during data collection). This modification was based on findings that some of the actual threats described by participants in Study 2A had been already occurring. "Asset sales", for instance, had been a recurrent theme in New Zealand news already (The New Zealand Herald, 2014) and was perceived as an economic threat in Study 2A.

In Study 2A, 12 words/expressions were meaningful to social threat, 18 were meaningful to economic threat, and five were meaningful to natural threat (see Table 4.1). Of these meaningful words/expressions, only "war" was evoked by more than one type of societal threat (i.e. economic and social threats) and was not included in the threat stimuli.

In order to design textual stimuli with the same size and to match the number of words/expressions to be included in the scenarios, six extra words/expressions evoked by social threat and 12 extra words/expressions evoked by natural threat were included in the scenarios. These extra words/expressions were the ones with the highest semantic weights in each type of threat after the meaningful words/expressions observed in Study 2A. The final threat stimuli included 17 words/expressions and 89 words per type of threat (Table 4.2). After the scenarios' design, two independent English-speaking referees evaluated the scenarios, suggesting grammatical changes. The scenarios kept the same number of words after their evaluation. 
Table 4.2

Frequency and semantic weight for the words/expressions included in the social, economic, and natural threat scenarios

\begin{tabular}{|c|c|c|c|c|c|c|c|c|}
\hline \multicolumn{3}{|c|}{ Social threat } & \multicolumn{3}{|c|}{ Economic threat } & \multicolumn{3}{|c|}{ Natural threat } \\
\hline Words & $N$ & $S W$ & Words & $N$ & $S W$ & Words & $N$ & $S W$ \\
\hline Gangs & 12 & 49 & Asset sales & 6 & 26 & Earthquakes & 55 & 255 \\
\hline Racism & 12 & 44 & Recession & 6 & 26 & Tsunamis & 31 & 105 \\
\hline Bullying & 9 & 35 & Greed & 6 & 23 & Floods & 22 & 74 \\
\hline Violence & 7 & 28 & Inequality & 6 & 21 & Fires & 11 & 32 \\
\hline Terrorists/terrorism & 7 & 28 & Unemployment & 6 & 20 & Global warming & 8 & 30 \\
\hline Rape & 7 & 21 & Bankruptcy & 5 & 17 & Drought & 8 & 18 \\
\hline Religion & 6 & 21 & Politics & 4 & 17 & Volcanic activity & 4 & 14 \\
\hline Fear & 8 & 17 & Job loss & 4 & 15 & Disease & 4 & 12 \\
\hline Intimidation & 4 & 16 & Debt & 5 & 14 & Climate change & 5 & 11 \\
\hline Guns & 5 & 15 & Corruption & 4 & 13 & Hurricanes & 4 & 11 \\
\hline Looting & 3 & 14 & Globalisation & 4 & 13 & Tornados & 4 & 11 \\
\hline Drug abuse & 3 & 10 & Depression & 3 & 12 & Destruction & 4 & 10 \\
\hline Rude & 2 & 10 & Inflation & 3 & 12 & Helplessness & 2 & 9 \\
\hline Assault & 2 & 9 & Capitalism & 3 & 11 & Meteorites & 3 & 9 \\
\hline Bomb & 3 & 9 & Economic crisis & 2 & 10 & Devastation & 2 & 8 \\
\hline Drugs & 2 & 9 & Competition & 3 & 9 & Forest fires & 2 & 8 \\
\hline Power & 2 & 9 & Money & 2 & 9 & Volcanic eruptions & 2 & 8 \\
\hline
\end{tabular}

Note. $N=$ frequency of words/expressions; $S W=$ Semantic Weight. Meaningful words/expressions in Study 2A are presented in boldface. 
After the content validation phase, one of four scenarios (social threat, economic threat, natural threat or control) and related questions were presented randomly to individuals who were passing by or seated in a shared study space at Victoria University's Kelburn campus. A total of 188 participants completed the paper-based study, but only 181 who were New Zealand-born, at least 18 years old and who described themselves as European New Zealanders (Pākehā) were included in the analyses. Overall, the mean age of the sample was 21.23 years $(S D=4.54), 55.8 \%$ were female, $63.1 \%$ had a high school degree, and $8.3 \%$ of the participants also described themselves as Māori or Pacific Islander.

Among the 181 participants, 45 read the control scenario, 45 read the economic threat scenario, 45 read the natural threat scenario and 46 read the social threat scenario.

Questionnaires were applied between the $8^{\text {th }}$ and the $15^{\text {th }}$ of August of 2013 . The study was approved by the School of Psychology Human Ethics Committee under delegated authority of the Victoria University of Wellington Human Ethics Committee (Reference number: RM019658).

\section{Apparatus and Materials}

Experimental manipulation. One of four scenarios was presented to each participant. The control scenario included a description of New Zealand's natural geography, while the three threat scenarios presented words associated to the different types of threat in Study 2A.

To begin, participants in the threat conditions read the following text implying changes in New Zealand:

(Introduction) Imagine that this is happening in New Zealand right now. For you personally, the situation is basically as you expected or planned it to be. Thus, your personal affairs concerning partnering, children, marriage, jobs, career, friends, etc. have not changed unexpectedly. However, while your personal affairs are going well, there have been dramatic and far-reaching changes in New Zealand at present. After reading this introductory paragraph, participants read one of the following experimental scenarios:

(Social threat) Gangs have taken up the streets and racism against various groups is high. Drug abuse has increased and there are drugs available everywhere. Violence, in the form of bullying, looting, intimidation, assault and rape, is taking place everywhere in New Zealand. Terrorist attacks, sometimes even with bombs, are also occurring. The possession of guns is legalized and New Zealand citizens have been buying them profusely. Religion extremism is visible across the country. People are rude and living for power. Fear is stamped on the faces of New Zealand citizens. 
(Economic threat) State-owned assets have been sold. New Zealand has accumulated a large debt and the economy is in recession. Some say the economy is even in depression. New Zealand is in an unprecedented economic crisis, with high inflation, job losses, unemployment and bankruptcy of various businesses. Politics is incomprehensible and corruption cases are broadcasted on the news and television almost daily. Inequality between the rich and the poor has risen. Life in New Zealand is now about greed, competition, money and capitalism. Globalization is reaching the country as never before.

(Natural threat) Strong earthquakes shook both the North and South Islands. Undersea earthquakes are also occurring, and tsunamis around the New Zealand coast are highly likely and have triggered tsunami alerts. Global warming and climate change are impacting New Zealand and a combination of diseases, drought, fires, floods, hurricanes and tornados are affecting many parts of the country. Forest fires are common, and volcanic activity is high with frequent volcanic eruptions. The possibility of a meteorite hitting New Zealand is also likely. Devastation, destruction and helplessness are consuming New Zealand citizens.

Finally, participants in the control condition read the following text:

(Introduction) Imagine that this is happening in New Zealand right now. For you personally, the situation is basically as you expected or planned it to be. Thus, your personal affairs concerning partnering, children, marriage, jobs, career, friends, etc. have not changed unexpectedly. Your personal affairs are going well, and there have been no dramatic or far-reaching changes in New Zealand at present.

(Control) New Zealand's location protects the country from unexpected changes. The country is made up of two main islands and some smaller islands, located near the centre of the water hemisphere (largest area of water of the Earth's surface), and far away from other big land masses. The country is situated some 1,500 kilometres east of Australia across the Tasman Sea, and roughly 1,000 kilometres south of some Pacific islands. New Zealand is long (over 1,600 kilometres) and narrow (with a maximum of 400 kilometres) if considered the main islands.

Participants were reminded to answer the questions based on the scenario they had just read. After reading the scenarios, participants completed three questions asking them to indicate the extent to which social, economic and natural threats were depicted on the given scenario on an 11-point scale varying from 0 (not present at all) to 10 (extremely present). These questions had the purpose of checking if the scenarios were distinguished as expected. 
Dependent variables. Three related political conservatism variables were used as dependent variables to investigate the viability of an experimental study including the textual stimulus as independent variable. First, participants were asked to think about an upcoming general election in a few days and about the scenario. Participants were then asked to choose one of the eight political parties with seats in New Zealand's Parliament. Besides their voting intention, participants were also asked to place themselves on both left/right and liberal/conservative continuums. Political orientation was answered on a 7-point scale varying from 1 (extremely left or extremely liberal) to 7 (extremely right or extremely conservative).

Control variables. The impact of the scenario and positive and negative affect were measured after the experiment in order to be entered as control variables in the analysis evaluating the viability of an experimental study. The impact of the scenario was evaluated through a question about the extent to which the scenario would impact the participant's life and result in negative consequences. Participants answered this question on a 5-point scale varying from 1 (not at all) to 5 (extremely).

Positive and negative affect were measured using the Positive and Negative Affect Schedule (PANAS; Watson, Clark, \& Tellegen, 1988). This measure comprehends two factors which enclose positive $(\alpha=.85)$ and negative $(\alpha=.88)$ affect. The measure is answered on a 5-point scale varying from 1 (very slightly or not at all) to 5 (extremely). The number of factors, as well as their high internal reliability, has been confirmed in previous research (Crawford \& Henry, 2004).

Participants were also asked for socio-demographic data. The information sheet, the main questionnaire per type of condition and the debriefing sheet are presented in Appendices $\mathrm{C} 1, \mathrm{C} 2$ and C3, respectively. Participants answered the questions in the order depicted in the main questionnaire.

\section{Data Analysis}

All participants answered the experimental manipulation questions about the perception of social, economic, and natural threats on the scenarios. Therefore, no data was imputed or participants were excluded from the dataset.

\section{Results}

The differential perception of the scenarios and the viability of using the scenarios as experimental stimuli in further studies were tested. In the following, results for the manipulation check and the differential prediction of political conservatism by threat are reported. 


\section{Manipulation Check}

An initial analysis was performed to test whether participants' evaluations of the threatening situations differed across conditions. The 4 (condition: economic threat, natural threat, social threat, control) x 3 (perception of threat: social threat, economic threat, natural threat) MANOVA was statistically significant, $F(9,531)=54.48, p<.001, \eta_{\mathrm{p}}{ }^{2}=.48$.

Given the violation of the hypothesis of homogeneity of variance for the three dependent variables, non-parametric tests of Kruskal-Wallis were conducted. ${ }^{4}$ The KruskalWallis tests showed that participants identified social, economic and natural threats differentially according to the scenario they read (all $p s<.001$ ). Mann-Whitney tests pairing two out of the four stimuli per analysis confirmed that participants reading the social, economic and natural threat scenarios identified more social, economic and natural threat, respectively, in the scenario they read (all $p s<.05)$. Means and standard deviations for the perception of social, economic and natural threats per condition are depicted in Table 4.3.

\section{Table 4.3}

Means and standard deviations for the perception of social, economic and natural threats in Study $2 B$

\begin{tabular}{llcc}
\hline \multirow{2}{*}{ Perception of threat } & \multicolumn{1}{c}{ Experimental stimuli } & $M$ & $S D$ \\
\hline \multirow{4}{*}{ Social } & Control & 2.11 & 1.75 \\
& Economic threat & 7.11 & 1.61 \\
& Natural threat & 6.47 & 2.53 \\
& Social threat & $\mathbf{9 . 0 4}$ & 1.07 \\
\hline \multirow{5}{*}{ Economic } & Control & 4.20 & 2.47 \\
& Economic threat & $\mathbf{8 . 5 6}$ & 1.34 \\
& Natural threat & 7.51 & 2.31 \\
& Social threat & 7.48 & 1.91 \\
\hline \multirow{3}{*}{ Natural } & Control & 4.42 & 2.39 \\
& Economic threat & 3.09 & 2.79 \\
& Natural threat & $\mathbf{9 . 6 9}$ & .63 \\
& Social threat & 2.61 & 2.53 \\
\hline
\end{tabular}

Note. $M=$ Mean; $S D=$ Standard Deviation. The highest means per type of perceived threat are presented in boldface.

\section{Differential Effect of Societal Threat on Political Conservatism}

\footnotetext{
${ }^{4}$ Before deciding to conduct non-parametric tests, the dependent variables were transformed using square root, logarithmic and Box-Cox transformations (Field, 2009; Osborne, 2010). However, Levene's test of equality of error variances continued to be significant when the transformed variables were entered in new analyses. Thus, non-parametric tests were implemented.
} 
A dummy variable enclosing voting intention was created based on findings from Study $1(0=$ intention to vote for liberal parties and $1=$ intention to vote for conservative parties). As only $5.1 \%$ of the participants indicated intention to vote for different political parties other than ACT, Green, Labour or National, the sample retained almost its original size (167 participants). The distribution of participants' answers on this variable and the sample size included in the study safeguarded the inclusion of dummy voting intention in a further multivariate analysis of covariance (MANCOVA; Lunney, 1970).

To investigate whether political orientation and voting intention differed across conditions, a 4 (condition: economic threat, natural threat, social threat, control) x 3 (political conservatism: left/right orientation, liberal/conservative orientation and dummy voting intention) MANCOVA was conducted. Impact of the scenario and positive and negative affect were controlled in this analysis although only a marginal univariate effect of negative affect on left/right orientation was detected, $F(1,153)=3.05, p=.083, \eta_{\mathrm{p}}{ }^{2}=.02$. Overall, these analyses showed that none of the multivariate effects was significant (all $p \mathrm{~s} \geq .359$ ). Associated univariate tests also did not show any significant effect of the experimental manipulation on political orientation or voting intention (all $p \mathrm{~s} \geq .553$ ). ${ }^{5,6}$

\section{Discussion}

Overall, the scenarios were perceived according to the type of stimulus they described, but there was no significant effect of condition on political conservatism. This absence of experimental effect could be explained by the study design (participants were approached in shared study spaces). Maybe participants were not able to focus appropriately on the study in a space filled with noise and distractions.

It is important to clarify that participants were not asked to think about the scenario while reporting their political orientation (i.e. left/right and liberal/conservative orientations). This limitation will be addressed in Studies 3A and 3B by asking participants to base their answers to the full questionnaire on the scenario (Duckitt \& Fisher, 2003).

Although the threat scenarios did not impact political conservatism, the results indicate that participants were able to distinguish the particular types of threat. That is, participants presented with the social threat scenario, for instance, related this particular scenario to social

\footnotetext{
${ }^{5}$ Similar results were obtained when the control variables were not entered in the analysis.

${ }^{6}$ Complementary analyses were performed by grouping all experimental conditions to compare with the control condition. The same pattern of results was observed when the control condition was compared to the grouped threat conditions.
} 
threat and not to economic or natural threats. This result supports the development and validation of pictorial experimental stimuli for further studies. Given that research has shown that images are more easily and frequently recalled than words, this feature could enhance the effect of the experimental stimulus on political conservatism (McBride \& Dosher, 2002; Shepard, 1967).

\section{Study 2C}

\section{Method}

\section{Participants and Procedure}

Images were searched online using the internet search engine Google Images. The 17 words/expressions obtained in Study 2A and used in Study 2B to design the textual scenarios were used separately as search terms. The expression "New Zealand territory" was searched to obtain images for the control condition. Overall, 340 images - 85 images per type of experimental stimulus (social threat, economic threat, natural threat and control condition) were selected, with five images selected per each word/expression. The search terms "rude", "power", "religion" and "depression" did not provide adequate images. These terms were modified to "rudeness", "power + in + relations, power-hungry, power-thirst", "religion + extremism" and "depression + economic", respectively. The expression "New Zealand" was included along the words/expressions to find images more intrinsically related to New Zealand's reality.

After the image selection process, 77 participants completed an online survey (using Qualtrics) between November and December of 2013. This survey evaluated the appropriateness of the images as experimental stimuli depicting social, economic and natural threats plus a control scenario. The participants were first-year psychology students at Victoria University of Wellington who took part in the study for partial course credit. Among the 77 participants, only 40 who were New Zealand-born with at least 18 years old and described themselves as European New Zealanders (Pākehā) were considered in the final analyses. Overall, the mean age of the sample was 20.73 years $(S D=3.33), 52.5 \%$ were female, and $17.5 \%$ also described themselves as Asian, Māori and/or Pacific Islander in addition to European.

The study was approved by the School of Psychology Human Ethics Committee under delegated authority of the Victoria University of Wellington Human Ethics Committee (Reference number: RM019658).

\section{Apparatus and Materials}


Each participant saw 85 images of the 340 images selected. The 85 images were presented in a random order. After the presentation of each image, participants were given descriptions for the categories of economic threat, natural threat, social threat and New Zealand natural territory (control scenario) in this order. After reading the descriptions, participants were asked to indicate which of the four categories best illustrated the image. Participants then answered how well the image illustrated the category they selected on an 11point scale varying from 0 (not at all) to 10 (very well). They also answered a question on the extent to which the image evoked positive and negative emotions (in two separate items) on an 11-point scale varying from 0 (not at all) to 10 (extremely). Participants completed these three tasks for all 85 images they assessed. ${ }^{7}$

The informed consent and debriefing sheets along with the main questionnaire are presented in Appendices D1, D2 and D3. As noted above, the first-year students completed the study for partial course credit and, given the learning nature of their participation in psychology research, they also answered questions about the study after the debriefing section (see Appendix D4). These questions were not evaluated in this study.

\section{Data Analysis}

Overall, five to 17 participants evaluated each of the 340 images selected. Images were included in the analysis if at least eight participants had evaluated them. Three criteria were then used in a hierarchical fashion to select the images. The first was based on the number of participants who assigned each image to the correct threat type. An image with at least eight correct answers $(80.0 \%$ of agreement if there were 10 participants evaluating the image) was considered and evaluated in the second criterion.

The second criterion was based on the emotion valence. A composite measure was created for each participant per image by subtracting the positive emotion rating from the negative emotion rating. This new composite score served the purpose of evaluating if the images were strongly negative or positive valenced, with a 0 (zero) indicating neutral emotional charge directed to the given image. Images selected based on the first criterion which had a mean score in this emotion valence measure around the middle point (i.e. $-8.00 \leq$ emotional valence $\leq+8.0$ ) were selected for the third and final criterion.

The ratings on how well each image illustrated the correct threat type were then used to select the best image representing each word/expression. The images with the highest

\footnotetext{
${ }^{7}$ This survey also comprised a question asking participants to evaluate four political discourses to be included in Studies 3B and 3C. The validation process for these political discourses is described in more detail in Appendix L.
} 
rating per word/expression were selected to be used as experimental stimuli. The 17 images with the highest ratings on how well each image illustrated the overall category of New Zealand natural territory were selected to be included as control stimuli.

\section{Results}

The main objective of this study was to select 17 images representing each of the threat types and New Zealand's natural territory following the selection criteria described previously. Table E1 in Appendix E shows the values and number of participants for the images that fulfilled the first and the second criteria. The selected images are presented in boldface (see also Appendix F).

Following the selection criteria, one image was selected for each of the 17 words/expressions that represented the psychological meaning of social threat (see Table 4.2). The criteria were not respected only for the word "bullying". The image initially selected for this word ("bullying 3") did not have the definition quality (resolution) required to fit a PowerPoint presentation used in the subsequent experimental study. The next image with the highest category representation score for this word was thus selected.

Similarly, one image was selected for each of the 17 words/expressions that represented the psychological meaning of economic threat (see Table 4.2). The selection criteria were not respected only for "politics" and "asset sales". The image selected for "politics" was chosen to prevent bias given that the other images with eight or more correct categorisations depicted specific and identifiable politicians. The image selected to represent "asset sales" portrayed a well-known politician in a section of the image. The politician was then excluded from the image using Windows Paintbrush and the image was retained. Interestingly, "money" was the only word to characterize (economic) threat to have images eliciting more positive than negative sentiments.

One image was also selected for each of the 17 words/expressions that represented the psychological meaning of natural threat (see Table 4.2). The criteria were not respected only for the word "helplessness". The images depicting this word were not correctly categorized as natural threat by any of the participants. The next image with the highest category representation score for natural threat was selected (“tornados4").

Finally, 17 images were selected for New Zealand's natural territory. The criteria were not respected only for one image which was similar to another already selected (i.e. both images depicted a mountain with snow on top and bushes around it), and also did not have the definition required to fit a PowerPoint presentation. The next image with the highest category 
representation score for New Zealand's natural territory was selected

("NewZealandterritory76"). An excerpt of the selected images is presented in Appendix F.

\section{Discussion}

The validation presented in this study had the aim to select images to design specific threat and control stimuli to be used in a subsequent experiment. Given that the aim of the study was to provide images to design specific stimuli to New Zealand and New Zealanders and the search terms for this material were based on specific findings from Study 2A, images validated in previous studies and balanced toward affect were not considered (Lang, Bradley, \& Cuthbert, 1997). The images connected to words/expressions elicited in Study 2A when participants were asked to think about social, economic and natural threats were expected to be negative valenced (and not neutral). In this study, only images searched for "money" were positive valenced.

Not all the selected images followed the criteria established before data collection. More attention could have been paid to the images during the image search process. Perhaps additional consideration during the initial selection could have avoided bias even before presenting the images to participants who took part in the study. Additionally, the images connected to "helplessness" were not even once categorized correctly as part of natural threat. This could have happened because helplessness is a sentiment that can be connected to many threatening elements in daily life, not being attached to only one specific type of threat. Another limitation of the study is that some of the images were seen by less than 10 participants. The criteria to choose the images had to be adapted to overcome this issue.

Despite these limitations, the present study achieved its goal of selecting 17 images for each of the social, economic and natural threat scenarios plus a control scenario. The overall set of images represent the words/expressions obtained in Study 2A and thus provide a set of validated stimuli which can be used in experimental studies (as discussed in Study 3C).

Next, we present a brief general discussion for Study 2.

\section{General discussion for Study 2}

Overall, the three studies presented in this chapter succeeded in: (1) establishing that social, economic and natural threats have different psychological meanings among European New Zealanders (Pākehā), (2) validating textual stimuli to be used in subsequent experimental studies, and (3) validating images to be included as pictorial stimuli in a subsequent experimental study. Some limitations can be noted, including not randomizing questions in 
Study 2A, approaching participants in shared and loud study spaces in Study 2B, and not selecting images with high resolution from the start in Study 2C. However, the present studies confirmed that the stimuli designed and selected in this chapter can be used to distinguish social, economic and natural threats. In the next chapter, we present three studies testing the full set of hypotheses presented in Chapter 2 and using the textual and pictorial stimuli described in the present chapter. 


\section{Chapter 5: Study 3}

\section{The Impact of Threatening Scenarios on Political Conservatism}

As noted previously, the literature has shown an association between the amount of societal threat in a particular period of time and subsequent political conservatism (Jost et al., 2003b). However, it is still not clear whether societal threat impacts political conservatism irrespective of people's previous level of political conservatism, or whether societal threat impacts political conservatism depending on one's previous level of political conservatism. Moreover, systematic studies verifying the causality of this relationship are scarce. Building on results from the previous empirical studies, the set of studies described in this chapter tried to fill this gap by evaluating experimentally direct and indirect ways in which societal threat impacts political conservatism. Experimental studies testing the impact of societal threat on political conservatism could be an optimal strategy to establish a causal chain between these variables (see, e.g. Duckitt \& Fisher, 2003; Jugert \& Duckitt, 2009; Spencer, Zanna, \& Fong, 2005).

\section{Societal Threat and the Prediction of Political Conservatism}

As presented in Chapter 2, there are two main views on the impact of societal threat on political conservatism. The first view suggests a direct impact of societal threat on political conservatism, and the second suggests that this impact depends on previous levels of political conservatism.

The first view is well portrayed by Jost et al.'s (2003b) seminal meta-analyses examining the relationship between political conservatism and several variables. Among the results, the authors found a positive and moderate weighted effect size $[r(7)=.47, p<.001]$ for the relationship between societal threat (named by the authors as system instability) and political conservatism. This effect implies that, as system instability grows, there is a shift toward conservatism. The authors also found a positive and moderate weighted effect size $[r(6)=.50, p<.001]$ for the relationship between death salience and political conservatism.

The second view is well portrayed by terror management theory (Rosenblatt et al., 1989). In our view, death salience evoked by societal threat could lead to a desire to subscribe to comforting cultural worldviews, as proposed by terror management theory. In this sense, liberal-oriented people would become more liberal when threatened, while conservativeoriented people would become more conservative when threatened. Based on these theoretical views, the following hypotheses were postulated: 
Hypothesis 1 (conservative shift). The hypothesis of conservative shift in the face of societal threat (Jost et al., 2003b) postulates that participants will become more politically conservative after the threat manipulation

Hypothesis 2 (cultural worldview enhancement). The hypothesis of cultural worldview enhancement elicited by societal threat (Burke et al., 2013) postulates that the threat manipulation will enhance participants' held political orientation

Burke et al. (2013) reported two meta-analyses testing conservative shift and cultural worldview enhancement resulting from death salience. In line with the conservative shift hypothesis, they observed a small weighted effect size $[r(25)=.22, p<.02]$ for the effect of death salience on political conservatism. At the same time, they observed a moderate weighted effect size $[r(13)=.35, p<.01]$ for studies that confirmed the cultural worldview enhancement hypothesis. Although numerically distinct, the difference in effect sizes was not statistically significant. These results suggest that both hypotheses have received some empirical support.

In sum, the empirical literature suggests that there is not an agreement regarding the nature of the relationship between threat and political conservatism, especially if considering death salience as an underlying aspect of threat. Some studies have suggested that people always shift their view toward conservatism when threatened, while other studies have suggested that people could shift their view toward conservatism or liberalism depending on their previous level of political conservatism. The three studies reported in this chapter evaluate these two main competing hypotheses for the effect of societal threat on political conservatism.

\section{Understanding How Societal Threat Impacts Political Conservatism}

Besides the hypotheses examining more direct effects of societal threat on political conservatism, the present set of studies also examined two other hypotheses concerning possible mediated and moderated effects of societal threat on political conservatism. The additional hypotheses are related to the socio-political attitudes of RWA and SDO, variables which have been differentially related to political conservatism (Altemeyer, 1981; Pratto, et al., 1994; Van Hiel \& Mervielde, 2002; Wilson \& Sibley, 2013). In this sense, political conservatism has been recognized as a combination of resistance to change (indexed by RWA) and support for inequality (indexed by SDO). 
As detailed in Chapter 2, Duckitt's dual-process motivational (DPM) model encompasses both RWA and SDO and provides a framework of how these variables explain prejudice and political conservatism (Duckitt, 2001). The initial DPM model posited that socialisation practices (punitive or unaffectionate socialisation) would impact personality traits (social conformity or tough-mindedness), which would impact worldviews (dangerous or competitive-jungle world). Worldviews would in turn impact socio-political attitudes (RWA or SDO), which would impact out-group and in-group attitudes. There were two main paths in this model: (1) Punitive socialisation $\rightarrow$ social conformity $\rightarrow$ dangerous worldview $\rightarrow$ RWA $\rightarrow$ out-group and in-group attitudes; and (2) Unaffectionate socialisation $\rightarrow$ toughmindedness $\rightarrow$ competitive-jungle worldview $\rightarrow$ SDO $\rightarrow$ out-group and in-group attitudes.

One of the modifications in the DPM model over the years was the replacement of socialisation practices by social/group contexts. In this new version of the model including context, a dangerous/threatening context (instead of punitive socialisation) would impact dangerous worldview and RWA, while an inequality/competition context (instead of unaffectionate socialisation) would impact competitive worldview and SDO (Duckitt \& Fisher, 2003). This modified model suggests that enduring different types of threat could impact differentially worldviews, RWA, SDO and the resulting political and ethnocentric behaviours (see also Duckitt \& Sibley, 2010). In accordance with the modified model, societal threat has been positively associated with worldviews and socio-political attitudes in empirical studies (Duckitt \& Fisher, 2003; Jugert \& Duckitt, 2009). Thus, based on the literature review and results from Study 1, the three studies presented in this chapter also evaluated the differential impact of societal threat on political conservatism via the DPM model variables. More specifically, the three experimental studies aimed to evaluate whether economic and social threats (compared to a control condition) impact differentially political conservatism via different DPM model pathways.

Hypothesis 3 (dual-process mediation). The hypothesis of dual-process mediation (Duckitt \& Fisher, 2003) postulates that world beliefs (competitive and dangerous) and socio-political attitudes (RWA and SDO) will differentially mediate the impact of the societal threat manipulation on political conservatism (Figure 5.1) 


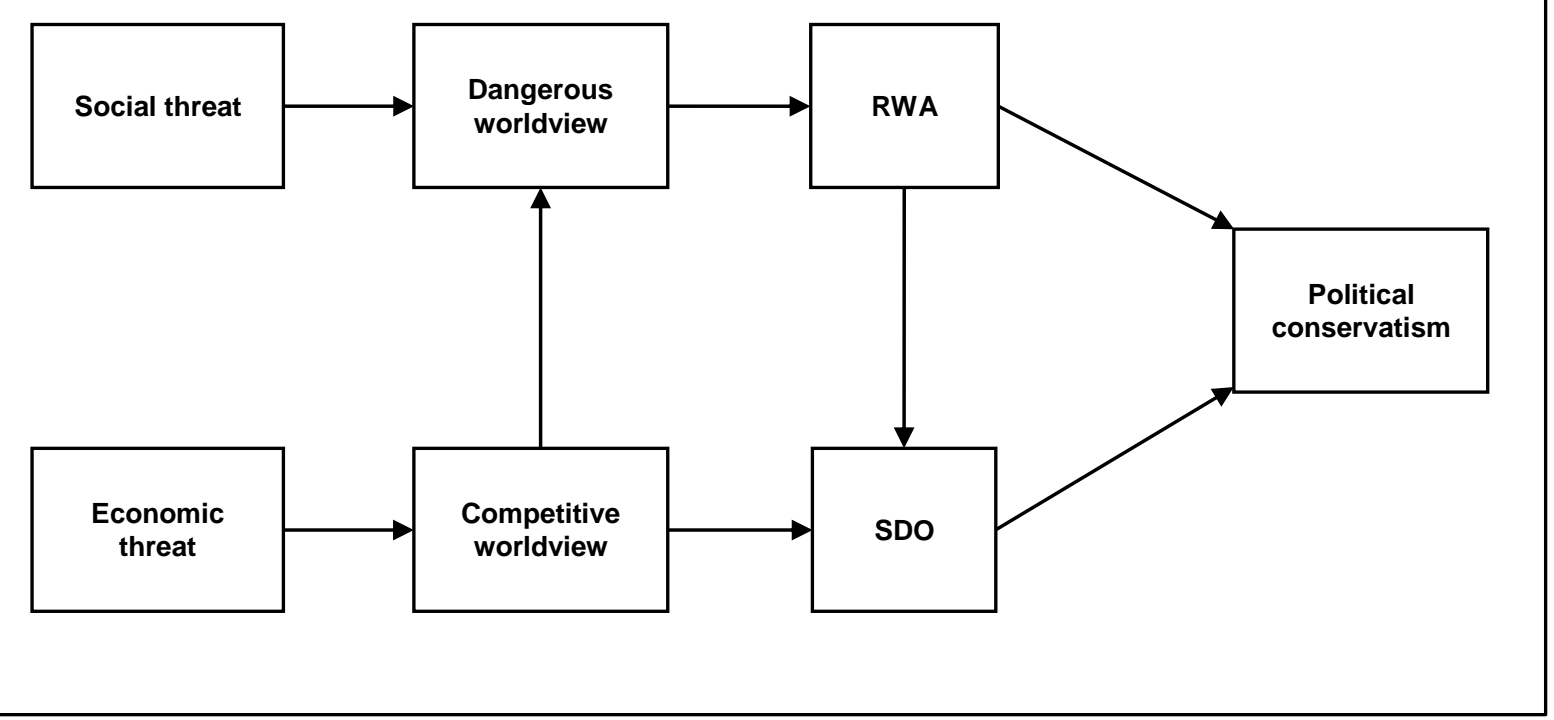

Figure 5.1. Causal model of the impact of economic and social threats based on Duckitt and Fisher's (2003) and Sibley and Duckitt's (2009) models.

In order to evaluate the differential mediation hypothesis, the three studies first evaluated whether there were differences in world beliefs and socio-political attitudes across conditions. Based on the DPM model, two more specific hypotheses were proposed:

Hypothesis 3A. Participants assigned to the social threat condition will score significantly higher on dangerous world beliefs and RWA than participants assigned to the economic threat or control conditions

Hypothesis 3B. Participants assigned to the economic threat condition will score significantly higher on competitive world beliefs and SDO than participants assigned to the social threat or control conditions

Finally, it has been unclear in the literature whether threat impacts other variables regardless of one's previous level of authoritarianism or whether only high authoritarians are impacted by threat. Thus, the present studies also explored an alternative hypothesis for the relationship between RWA measured before the experiment and societal threat (Feldman, 2013). More specifically, the three studies presented in this chapter also sought to evaluate the activation of authoritarianism by social threat taking into account the DPM model (Figure 5.2): 
Hypothesis 4 (activation of authoritarianism by social threat). The hypothesis of activation of authoritarianism by social threat (Feldman \& Stenner, 1997) postulates that the interaction between RWA measured before the experiment (pre-RWA) and the social threat manipulation (compared to the control manipulation) will enhance dangerous world beliefs

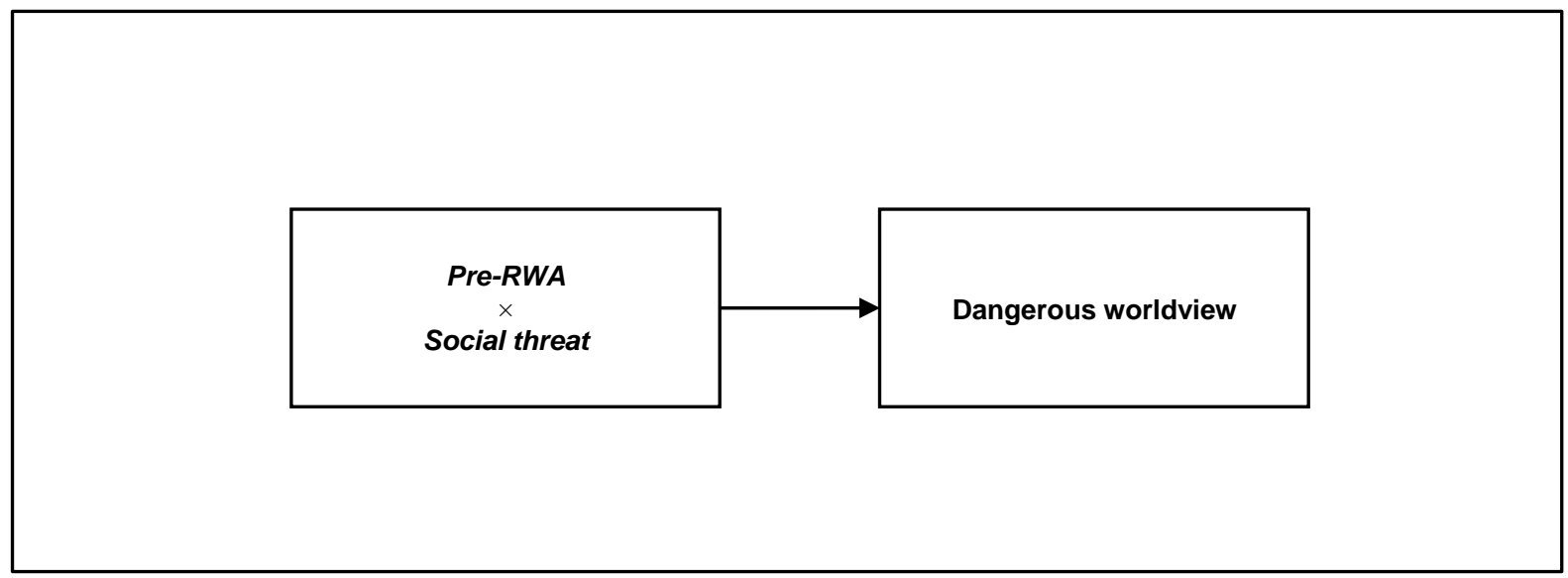

Figure 5.2. Causal model of the impact of the interaction between RWA measured before the experiment and social threat on dangerous world beliefs.

\section{The Impact of Different Types of Societal Threat on Political Conservatism}

As reported in Chapter 2, studies considering the impact of societal threat on political conservatism have mainly considered the impact of threatening periods on political conservatism (Jost et al., 2003b; McCann, 2009). In these studies, the definition of threatening periods has been mainly based on economic, social and political indices. Natural threat, as an overall construct, has not been considered in these studies. Therefore, based on results from Study 2, the three studies presented in this chapter also aim to explore systematically how different types of societal threat (economic, social and natural) impact political conservatism.

\section{Detail of Studies}

The extant literature provides empirical and theoretical support for the impact of societal threat on political conservatism and for the inclusion of world beliefs and sociopolitical attitudes as possible mediators of this relationship. Next, we describe three experimental studies which evaluated the full set of hypotheses using a combination of different settings and types of experimental stimulus: Study $3 \mathrm{~A}$ was completed online with 
textual stimuli, Study 3B was completed in a lab with textual stimuli, and Study 3C was completed in a lab with pictorial stimuli.

\section{Study 3A}

\section{Method}

\section{Participants and Procedure}

The participants of Study 3A were first-year psychology students at Victoria University of Wellington who took part in the study for partial course credit. Data for the preexperimental measures were obtained from an online mass testing (using SurveyMonkey) conducted by the School of Psychology in July of $2013(N=251)$, which included several measures unrelated to this study. Data for the post-experimental measures were obtained from an online study (using Qualtrics) conducted between August and September of the same year. The study including the experimental stimuli and a post-experimental survey was approved by the School of Psychology Human Ethics Committee under delegated authority of the Victoria University of Wellington Human Ethics Committee (Reference number: RM019658).

Participants could answer the experimental study whenever it suited them by accessing the online link for the study from any computer.

A total of 250 participants completed the experimental study, but only 221 participants who were New Zealand-born, at least 18 years old and described themselves as European New Zealanders (Pākehā) were considered in the final analyses. From these participants, only 142 who completed both the mass testing and the experimental study were considered in the analysis including pre and post-experimental data. This was the main sample considered in the present study. Overall, $74.6 \%$ of the participants were female and the mean age of the sample was 19.23 years $(S D=2.91)$. Only one participant had children and $11.3 \%$ of the participants also described themselves as Māori or Pacific Islander in addition to Pākehā.

Participants were randomly assigned to one of four experimental scenario conditions and then asked to complete all other measures thinking about the given scenario. Thirty-eight participants read the control scenario, 30 read the economic threat scenario, 37 read the natural threat scenario, and 37 read the social threat scenario.

\section{Apparatus and Materials}

Experimental manipulation. The experimental manipulation included the threat and control textual stimuli validated previously (as detailed in Study 2B). More specifically, an experimental text depicting a control, economic threat, natural threat or social threat scenario was presented after participants read an introductory text. After reading the scenario text, 
participants were asked to "type the first few words that come to mind when thinking about this scenario" to increase their attention on the manipulated scenario. A set time of two minutes was fixed for reading the introductory and experimental texts and answering the open-ended question so that participants could only progress further in the survey after two minutes had passed. After this elapsed time, participants were asked to complete three questions presented in random order about the extent to which economic, natural and social threats were depicted in the given scenario on an 11-point scale, varying from 0 (not present at all) to 10 (extremely present).

Mediating variables. Competitive and dangerous worldviews were measured only after the experiment, while RWA and SDO were measured both before and after the experiment.

Competitive and dangerous worldviews. The measure proposed by Perry and Sibley (2010) was used to measure both worldviews by asking participants to indicate the percentage of people in the country they believe acted in a specific way "just because they can". The scale comprises nine items in each of the factors of competitive (e.g. "Charm someone to manipulate them") and dangerous (e.g. "Rob someone") worldviews and was answered on a scale varying from $0.0 \%$ to $100.0 \%$.

$\boldsymbol{R} \boldsymbol{W A}$. Right-wing authoritarianism was measured before the experiment with 30 items from Altemeyer's (1996) original 34-items RWA scale. This scale has an equal number of pro-trait (e.g. "Once our government leaders give us the "go ahead", it will be the duty of every patriotic citizen to help stomp out the rot that is poisoning our country from within") and con-trait (e.g. "Everyone should have their own lifestyle, religious beliefs, and sexuality, even if it makes them different from everyone else") items. Participants rated their level of agreement to each item on a 7-point scale varying from 1 (strongly disagree) to 7 (strongly agree).

A short version of Duckitt et al.'s (2010) ACT scale was used to measure RWA after the experiment. The measure includes 18 items rated on a 9-point scale varying from -4 (very strongly disagree) to +4 (very strongly agree) which capture authoritarianism (e.g. "The facts on crime and the recent public disorders show we have to crack down harder on troublemakers, if we are going preserve law and order"), conservatism (e.g. "Our country will be great if we show respect for authority and obey our leaders"), and traditionalism (e.g. "The old-fashioned ways and old-fashioned values still show the best way to live"). In the present study only the overall RWA score was considered. 
SDO. Morselli et al.'s (2012) 4-item scale was used to measure social dominance orientation before the experiment (e.g. "In setting priorities, we must consider ALL groups"). Considering samples from 17 countries including New Zealand, the authors confirmed the reliability and measurement invariance of the scale across cultures. The measure was answered on a 7-point scale varying from 1 (strongly disagree) to 7 (strongly agree).

A new version of the SDO scale (Ho et al., 2012) with equal number of pro-trait and con-trait items was used to measure SDO after the experiment. The scale includes 16 items rated on a 7-point scale varying from 1 (strongly disagree) to 7 (strongly agree) which capture dominance (e.g. "Having some groups on top really benefits everybody") and egalitarianism (e.g. "We should not push for group equality"). In the present study only the overall SDO score was considered.

Dependent variables. Two related political conservatism constructs were used as dependent variables. These constructs were accessed both before and after the experiment.

Political orientation. Two variables were used to measure political orientation. Participants were asked to place themselves on both left/right and liberal/conservative continuums. Their answer could vary from 1 (extremely left or extremely liberal) to 7 (extremely right or extremely conservative).

Voting intention. Participants were asked to indicate in which political party they would vote for if a general election was to be held. This question was open-ended before the experiment and included eight multiple-choice options after the experiment. The eight multiple-choice options included the eight political parties with seats in the New Zealand Parliament.

Control variables. Impact of the scenario, positive and negative affect, and values were measured after the experiment in order to be entered as control variables in the analyses (see Appendix G1 for a description of the measures). However, given the limited overall sample size $(N=221)$, the main analyses reported in the present study do not include these control variables.

Participants were also asked for socio-demographic data, their sentiments toward New Zealand political parties and their identification with New Zealand and New Zealanders after the experimental study. While the variables enclosing sentiments toward New Zealand political parties (varying from $1=$ strongly oppose to 7 = strongly support) were included in preliminary analyses, all other socio-demographic data only served the purpose of describing the sample and linking data between the pre-experimental and post-experimental phases of the study. Identification with New Zealand and New Zealanders was not included in the analyses 
described in the present study. The questionnaire used in the post-experimental phase of the study is presented in Appendix $\mathrm{H}$.

\section{Data Analysis}

Participants with more than $5.0 \%$ of their responses missing were excluded from the pre and post-experimental datasets in order to safeguard the main analyses (Tabachnick \& Fidell, 2007). Outliers and normality analyses were also undertaken but no participant was discarded. Multiple imputation using the expectation maximization algorithm was used to replace isolated missing data in the post-experimental dataset (applied in one case). On the pre-experimental dataset no multiple imputation was performed given that the maximum number of missing answers per case was only one. SPSS 20 was used to conduct analyses of variance and chi-square tests, while AMOS 22 was used to conduct structural equation models.

\section{Results}

\section{Preliminary Analysis}

Appendix I presents descriptive statistics, reliability estimates and correlations between all variables considered in the present study. Besides these basic statistics, the preliminary analysis focused on the voting intention variable and manipulation check analysis detailed below.

Voting intention. The variables measuring voting intention before and after the experiment were created by grouping intention to vote for liberal versus conservative political parties. This grouping was based on correlations reported in Study 1 and similar correlations observed in the present study. The dataset for this analysis included participants who reported voting for the ACT, Green, Labour, National, or NZ First political parties after the experiment. Overall, sentiments toward the Green and Labour parties were positively correlated, sentiments toward the ACT and National political parties were positively correlated, and sentiments toward liberal (Green and Labour) and conservative (ACT and National) parties were negatively correlated (Appendix J). ${ }^{8}$ The only unexpected relationship was the non-significant correlation between sentiments toward the ACT and Labour parties.

\footnotetext{
${ }^{8}$ Given that sentiments toward political parties were measured after the experimental manipulation, one-way ANOVAs were performed to examine any effect of experimental condition on this variable. Sentiments toward $\operatorname{ACT}(p=.318)$, Green $(p=.515)$, Labour $(p=.574)$, and National parties $(p=.621)$ did not statistically differ across experimental conditions. On the other hand, sentiments toward NZ First $\left[F(3,211)=2.74, p=.044, \eta_{\mathrm{p}}^{2}\right.$ $=.04]$ statistically differed. Follow-up Bonferroni post-hoc tests showed that participants in the social threat condition evaluated this political party more positively than participants in the control condition $(p=.030)$.
} 
Dummy variables were thus created grouping intention to vote for more liberal (Green or Labour $=0$ ) and more conservative (ACT or National =1) political parties. All analyses considering both voting intention measured before and after the experiment were limited to participants who asserted intention to vote for one of these political parties $(n=89)$. As expected, liberal/conservative voting intention measured before the experiment was positively correlated to left/right $(r=.49)$ and liberal/conservative $(r=.30)$ political orientations measured before the experiment, and these political orientations were highly correlated $(r=$ .64). Similarly, liberal/conservative voting intention measured after the experiment was positively correlated to left/right $(r=.36)$ and liberal/conservative $(r=.28)$ political orientations measured after the experiment, and these political orientations were highly correlated $(r=.60)$.

Manipulation check. An initial analysis was performed to test whether participants' evaluations of the threatening situations differed across conditions. The 4 (condition: economic threat, natural threat, social threat, control) x 3 (perception of threat: economic threat, natural threat, social threat) MANOVA was statistically significant, $F(9,651)=55.80$, $p<.001, \eta_{\mathrm{p}}^{2}=.44$. Given the violation of the hypothesis of homogeneity of variance for the three dependent variables, Kruskal-Wallis tests were conducted. ${ }^{9}$ The Kruskal-Wallis tests showed that participants identified economic, natural and social threats differentially according to the scenario they read (all $p s<.001$ ).

Overall, follow-up Mann-Whitney tests pairing two out of the four conditions per analysis confirmed predictions. Participants reading the natural and the social threat scenarios identified more natural and social threat, respectively (all $p s<.001$ ). Participants reading the economic threat scenario only marginally identified more economic threat than participants reading the social threat scenario $(p=.093)$, but the mean perception of economic threat was higher for participants reading the economic threat scenario (Table 5.1). Based on the overall pattern of results, the economic threat, natural threat, social threat and control conditions were considered separately in subsequent analyses.

\footnotetext{
Overall, these results show that the experimental manipulation did not exert a strong impact on sentiments toward political parties and that this variable could be included in the main analyses.

${ }^{9}$ Before deciding to conduct the non-parametric tests presented in all studies of this chapter, the dependent variables were transformed using square root, logarithmic and Box-Cox transformations (Field, 2009; Osborne, 2010). However, Levene's test of equality of error variances continued to be significant when the transformed variables were entered in new analyses. Thus, non-parametric tests were implemented.
} 
Table 5.1

Means and standard deviations for the perception of economic, natural and social threats in Study $3 A$

\begin{tabular}{llcc}
\hline \multirow{2}{*}{ Perception of threat } & \multicolumn{1}{c}{ Experimental stimuli } & $M$ & $S D$ \\
\hline \multirow{5}{*}{ Economic } & Control & 3.08 & 2.33 \\
& Economic threat & $\mathbf{8 . 6 7}$ & 1.41 \\
& Natural threat & 6.52 & 2.85 \\
& Social threat & 8.04 & 1.94 \\
\hline \multirow{5}{*}{ Natural } & Control & 3.62 & 2.60 \\
& Economic threat & 2.84 & 2.49 \\
& Natural threat & $\mathbf{9 . 2 8}$ & 1.12 \\
\multirow{5}{*}{ Social } & Social threat & 2.95 & 3.14 \\
& Control & 2.44 & 2.06 \\
& Economic threat & 7.59 & 2.08 \\
& Natural threat & 6.48 & 2.69 \\
& Social threat & $\mathbf{9 . 3 5}$ & 1.14 \\
\hline
\end{tabular}

Note. $M=$ Mean; $S D=$ Standard Deviation. The highest means per type of perceived threat are presented in boldface.

\section{Conservative Shift versus Cultural Worldview Enhancement}

The first set of hypotheses concerned the effect of the experimental manipulation on political orientation and voting intention. The results for left/right and liberal/conservative orientations are presented first, followed by the results for voting intention.

Political orientation. Regarding left/right and liberal/conservative political orientations, the data suggested that participants became generally more rightwing/conservative after reading the control and the economic and natural threat scenarios (compared to the social threat scenario; see Table 5.2).

Table 5.2

Means, standard deviations and frequencies for political conservatism across experimental conditions in Study $3 \mathrm{~A}$

\begin{tabular}{|c|c|c|c|c|c|c|c|c|c|c|c|c|}
\hline \multirow{3}{*}{ Condition } & \multicolumn{4}{|c|}{$\begin{array}{c}\text { Left/right } \\
\text { orientation }\end{array}$} & \multicolumn{4}{|c|}{$\begin{array}{c}\text { Liberal/conservative } \\
\text { orientation }\end{array}$} & \multicolumn{4}{|c|}{ Voting intention } \\
\hline & \multicolumn{2}{|c|}{ Pre-test } & \multicolumn{2}{|c|}{ Post-test } & \multicolumn{2}{|c|}{ Pre-test } & \multicolumn{2}{|c|}{ Post-test } & \multicolumn{2}{|c|}{ Pre-test } & \multicolumn{2}{|c|}{ Post-test } \\
\hline & $M$ & $S D$ & $M$ & $S D$ & $M$ & $S D$ & $M$ & $S D$ & $F l$ & $F_{C}$ & $F l$ & $F_{C}$ \\
\hline Control & 3.29 & 1.35 & 3.34 & 1.02 & 3.08 & 1.50 & 3.21 & 1.17 & 16 & 10 & 17 & 9 \\
\hline Economic threat & 3.23 & 1.10 & 3.30 & 1.24 & 3.10 & 1.09 & 3.13 & 1.17 & 9 & 10 & 12 & 7 \\
\hline Natural threat & 3.14 & 1.16 & 3.22 & 1.16 & 3.32 & 1.23 & 3.46 & 1.22 & 18 & 6 & 18 & 6 \\
\hline Social threat & 3.68 & 1.11 & 3.62 & 1.06 & 3.43 & 1.24 & 3.27 & 1.07 & 7 & 13 & 12 & 8 \\
\hline
\end{tabular}

Note. $M=$ Mean; $S D=$ Standard Deviation $F l=$ Frequency liberal $F c=$ Frequency conservative. 
To test the conservative shift (H1) and the cultural worldview enhancement (H2) hypotheses for left/right orientation more formally, a mixed-design ANOVA was conducted. Before conducting this analysis, left/right orientation measured before the experiment was split into low and high groups, creating the variable pre-left/right categorisation. ${ }^{10}$ Then, a mixed-design ANOVA with left/right orientation (measured before and after the experiment) as a within-subjects factor and condition (economic threat, natural threat, social threat, control) and pre-left/right categorisation (left, right) as between-subjects factors was conducted.

A two-way interaction between left/right orientation and condition would support H1 with participants in the threat conditions becoming more right oriented after the experimental manipulation. On the other hand, a three-way interaction between left/right orientation, condition and pre-left/right categorisation would support H2. In order to support H2, this interaction should show: (1) participants with prior high levels of right political orientation becoming more right oriented in the threat conditions after the experimental manipulation, and (2) participants with prior high levels of left political orientation becoming more left oriented in the threat conditions after the experimental manipulation. Similar results were expected in order to confirm $\mathrm{H} 1$ and $\mathrm{H} 2$ in further analyses focusing on left/right and liberal/conservative orientations.

The between-subjects analysis revealed a main effect of pre-left/right categorisation, $F(1,134)=182.66, p<.001, \eta_{\mathrm{p}}^{2}=.58$. The within-subjects analysis revealed that this effect was qualified by a significant interaction between left/right orientation and pre-left/right categorisation, $F(1,134)=26.01, p<.001, \eta_{\mathrm{p}}{ }^{2}=.16$. Follow-up paired samples $t$-tests per pre-left/right categorisation showed that left-oriented participants $(M=2.25, S D=.73)$ became more right oriented after the experiment $(M=2.78, S D=1.04), t(64)=-4.21, p<$ $.001, d=.59$, while right-oriented participants $(M=4.26, S D=.57)$ became less right oriented after the experiment $(M=3.87, S D=.92), t(76)=3.29, p=.002, d=-.51$. No other main effect or interaction was statistically significant (all $p s \geq .328$ ). Overall, these results confirm

\footnotetext{
${ }^{10}$ A median split was initially conducted, but this procedure yielded less than five participants in some cells when a mixed-design ANOVA was conducted. For this reason, left/right orientation measured before the experiment was split as to include participants with scores below the median as left and participants with scores equal or above the median as right. When a similar analysis was run with the new pre-left/right categorisation variable, there were five or more participants in all cells.
} 
neither the hypothesis of conservative shift (H1) nor the hypothesis of cultural worldview enhancement (H2) for left/right orientation. ${ }^{11}$

A similar mixed-design ANOVA was also conducted to test the conservative shift (H1) and the cultural worldview enhancement (H2) hypotheses for liberal/conservative orientation. Before conducting this analysis, liberal/conservative orientation measured before the experiment was split by the median to form two groups, creating the variable preliberal/conservative categorisation. Then, the mixed-design ANOVA with liberal/conservative orientation (measured before and after the experiment) as a within-subjects factor and condition (economic threat, natural threat, social threat, control) and pre-liberal/conservative categorisation (liberal, conservative) as between-subjects factors was conducted.

The between-subjects analysis revealed a main effect of pre-liberal/conservative categorisation, $F(1,134)=164.31, p<.001, \eta_{\mathrm{p}}{ }^{2}=.55$. The within-subjects analysis revealed that this effect was qualified by a significant interaction between liberal/conservative orientation and pre-liberal/conservative categorisation, $F(1,134)=23.11, p<.001, \eta_{\mathrm{p}}{ }^{2}=$ $.26{ }^{12}$ Follow-up paired samples $t$-tests per pre-liberal/conservative categorisation showed that liberal participants $(M=2.19, S D=.74)$ became more conservative after the experiment $(M=$ 2.79, $S D=1.12), t(72)=-5.32, p<.001, d=.63$, while conservative participants $(M=4.35$, $S D=.61)$ became less conservative after the experiment $(M=3.78, S D=.95), t(68)=4.66, p$ $<.001, d=-.71$. No other main effect or interaction was statistically significant (all $p \mathrm{~s} \geq$ .120). These results confirm neither the hypothesis of conservative shift (H1) nor the hypothesis of cultural worldview enhancement $(\mathrm{H} 2)$ for liberal/conservative orientation. ${ }^{13}$

Voting intention. Pearson's chi-square tests were performed to evaluate if there was a significant shift in the frequency of liberal/conservative voting intention after the experimental manipulation. The chi-square test was more appropriate for this variable given its dichotomous nature (liberal parties $=0$ and conservative parties $=1$ ). In this analysis,

\footnotetext{
${ }^{11}$ Complementary analyses were performed by grouping all experimental conditions to compare with the control condition. The same pattern of results was observed when the control condition was compared to the grouped threat conditions.

${ }^{12}$ Levene's test of equality of error variance was significant for liberal/conservative orientation measured before the experiment. Before including this variable in a new analysis of variance, it was transformed using square root, logarithmic and Box-Cox transformations (Field, 2009; Osborne, 2010). However, Levene's test continued to be significant. As there is no consensus in the literature on which non-parametric procedure to adopt in replacement of a mixed-design ANOVA, the analysis reported in this section was run with the original untransformed variable. The same procedures described in this footnote were adopted for all similar analyses described in this chapter.

${ }^{13}$ The same pattern of results was observed when the control condition was compared to the grouped threat conditions. The only difference was that the interaction between condition and pre-liberal/conservative categorisation was significant, $F(1,138)=5.73, p=.018, \eta_{\mathrm{p}}^{2}=.04$.
} 
condition was entered as "layer", voting intention measured before the experiment as "row", and voting intention measured after the experiment as "column". The dichotomous nature of the data did not enable us to test the cultural worldview enhancement hypothesis (H2) for this variable.

The chi-square tests showed significant effects when considering all four experimental conditions $\left[\chi^{2}(1, N=89)=51.338, p<.001\right.$, Cramér's $\left.V=.76\right]$, as well as for each specific condition: economic threat $\left[\chi^{2}(1, N=19)=9.975, p=.003\right.$, Cramér's $\left.V=.72\right]$, natural threat $\left[\chi^{2}(1, N=24)=14.519, p=.001\right.$, Cramér's $\left.V=.78\right]$, social threat $\left[\chi^{2}(1, N=20)=7.179, p=\right.$ .015 , Cramér's $V=.60]$, and control condition $\left[\chi^{2}(1, N=26)=22.024, p<.001\right.$, Cramér's $V=$ .92]. However, the cross-tabulation table showed that participants who reported intention to vote for liberal or conservative parties before the experiment reported similar voting intention after the experimental manipulation across all conditions (see Table 5.2). These results indicate no change in voting intention after the experimental manipulation. ${ }^{14}$ Thus, the conservative shift hypothesis (H1) could not be confirmed when considering voting intention.

\section{Dual-Process Mediation of the Impact of Societal Threat on Political Conservatism}

The results reported previously reveal that the experimental condition did not impact political conservatism directly. It is plausible, however, that the experimental manipulation might impact political conservatism indirectly via world beliefs and socio-political attitudes in line with the DPM model. This section explores this possibility which is outlined in H3.

Differences in world beliefs and socio-political attitudes across scenarios. The first step was to examine whether the experimental manipulation had an effect on the world beliefs and socio-political attitude measures. Table 5.3 displays the means and standard deviations for these measures per condition.

\footnotetext{
${ }^{14}$ The same pattern of results was observed when the control condition was compared to the grouped threat conditions.
} 
Table 5.3

Means and standard deviations per experimental condition for variables included in Duckitt's DPM model (2001) in Study $3 A$

\begin{tabular}{lcccccccccc}
\hline \multirow{2}{*}{$\begin{array}{c}\text { Dependent } \\
\text { variables }\end{array}$} & \multicolumn{2}{c}{ Control } & \multicolumn{2}{c}{$\begin{array}{c}\text { Economic } \\
\text { threat }\end{array}$} & \multicolumn{2}{c}{$\begin{array}{c}\text { Natural } \\
\text { threat }\end{array}$} & \multicolumn{2}{c}{$\begin{array}{c}\text { Social } \\
\text { threat }\end{array}$} & \multicolumn{2}{c}{$\begin{array}{c}\text { ANOVA } \\
\end{array}$} \\
\cline { 2 - 8 } & $M$ & $S D$ & $M$ & $S D$ & $M$ & $S D$ & $M$ & $S D$ & $F$ \\
\hline $\begin{array}{l}\text { Competitive } \\
\text { worldview }\end{array}$ & $34.53^{\mathrm{a}}$ & 20.01 & 39.33 & 18.62 & $33.61^{\mathrm{b}}$ & 17.30 & $47.81^{\mathrm{a}, \mathrm{b}}$ & 21.49 & $6.23^{*}$ \\
$\begin{array}{l}\text { Dangerous } \\
\text { worldview }\end{array}$ & $17.20^{\mathrm{c}, \mathrm{d}}$ & 14.39 & $25.12^{\mathrm{c}}$ & 17.39 & 24.10 & 16.43 & $30.35^{\mathrm{d}}$ & 16.91 & $6.57^{*}$ \\
$\begin{array}{l}\text { Right-wing } \\
\text { authoritarianism }\end{array}$ & -.63 & 1.11 & -.83 & 1.07 & -.69 & .96 & -.50 & .93 & .90 \\
$\begin{array}{l}\text { Social dominance } \\
\text { orientation }\end{array}$ & 2.86 & .78 & 2.93 & .95 & 3.05 & .95 & 2.85 & .89 & .58 \\
\hline
\end{tabular}

Note. $M=$ Mean; $S D=$ Standard Deviation. ${ }^{*} p<.05$. Means with similar superscripts differ significantly $(p<.05)$.

One-way ANOVAs showed non-significant effects of experimental condition on RWA $(p=.441)$ and SDO $(p=.627)$. However, the effect of experimental condition on dangerous and competitive worldviews was significant $\left[F(3,217)=6.57, p<.001, \eta_{\mathrm{p}}^{2}=.08\right.$; $F(3,217)=6.23, p<.001, \eta_{\mathrm{p}}{ }^{2}=.08$, respectively]. Follow-up Bonferroni post-hoc tests showed that dangerous world beliefs were higher in the social threat $(p<.001)$ and economic threat $(p=.067)$ conditions than in the control condition. These tests also showed that competitive world beliefs were significantly higher in the social threat condition than in both the control $(p=.002)$ and natural threat $(p=.001)$ conditions. These experimental effects are further explored considering the DPM model below.

\section{Indirect effects of the scenarios on political conservatism: Mediational path}

model. Given that the sample size for each of the four experimental conditions varied from 48 to 60 participants, it was not possible to explore the differences between the four different conditions in a stable fashion. As a result, the path analysis focused on the comparison between the control and the grouped threat conditions. The control (0) versus the grouped threat (1) condition was used as a dichotomous exogenous variable in this analysis.

Preliminary independent samples $t$-tests comparing the control with the threat conditions revealed non-significant effects of condition on RWA $(p=.814)$ and $\operatorname{SDO}(p=$ .524). However, a significant effect of condition on dangerous worldview was detected, $t(134.01)=-4.15, p<.001, d=.60$, with participants who read one of the threat scenarios $(M$ $=26.59, S D=17.02$ ) perceiving the world as more dangerous than participants who read the 
control scenario $(M=17.20, S D=14.39)$. The effect of condition on competitive worldview was also marginally significant, $t(219)=-1.94, p=.053, d=.29$, with participants who read one of the threat scenarios $(M=40.33, S D=20.03)$ perceiving the world as more competitive than participants who read the control scenario $(M=34.53, S D=20.01)$. Thus, the path analysis model investigating the indirect effect of societal threat (versus the control condition) on political conservatism was credible.

Exploratory path analysis models with maximum likelihood estimation were therefore computed to test the differential indirect effect of societal threat (economic, natural and social threats) on political conservatism. Due to the mediational nature of the DPM model, bootstrapping procedures were implemented (with 1000 re-samplings) to calculate the indirect effects. Four indicators of fit were considered: the ratio $\chi^{2} / d f$ (chi-square over degrees of freedom), the comparative fit index (CFI), the standardized root mean square residual (sRMR), and the root mean square error of approximation (RMSEA). Values of $\chi^{2} / d f$ smaller than two suggest good fit and values between two and three indicate acceptable fit (Bollen \& Long, 1993). Models with CFI values close to .95 indicate an acceptable fit, while SRMR and RMSEA having values close to .08 and .06, respectively, indicate an acceptable fit (Hu \& Bentler, 1999).

An initial model was run including all predicted paths from the DPM model (Sibley \& Duckitt, 2009) and direct paths from societal threat to world beliefs, socio-political attitudes and political conservatism. The non-significant paths were excluded and additional paths included based on modification indices. A similar approach was implemented to each of the political conservatism variables. Table 5.4 shows the model fit indices for the final models. 
Table 5.4

Model fit indices for the path analysis models including societal threat, world beliefs, sociopolitical attitudes and political conservatism in Study $3 \mathrm{~A}$

\begin{tabular}{lcccccc}
\hline \multicolumn{1}{c}{ Model } & $X^{2}$ & $d f$ & $X^{2} / d f$ & CFI & sRMR & $\begin{array}{c}\text { RMSEA } \\
(90 \% \text { CI })\end{array}$ \\
\hline $\begin{array}{l}\text { Left/right orientation } \\
\text { Liberal/conservative }\end{array}$ & 10.13 & 9 & 1.13 & .99 & .039 & $\begin{array}{c}.025 \\
(.000 \leq .084) \\
\text { orientation }\end{array}$ \\
\begin{tabular}{l} 
Voting intention \\
\hline
\end{tabular} & 9.41 & 9 & 1.04 & 1.00 & .036 & $\begin{array}{c}.015 \\
.000 \leq .080) \\
.000\end{array}$ \\
\hline
\end{tabular}

Note. $X^{2}=$ value of the chi-square test statistic; $d f=$ degrees of freedom; $X^{2} / d f=$ value of the chi-square test statistic divided by the number of degrees of freedom; $\mathrm{CFI}=$ comparative fit index; $\mathrm{sRMR}=$ standardized root mean square residual; RMSEA = root mean square error of approximation; $90 \% \mathrm{CI}=$ $90 \%$ confidence interval.

As can be seen in Figure 5.3, the models were very similar across the dependent variables. Threat conditions (compared to the control) increased both dangerous and competitive worldviews. More importantly, societal threat enhanced political conservatism via competitive world beliefs and RWA. ${ }^{15}$ These results provide partial support for the dualprocess mediation hypothesis $(\mathrm{H} 3)$ and the differential impact of societal threat on political conservatism via some of the variables included in Duckitt's (2001) DPM model. However, it is worth noting that competitive and dangerous world beliefs did not predict SDO and RWA directly as expected in these models - only competitive worldview predicted RWA directly. This lack of hypothesized effect will be discussed further in the General Discussion for Study 3.

\footnotetext{
15 The statistically significant $(p<.05)$ indirect effects of condition on SDO, left/right orientation, liberal/conservative orientation and voting intention had the same magnitude (all $\left.\beta_{\text {indirect effect }}=.01\right)$. The statistically marginally significant $(p<.10)$ indirect effects of condition were as follows: dangerous worldview $\left(\beta_{\text {indirect effect }}=.09\right)$ and $\mathrm{RWA}\left(\beta_{\text {indirect effect }}=.02\right)$.
} 


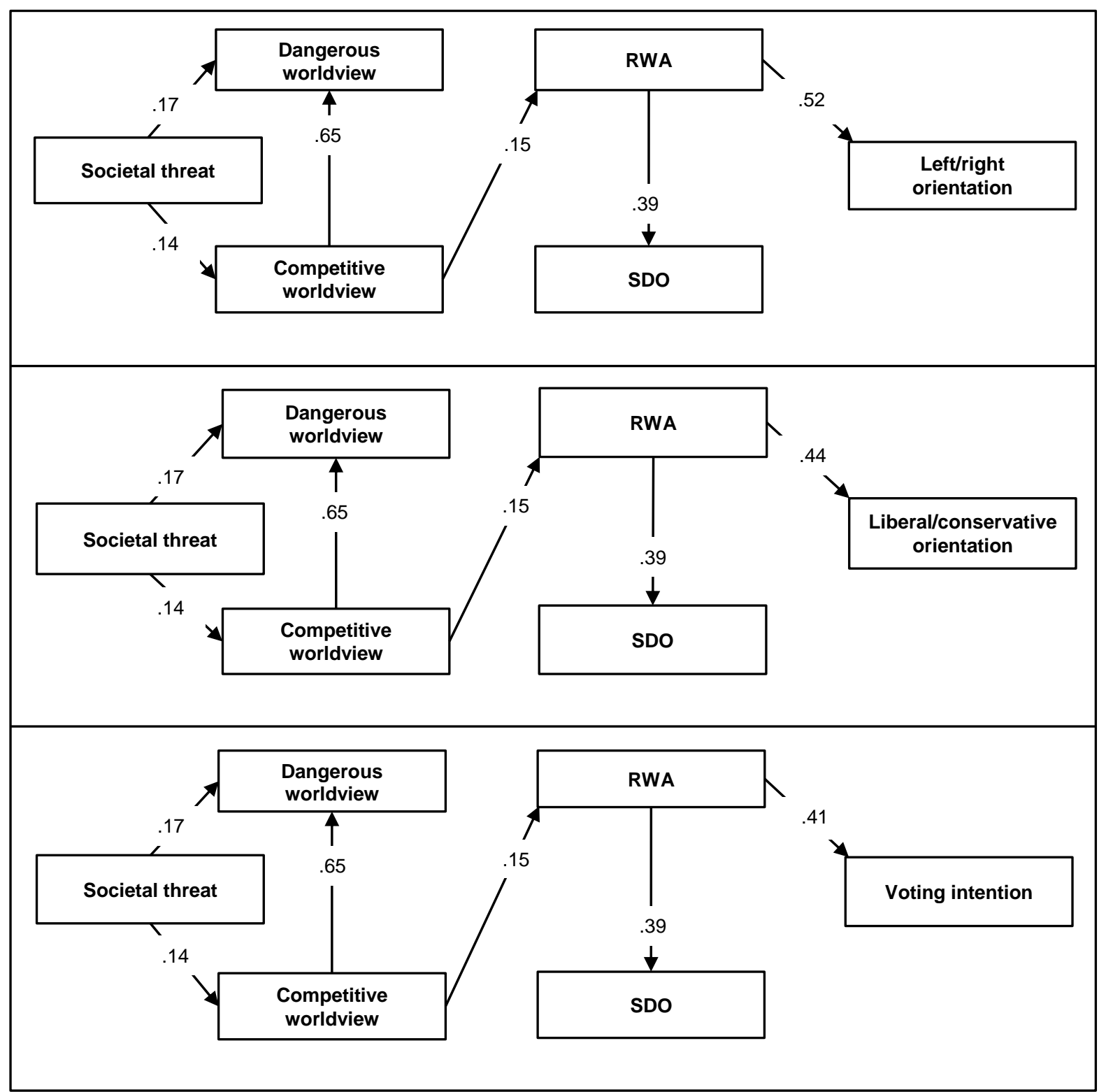

Figure 5.3. Path analysis models of the associations between societal threat, world beliefs, socio-political attitudes and political conservatism in Study 3A. Only statistically significant paths $(p<.05)$ are shown.

\section{Activation of Authoritarianism by Social Threat}

The present study also aimed to test whether pre-RWA would interact with the social threat manipulation, affecting dangerous world beliefs (H4; Feldman \& Stenner, 1997). A moderated path analysis model showed a non-significant effect of the interaction term pre- 
$R W A \times$ social threat on dangerous worldview $(\beta=-.36, p=.410) .{ }^{16}$ This result does not confirm the differential impact of social threat on high and low authoritarians (H4).

\section{Discussion}

The extant literature has suggested a link between threatening situations and political conservatism (Jost et al., 2003b). Providing a systematic investigation of this relationship, the present experimental study examined how different types of societal threat impact political conservatism. Four main findings were observed: (1) the societal threat manipulation did not enhance political conservatism directly, (2) the societal threat manipulation did not enhance the prior political orientation of the participants, (3) the indirect effect of the societal threat manipulation on political conservatism via variables included in the DPM model was only partially confirmed - societal threat (mainly economic and social threats) impacted differentially world beliefs in analyses of variance, and exploratory path analysis models showed that societal threat enhanced political conservatism via both competitive world beliefs and RWA, and (4) RWA measured before the experiment and the social threat manipulation did not interact in predicting dangerous world beliefs.

Overall, the results show experimental effects in the predicted direction. However, these effects do not fully confirm any of the hypotheses. Only H3 was partially supported, while all other hypotheses were rejected. The next study attempts to provide a methodologically more sound test of the hypothesized experimental effects by conducting the experiment in a more controlled environment and using other measures to evaluate competitive and dangerous world beliefs and political conservatism.

\section{Study 3B}

\section{Method}

\section{Participants and Procedure}

The participants of Study 3B were first-year psychology students at Victoria University of Wellington who took part in the study for partial course credit. Data for the preexperimental measures were obtained from an online mass testing (using SurveyMonkey)

\footnotetext{
${ }^{16}$ A similar analysis including only participants with scores in the first or fourth quartiles of pre-RWA was also performed. The analysis considering these extreme low and extreme high pre-RWA scores yielded a similar result $(\beta=-.45, p=.376)$. For completeness, an additional analysis including SDO measured before the experiment was also performed to test the possibility that pre-SDO would interact with the economic threat manipulation, affecting competitive worldview. The effect of the interaction term pre-SDO $\times$ economic threat was non-significant $(\beta=-.05, p=.883)$.
} 
conducted by the School of Psychology in the beginning of July of $2014(N=412)$, which included several measures unrelated to this study. Data for the post-experimental measures were obtained in scheduled time slots in a computer lab between July and August of the same year. The post-experimental measures were hosted in an online platform (Qualtrics). The study including the experimental stimuli and a post-experimental survey was approved by the School of Psychology Human Ethics Committee under delegated authority of the Victoria University of Wellington Human Ethics Committee (Reference number: 0000020636).

A total of 149 students completed the experimental study, but only 140 participants who were New Zealand-born, at least 18 years old and described themselves as European New Zealanders (Pākehā) were considered in the final analyses. From these participants, only 121 who completed both the mass testing and the experimental study were considered in the analysis including pre and post-experimental data. This was the main sample considered in the present study. Overall, $81.8 \%$ of these participants were female and the mean age of the sample was 19.05 years $(S D=1.91)$. Only one of the participants had children and $20.7 \%$ of the participants also described themselves as Māori, Pacific Islander, Indian or Asian, in addition to Pākehā.

Participants were randomly assigned to one of four experimental scenario conditions and asked to complete all other measures thinking about the given scenario. Thirty participants read the control scenario, 29 read the economic threat scenario, 29 read the natural threat scenario, and 33 read the social threat scenario.

\section{Apparatus and Materials}

Most of the measures and instruments included in Study 3A were included in the present study. The only differences were the replacement of the measure used to evaluate SDO before the experiment, and the addition of three new measures evaluating competitive and dangerous world beliefs, emotion elicited by the scenario, and political conservatism (political discourse preference) to the present study. These new measures are described below, with the exception of the measure evaluating emotion (see Appendix G2 for further information).

Competitive and dangerous worldviews. The present study included two worldview measures. The first was the measure proposed by Perry and Sibley (2010) described in Study 3A. Since competitive and dangerous worldviews evaluated using this measure only correlated significantly and highly $(r=.67)$ with each other in Study 3A, a new measure including items selected by Sibley et al. (2007) was also included in the present study. The new balanced measure included 16 items developed by Duckitt, Wagner, Du Plessis and 
Birum (2002) and used by Sibley et al. (2007) to measure competitive (e.g. "It's a dog-eatdog world where you have to be ruthless at times.") and dangerous worldviews (e.g. "Every day as society become more lawless and bestial, a person's chances of being robbed, assaulted, and even murdered go up and up."). Items were answered on a 7-point scale varying from 1 (strongly disagree) to 7 (strongly agree). Similarly to Study 3A, the Perry and Sibley (2010) measure showed lower correlations to the other variables (see Appendix K). For this reason, all analyses reported below only consider scores on Sibley et al.'s (2007) competitive and dangerous worldview measure.

SDO. The same scale used to measure SDO after the experiment in Study 3A was used to measure SDO before and after the experiment in Study 3B (Ho, et al., 2012; Ho et al., in press). ${ }^{17}$

Political discourse preference. Political discourses were designed to portray the values, visions and principles of four New Zealand political parties: ACT, Green, Labour and National. These political parties were chosen based on results from Study 1. The discourses were presented without naming any political party. After reading the discourses, participants were asked to indicate their preferred discourse thinking about the scenario they read (see Appendix L for further information). This variable was measured only after the experimental manipulation.

Similarly to Study 3A, the impact of the scenario, positive and negative affect, values, and emotion were measured after the experiment in order to be entered as control variables in the analyses. Again, given the limited overall sample size $(N=140)$, the main analyses described in the present study do not include these control variables. The description of the control variables is presented in Appendices G1 and G2. All the new measures included in the present study and answered after the experiment are presented in Appendix M.

\section{Data Analysis}

The same data analysis procedures described in Study 3A were deployed in the present study. Apart from participants with $5.0 \%$ or more data missing, no other participants were discarded. The maximum number of missing answers per case was two and these missing answers were limited to the pre-experimental dataset.

\section{Results}

\section{Preliminary Analysis}

\footnotetext{
${ }^{17}$ The study included a later version of the scale to measure SDO before the experiment (Ho et. al., in press) which differed in one item from the previous version (Ho et al., 2012).
} 
Appendix K presents descriptive statistics, reliability estimates and correlations between all variables considered in this study. Besides these basic statistics, the preliminary analysis focused on the voting intention and political discourse preference variables and manipulation check analysis detailed below.

Voting intention and political discourse preference. The variables measuring voting intention before and after the experiment and political discourse preference after the experiment were created by grouping intention to vote for liberal versus conservative political parties/discourses. This grouping was based on correlations reported in Study 1 and similar correlations observed in the present study. The dataset for this analysis included participants who reported voting for the ACT, Green, Labour, National, or NZ First political parties after the experiment. Overall, sentiments toward the Green and Labour parties were positively correlated, sentiments toward the ACT and National political parties were positively correlated, and sentiments toward liberal (Green and Labour) and conservative (ACT and National) parties were negatively correlated (Appendix N). ${ }^{18}$ The only unexpected relationships were the non-significant correlations between sentiments toward the ACT party with sentiments toward the Green and Labour parties. Dummy variables were thus created grouping intention to vote for more liberal (Green or Labour $=0$ ) and more conservative (ACT or National $=1$ ) political parties/discourses. All analyses considering both voting intention measured before and after the experiment were limited to participants who asserted intention to vote for one of these political parties $(n=73)$.

As expected, liberal/conservative voting intention measured before the experiment was positively correlated to left/right $(r=.50)$ and liberal/conservative $(r=.34)$ political orientations measured before the experiment, and these political orientations were highly correlated $(r=.70)$. Similarly, liberal/conservative voting intention measured after the experiment was positively correlated to liberal/conservative political discourse preference $(r=$ $.32)$ and left/right $(r=.38)$ and liberal/conservative $(r=.35)$ political orientations measured after the experiment. Left/right and liberal/conservative political orientations were highly correlated $(r=.58)$ and correlated positively to liberal/conservative political discourse preference (both $r \mathrm{~s}=.32$ ).

\footnotetext{
${ }^{18}$ Given that sentiments toward political parties were measured after the experimental manipulation, one-way ANOVAs were performed to examine any effect of experimental condition on this variable. Sentiments toward $\operatorname{ACT}(p=.471)$, Green $(p=.187)$, Labour $(p=.233)$, National $(p=.116)$, and NZ First $(p=.755)$ parties did not statistically differ across experimental conditions. Overall, these results show that the experimental manipulation did not impact sentiments toward political parties and that this variable could be included in the main analyses.
} 
Manipulation check. An initial analysis was performed to test whether participants' evaluations of the threatening situations differed across conditions. The 4 (condition: economic threat, natural threat, social threat, control) x 3 (perception of threat: economic threat, natural threat, social threat) MANOVA was statistically significant, $F(9,408)=41.90$, $p<.001, \eta_{\mathrm{p}}{ }^{2}=.48$. Given the violation of the hypothesis of homogeneity of variance for the three dependent variables, Kruskal-Wallis tests were conducted. The Kruskal-Wallis tests showed that participants identified economic, natural and social threats differentially according to the scenario they read (all $p s<.001$ ). Follow-up Mann-Whitney tests pairing two conditions per analysis confirmed predictions. Participants reading the economic, natural and social threat scenarios identified more economic, natural and social threat, respectively, in the scenarios they read (all $p \mathrm{~s}<.001$ ). Means and standard deviations for the perception of economic, natural, and social threats per condition are depicted in Table 5.5.

Table 5.5

Means and standard deviations for the perception of economic, natural and social threats in Study $3 B$

\begin{tabular}{llcc}
\hline \multirow{2}{*}{ Perception of threat } & \multicolumn{1}{c}{ Experimental stimuli } & $M$ & $S D$ \\
\hline \multirow{5}{*}{ Economic } & Control & 2.88 & 1.92 \\
& Economic threat & $\mathbf{9 . 5 1}$ & .89 \\
& Natural threat & 5.82 & 3.33 \\
& Social threat & 8.46 & 1.28 \\
\hline \multirow{5}{*}{ Natural } & Control & 3.35 & 2.32 \\
& Economic threat & 2.91 & 2.68 \\
& Natural threat & $\mathbf{9 . 2 9}$ & 1.82 \\
\multirow{5}{*}{ Social } & Social threat & 2.41 & 2.68 \\
& Control & 2.44 & 1.80 \\
& Economic threat & 8.20 & 1.68 \\
& Natural threat & 5.59 & 3.24 \\
& Social threat & $\mathbf{9 . 6 2}$ & .98 \\
\hline
\end{tabular}

Note. $M=$ Mean; $S D=$ Standard Deviation. The highest means per type of perceived threat are presented in boldface.

\section{Conservative Shift versus Cultural Worldview Enhancement}

The first set of hypotheses concerned the effect of the experimental manipulation on political orientation, voting intention, and political discourse preference. The results for left/right and liberal/conservative orientations are presented first, followed by the results for voting intention and political discourse preference.

Political orientation. Regarding left/right and liberal/conservative political orientations, the data suggested that participants became generally more right- 
wing/conservative after reading the threat scenarios (compared to the control scenario; see Table 5.6).

Table 5.6

Means, standard deviations and frequencies for political conservatism across experimental conditions in Study $3 B$

\begin{tabular}{|c|c|c|c|c|c|c|c|c|c|c|c|c|}
\hline \multirow{3}{*}{ Condition } & \multicolumn{4}{|c|}{$\begin{array}{l}\text { Left/right } \\
\text { orientation }\end{array}$} & \multicolumn{4}{|c|}{$\begin{array}{c}\text { Liberal/conservative } \\
\text { orientation }\end{array}$} & \multicolumn{4}{|c|}{ Voting intention } \\
\hline & \multicolumn{2}{|c|}{ Pre-test } & \multicolumn{2}{|c|}{ Post-test } & \multicolumn{2}{|c|}{ Pre-test } & \multicolumn{2}{|c|}{ Post-test } & \multicolumn{2}{|c|}{ Pre-test } & \multicolumn{2}{|c|}{ Post-test } \\
\hline & $M$ & $S D$ & $M$ & $S D$ & $M$ & $S D$ & $M$ & $S D$ & $F l$ & $F c$ & $F l$ & $F c$ \\
\hline Control & 3.37 & .89 & 3.20 & 1.00 & 3.30 & .99 & 3.07 & 1.08 & 6 & 12 & 9 & 9 \\
\hline Economic threat & 3.00 & 1.19 & 3.39 & .83 & 2.96 & 1.43 & 3.04 & 1.00 & 7 & 9 & 9 & 7 \\
\hline Natural threat & 3.18 & 1.54 & 3.21 & 1.26 & 3.00 & 1.25 & 3.00 & 1.02 & 11 & 4 & 11 & 4 \\
\hline Social threat & 3.39 & 1.22 & 3.55 & 1.09 & 3.09 & 1.47 & 3.12 & .93 & 9 & 15 & 8 & 16 \\
\hline
\end{tabular}

Note. $M=$ Mean; $S D=$ Standard Deviation; $F l=$ Frequency liberal; $F c=$ Frequency conservative.

To formally test the conservative shift (H1) and the cultural worldview enhancement (H2) hypotheses for left/right orientation, a mixed-design ANOVA was conducted. Before conducting this analysis, left/right orientation measured before the experiment was split by the median to form two groups, creating the variable pre-left/right categorisation. Then, the mixed-design ANOVA with left/right orientation (measured before and after the experiment) as a within-subjects factor and condition (economic threat, natural threat, social threat, control) and pre-left/right categorisation (left, right) as between-subjects factors was conducted.

The between-subjects analysis revealed a main effect of pre-left/right categorisation and an interaction effect of condition and pre-left/right categorisation, $[F(1,112)=244.04, p$ $<.001, \eta_{\mathrm{p}}^{2}=.69 ; F(3,112)=2.75, p=.046, \eta_{\mathrm{p}}^{2}=.07$, respectively]. The within-subjects analysis showed that these effects were qualified by an interaction between left/right orientation and pre-left/right categorisation, $F(1,112)=18.82, p<.001, \eta_{\mathrm{p}}^{2}=.14$. Follow-up paired samples $t$-tests per pre-left/right categorisation revealed that left-oriented participants $(M=2.23, S D=.69)$ became more right oriented after the experiment $(M=2.69, S D=.90)$, $t(60)=-3.44, p=.001, d=.57$, while right-oriented participants $(M=4.27, S D=.64)$ became less right oriented after the experiment $(M=4.03, S D=.69), t(58)=3.05, p=.003, d=-.36{ }^{19}$ No other main effect or interaction was statistically significant (all $p s \geq .202$ ). Overall, these

\footnotetext{
${ }^{19}$ Levene's test of equality of error variance was significant for left/right orientation measured before the experiment.
} 
results confirm neither the hypothesis of conservative shift (H1) nor the hypothesis of cultural worldview enhancement (H2) for left/right orientation. ${ }^{20}$

To test the conservative shift (H1) and the cultural worldview enhancement $(\mathrm{H} 2)$ hypotheses for liberal/conservative orientation, a similar mixed-design ANOVA was conducted including liberal/conservative orientation as within-subjects factor and condition and pre-liberal/conservative categorisation as between-subjects factors.

The between-subjects analysis revealed a main effect of pre-liberal/conservative categorisation, while the within-subjects analysis revealed a significant interaction between liberal/conservative orientation and pre-liberal/conservative categorisation $[F(1,112)=$ $282.71, p<.001, \eta_{\mathrm{p}}{ }^{2}=.72 ; F(1,112)=22.83, p<.001, \eta_{\mathrm{p}}{ }^{2}=.17$, respectively]. ${ }^{21}$ These effects were qualified by a three-way interaction between liberal/conservative orientation, condition and pre-liberal/conservative categorisation, $F(3,112)=2.69, p=.050, \eta_{\mathrm{p}}{ }^{2}=.07$.

Follow-up paired samples $t$-tests per condition and category of pre-liberal/conservative categorisation showed that participants categorised as liberal became more conservative after reading the economic and social threat scenarios $\left[M_{\text {pre }}=2.11, S D_{\text {pre }}=.74\right.$, and $M_{\text {post }}=2.58$, $S D_{\text {post }}=.77, t(18)=-4.02, p<.001, d=.62 ; M_{\text {pre }}=2.19, S D_{\text {pre }}=.68$, and $M_{\text {post }}=2.62, S D$ post $=.80, t(20)=-2.42, p=.025, d=.58$, respectively]. In contrast, participants categorised as conservative became marginally less conservative after reading the same scenarios $\left[M_{\text {pre }}=\right.$ 4.50, $S D_{\text {pre }}=.97$, and $M_{\text {post }}=3.80, S D_{\text {post }}=.92, t(9)=1.91, p=.089, d=-.74 ; M_{\text {pre }}=4.67$, $S D_{\text {pre }}=1.07$, and $M_{\text {post }}=4.00, S D_{\text {post }}=.00, t(11)=2.15, p=.054, d=-.89$, respectively] . No significant interaction effects were observed for the natural threat (both $p s \geq .164$ ) and control (both $p s \geq .270$ ) conditions. No other main effect or interaction was statistically significant (all $p \mathrm{~s} \geq .115$ ).

Overall, these results support neither the hypothesis of conservative shift (H1) nor the hypothesis of cultural worldview enhancement $(\mathrm{H} 2)$ for liberal/conservative orientation. ${ }^{22}$

\footnotetext{
${ }^{20}$ The same pattern of results was observed when the control condition was compared to the grouped threat conditions. The only differences were that the interaction between condition and pre-left/right categorisation was not significant $(p=.184)$, and that the interaction between left/right orientation and condition was marginally significant, $F(1,116)=3.44, p=.066, \eta_{\mathrm{p}}{ }^{2}=.03$. Follow-up paired samples $t$-tests per condition showed that participants in one of the grouped threat conditions became significantly more right oriented after the experimental manipulation $\left(M_{\text {pre }}=3.19, S D_{\text {pre }}=1.31\right.$, and $\left.M_{\text {post }}=3.40, S D_{\text {post }}=1.07\right), t(89)=-2.13, p=.036, d$ $=.18$.

${ }^{21}$ Levene's test of equality of error variance was significant for liberal/conservative orientation measured before and after the experiment.

${ }^{22}$ The same pattern of results was observed when the control condition was compared to the grouped threat conditions. The only difference was that the effect of liberal/conservative orientation was marginally significant, $F(1,116)=3.16, p=.078, \eta_{\mathrm{p}}^{2}=.03$. In addition, paired samples $t$-tests were conducted to investigate the threeway interaction between liberal/conservative orientation, condition and pre-liberal/conservative categorisation. These additional analyses showed that liberal participants became more conservative and conservative
} 
More specifically, the significant interaction between liberal/conservative orientation, condition and pre-liberal/conservative categorisation suggests that participants categorised as liberal became more conservative after being submitted to threat stimuli, while participants categorised as conservative became more liberal after being submitted to threat stimuli. This effect is the opposite of what was expected according to H2 (cultural worldview enhancement hypothesis) - that societal threat would enhance participants' prior political orientation.

Voting intention and political discourse preference. When considering voting intention, Pearson's chi-square tests showed significant effects for all four experimental scenarios $\left[\chi^{2}(1, N=73)=45.080, p<.001\right.$, Cramér's $\left.V=.79\right]$, as well as for each specific condition: economic threat $\left[\chi^{2}(1, N=16)=9.679, p=.003\right.$, Cramér's $\left.V=.78\right]$, natural threat $\left[\chi^{2}(1, N=15)=15.000, p=.001\right.$, Cramér's $\left.V=1.00\right]$, social threat $\left[\chi^{2}(1, N=24)=12.800, p\right.$ $=.001$, Cramér's $V=.73]$, and control condition $\left[\chi^{2}(1, N=18)=9.000, p=.009\right.$, Cramér's $V$ $=.71]$. However, the cross-tabulation table showed that participants who reported intention to vote for liberal or conservative parties before the experiment reported similar voting intention after the experiment across all conditions. These results indicate no change in voting intention after the experiment (see Table 5.6).

A Pearson's chi-square test was also performed to test the effect of experimental condition on political discourse preference given that this variable was dichotomous (liberal parties $=0$ and conservative parties $=1$ ). As this variable was only measured after the experiment and included two categories, the test only evaluated the hypothesis of conservative shift (H1). The Pearson's chi-square test was non-significant ( $p=.153)$, showing that participants did not show stronger preference for conservative political discourses after the threat manipulation. Once again, the conservative shift hypothesis (H1) could not be confirmed when considering voting intention and political discourse preference. ${ }^{23}$

\section{Dual-Process Mediation of the Impact of Societal Threat on Political Conservatism}

This section explores the possibility of an indirect effect of societal threat on political conservatism via world beliefs and socio-political attitudes (H3).

Differences in world beliefs and socio-political attitudes across scenarios. Table 5.7 displays the means and standard deviations for competitive and dangerous worldviews, RWA and SDO per condition.

participants became less conservative in the grouped threat condition $\left[M_{\text {pre }}=2.11, S D_{\text {pre }}=.69\right.$, and $M_{\text {post }}=2.51$, $S D_{\text {post }}=.77, t(54)=-4.34, p<.001, d=.55 ; M_{\text {pre }}=4.43, S D_{\text {pre }}=.88$, and $M_{\text {post }}=3.89, S D_{\text {post }}=.58, t(34)=3.28$, $p=.002, d=-.72$, respectively].

${ }^{23}$ The same pattern of results was observed when the control condition was compared to the grouped threat conditions. 
Table 5.7

Means and standard deviations per experimental condition for variables included in Duckitt's DPM model (2001) in Study 3B

\begin{tabular}{|c|c|c|c|c|c|c|c|c|c|}
\hline \multirow{2}{*}{ Dependent variables } & \multicolumn{2}{|c|}{ Control } & \multicolumn{2}{|c|}{$\begin{array}{l}\text { Economic } \\
\text { threat }\end{array}$} & \multicolumn{2}{|c|}{$\begin{array}{c}\text { Natural } \\
\text { threat }\end{array}$} & \multicolumn{2}{|c|}{ Social threat } & \multirow{2}{*}{$\begin{array}{c}\text { ANOVA } \\
F\end{array}$} \\
\hline & $M$ & $S D$ & $M$ & $S D$ & $M$ & $S D$ & $M$ & $S D$ & \\
\hline $\begin{array}{l}\text { Competitive } \\
\text { worldview (Duckitt } \\
\text { et al., 2002) }\end{array}$ & 2.47 & .59 & $2.93^{\mathrm{a}}$ & 0.96 & $2.39^{\mathrm{a}}$ & .97 & 2.51 & .70 & $3.03^{*}$ \\
\hline $\begin{array}{l}\text { Dangerous } \\
\text { worldview (Duckitt } \\
\text { et al., 2002) }\end{array}$ & $3.64^{\mathrm{b}}$ & .71 & 4.06 & 1.01 & 3.68 & .95 & $4.18^{b}$ & .79 & $3.46^{*}$ \\
\hline $\begin{array}{l}\text { Right-wing } \\
\text { authoritarianism }\end{array}$ & -.88 & 1.15 & -.88 & 1.02 & -1.32 & 1.41 & -1.09 & 1.02 & 1.15 \\
\hline $\begin{array}{l}\text { Social dominance } \\
\text { orientation }\end{array}$ & 2.76 & .78 & 2.86 & .99 & 2.69 & 1.13 & 2.83 & 1.06 & .21 \\
\hline
\end{tabular}

Note. $M=$ Mean; $S D=$ Standard Deviation. $* p<.05$. Means with similar superscripts differ significantly or marginally $(p<.10)$.

One-way ANOVAs showed non-significant effects of experimental condition on RWA $(p=.333)$ and SDO $(p=.891)$. However, the effects of experimental condition on dangerous, $F(3,136)=3.46, p=.018, \eta_{\mathrm{p}}^{2}=.07$, and competitive world beliefs, $F(3,136)=$ 3.03, $p=.032, \eta_{\mathrm{p}}^{2}=.06$, were significant. Follow-up Bonferroni post-hoc tests showed that dangerous world beliefs were marginally higher in the social threat condition than in the control condition $(p=.055)$, and that competitive world beliefs were significantly higher in the economic threat condition than in the natural threat condition $(p=.043)$. These experimental effects are further discussed considering the DPM model below.

\section{Indirect effects of the scenarios on political conservatism: Mediational path}

model. Following the criteria described in Study 3A, path analysis models with maximum likelihood estimation were computed. Given that the sample size for each of the four experimental conditions varied from 32 to 35 participants, the present study could not explore further the differences between the four conditions in a stable fashion. Thus, the path analysis focused on the comparison between the control condition and the grouped threat conditions. The control (0) versus the grouped threat (1) condition was used as a dichotomous exogenous variable in this analysis.

Preliminary independent samples $t$-tests comparing the control to the grouped threat conditions revealed non-significant effects of condition on competitive worldview ( $p=.378$ ), RWA $(p=.342)$ and SDO $(p=.842)$. However, a significant effect of condition on dangerous 
worldview was detected, $t(138)=-2.00, p=.048, d=.42$, with participants who read one of the grouped threat scenarios $(M=3.98, S D=.93)$ perceiving the world as more dangerous than participants who read the control scenario $(M=3.64, S D=.71)$. Therefore, the path analysis model investigating the indirect effect of societal threat (versus the control condition) on political conservatism was credible.

Similarly to Study 3A, an initial model was run including all predicted paths from the DPM model (Sibley \& Duckitt, 2009) and direct paths from societal threat to world beliefs, socio-political attitudes and political conservatism. The non-significant paths were excluded and additional paths included based on modification indices. A similar approach was implemented to each of the political conservatism variables. Table 5.8 shows the model fit indices for the final models.

Table 5.8

Model fit indices for the path analysis models including societal threat, world beliefs, sociopolitical attitudes and political conservatism in Study $3 B$

\begin{tabular}{lcccccc}
\hline \multicolumn{1}{c}{ Model } & $X^{2}$ & $d f$ & $X^{2} / d f$ & CFI & sRMR & $\begin{array}{c}\text { RMSEA } \\
(90 \% \text { CI })\end{array}$ \\
\hline $\begin{array}{l}\text { Left/right orientation } \\
\begin{array}{l}\text { Liberal/conservative } \\
\text { orientation }\end{array}\end{array}$ & 7.58 & 5 & 1.52 & .98 & .060 & $\begin{array}{c}.063 \\
(.000 \leq .147)\end{array}$ \\
$\begin{array}{l}\text { Voting intention } \\
\begin{array}{l}\text { Political discourse } \\
\text { preference }\end{array}\end{array}$ & 3.37 & 5 & .67 & 1.00 & .034 & $\begin{array}{c}.062 \\
(.000 \leq .146) \\
.000\end{array}$ \\
\hline
\end{tabular}

Note. $X^{2}=$ value of the chi-square test statistic; $d f=$ degrees of freedom; $X^{2} / d f=$ value of the chi-square test statistic divided by the number of degrees of freedom; CFI = comparative fit index; $\mathrm{sRMR}=$ standardized root mean square residual; RMSEA = root mean square error of approximation; $90 \% \mathrm{CI}=$ $90 \%$ confidence interval.

Figure 5.4 presents the final model for each political conservatism variable. As the threat conditions (compared to the control) did not predict any variable in the models, societal threat is not included in the figure. Similar to results reported in Study 3A, competitive world beliefs directly predicted RWA across all models. Overall, these results do not provide support for the differential impact of societal threat on political conservatism via variables included in the DPM model (H3). 


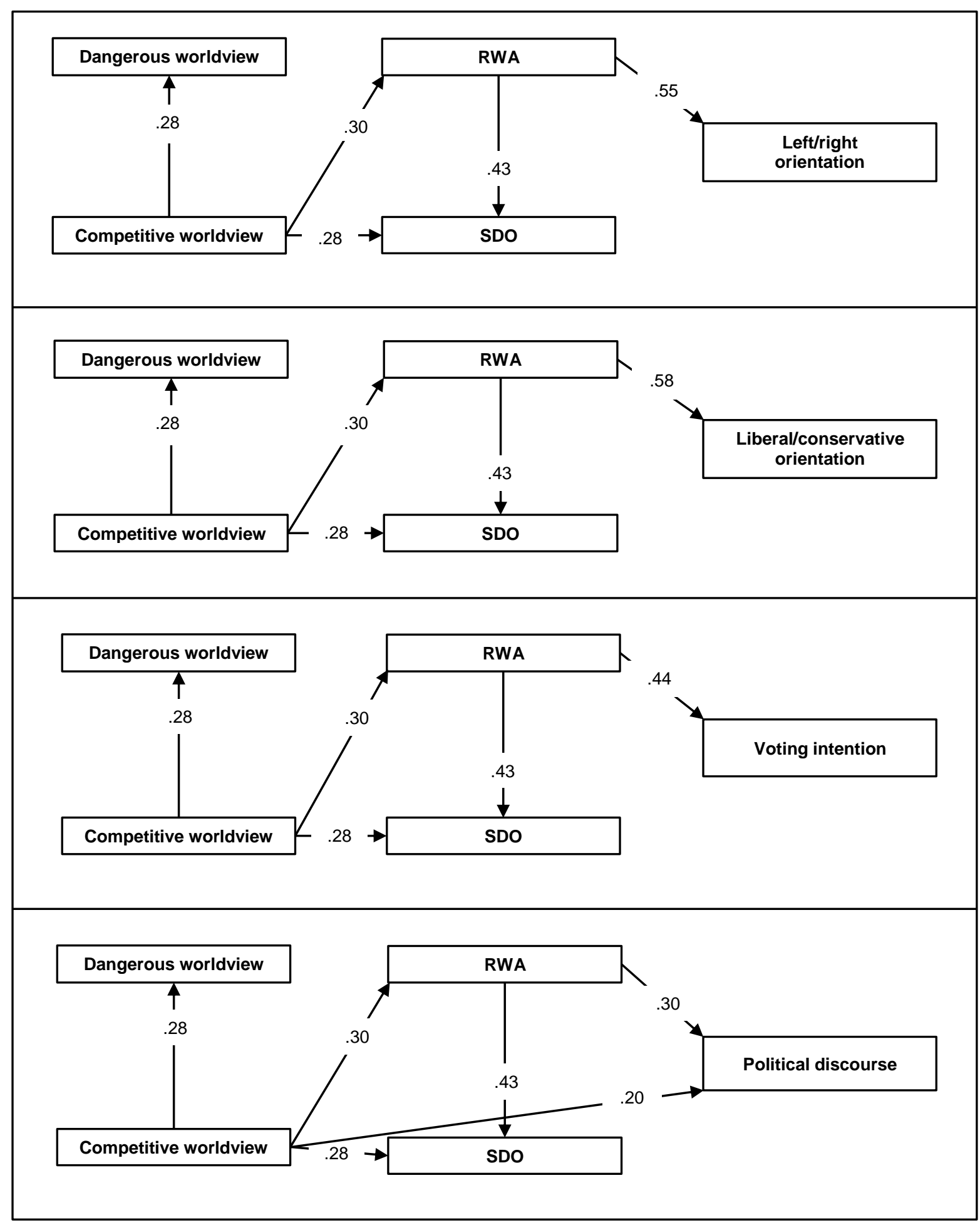

Figure 5.4. Path analysis models of the associations between societal threat, world beliefs, socio-political attitudes and political conservatism in Study 3B. Only statistically significant paths $(p<.05)$ are shown.

\section{Activation of Authoritarianism by Social Threat}


Similarly to Study 3A, a moderated path analysis model showed a non-significant effect of the interaction term pre-RWA $\times$ social threat on dangerous world beliefs $(\beta=-.13, p$ $=.761) .{ }^{24}$ This result does not provide any evidence for the differential impact of social threat on high and low authoritarians (H4).

\section{Discussion}

The present study advanced Study $3 \mathrm{~A}$ by conducting the experiment in a lab environment to examine key theoretical predictions from the literature regarding societal threat and political conservatism. Four main findings were observed: (1) the societal threat manipulation did not enhance political conservatism directly, (2) participants' previous level of political conservatism (as indexed by liberal/conservative orientation) interacted with the threat manipulation in predicting political conservatism variation, but not in the expected direction, (3) the indirect effect of the societal threat manipulation on political conservatism via variables included in the DPM model was not confirmed - threat only impacted differently world beliefs in analyses of variance, and exploratory path analysis models did not show any significant impact of societal threat on any other variable included in the models, and (4) RWA measured before the experiment and the social threat manipulation did not interact in predicting dangerous world beliefs.

Overall, the findings do not support the theoretical and empirical view that experiencing a threatening situation will make people more conservative or that this effect will depend on people being conservative at onset. The findings also do not support that the influence of societal threat on political conservatism is mediated by particular worldviews and socio-political attitudes in line with the DPM model. Study 3C will explore these findings further by making the threatening situations more salient with the use of images instead of texts. Research has shown that images are more easily and frequently recalled by people than words (McBride \& Dosher, 2002; Shepard, 1967).

\section{Study 3C}

\section{Method}

\footnotetext{
${ }^{24}$ A similar analysis including only participants with scores in the first or fourth quartiles of pre-RWA was also performed. The analysis considering these extreme low and extreme high pre-RWA scores yielded a similar result $(\beta=-.62, p=.104)$. For completeness, an additional analysis including SDO measured before the experiment was also performed to test the possibility that pre-SDO would interact with the economic threat manipulation, affecting competitive worldview. The effect of the interaction term pre-SDO $\times$ economic threat was also non-significant $(\beta=.46, p=.238)$.
} 


\section{Participants and Procedure}

The participants of Study 3C were first-year psychology students at Victoria University of Wellington who took part in the study for partial course credit. Data for the preexperimental measures were obtained from an online mass testing (using SurveyMonkey) conducted by the School of Psychology in the beginning of July of $2014(N=412)$, which included several unrelated measures to this study. Data for the post-experimental measures were obtained in scheduled time slots in a computer lab between July and August of the same year. The post-experimental measures were hosted in an online platform (Qualtrics). The study including the experimental stimuli and a post-experimental survey was approved by the School of Psychology Human Ethics Committee under delegated authority of the Victoria University of Wellington Human Ethics Committee (Reference number: 0000020636).

A total of 126 participants completed the experimental study, but only 115 participants who were New Zealand-born, at least 18 years old and described themselves as European New Zealanders (Pākehā) were considered in the final analyses. From these participants, only 99 who completed both the mass testing and the experimental study were considered in the analysis including pre and post-experimental data. This was the main sample considered in the present study. Overall, $85.9 \%$ of these participants were female and the mean age of the sample was 18.94 years $(S D=1.77)$. Only one participant had children and $17.2 \%$ of the participants also described themselves as Māori, Pacific Islander, Asian, or "other ethnicity" in addition to Pākehā.

Participants were randomly assigned to one of four experimental scenario conditions and then asked to complete all other measures thinking about the given scenario. Twenty-one participants saw the control scenario, 29 saw the economic threat scenario, 26 saw the natural threat scenario, and 23 saw the social threat scenario.

\section{Apparatus and Materials}

The same measures used in Study 3B were included in the present study. Only the experimental manipulation differed between Study 3B and the present study, which is described below.

Experimental manipulation. The experimental manipulation included the threat and control pictorial stimuli validated previously (as detailed in Study 2C). More specifically, participants were randomly allocated to one of the four experimental conditions. A set of images depicting a control, economic threat, natural threat or social threat scenario was presented after participants read the introductory text described in Study 2B. The introductory text and the images were presented one at a time on a slide presentation converted into a 
Windows Media Video File. The video was hosted on Qualtrics online platform. After seeing the experimental scenario, participants were asked to "type the first few words that come to mind when thinking about this scenario" to focus their attention on the experimental condition. A set time of two minutes was fixed for reading the introductory text, seeing the experimental scenario and answering the open-ended question so that participants could only progress further in the survey after two minutes had passed.

Participants were presented with the introductory text for 20 seconds and the images for 51 seconds (three seconds per image). The order of presentation of the images was randomly assigned within each condition. It was expected that participants would take nine seconds to successfully load the video and start watching it, giving them at least 40 seconds to envision the scenario they were assigned to. After the two minutes, participants were asked to complete three questions presented in random order about the extent to which economic, natural and social threats were depicted in the given scenario on an 11-point scale, varying from 0 (not present at all) to 10 (extremely present).

As in Study 3B, impact of the scenario, positive and negative affect, values, and emotion were measured after the experiment in order to be entered as control variables in the analyses. However, given the limited overall sample size $(N=115)$, the main analyses reported in the present study do not include these control variables.

\section{Data Analysis}

The same data analysis procedures described in Study 3A were employed in the present study. Apart from participants with $5.0 \%$ or more data missing, no other participants were discarded. The maximum number of missing answers per case was two and these missing answers were limited to the pre-experimental dataset.

\section{Results}

\section{Preliminary analysis}

Appendix $\mathrm{O}$ presents descriptive statistics, reliability estimates and correlations between all variables included in this study. Besides these basic statistics, the preliminary analysis focused on the voting intention and political discourse preference variables and manipulation check analysis detailed below.

Voting intention and political discourse preference. The variables measuring voting intention before and after the experiment and political discourse preference after the experiment were created based on how sentiments toward liberal and conservative political parties related to each other (see Study 1 for further details). The dataset for this analysis 
included participants who reported voting for the ACT, Green, Labour, National, or NZ First political parties after the experiment. Overall, sentiments toward the Green and Labour parties were positively correlated, sentiments toward the ACT and National political parties were positively correlated, and sentiments toward liberal (Green and Labour) and conservative (ACT and National) parties were negatively correlated (Appendix P). ${ }^{25}$ The only unexpected relationship was the non-significant correlation between sentiments toward the ACT and Labour parties. Dummy variables were thus created grouping intention to vote for more liberal (Green or Labour $=0$ ) and more conservative (ACT or National $=1$ ) political parties/discourses. All analyses considering both voting intention measured before and after the experiment were limited to participants who asserted intention to vote for one of these political parties $(n=65)$.

As expected, liberal/conservative voting intention measured before the experiment was positively correlated to left/right $(r=.54)$ and liberal/conservative $(r=.47)$ political orientations measured before the experiment, and these political orientations were highly correlated $(r=.64)$. Similarly, liberal/conservative voting intention measured after the experiment was positively correlated to liberal/conservative political discourse preference $(r=$ $.27)$ and left/right $(r=.34)$ and liberal/conservative $(r=.37)$ political orientations measured after the experiment. Left/right and liberal/conservative political orientations were highly correlated $(r=.67)$, and liberal/conservative political orientation correlated significantly to liberal/conservative political discourse preference $(r=.20)$. The correlation between left/right political orientation and liberal/conservative political discourse preference was positive but not statistically significant $(r=.18)$.

Manipulation check. The 4 (condition: economic threat, natural threat, social threat, control) x 3 (perception of threat: economic threat, natural threat, social threat) MANOVA was statistically significant, $F(9,333)=38.61, p<.001, \eta_{\mathrm{p}}{ }^{2}=.51$. Given the violation of the hypothesis of homogeneity of variance for the three dependent variables, Kruskal-Wallis tests were conducted. The Kruskal-Wallis tests showed that participants identified economic, natural and social threats differentially according to the scenario they saw (all $p \mathrm{~s}<.001$ ). Mann-Whitney tests pairing two conditions per analysis confirmed that participants seeing the economic, natural and social threat scenarios identified more economic, natural and social

\footnotetext{
${ }^{25}$ Given that sentiments toward political parties were measured after the experimental manipulation, one-way ANOVAs were performed to examine any effect of condition on this variable. Sentiments toward ACT ( $p$ $=.990)$, Green $(p=.354)$, Labour $(p=.124)$, National $(p=.919)$ and NZ First $(p=.184)$ did not statistically differ across experimental conditions. Overall, these results show that the experimental manipulation did not impact sentiments toward political parties and that this variable could be included in the main analyses.
} 
threat, respectively, in the scenarios they saw (all $p s<.01$ ). Means and standard deviations for the perception of economic, natural and social threats per condition are depicted in Table 5.9.

Table 5.9

Means and standard deviations for the perception of economic, natural and social threats in Study $3 C$

\begin{tabular}{llcc}
\hline \multicolumn{1}{c}{ Perception of threat } & \multicolumn{1}{c}{ Experimental stimuli } & $M$ & $S D$ \\
\hline \multirow{4}{*}{ Economic } & Control & 1.78 & 1.55 \\
& Economic threat & $\mathbf{9 . 0 3}$ & 1.13 \\
& Natural threat & 6.11 & 3.60 \\
& Social threat & 7.48 & 1.34 \\
\hline \multirow{5}{*}{ Natural } & Control & 3.19 & 2.70 \\
& Economic threat & 3.61 & 2.69 \\
& Natural threat & $\mathbf{9 . 7 1}$ & .76 \\
& Social threat & 2.85 & 2.49 \\
\hline \multirow{3}{*}{ Social } & Control & 1.19 & 1.39 \\
& Economic threat & 6.97 & 2.69 \\
& Natural threat & 4.57 & 3.32 \\
& Social threat & $\mathbf{9 . 2 2}$ & 1.12 \\
\hline
\end{tabular}

Note. $M=$ Mean; $S D=$ Standard Deviation. The highest means per type of perceived threat are presented in boldface.

\section{Conservative Shift versus Cultural Worldview Enhancement}

The first set of hypotheses focused on the effect of the experimental manipulation on political orientation, voting intention and political discourse preference. As before, the results for left/right and liberal/conservative orientations are presented first, followed by the results for voting intention and political discourse preference.

Political orientation. Descriptive statistics for left/right and liberal/conservative orientations suggested that participants became generally more right-wing/conservative after seeing the threat scenarios (compared to the control scenario; see Table 5.10). 
Table 5.10

Means, standard deviations and frequencies for political conservatism across experimental conditions in Study $3 C$

\begin{tabular}{|c|c|c|c|c|c|c|c|c|c|c|c|c|}
\hline \multirow{3}{*}{ Condition } & \multicolumn{4}{|c|}{$\begin{array}{l}\text { Left/right } \\
\text { orientation }\end{array}$} & \multicolumn{4}{|c|}{$\begin{array}{l}\text { Liberal/conservative } \\
\text { orientation }\end{array}$} & \multicolumn{4}{|c|}{ Voting intention } \\
\hline & \multicolumn{2}{|c|}{ Pre-test } & \multicolumn{2}{|c|}{ Post-test } & \multicolumn{2}{|c|}{ Pre-test } & \multicolumn{2}{|c|}{ Post-test } & \multicolumn{2}{|c|}{ Pre-test } & \multicolumn{2}{|c|}{ Post-test } \\
\hline & $M$ & $S D$ & $M$ & $S D$ & $M$ & $S D$ & $M$ & $S D$ & $F l$ & $F c$ & $F l$ & $F c$ \\
\hline Control & 3.48 & 1.69 & 3.19 & 1.33 & 3.00 & 1.70 & 2.81 & 1.08 & 7 & 6 & 6 & 7 \\
\hline Economic threat & 3.79 & 1.18 & 3.79 & .56 & 3.17 & 1.10 & 3.31 & .93 & 8 & 11 & 9 & 10 \\
\hline Natural threat & 2.96 & 1.22 & 3.19 & .94 & 2.81 & 1.27 & 3.15 & 1.16 & 10 & 8 & 11 & 7 \\
\hline Social threat & 3.00 & 1.21 & 3.13 & .97 & 2.83 & 1.23 & 3.30 & 1.22 & 6 & 9 & 6 & 9 \\
\hline
\end{tabular}

Note. $M=$ Mean; $S D=$ Standard Deviation; $F l=$ Frequency liberal; $F c=$ Frequency conservative.

Before conducting a mixed-design ANOVA to formally test $\mathrm{H} 1$ and $\mathrm{H} 2$ for left/right orientation, left/right orientation measured before the experiment was split into high and low groups, creating the variable pre-left/right categorisation. ${ }^{26}$ Then, the mixed-design ANOVA with left/right orientation (measured before and after the experiment) as a within-subjects factor and condition (economic threat, natural threat, social threat, control) and pre-left/right categorisation (left, right) as between-subjects factors was conducted.

The between-subjects analysis revealed main effects of both pre-left/right categorisation and condition $\left[F(1,91)=169.04, p<.001, \eta_{\mathrm{p}}{ }^{2}=.65 ; F(3,91)=2.79, p=.045\right.$, $\eta_{\mathrm{p}}^{2}=.08$, respectively]. The interaction between these two variables was also significant, $F(3$, $91)=3.61, p=.016, \eta_{\mathrm{p}}^{2}=.11$. The within-subjects analysis showed that these effects were qualified by an interaction between left/right orientation and pre-left/right categorisation, $F(1$, $91)=27.85, p<.001, \eta_{\mathrm{p}}^{2}=.23$. Follow-up paired samples $t$-tests per pre-left/right categorisation showed that left-oriented participants $(M=2.13, S D=.81)$ became more right oriented after the experiment $(M=2.69, S D=.92), t(44)=-4.58, p<.001, d=.65$, while right-oriented participants $(M=4.31, S D=.77)$ became less right oriented after the experiment $(M=3.91, S D=.62), t(53)=3.25, p=.002, d=-.57 .{ }^{27}$ No other main effect or interaction was statistically significant (all $p s \geq .293$ ). Overall, these results confirm neither

\footnotetext{
${ }^{26}$ A median split was initially conducted, but this procedure yielded less than five participants in some cells when a mixed-design ANOVA was conducted. For this reason, left/right orientation measured before the experiment was split as to include participants with scores below the median as left and participants with scores equal or above the median as right. When a similar analysis was run with the new pre-left/right categorisation variable, there were five or more participants in all cells.

${ }^{27}$ Levene's test of equality of error variance was significant for left/right orientation measured before and after the experiment.
} 
the hypothesis of conservative shift (H1) nor the hypothesis of cultural worldview enhancement (H2) for left/right orientation. ${ }^{28}$

A similar mixed-design ANOVA was also conducted to test $\mathrm{H} 1$ and $\mathrm{H} 2$ for liberal/conservative orientation. Before conducting this analysis, liberal/conservative orientation measured before the experiment was split by the median into two groups, creating the variable pre-liberal/conservative categorisation. Then, a mixed-design ANOVA with liberal/conservative orientation (measured before and after the experiment) as a withinsubjects factor and condition (economic threat, natural threat, social threat, control) and preliberal/conservative categorisation (liberal, conservative) as between-subjects factors was conducted.

The between-subjects analysis revealed a main effect of pre-liberal/conservative categorisation and an interaction effect of condition and pre-liberal/conservative categorisation $\left[F(1,91)=188.87, p<.001, \eta_{\mathrm{p}}{ }^{2}=.67 ; F(3,91)=2.47, p=.067, \eta_{\mathrm{p}}{ }^{2}=.08\right.$, respectively]. The within-subjects analysis revealed that these effects were qualified by a significant interaction between liberal/conservative orientation and pre-liberal/conservative categorisation, $F(1,91)=17.80, p<.001, \eta_{\mathrm{p}}{ }^{2}=.16 .{ }^{29}$ Follow-up paired samples $t$-tests per pre-liberal/conservative categorisation showed that liberal participants $(M=2.04, S D=.82)$ became significantly more conservative after the experiment $(M=2.58, S D=.94), t(56)=-$ $4.34, p<.001, d=.61$, while conservative participants $(M=4.21, S D=.61)$ became marginally less conservative after the experiment $(M=3.95, S D=.73), t(41)=1.92, p=.062$, $d=-.39$.

The within-subjects analysis also revealed that the interaction between liberal/conservative orientation and condition was marginally significant, $F(3,91)=2.24, p=$ $.089, \eta_{\mathrm{p}}^{2}=.07$. Follow-up paired samples $t$-tests per condition showed that participants who saw the natural and social threat scenarios became more conservative after the experiment $\left[M_{\text {pre }}=2.81, S D_{\text {pre }}=1.27\right.$, and $M_{\text {post }}=3.15, S D_{\text {post }}=1.16, t(25)=-2.37, p=.026, d=.28$; $M_{\text {pre }}=2.83, S D_{\text {pre }}=1.23$, and $M_{\text {post }}=3.30, S D_{\text {post }}=1.22, t(22)=-2.42, p=.024, d=.38$, respectively]. The variation between liberal/conservative orientation measured before and

\footnotetext{
${ }^{28}$ The same pattern of results was observed when the control condition was compared to the grouped threat conditions. The only differences were that the effect of condition was not significant $(p=.471)$ and the interaction between left/right orientation and condition was marginally significant, $F(1,95)=3.02, p=.085, \eta_{\mathrm{p}}^{2}$ $=.03$. Follow-up paired samples $t$-tests per condition did not show any significant effect (both $p \mathrm{~s} \geq .267$ ).

${ }^{29}$ Levene's test of equality of error variance was significant for liberal/conservative orientation measured before the experiment. However, when the largest variance was divided by the smallest variance between conditions, the value was just slightly above two - the cut-off value for safely confirming the hypothesis of homogeneity of variance (Field, 2009).
} 
after the experiment was not significant in the economic threat $(p=.489)$ and control $(p=$ .463) conditions.

No other main effect or interaction was statistically significant (all $p s \geq .154$ ). Overall, these results provide more support for the hypothesis of conservative shift (H1) than for the hypothesis of cultural worldview enhancement (H2) for liberal/conservative orientation. ${ }^{30}$ According to the results, the natural and social threat scenarios made participants more conservatively oriented. However, this effect was only marginally significant and small in terms of effect size.

Voting intention and political discourse preference. When considering voting intention, Pearson's chi-square tests showed significant effects for all four experimental scenarios $\left[\chi^{2}(1, N=65)=53.597, p<.001\right.$, Cramér's $\left.V=.91\right]$, as well as for each specific scenario: economic threat $\left[\chi^{2}(1, N=19)=15.354, p<.001\right.$, Cramér's $\left.V=.90\right]$, natural threat $\left[\chi^{2}(1, N=18)=14.318, p<.001\right.$, Cramér's $\left.V=.89\right]$, social threat $\left[\chi^{2}(1, N=15)=15.000, p<\right.$ .001 , Cramér's $V=1.00]$, and control scenario $\left[\chi^{2}(1, N=13)=9.551, p=.005\right.$, Cramér's $V=$ .86]. However, the cross-tabulation table suggested again no significant change in voting intention across conditions after the experimental manipulation (see Table 5.10).

When considering political discourse preference, the Pearson chi-square test evaluating the hypothesis of conservative shift (H1) was non-significant ( $p=.117)$. As in Study 3B, the conservative shift hypothesis (H1) was not supported when considering voting intention and political discourse preference. ${ }^{31}$

\section{Dual-process Mediation of the Impact of Societal Threat on Political Conservatism}

As in Studies 3A and 3B, this section explores the possibility of an indirect effect of societal threat on political conservatism via world beliefs and socio-political attitudes (H3).

Differences in world beliefs and socio-political attitudes across scenarios. Table 5.11 presents the means and standard deviations for competitive and dangerous worldviews, RWA and SDO per condition.

\footnotetext{
${ }^{30}$ The same pattern of results was observed when the control condition was compared to the grouped threat conditions. In addition, paired samples $t$-tests were conducted to investigate the two-way interaction between liberal/conservative orientation and condition. This additional analysis showed that only participants seeing one of the threatening stimuli became more conservative after the experimental manipulation $\left[M_{\text {pre }}=2.95, S D_{\text {pre }}=\right.$ 1.19 , and $\left.M_{\text {post }}=3.26, S D_{\text {post }}=1.09, t(77)=-2.92, p=.005, d=.27\right]$.

${ }^{31}$ The same pattern of results was observed when the control condition was compared to the grouped threat conditions.
} 
Table 5.11

Means and standard deviations per experimental condition for variables included in Duckitt's DPM model (2001) in Study $3 C$

\begin{tabular}{|c|c|c|c|c|c|c|c|c|c|}
\hline \multirow[t]{2}{*}{ Dependent variables } & \multicolumn{2}{|c|}{ Control } & \multicolumn{2}{|c|}{$\begin{array}{l}\text { Economic } \\
\text { threat }\end{array}$} & \multicolumn{2}{|c|}{$\begin{array}{c}\text { Natural } \\
\text { threat }\end{array}$} & \multicolumn{2}{|c|}{$\begin{array}{l}\text { Social } \\
\text { threat }\end{array}$} & \multirow{2}{*}{$\begin{array}{c}\text { ANOVA } \\
F\end{array}$} \\
\hline & $M$ & $S D$ & $M$ & $S D$ & $M$ & $S D$ & $M$ & $S D$ & \\
\hline $\begin{array}{l}\text { Competitive } \\
\text { worldview (Duckitt } \\
\text { et al., 2002) }\end{array}$ & 2.44 & .57 & 2.64 & .90 & 2.24 & 0.75 & 2.63 & .60 & 1.96 \\
\hline $\begin{array}{l}\text { Dangerous } \\
\text { worldview (Duckitt } \\
\text { et al., 2002) }\end{array}$ & $3.64^{\mathrm{a}}$ & .83 & $4.32^{\mathrm{a}}$ & .87 & 4.08 & 1.06 & 4.13 & .70 & $3.10^{*}$ \\
\hline $\begin{array}{l}\text { Right-wing } \\
\text { authoritarianism }\end{array}$ & -.76 & 1.29 & -1.11 & 1.22 & -1.15 & .97 & -.78 & .87 & 1.01 \\
\hline $\begin{array}{l}\text { Social dominance } \\
\text { orientation }\end{array}$ & 2.74 & .72 & 3.06 & 1.14 & 2.76 & .88 & 3.29 & .81 & $2.29 \dagger$ \\
\hline
\end{tabular}

Note. $M=$ Mean; $S D=$ Standard Deviation. ${ }^{*} p<.05 ; \dagger p<.10$. Means with similar superscripts differ significantly $(p<.05)$.

One-way ANOVAs showed non-significant effects of experimental condition on competitive worldview ( $p=.124)$ and RWA $(p=.393)$. In addition, the impact of condition on SDO was only marginally significant, $F(3,111)=2.29, p=.082, \eta_{\mathrm{p}}^{2}=.06$, while the impact of condition on dangerous worldview was statistically significant, $F(3,111)=3.10, p$ $=.030, \eta_{\mathrm{p}}{ }^{2}=.08$. Follow-up Bonferroni post-hoc tests did not show any differences across conditions for SDO (all $p \mathrm{~s} \geq .174$ ), but showed that dangerous world beliefs were significantly higher in the economic threat condition than in the control condition $(p=.021)$. The significant differences between experimental conditions are further discussed considering the DPM model below.

\section{Indirect effects of the scenarios on political conservatism: Mediational path}

model. Following the criteria described in Study 3A, path analysis models with maximum likelihood estimation were computed. Given that the sample size for each of the four experimental conditions varied from 26 to 31 participants, the present study could not explore further the differences between the four conditions in a stable fashion. Therefore, as in Studies $3 \mathrm{~A}$ and $3 \mathrm{~B}$, the path analysis focused on the comparison between the control condition and the grouped threat conditions. The control (0) versus the grouped threat (1) condition was used as a dichotomous exogenous variable in this analysis.

Preliminary independent samples $t$-tests comparing the control to the grouped threat conditions revealed non-significant effects of condition on competitive worldview ( $p=.659$ ), RWA $(p=.290)$ and SDO $(p=.152)$. However, a significant effect of condition on dangerous 
worldview was detected, $t(113)=-2.85, p=.005, d=.64$, with participants who saw the grouped threat scenarios $(M=4.19, S D=.88)$ perceiving the world as more dangerous than participants who saw the control scenario $(M=3.64, S D=.83)$. Thus, the path analysis model investigating the indirect effect of societal threat on political conservatism was credible.

Similarly to Studies 3A and 3B, an initial model was run including all predicted paths from the DPM model (Sibley \& Duckitt, 2009) and direct paths from societal threat to world beliefs, socio-political attitudes and political conservatism. The non-significant paths were excluded and additional paths included based on modification indices. Table 5.12 shows the model fit indices for the final models.

Table 5.12

Model fit indices for the path analysis models including societal threat, world beliefs, sociopolitical attitudes and political conservatism in Study $3 C$

\begin{tabular}{lcccccc}
\hline \multicolumn{1}{c}{ Model } & $X^{2}$ & $d f$ & $X^{2} / d f$ & CFI & sRMR & $\begin{array}{c}\text { RMSEA } \\
(90 \% \text { CI })\end{array}$ \\
\hline $\begin{array}{l}\text { Left/right orientation } \\
\begin{array}{l}\text { Liberal/conservative } \\
\text { orientation }\end{array}\end{array}$ & 13.39 & 9 & 1.49 & .95 & .078 & $\begin{array}{c}.067 \\
(.000 \leq .136) \\
.040\end{array}$ \\
$\begin{array}{l}\text { Voting intention } \\
\begin{array}{l}\text { Political discourse } \\
\text { preference }\end{array}\end{array}$ & 8.22 & 7 & 1.17 & .98 & .055 & $\begin{array}{c}(.000 \leq .128) \\
.051 \\
(.000 \leq .129) \\
.000\end{array}$ \\
\hline
\end{tabular}

Note. $X^{2}=$ value of the chi-square test statistic; $d f=$ degrees of freedom; $X^{2} / d f=$ value of the chi-square test statistic divided by the number of degrees of freedom; CFI = comparative fit index; $\mathrm{sRMR}=$ standardized root mean square residual; RMSEA = root mean square error of approximation; $90 \% \mathrm{CI}=$ $90 \%$ confidence interval.

As can be seen in Figure 5.5, the grouped threat conditions (compared to the control condition) increased political conservatism via dangerous world beliefs, RWA, and SDO. ${ }^{32}$ Also, societal threat impacted directly only liberal/conservative orientation (as shown in previous analyses). Finally, only RWA predicted left/right and liberal/conservative orientations, only SDO predicted political discourse preference, and both RWA and SDO predicted voting intention. These results provide partial support for the dual-process

\footnotetext{
${ }^{32}$ The statistically significant $(p<.05)$ indirect effects of condition were as follows: RWA $\left(\beta_{\text {indirect effect }}=.05\right)$, $\operatorname{SDO}\left(\beta_{\text {indirect effect }}=.01\right)$, left/right orientation $\left(\beta_{\text {indirect effect }}=.02\right)$, liberal/conservative orientation $\left(\beta_{\text {indirect effect }}\right.$ $=.02)$, voting intention $\left(\beta_{\text {indirect effect }}=.02\right)$ and political discourse preference $\left(\beta_{\text {indirect effect }}=.003\right)$.
} 
mediation hypothesis (H3) and the differential impact of societal threat on political conservatism via some of the variables included in Duckitt's (2001) DPM model.

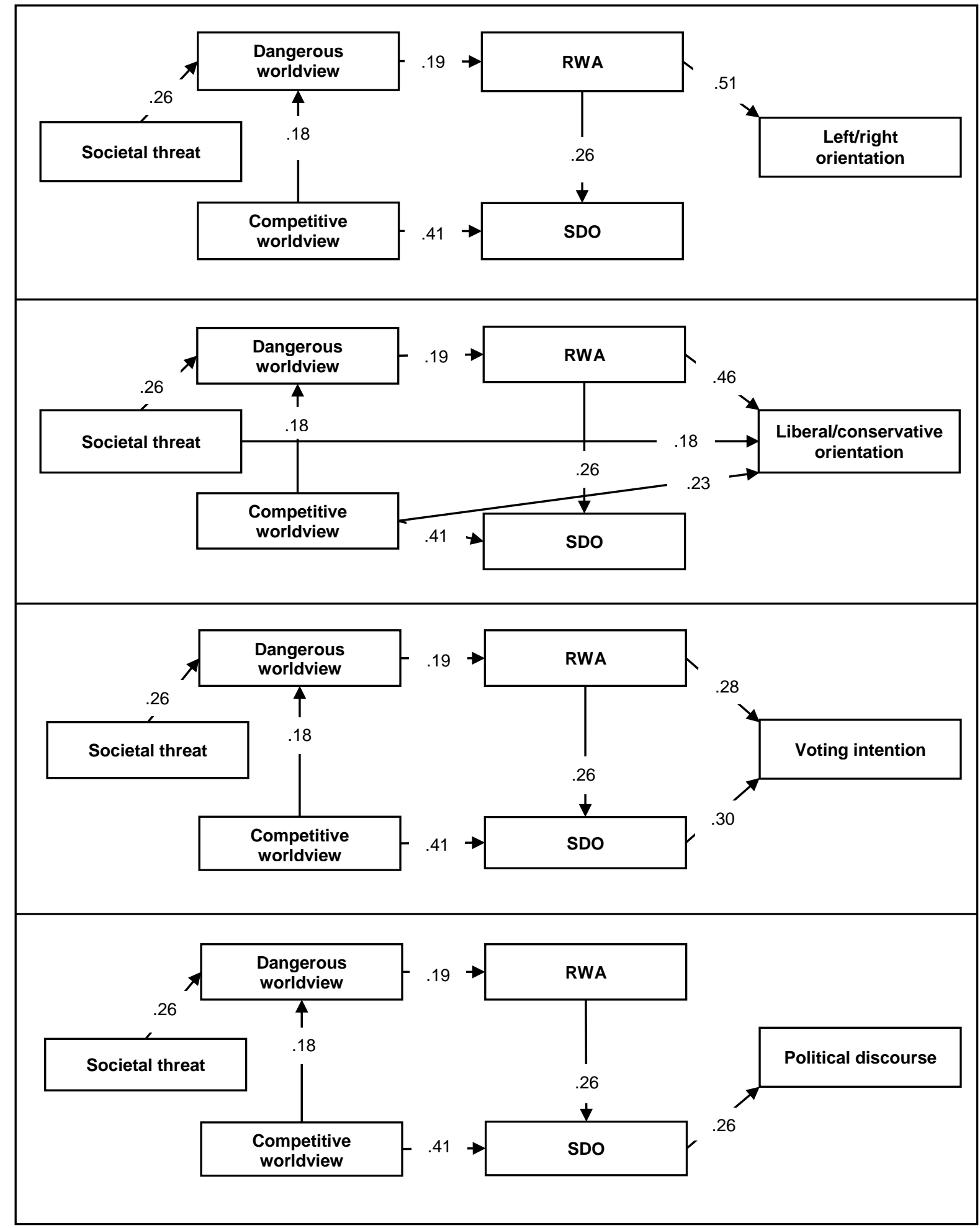

Figure 5.5. Path analysis models of the associations between societal threat, world beliefs, socio-political attitudes and political conservatism in Study 3C. Only statistically significant paths $(p<.05)$ are shown. 


\section{Activation of Authoritarianism by Social Threat}

Similarly to Studies 3A and 3B, a moderated path analysis model showed a nonsignificant effect of the interaction term pre-RWA $\times$ social threat on dangerous world beliefs $(\beta=-.70, p=.199) .{ }^{33}$ This result does not provide any evidence for the differential impact of social threat on high and low authoritarians (H4).

\section{Discussion}

Investigating further the relationship between societal threat and political conservatism with an experiment conducted in a lab and with visual stimuli, four main findings were observed in the present study: (1) the societal threat manipulation enhanced political conservatism directly (as indexed by liberal/conservative orientation), (2) the societal threat manipulation did not enhance the prior political orientation of the participants, (3) the indirect effect of the societal threat manipulation on political conservatism via variables included in the DPM model was only partially confirmed - societal threat (mainly economic threat) differently impacted dangerous world beliefs in analyses of variance, and exploratory path analysis models showed that societal threat enhanced political conservatism via dangerous world beliefs, RWA and/or SDO, and (4) RWA measured before the experiment and the social threat manipulation did not interact in predicting dangerous world beliefs. Overall, the results show some interesting experimental effects in the predicted direction. Next, we present the general discussion for Study 3.

\section{General Discussion for Study 3}

The extant literature has suggested a link between threatening situations and political conservatism, although it is not clear how these variables are connected. In order to clarify these relationships, three experimental studies were conducted using different methodologies. Overall, the three experiments suggested more support for the conservative shift (H1) than for the cultural worldview enhancement hypothesis $(\mathrm{H} 2)$. Additionally, the indirect effects of societal threat on political conservatism via some of the variables in the DPM model were

\footnotetext{
${ }^{33}$ A similar analysis including only participants with scores in the first or fourth quartiles of pre-RWA was also performed. The analysis considering these extreme low and extreme high pre-RWA scores yielded a similar result $(\beta=-.52, p=.441)$. For completeness, an additional analysis including SDO measured before the experiment was also performed to test the possibility that pre-SDO would interact with the economic threat manipulation, affecting competitive worldview. The effect of the interaction term pre-SDO $\times$ economic threat was also non-significant $(\beta=.10, p=.828)$.
} 
observed in two of the three studies (H3). Finally, the interaction between RWA measured before the experiment and the social threat manipulation did not impact dangerous world beliefs in any of the studies (H4). These findings are discussed in more detail below. Limitations of the experimental studies and direction for further studies will be discussed in detail in the final chapter of the thesis.

\section{Conservative Shift versus Cultural Worldview Enhancement}

The hypothesis of conservative shift (H1; Jost et al., 2003b) predicted that participants would become more politically conservative after the threat manipulation. On the other hand, the related hypothesis of cultural worldview enhancement (H2; Burke et al., 2013) predicted that only participants who were already conservative would become more conservative after the threat manipulation. Overall, the studies presented in this chapter provided more support for the conservative shift than for the cultural worldview enhancement hypothesis, although this support was limited to a marginally significant effect for liberal/conservative orientation in Study 3C.

This marginally significant effect showed that participants in the natural and social threat (but not in the economic threat and control) conditions became more conservative after the experiment. Additionally, when the control condition was compared to the grouped threat conditions, the same effect was observed. Compared to participants in the control condition, participants in the grouped threat conditions became more conservative after the experimental manipulation.

These results suggest that economic, natural and social threats have different effects, with only the natural and social threat manipulations impacting liberal/conservative political orientation. This distinct impact of the threat types could be linked to the cross-sectional findings of Study 1. We observed in that study that liberal/conservative orientation was more strongly influenced by RWA (which according to the DPM model should be impacted more strongly by social threatening situations), which support the stronger influence of the social threat manipulation on liberal/conservative orientation when compared to the economic threat manipulation. No specific predictions were made for the natural threat manipulation, but its influence on liberal/conservative orientation might be linked to findings indicating a strong effect of natural threat situations on RWA (Fritsche, et al., 2012).

Some support for the conservative shift hypothesis was only observed in Study 3C, which was the only experimental study including pictorial stimuli. It is possible that stronger experimental manipulations including images would confirm this hypothesis in a broader sense also for other political conservatism variables. Given that pictorial stimuli is better 
recalled than words (McBride \& Dosher, 2002; Shepard, 1967), future studies should focus on using stronger images to evoke threatening situations, respecting the appropriate ethical guidelines.

There was also another consistent effect (albeit only statistically significant in Study 3B) observed in the analyses reported in the present chapter. Liberal-oriented participants became significantly more conservative after the experiment in the economic and social threat conditions. On the other hand, conservative-oriented participants became marginally less conservative after the experiment also in the economic and social threat conditions. These results suggest exactly the opposite of what should be expected according to the cultural worldview enhancement hypothesis - that societal threat would enhance participants' prior political view. Therefore, it was expected that only participants with already high levels of conservatism would become more conservative after the experimental manipulation.

This unexpected effect was somewhat consistent not only for liberal/conservative orientation but also for left/right orientation. Indeed, although not statistically significant, this pattern of results appears in 44 out of the 48 analyses across all experimental conditions and studies. That is, left/liberal-oriented participants became significantly more rightwing/conservative while right-wing/conservative-oriented participants became less rightwing/conservative (as depicted in the two-way interactions between left/right orientation and pre-left/right categorisation and between liberal/conservative orientation and preliberal/conservative categorisation). One possible explanation for this pattern of results is regression toward the mean. Here participants with higher scores in any of the dependent variables will lower their scores in a subsequent measurement, while participants with lower scores will increase their scores. We expected that the experimental manipulation would override this statistical phenomenon, but the pattern of findings suggest this was not accomplished. Again, this suggests that stronger threat manipulations are required.

Previous literature considering mainly archival data and proxy measures of political conservatism (e.g. conversion to authoritarian churches) has provided support for both the hypotheses of conservative shift (Jost et al., 2003b) and cultural worldview enhancement (Burke et al., 2013). The limited effects presented in the present research (in particular the opposite effects regarding H2) might be understood in terms of the experimental nature of the studies. It is possible that political orientation only changes consistently after enduring periods of societal threat, and not after experimental manipulation. Hence, although able to detect causal relationships more reliably (Spencer et al., 2005), experimental studies might not be the best option when evaluating political orientation change. Despite this consideration, 
we still believe experimental designs should be able to detect the impact of threatening situation on political orientations (e.g. see Duckitt \& Fisher, 2003), but that the experimental manipulation might need to be stronger in order to induce the effect as tentatively shown in Study 3C.

At the same time, no consistent overall pattern was observed across the dependent variables (left/right orientation, liberal/conservative orientation, voting intention and political discourse preference), even though they are all positively correlated. This observation suggests it might be too simplistic to expect that the dependent variables considered are organised in a single continuum of liberal-conservativeness that could be used to explain alone conservative shift. Past studies have already contested the traditional left/right or liberal/conservative continuum by showing that political orientation should include at least economic and social dimensions (e.g. Feldman \& Johnston, 2014; Jost et al., 2009). Likewise, although these dimensions have been treated as similar constructs in the literature (Jost et al., 2009) and are often strongly correlated, the observed distinct effects on left/right and liberal/conservative orientations suggest that these variables enclose a few distinct aspects of political conservatism. In addition, scholars have also posited that the positions each political party would take on particular issues is determined by the number of cultural, attitudinal and political cleavages existing in the country (e.g. socioeconomic class, post-materialism, ethnicity, economic interventionism and social conservatism; Nagel, 1994). Future experimental studies should take these suggestions into consideration.

\section{Dual-Process Mediation of the Impact of Societal Threat on Political Conservatism}

The dual-process mediation hypothesis (H3; Duckitt \& Fisher, 2003) predicted that world beliefs (competitive and dangerous) and socio-political attitudes (RWA and SDO) would differentially mediate the impact of the societal threat manipulation on political conservatism. More specifically, it tested whether economic and social threats (compared to the control condition) impacted political conservatism via different paths of the DPM model (Duckitt, 2001). This hypothesis was tested with preliminary analyses of variance, followed by path analysis models.

Overall, only scores on competitive and dangerous world beliefs varied across conditions in analyses of variance. In five of the seven significantly or marginally significant comparisons, participants in the economic or social threat conditions perceived the world as more competitive or dangerous than participants in the control condition. More specifically, participants in the economic or social threat conditions perceived the world as more dangerous than participants in the control condition in four of the comparisons, and 
participants in the social threat condition perceived the world as more competitive than participants in the control condition in one of the comparisons.

The results only supported H3A partially by showing that participants in the social threat condition perceived the world as more dangerous than participants in the control condition. The absence of significant differences in the perception of the world as competitive and dangerous between the economic and social threat conditions might suggest that both world beliefs are impacted by economic and social threats (see Duckitt \& Sibley, 2010). It also might suggest that, overall, these types of threat impact dangerous (and not competitive) world beliefs to a major extent (see Duckitt \& Fisher, 2003). That both economic and social threat impact more strongly dangerous than competitive world beliefs resonates with evolutionary psychology accounts of human reaction to threatening situations. When experiencing threatening events there is a necessity of a rapid response/action toward fighting or fleeing the threat (Öhman, 1997), and the perception of the world as dangerous might be more adaptive, pressing and fast in eliciting prompt reactions to threat than the perception of the world as competitive.

In general, the analyses of variance also showed that participants in both the control and the natural threat conditions perceived the world as less competitive than participants in the economic and social threat conditions. These results might suggest that natural threat is perceived as a more mild type of threat than economic and social threats. On the other hand, this could be alternatively explained by the location in which the data were collected. The data were collected in a city located in an earthquake-generating tectonic collision zone, and where residents already expect the occurrence of earthquakes (one of the natural hazards depicted in the natural threat condition; see McClure et al., 2015). This means that the natural threat manipulation might have been less efficient in residents of this city compared to residents from other cities, and that the economic and social threat conditions might have had a greater impact. Given that past research has shown an increase on authoritarianism in response to a specific type of natural threat (e.g. climate change; Fritsche, et al., 2012), further exploration of the role of natural threat in impacting conservatism is needed.

Moving on to the path models, the results showed a consistent indirect effect of societal threat on political conservatism in two of the three studies, albeit the strength of this indirect effect was only weak. In particular, societal threat (compared to the control condition) increased political conservatism via competitive world beliefs and RWA in Study 3A, and increased political conservatism via dangerous world beliefs, RWA and/or SDO in Study 3C. Societal threat impacted directly only liberal/conservative orientation in Study 3C. Overall, 
these results provide support for the mediated impact of societal threat on political conservatism via DPM model variables (e.g. Duckitt \& Fisher, 2003).

Regarding the particular mediators, the results showed some consistency for RWA, which acted as the main mediator in these models. This result supports the important role of authoritarianism in underpinning political conservatism (Wilson \& Sibley, 2013) as well as its importance for understanding the effect of societal threat (Duckitt, 2013). This consistent mediation role of RWA would suggest a similar mediation role for dangerous world beliefs, following the DPM model. However, the mediation role of dangerous (and also competitive) world beliefs varied across studies. While dangerous world beliefs mediated the impact of societal threat on political conservatism in Study 3C, competitive world beliefs mediated the impact of societal threat on political conservatism in Study 3A. Perhaps the type of measure used to access world beliefs can explain these differences.

Study 3A included the measure proposed by Perry and Sibley (2010) in the main analyses and Study 3C included the measure proposed by Sibley et al. (2007) in the main analyses. While competitive mean scores were higher than dangerous mean scores when the Perry and Sibley measure was used $[t(209)=10.66, p<.001]$, the opposite pattern was observed when the Sibley et al. measure was used $[t(110)=-22.61, p<.001]$. It is possible that this observed effect could have contributed for competitive world beliefs to act as the mediator in Study 3A and for dangerous world beliefs to act as the mediator in Study 3C.

Another point worth noting is the strength of the difference between the mean perception of the world as dangerous in the grouped threat condition and in the control condition in Studies 3B and 3C. Both studies used the same world beliefs measure but varied in the type of experimental manipulation used. The strength of the difference in the scores of dangerous world beliefs was stronger in the experiment using pictorial stimuli (Study 3C) than in the study using textual stimuli (Study 3B). Given that images have been shown to be better recalled than words, this result was as expected (McBride \& Dosher, 2002; Shepard, 1967).

In conclusion, only a limited number of studies have investigated the mechanism underlying the impact of societal threat on political conservatism (but see Duckitt \& Fisher, 2003). In this sense, the differences in the mediation of the effect of societal threat on political conservatism by world beliefs and socio-political attitudes should be explored in future studies. Moreover, only a limited number of studies have investigated the association between societal threat and political conservatism experimentally. The present research advances the 
area by showing that societal threat enhances political conservatism via variables in the DPM model.

\section{Activation of Authoritarianism by Social Threat}

Finally, the hypothesis of activation of authoritarianism by social threat (H4; Feldman \& Stenner, 1997) predicted that the interaction between RWA measured before the experiment and the social threat manipulation (compared to the control manipulation) would enhance dangerous world beliefs. None of the interaction terms between RWA measured before the experiment and the social threat manipulation were significant in predicting dangerous world beliefs. These results support the non-significant interaction reported by Duckitt and Fisher (2003). Experimental evidence provided in the present research and by Duckitt and Fisher suggests that the previous level of authoritarianism does not influence individuals' reaction to threatening scenarios.

The impact of the interaction between authoritarianism and threat on other variables has been discussed and tested empirically in the literature for some time now, but the prevalence of this effect is yet to be confirmed (McCann, 2009). The theme even deserved a special edition in the International Journal of Psychology (Duckitt, 2013). As observed by one of the key authors in the field, threat has been sometimes conceived as a moderator of the impact of authoritarianism on other variables (as tested in our H4), and sometimes it has been conceived as the predictor of other variables independent of pre-existing levels of authoritarianism (Feldman, 2013). Overall, the accumulated evidence in the present studies showed that societal threat increased directly liberal/conservative orientation $(\mathrm{H} 1)$, that societal threat increased indirectly political conservatism via variables in the DPM model (H3), and that RWA did not interact with social threat in the prediction of dangerous world beliefs (H4).

A limitation of the overall findings regarding $\mathrm{H} 4$ is that the levels of authoritarianism measured before the experiment were not especially high in the three studies presented in this chapter (see Appendices I, K and $\mathrm{O}$ for further information), which might have limited the possible interaction between RWA and social threat in the present research and also in the undergraduate sample considered in Duckitt and Fisher (2003). In particular, the levels of RWA measured before the experimental manipulation were below the scale middle point in Studies 3A, 3B and 3C $[t(74)=-8.43, p<.001 ; t(62)=-9.22, p<.001 ; t(43)=-6.67, p<$ .001 , respectively]. Maybe with a more representative sample from the authoritarianism spectrum, the predicted interaction could have emerged.

Next, we present the general discussion for the present thesis. 
This thesis had the main goal of providing a systematic evaluation of how societal threat impacts political conservatism, as indexed by political orientation, voting intention and political discourse preference. Alongside this main goal, the thesis also had the secondary goal of evaluating whether or not different types of societal threat - namely economic, natural and social threats - impact differentially political conservatism. In order to achieve the main and secondary goals, seven empirical studies were conducted. The first four empirical studies provided the grounding empirical basis for the last three experimental studies testing four specific hypotheses targeting the relationship between societal threat and political conservatism.

The experimental studies tested first whether participants became more conservative after the threat manipulation (conservative shift hypothesis, H1; Jost et al., 2003b) or whether only participants who had high levels of conservatism before the threat manipulation became more conservative after it (cultural worldview enhancement hypothesis, H2; Burke et al., 2013). After testing these two main hypotheses, the experimental studies moved on to test a mediation hypothesis and a moderation hypothesis. The mediation hypothesis focused on whether societal threat impacted political conservatism indirectly via world beliefs and sociopolitical attitudes as proposed in the dual-process motivational (DPM) model (dual-process mediation hypothesis, H3; Duckitt \& Fisher, 2003). Moreover and in line with the DPM model, the studies also tested whether participants assigned to the social threat condition (compared to the economic threat and control conditions) scored significantly higher on dangerous world beliefs and RWA (H3A), and whether participants assigned to the economic threat condition (compared to the social threat and control conditions) scored significantly higher on competitive world beliefs and SDO (H3B). Finally, the moderation hypothesis focused on whether the interaction between previous levels of RWA and social threat impacted dangerous world beliefs (activation of authoritarianism by social threat hypothesis, H4; Feldman \& Stenner, 1997). In the following, we provide an overview of the seven empirical studies and the findings of the experimental test of the four hypotheses.

\section{Overview of Research Findings}

\section{Duckitt's DPM model and the prediction of voting intention and political}

orientation. The first study included in this thesis relied on a secondary dataset enclosing 2,884 New Zealanders: (1) to test an expanded DPM model including the big-five personality 
traits following the model observed in Sibley and Duckitt (2009); and (2) to test whether this model could predict political conservatism as indexed by voting intention and political orientation. The findings showed that a modified model provided better fit to the data than the model reported by Sibley and Duckitt (2009). Different from their model, the best-fitting model for our data excluded three paths (i.e. extraversion $\rightarrow$ dangerous worldview, agreeableness $\rightarrow$ SDO, and emotional stability $\rightarrow$ RWA) and included three new paths (i.e. emotional stability $\rightarrow$ SDO, dangerous worldview $\rightarrow$ SDO, and extraversion $\rightarrow$ RWA). Despite these minor distinctions, the only path theoretically predicted that was not found in our study was the path from agreeableness to SDO. In our study, agreeableness only impacted SDO indirectly.

The modified model was then tested in predicting voting intention and political orientation. The final models presented moderate fit to the data and adequately predicted the dependent variables. The only distinction among the models was that SDO predicted voting intention and left/right orientation more strongly than RWA, while RWA predicted liberal/conservative orientation more strongly than SDO. The overall results from Study 1 showed that world beliefs (dangerous and competitive) and socio-political attitudes (RWA and SDO) explained political conservatism, suggesting that they could be considered as mediators of the impact of societal threat on political conservatism in further experimental studies.

Threat manipulation design. Three studies were then conducted in order to design experimental stimuli for the last three experimental studies. First, Study 2A investigated the psychological meanings of economic, natural and social threats among 78 Pākehā New Zealanders (Figueroa, González, \& Solís, 1981; Reyes-Lagunes, 1993). The descriptions used to elicit the psychological meaning of economic and social threats were based on descriptions of competitive and dangerous world beliefs provided by Perry and Sibley (2010). Results indicated 12 meaningful words/expressions for social threat, 18 for economic threat, and five for natural threat. Among these, only "war" was evoked by more than one type of societal threat (i.e. social and economic threats), and therefore not considered in subsequent studies. Additionally, the frequency of words/expressions elicited by natural and social threats was statistically higher than the frequency of words/expressions elicited by economic threat. These results suggest that participants had more difficulty in attributing meaning to economic threat compared to the other threat types, and that this type of societal threat includes a broad range of concepts not so tightly related to its meaning. 
Building on these results, Study 2B had the goal of validating textual experimental stimulus. This study relied on answers from 181 Pākehā New Zealanders and used experimental scenarios based on those used by Duckitt and Fisher (2003). More specifically, participants were assigned randomly to one of four scenarios (control, economic threat, natural threat or social threat) and answered questions related to the given scenario. The results showed that participants who read the economic, natural and social threat scenarios identified more economic, natural and social threat, respectively, in the scenarios they read. However, when it was investigated whether or not voting intention and left/right and liberal/conservative orientations varied across conditions, no significant differences were observed. Still, given that the different scenarios were perceived differently, the scenarios were considered in subsequent experimental studies without further amendments.

Study $2 \mathrm{C}$ then validated images to be used as pictorial experimental stimulus in a further experimental study. This study relied on answers from 40 Pākehā New Zealanders to select images characterizing economic, natural and social threats. The participants also evaluated images characterizing New Zealand's natural geography to be used in the control stimulus. Except for the image selected for "money", all the other images elicited more negative than positive emotions. Based on three different criteria, 17 images were selected per type of societal threat and control conditions.

The impact of threatening scenarios on political conservatism. Three experimental studies were then conducted in order to formally test the four specific hypotheses described previously. As a secondary goal, the experimental studies also evaluated whether economic, natural and social threats differentially impact political conservatism. Study 3A was completed online with textual stimuli, Study 3B was completed in a lab with textual stimuli, and Study 3C was completed in a lab with pictorial stimuli. These studies included 142, 121 and 99 Pākehā New Zealander undergraduate students, respectively. Supporting the experimental manipulation, participants generally identified more economic, natural and social threat when seeing the economic, natural and social threat scenarios, respectively. The only exception was for participants in the economic threat condition in Study 3A who identified only marginally more economic threat than participants reading the social threat scenario.

Only the results from Study 3C (using pictorial experimental stimulus) provided some confirmation for H1 (conservative shift hypothesis; Jost et al., 2003b) over H2 (cultural worldview enhancement hypothesis; Burke et al., 2013). More specifically, there was a marginally significant effect of the experimental manipulation on liberal/conservative 
orientation, with participants tending to become more conservative after seeing the natural and social threat scenarios. Importantly and confirming H1, the effect was significant when comparing the control condition with the grouped threat conditions, with participants in the grouped threat conditions becoming more conservative while those in the control condition did not shift their political orientation.

Surprisingly, Study 3B showed the exact opposite pattern of results that would be expected according to $\mathrm{H} 2$. Participants categorised as liberal before the experiment became significantly more conservative after reading the economic or social threat scenarios, while participants categorised as conservative became marginally more liberal after reading the same scenarios. Although this unexpected effect was not significant in other studies (or even when considering left/right orientation), the same pattern of results was observed across all three experiments when considering both liberal/conservative and left/right orientations and different experimental conditions.

Some support was observed for H3 (dual-process mediation hypothesis; Duckitt \& Fisher, 2003). First, the results partially confirmed H3A by showing that participants in the social threat condition perceived the world as more dangerous than participants in the control condition. Overall, the results also showed that participants in the social or economic threat conditions scored higher on competitive and/or dangerous world beliefs than participants in the control condition. Higher scores on competitive world beliefs were also observed in two of the experiments for participants in the social and economic threat conditions compared to participants in the natural threat condition. Second, path models showed that the impact of societal threat on political conservatism was mediated by world beliefs and socio-political attitudes in two of the experiments. While societal threat impacted political conservatism via competitive world beliefs and RWA in Study 3A, societal threat impacted political conservatism via dangerous world beliefs, RWA and/or SDO in Study 3C.

Finally, moderated path models examined H4 (activation of authoritarianism by social threat hypothesis; Feldman \& Stenner, 1997). The results showed no support for this hypothesis. High authoritarians were not more sensitive to social threat, and the pre-RWA $\times$ social threat interaction term did not impact dangerous world beliefs measured after the experimental manipulation.

The seven empirical studies presented in this thesis contribute to the literature in a number of ways, and their findings were discussed in each of the specific chapters. Next, we discuss general theoretical contributions of the present thesis.

\section{Theoretical Contributions of the Thesis}


The present thesis provides seven main theoretical contributions for the extant literature. The first contribution of this thesis was to provide a "conceptual map" of distinct but related predictions derived from the research area investigating the impact of threat on political conservatism. This conceptual map emerged from a number of distinct theoretical models and culminated on the explicit hypotheses tested in the present research. The frameworks of system justification theory (Jost \& Banaji, 1994) and terror management theory (Rosenblatt et al., 1989) were both reviewed in order to formulate the two main competing hypotheses (i.e. conservative shift hypothesis, H1; cultural worldview enhancement hypothesis, $\mathrm{H} 2$, respectively).

In addition, two different frameworks related to the mechanism underlying the impact of threat on political conservatism were also reviewed. The dual-process motivational model framework (Duckitt, 2001) led to the dual-process mediational hypothesis (H3), while the activation of authoritarianism by threat framework (Feldman \& Stenner, 1997) led to the activation of authoritarianism by social threat hypothesis (H4). Whilst all these hypotheses are related, they had not been conceptually organised, integrated and considered jointly in previous studies (but see Huddy \& Feldman, 2011). The present thesis identified the key predictions of these distinct theoretical traditions, and then elaborated, described and tested four hypotheses identified under these different frameworks. The conceptual map integrating theoretical arguments accessing the influence of threat on political conservatism is useful in guiding future research.

The present research also extends past studies by experimentally examining the impact of societal threat on political conservatism. A number of studies have examined the impact of societal threat on political conservatism, but this impact has been studied mainly using archival data (e.g. Jost et al., 2003b). By developing and implementing three experiments with distinct methodologies, the present research provides a more systematic study of the threatpolitical conservatism relation. In particular, the experimental design used in the present research complements the extant literature by testing hypotheses originated from correlational designs in a more controlled fashion, diminishing the impact of confounding variables. In this sense, the studies described in the present thesis advance the area by providing evidence that there is a limited but visible effect of societal threat on political conservatism in a more controlled experimental environment. In addition, the experimental studies described in the present thesis also complement past correlational studies by enabling arguments of causality. In this sense, we advance the research in the area by providing some experimental evidence that societal threat impacts political conservatism. 
Another important theoretical contribution refers to the dependent variables considered in the present thesis. Past research has often focused on proxy measures of political conservatism such as conversion to authoritarian churches, authoritarian letters to newspaper editors or authoritarian comics (Jost et al., 2003b; Perrin, 2005; Peterson \& Gerstein, 2005). Perrin (2005), for instance, examined letters to the editor published in 17 different newspapers in the USA before and after the 9/11 terrorist attack, and found that letters published after the 9/11 attacks exhibited both more authoritarian and anti-authoritarian ideas than letters published before the attacks. In the present thesis, we advance past studies by using more direct and broad measures of political conservatism (i.e. left/right orientation, liberal/conservative orientation, voting intention and political discourse preference). Even though the impact of societal threat was not generalised across all the dependent variables in Study 3C (using pictorial stimuli), we believe that the limited impact of societal threat on political conservatism leads to important conclusions about the nature of political conservatism. More specifically, the impact of societal threat on political conservatism was limited to conservative orientation and not the other indicators. This result suggests that conservative orientation has a different meaning from right orientation, conservative voting intention and preference for conservative political discourse, even though these variables are intrinsically related (Jost et al., 2009).

Additionally, the apparent lack of experimental impact on conservative voting intention and conservative political discourse preference might imply that these variables enclose more than the often assumed liberal-conservative continuum, enclosing also worldviews related to different cultural, attitudinal and political cleavages (e.g. socioeconomic class, post materialism, ethnicity, economic interventionism, and social conservatism; Nagel, 1994). This might explain why researchers have mainly examined preference for different conservative policies and other proxy measures but not conservative voting per se in previous studies (Burke et al., 2013; Jost et al., 2003b). Another alternative explanation for the apparent lack of experimental effect on conservative voting intention across studies might be that some political variables might be less changeable by experimental manipulation than others, being perhaps more impacted by factors in place long before the experiment. Indeed, longitudinal studies have shown that conservative orientation can be formed at young age and is associated, for instance, to authoritarian parenting attitudes and psychological characteristics in early childhood (Block \& Block, 2006; Fraley, Griffin, Belsky, \& Roisman, 2012). Studies have also shown an association between political attitudes and genome characteristics (Jost \& Amodio, 2012). 
A fourth important theoretical contribution of the present thesis was to provide empirical support for the role of variables in the DPM model as mediators of the impact of societal threat on political conservatism (Duckitt \& Fisher, 2003; Duckitt \& Sibley, 2010). The model tested in the present thesis was based on previous theoretical and empirical work showing that (1) different social contexts (threatening and competitive-jungle) differentially impact world beliefs (dangerous and competitive) and socio-political attitudes (RWA and SDO) (e.g. Duckitt \& Fisher, 2003), and (2) that different social contexts, world beliefs and socio-political attitudes could impact differentially right-wing politics (e.g. Duckitt \& Sibley, 2010). By testing the impact of societal threat on political conservatism via world beliefs and socio-political attitudes, our studies showed that societal threat impacts political conservatism mainly indirectly via these variables and not directly. Based on the present results, we argue that the DPM model is a parsimonious framework to test the impact of societal threat on political conservatism by integrating the "real world" (societal threat) to the "perceived world" (world beliefs), and integrating these to the main factors enclosed by political conservatism (RWA and SDO) and political conservatism per se. Parsimonious and measurable models for the impact of societal threat on political conservatism such as the DPM model should be preferred rather than integrative but too large models that might be untestable (see Jost et al., 2003b).

Additionally, the experimental studies presented in this thesis also support the meaningful role of both dangerous world beliefs and RWA in mediating the impact of societal threat on political conservatism. As mentioned in Chapter 2, RWA has been the variable most studied alongside threat when examining conservative orientation. Authoritarianism has also been recognized as an important variable for the understanding of reactions toward threat, although the nature of this relationship is still unclear (see Altemeyer, 2006; Feldman \& Stenner, 1997). Thus, given the close relationship between RWA and dangerous world beliefs in the DPM model, the mediational role of these two variables on the impact of societal threat on political conservatism was as expected, highlighting their importance in explaining the impact of societal threat on political conservatism.

Also noteworthy is that our results might imply that dangerous world beliefs and RWA are more important when reacting to societal threat than competitive world beliefs and SDO. In this sense, dangerous world beliefs and RWA might have evolutionary advantages when reacting to threat. From an evolutionary psychology standpoint, fighting or fleeing threat is adaptive for survival (Öhman, 1997). Our results show that the threat manipulation had a more consistent impact on dangerous world beliefs (with a subsequent impact on 
RWA). In this sense, perceiving the world as dangerous appears to be the mechanism by which a threatening situation is processed to culminate in the behavioural response to flight or flee.

A fifth theoretical contribution refers to the test of the activation of authoritarianism by threat (Feldman \& Stenner, 1997). The contradictory relationship between threat and authoritarianism has been discussed for many years in the literature (Feldman, 2013). While some researchers argue that threat impacts other variables irrespective of people's prior level of authoritarianism, other researchers argue that people who score highly on authoritarianism are more prone to react and be impacted by threat (Feldman, 2013; Feldman \& Stenner, 1997). Given the conflicting ways in which the relationship between authoritarianism and threat has been studied, this thesis also tried to resolve this impasse experimentally by testing the differential effect of the interaction between pre-RWA $\times$ social threat on dangerous world beliefs. In agreement with results reported in Duckitt and Fisher (2003), the present research did not support the activation of authoritarianism by threat. This suggests that threat might induce political conservatism irrespective of prior levels of authoritarianism. At the same time, it is still possible that this lack of significant interaction in predicting dangerous world beliefs resulted from the type of threat manipulation used. In both the present study and in the study by Duckitt and Fischer (2003), societal threat (and not subjective perceptions of external threat) was considered (but see also Hastings \& Shaffer, 2005). On the other hand, Feldman and Stenner (1997), the precursors of the activation of authoritarianism by threat hypothesis, considered participants' subjective perception of threat evoked by societally threatening situations. This suggests that the inconclusive relationship between threat and authoritarianism might be a result of the differential focus on societal threat versus subjective perceptions of external threat (see also Kossowska et al., 2011). That subjective perception might be more important in the interaction with authoritarianism is related to a previous model suggesting that perceived control in the face of threat can be more important than threat itself (Fritsche et al., 2011). In particular, these authors argued that perceived control is more meaningful than threat per se in impacting ethnocentric tendencies.

A sixth important theoretical contribution of the present thesis is the systematic evaluation of the impact of different types of societal threat (i.e. economic threat, natural threat and social threat) on political conservatism. Previous research has mainly included aggregated indicators of societal threat based on economic, social and political indicators or expert opinions (Jost et al., 2003b). In addition, the impact of natural threat on political conservatism has been mainly studied in terms of specific natural disasters (e.g. climate 
change, Fritsche et al., 2012) and variables related to political conservatism such as authoritarianism. Advancing previous research, the present thesis provided empirical support for the distinction between economic, natural and social threats. More particularly, Study 3C showed that participants became more conservative after being exposed to social and natural threats but not after being exposed to a control scenario or economic threat. Also advancing previous research, Studies 3A, 3B and 3C showed that participants perceived the world as more dangerous in the economic and social threat conditions than in the control condition and as more competitive in the economic and social threat conditions than in the control and natural threat conditions. These results provide empirical support for the claim that societal threat impacts differentially world beliefs (Duckitt \& Fisher, 2003; Duckitt \& Sibley, 2010).

The final important theoretical contribution of the present thesis is the design of valid experimental stimuli. When designing the textual and pictorial stimuli, we tried not to focus on direct in-group/out-group conflict, even though some of the variables proposed as mediators of the impact of societal threat on political conservatism were intrinsically related to the group level (i.e. RWA and SDO). In addition, the experimental stimulus designed for the three last experimental studies did not specifically focus on consequences of the different types of societal threat as previously done (Fritsche et al., 2012). Furthermore, it was also our interest to base the threat manipulation on what European New Zealanders regularly felt as threatening in Wellington, New Zealand, and not on what academics felt as threatening (McCann \& Stewin, 1990). To the best of our knowledge, no experimental study focusing on threat and voting intention or political orientation has used images as stimulus for threat enhancement (but see Butler, 2013). Studies have shown that images are more easily and frequently recalled by people than words (McBride \& Dosher, 2002; Shepard, 1967), and participants in our studies were also requested to recall the scenario while answering the questions. Using this methodology (images and recall) to enhance the effect of the experimental manipulation advances previous research.

Next, we describe limitations of the present research and some future directions for the research area focusing on the societal threat - political conservatism link.

\section{Limitations and Future Research}

Regarding the textual and pictorial scenarios validation studies, there are two main methodological points that should be addressed in future studies. First, in the study validating textual experimental stimulus, it would have been more methodologically sound to present the descriptions of economic, natural and social threats in a random order and not in a fixed order as done in Study 2B. Second, we acknowledge that the process of searching for images to be 
used as experimental stimulus could have followed stricter inclusion criteria that also accounted for definition and size of the images before validating the images. Also connected to this point, it would have been interesting to have more evaluators selecting the images, granting greater reliability to the process.

Regarding the three experimental studies, it would have been more worthwhile to have measured political orientation in terms of its economic and social dimensions as discussed by Feldman and Johnston (2014) and Jost et al. (2009). These variables could have added to the understanding of how different types of societal threat impact different niches of political conservatism. It would be important to understand more deeply whether or not economic and social threats impact only political orientation in niches they are directly connected to.

Also, due to a methodological flaw, identity with New Zealanders and New Zealand was measured after participants read or saw the experimental manipulation. It would have been valuable to have measured this variable beforehand as this could be used in evaluating whether it moderates the impact of societal threat on political conservatism. Research has already shown that identity can moderate the effect of experimental manipulations (e.g. Fischer, Ferreira, Milfont, \& Pilati, 2014), and models such as the one presented by Fritsche et al. (2011) have already pointed out the relevance of group membership for understanding the impact of (sense of control over) threat on ethnocentric tendencies. Thus, group membership and identity should be considered in future studies. Sense of control over threat could also be a significant variable to include in future studies, given that the model proposed by Fritsche et al. (2011) has also shown that sense of control over threat might be a more important factor when focusing on the impact of threat over other variables than threat per se.

The levels of authoritarianism in the experimental samples included in the present thesis were overall low. More particularly, the levels of RWA measured before the experimental manipulation were below the scale middle point in all studies [Study $3 \mathrm{~A}: t(74)=$ -8.43, $p<.001$; Study 3B: $t(62)=-9.22, p<.001$; Study 3C: $t(43)=-6.67, p<.001]$. Therefore, future tests of the activation of threat by authoritarianism should also consider a more representative sample of the authoritarian spectre (Feldman \& Stenner, 1997). A more representative sample would test the alternative explanation that the lack of significance for the interaction between pre-RWA $\times$ social threat in our studies was related to the nonrepresentation of the full authoritarian spectre in our samples.

Moreover, the three experimental studies tested the hypothesis that societal threat led to cultural worldview enhancement (H2; Burke et al., 2013) based on our view that societal threat might remind people of the salience of their deaths. However, it was not measured 
whether or not the experimental manipulation made mortality more salient. Future studies could try to elucidate the connection between societal threat, death salience and political conservatism further by measuring how much participants were reminded of their own death by the threatening stimulus.

Furthermore, significant differences between experimental conditions were not observed across studies for RWA and SDO scores. These results might suggest that, unlike world beliefs, RWA and SDO scores require deeper, more widespread and continuous societal threat to be modified. These results might also alternatively suggest that the stimuli used in the present studies were not strong enough to evoke these changes systematically as shown in Duckitt and Fisher (2003). In this sense, the pictorial stimuli used in the present study could be strengthen in order to evoke change in RWA and SDO. An alternative and reliable way to study this change would be through longitudinal studies including actual scores of participants in these variables and scores for systemic threat based on economic, natural and social indicators. This type of initiative has been in place already. One example of such an initiative is the New Zealand Attitudes and Values Survey (NZAVS) which through longitudinal data collection enables this type of meticulous test (Sibley, 2015).

We encountered different technical problems when collecting data for the last two experimental studies. For example, the PowerPoint presentation included in the last study would occasionally not play properly to participants, or participants in both studies were sometimes disconnected from the online platform. These technical problems led to the loss of some participants given that it would have not been methodologically sound to let participants restart the study seeing or reading a new random scenario. This loss of participants impacted the analyses conducted to test the differential effect of economic, natural and social threats on political conservatism. Future studies should try to address this differential impact systematically given that it remains under researched, even though theoretical support for the differential impact of economic and social threats has been provided (Duckitt \& Sibley, 2010).

Finally, four out of the seven studies presented in this thesis included only undergraduate students who categorised themselves as European (Pākehā) New Zealanders. When the studies were first designed, we intended to include members of the general population and from different ethnicities. However, time frame constraints led to the inclusion of only members of the ethnically dominant group in order to avoid misleading findings linked to the association between ethnicity and political behaviour. This inclusion criterion was intentional so as to have more homogeneous participants across studies. The same time 
constraints described above were responsible for the inclusion only of undergraduate students in the three last experimental studies. Future studies investigating the impact of societal threat on political conservatism should try to extend our findings by also including different ethnic groups and participants from the general population.

\section{Concluding Remarks}

Overall, the present research shows that societal threat impacts political conservatism when considering more vivid experimental scenarios including images. The present research also shows that societal threat does not generally enhance political conservatism directly, but that the influence of societal threat on political conservatism happens via world beliefs and socio-political attitudes. These results highlight the importance of examining the underlying mechanisms of the relationship between societal threat and political conservatism, increasing chances to intervene in variables that could actually diminish the power of threat. Given that the world we live in is far different from the one our ancestors from 10,000 years ago lived in, the evolutionary response to threat might not be always the most adequate one.

In a world in which often liberals and conservatives see each other as less deserving and some researchers attribute conservative political orientation to "bad childhood" and "ugly personality traits" (Haidt, 2012), it is important to make it clear that the main application of this thesis is not to use societal threat, world beliefs, RWA and SDO to make people more left-oriented/liberal or more right-oriented/conservative. Instead, we suggest that the main application of our findings is to provide systematic knowledge about what to expect politically during threatening periods of time. Only systematic knowledge would make it possible to justify regulations that could, for instance, limit the use of societal threat in political campaigns around the world. In our research, societal threat enhanced political conservatism, but this enhancement was via world beliefs, RWA and SDO, variables also associated to prejudice and discrimination. It is not reasonable to assume that societal threat could be used freely to enhance political conservatism by politicians if there are also other societal consequences connected to it that could generate a social crisis.

Finally, we agree that direct threats require decisive action as pointed out by Dick Cheney during the 2004 World Economic Forum (Associated Press, 2004). However, we believe that this decisive action should never include the use of societal threat as a political subterfuge to convince people to act in a specific way, enhancing authoritarianism, social dominance orientation and discrimination in return. 


\section{References}

Adorno, T., Frenkel-Brunswick, E., Levinson, D., \& Sanford, R. (1950). The authoritarian personality. New York: Harper.

Altemeyer, B. (1981). Right-wing authoritarianism. Winnipeg, Canada: University of Manitoba Press.

Altemeyer, B. (1996). The authoritarian specter. Cambridge, MA: Harvard University Press.

Altemeyer, B. (1998). The other 'authoritarian personality.' In M. P. Zanna (Ed.), Advances in Experimental Social Psychology (Vol. 30, pp. 47-92). San Diego: Academic Press.

Altemeyer, B. (2004). Highly dominating, highly authoritarian personalities. The Journal of Social Psychology, 144(4), 421-447. Retrieved from http://www.tandfonline.com/toc/vsoc20/current

Altemeyer, B. (2006). The authoritarians. Unpublished manuscript, Department of Psychology, University of Manitoba, Winnipeg, Canada.

Anson, J. M., Pyszczynski, T., Solomon, S., \& Greenberg, J. (2009). Political ideology in the $21^{\text {st }}$ century: A terror management perspective on maintenance and change of the status quo. In J. T. Jost, A. C., Kay, \& H. Thorisdottir (Eds.), Social and Psychological Bases of Ideology and System Justification (pp. 210-240). New York: Oxford University Press.

Associated Press (2004, January 24). Cheney: Direct threats require 'decisive action'. NBC News. Retrieved from http://www.nbcnews.com/id/4047585/ns/politics/t/cheney-directthreats-require-decisive-action/

Blascovich, J., \& Tomaka, J. (1996). The biopsychosocial model of arousal regulation. In M. P. Zanna (Ed.), Advances in experimental social psychology (Vol. 29, pp. 1-51). San Diego: Academic Press.

Block, J., \& Block, J. H. (2006). Nursery school personality and political orientation two decades later. Journal of Research in Personality, 40, 734-749. doi:10.1016/j.jrp.2005.09.005

Bollen, K., \& Long, J. (Eds). (1993). Testing structural equation models. Newbury Park, CA: Sage.

Bonanno, G. A., \& Jost, J.T. (2006). Conservative shift among high-exposure survivors of the September 11th terrorist attacks. Basic and Applied Social Psychology, 28, 311-323. doi: 10.1207/s15324834basp2804_4 
Bradley M. M., \& Lang, P. J. (1994). Measuring emotion: The self-assessment manikin and the semantic differential. Journal of Behavior Therapy and Experimental Psychiatry, 25, 49-59. doi: 10.1016/0005-7916(94)90063-9

Broder, J. M. (2012, November 9). Climate change report outlines perils for U.S. military. The New York Times. Retrieved from http://www.nytimes.com/2012/11/10/science/earth/climate-change-report-outlinesperils-for-us-military.html?_r=0

Burke, B. L., Kosloff, S., Landau, M. J. (2013). Death goes to the polls: A meta-analysis of mortality salience effects on political attitudes. Political Psychology, 34, 183-200. doi: 10.1111/pops. 12005

Burke, B. L., Martens, A., \& Faucher, E. H. (2010). Two decades of Terror Management Theory: A meta-analysis of mortality salience research. Personality and Social Psychology Review, 14, 155-195. doi: 10.1177/1088868309352321

Butler, J. C. (2013). Authoritarianism and fear responses to pictures: The role of social differences. International Journal of Psychology, 48, 18-24. doi: $10.1080 / 00207594.2012 .698392$

Byrne, B. M. (2001). Structural equation modeling with AMOS: Basic concepts, applications, and programming. Mahwah, NJ, US: Lawrence Erlbaum Associates Publishers.

Cohrs, J. C., \& Asbrock, F. (2009). Right-wing authoritarianism, social dominance orientation, and prejudice against threatening and competitive ethnic groups. European Journal of Social Psychology, 39, 270-289. doi: 10.1002/ejsp.545

Cohrs, J. C., Maes, J., Moschner, B., \& Kielmann, S. (2007). Determinants of human rights attitudes and behavior: A comparison and integration of psychological perspectives. Political Psychology, 28, 441-469. doi: 10.1111/j.1467-9221.2007.00581.x

Cohrs, J. C., \& Stelzl, M. (2010). Right wing authoritarianism and social dominance orientation as predictors of host society member's attitudes toward immigrants: Toward understanding cross-national differences. Journal of Social Issues, 66, 673694. doi: 10.1111/j.1540-4560.2010.01670.x

Crawford, J. R., \& Henry, J. D. (2004). The positive and negative affect schedule (PANAS): Construct validity, measurement properties and normative data in a large non-clinical sample. British Journal of Clinical Psychology, 43, 245-265. doi: $10.1348 / 0144665031752934$ 
Crowson, H. M. (2007). Authoritarianism and human rights attitudes in US law students: A brief look. Individual Differences Research, 5(4), 260-266. Retrieved from http://www.idr-journal.com/

Crowson, H. M. (2009). Right-wing authoritarianism and social dominance orientation as mediators of worldview beliefs on attitudes related to the war on terror. Social Psychology, 40, 93-103. doi: 10.1027/1864-9335.40.2.93

Díaz, E. M., Tapia, K. M., Estrada, C., \& Leiva-Bianchi, M. (2012). Red semántica de terremoto y maremoto en personas expuestas directa y vicariamente [Semantic network of earthquake and tsunami in individuals exposed directly and vicariously]. Psicologia em Estudo, 17(4), 557-565. http://dx.doi.org/10.1590/S141373722012000400002

Doty, R., Peterson, B., \& Winter, D. (1991). Threat and authoritarianism in the United States, 1978-1987. Journal of Personality and Social Psychology, 61, 629-640. Retrieved from http://www.apa.org/pubs/journals/psp/

Duckitt, J. (2001). A dual-process cognitive-motivational theory of ideology and prejudice. In M. P. Zanna (Ed.), Advances in experimental social psychology (Vol. 33, pp. 41-113). San Diego: Academic Press.

Duckitt, J. (2006). Differential effects of right wing authoritarianism and social dominance orientation on outgroup attitudes and their mediation by threat from competitiveness to outgroups. Personality and Social Psychology Bulletin, 32, 684-696. doi: 10.1177/0146167205284282 10.1177/0146167205284282

Duckitt, J. (2013). Introduction to the special section on authoritarianism in societal context: The role of threat. International Journal of Psychology, 48, 1-5. doi: 10.1080/00207594.2012.738298 10.1080/00207594.2012.738298

Duckitt, J., Bizumic, B., Krauss, S. W., \& Heled, E. (2010). A tripartite approach to rightwing authoritarianism: The authoritarianism- conservatism- traditionalism model. Political Psychology, 31, 685-715. doi: 10.1111/j.1467-9221.2010.00781.x

Duckitt, J., \& Fisher, K. (2003).The impact of social threat on worldview and ideological attitudes. Political Psychology, 24(1), 199-222. Retrieved from http://onlinelibrary.wiley.com/journal/10.1111/(ISSN)1467-9221

Duckitt, J., \& Sibley, C. G. (2009). A dual process model of ideological attitudes and system justification. In J. T. Jost, A. C. Kay, \& H. Thorisdottir (Eds.), Social and psychological bases of ideology and system justification (pp. 292-313). New York: Oxford University Press. 
Duckitt, J., \& Sibley, C. G. (2010). Personality, ideology, prejudice, and politics: A DualProcess Motivational Model. Journal of Personality, 78, 1861-1894. doi: 10.1111/j.1467-6494.2010.00672.x

Duckitt, J., Wagner, C., Du Plessis, I., \& Birum, I. (2002). The psychological bases of ideology and prejudice: Testing a dual process model. Journal of Personality and Social Psychology, 83, 75-93. doi: 10.1037//0022-3514.83.1.75

Dunlap, R. E., Gallup Jr., G. H., \& Gallup, A. M. (1993). Of global concern: Results of the health of the planet survey. Environment, 35(9), 6-15.

Echebarria-Echabe, A., \& Fernandez-Guede, E. (2006). Effects of terrorism on attitudes and ideological orientation. European Journal of Social Psychology, 36, 259-265. doi: 10.1002/ejsp.294

Eugenio, B. D. \& Glass, M. (2004). The Kappa statistic: a second look. Computational linguistics, 30(1), 95-101. Retrieved from http://cljournal.org/

Feldman, S. (2013). Comments on: Authoritarianism in social context: The role of threat. International Journal of Psychology, 48, 55-59. doi: 10.1080/00207594.2012.742196

Feldman, S., \& Johnston, C. (2014). Understanding the Determinants of Political Ideology: Implications of Structural Complexity. Political Psychology, 35, 337-358. doi: 10.1111/pops. 12055

Feldman, S., \& Stenner, K. (1997). Perceived threat and authoritarianism. Political Psychology, 18(4), 741-770. Retrieved from http://onlinelibrary.wiley.com/journal/10.1111/(ISSN)1467-9221

Field, A. (2009). Discovering statistics using SPSS (3rd ed.). Thousand Oaks, CA: SAGE. Figueroa, J. G., González, E. G., \& Solís, V. M. (1976). An approach to the problem of meaning: Semantic networks. Journal of Psycholinguistics Research, 5(2), 107-115. Retrieved from http://link.springer.com/journal/10936

Figueroa, J. G., González, E. G., \& Solís, V. M. (1981). Una aproximacion al problema Del significado: Las redes semânticas [An approximation to the problem of meaning: Semantic networks]. Revista Latinoamericana de Psicología, 13, 447-458.

Fischer, R., Ferreira, M. C., Milfont, T. L., \& Pilati, R. (2014). Culture of corruption? The effects of priming corruption images in a high corruption context. Journal of CrossCultural Psychology, 45, 1594-1605. doi: 10.1177/0022022114548874

Fraley, R. C., Griffin, B. N., Belsky, J., \& Roisman, G. I. (2012). Developmental antecedents of political ideology: A longitudinal investigation from birth to age 18 years. Psychological Science, 23, 1425-1431. doi: 10.1177/0956797612440102 
Fritsche, I., Cohrs, J. C., Kessler, T., \& Bauer, J. (2012). Global warming is breeding social conflict: The subtle impact of climate change threat on authoritarian tendencies. Journal of Environmental Psychology, 32, 1-10. doi: 10.1016/j.jenvp.2011.10.002

Fritsche, I., Jonas, E., \& Kessler, T. (2011). Collective reactions to threat: Implications for intergroup conflict and for solving societal crises. Social Issues and Policy Review, 5, 101-136. doi: 10.1111/j.1751-2409.2011.01027.x

GeoNet, Earthquake Commission, GNS Science. (2015). Felt quakes. Retrieved from http://www.geonet.org.nz/

Gerbing, D. W., \& Anderson, J. C. (1987). Improper solutions in the analysis of covariance structures: Their interpretability and a comparison of alternate respecifications. Psychometrika, 52(1), 99-111. Retrieved from http://link.springer.com/journal/11336

Gonzalez, K. V., Verkuyten, M., Weesie, J., \& Poppe, E. (2008). Prejudice towards Muslims in the Netherlands: Testing integrated threat theory. British Journal of Social Psychology, 47, 667-685. doi: 10.1348/014466608X284443

Gosling, S. D., Rentfrow, P. J., \& Swann, W. B., Jr. (2003). A Very Brief Measure of the Big Five Personality Domains. Journal of Research in Personality, 37, 504-528.doi: 10.1016/S0092-6566(03)00046-1

Greenberg, J., \& Jonas, E. (2003). Psychological Motives and Political Orientation-The Left, the Right, and the Rigid: Comment on Jost et al (2003). Psychological Bulletin, 129, 376-382. doi: 10.1037/0033-2909.129.3.376

Haidt, J. (2012). The Righteous Mind: Why Good People Are Divided by Politics and Religion. New York: Pantheon Books.

Harmon-Jones, E., Simon, L., Solomon, S., Pyszczynski, T., \& McGregor, H. (1997). Terror management theory and self-esteem: evidence that increased self-esteem reduces mortality salience effects. Journal of Personality and Social Psychology, 72(1), 24-36. Retrieved from http://www.apa.org/pubs/journals/psp/

Harvey, M. L., \& Belt, P. A. (1995).The moderating effect of threat on the relationship between population concern and environmental concern. Population and Environment, 17(2), 123-133. Retrieved from http://www.springer.com/social+sciences/population+studies/journal/11111

Hastings, B.M., \& Shaffer, B. A. (2005). Authoritarianism and sociopolitical attitudes in response to threats of terror. Psychological Reports, 97, 623-630. doi: 10.2466/pr0.97.2.623-630 
Henderson-King, D., Henderson-King E., Bolea, B., Koches, K., \& Kauffman, A. (2004). Seeking bombs or sending bombs: Beliefs as predictors of responses to terrorism. Peace and Conflict: Journal of Peace Psychology, 10(1), 67-84. Retrieved from http://www.apa.org/pubs/journals/pac/

Henry, P. J., Sidanius, J., Levin, S., \& Pratto, F. (2005). Social dominance orientation, authoritarianism, and support for intergroup violence between the Middle East and America. Political Psychology, 26, 569-583. doi: 10.1111/j.1467-9221.2005.00432.x

Ho, A. K., Sidanius, J., Kteily, N., Sheehy-Skeffington, J., Pratto, F., Henkel, K., ...Stewart, A. (in press). The nature of social dominance orientation: Introducing the Social Dominance Orientation-7 scale.

Ho, A. K., Sidanius, J., Pratto, F. Levin, S., Thomsen, L., Kteily, N., \& Sheehy-Skeffington, J. (2012). Social dominance orientation: Revisiting the structure and function of a variable predicting social and political attitudes. Personality and Social Psychology Bulletin, 38, 583-606. doi: 10.1177/0146167211432765

Hsiang, S. M., Burke, M., \& Miguel, E. (2013). Quantifying the Influence of Climate on Human Conflict. Science, 341, 1212-1226. doi: 10.1126/science.1235367

Hu, L., \& Bentler, P. M. (1999). Cutoff criteria for fit indexes in covariance structure analysis: Conventional criteria versus new alternatives. Structural Equation Modeling, 6, 1-55. doi: 10.1080/10705519909540118

Huddy, L., \& Feldman, S. (2011). Americans respond politically to 9/11: Understanding the impact of the terrorist attacks and their aftermath. American Psychologist, 66, 455467. doi: $10.1037 / \mathrm{a} 0024894$

Huddy, L., Feldman, S., Capelos, T., \& Provost, C. (2002). The consequences of terrorism: Disentangling the effects of personal and national threat. Political Psychology, 23(3), 485-509. Retrieved from http://onlinelibrary.wiley.com/journal/10.1111/(ISSN)14679221

IPCC - Intergovernmental Panel on Climate Change, Task force on climate change. (2014). Climate change 2014: Impacts, adaptation, and vulnerability. Retrieved from http://www.ipcc.ch/report/ar5/wg2/

Jost, J. T. (2006). The end of the end of ideology. American Psychologist, 61, 651-670. doi: 10.1037/0003-066X.61.7.651

Jost, J. T., \& Amodio, D. M. (2012). Political ideology as motivated social cognition: Behavioral and neuroscientific evidence. Motivation and emotion, 36, 55-64. doi: 10.1007/s11031-011-9260-7 
Jost, J. T., \& Banaji, M. R. (1994). The role of stereotyping in system-justification and the production of false consciousness. British Journal of Social Psychology, 33, 1-27. doi: 10.1111/j.2044-8309.1994.tb01008.x

Jost, J. T., Banaji, M. R., \& Nosek, B. A. (2004). A decade of system justification theory: Accumulated evidence of conscious and unconscious bolstering of the status-quo. Political Psychology, 25, 881-919. doi: 10.1111/j.1467-9221.2004.00402.x

Jost, J. T., Federico, C. M., \& Napier, J. L. (2009). Political ideology: Its structure, functions and elective affinities. Annual Review of Psychology, 60, 307-337. doi: 10.1146/annurev.psych.60.110707.163600

Jost, J. T., Glaser, J., Kruglanski, A. W., \& Sulloway, F. J. (2003a). Exceptions that prove the rule - using a theory of Motivated Social Cognition to account for ideological incongruities and political anomalies: Reply to Greenberg and Jonas (2003). Psychological Bulletin, 129, 383-393. doi: 10.1037/0033-2909.129.3.383

Jost, J. T., Glaser, J., Kruglanski, A. W., \& Sulloway, F. J. (2003b). Political conservatism as motivated social cognition. Psychological Bulletin, 129, 339-375. doi: 10.1037/00332909.129.3.339

Jost, J. T., \& Thompson, E. P. (2000). Group-based dominance and opposition to equality as independent predictors of self-esteem, ethnocentrism, and social policy attitudes among African Americans and European Americans. Journal of Experimental Social Psychology, 36, 209-232. doi: 10.1006/jesp.1999.1403

Jugert, P., \& Duckitt, J. (2009). A motivational model of authoritarianism: Integrating personal and situational determinants. Political Psychology, 30, 693-719. doi: 10.111/j.14 67-9221.2009.00722.

Kessler, T., \& Cohrs, J. C. (2008). The evolution of authoritarian processes: Fostering cooperation in large-scale groups. Group Dynamics: Theory, Research, and Practice, 12, 73-84. doi: 10.1037/1089-2699.12.1.73

Kossowska, M., Trejtowicz, M., de Lemus, S., Bukowski, M., Van Hiel, A., \& Goodwin, R. (2011). Relationships between right-wing authoritarianism, terrorism threat, and attitudes towards restrictions of civil rights: A comparison among four European countries. British Journal of Psychology, 102, 245-259. doi: $10.1348 / 000712610 \times 517262$

Kottner, J., Audigé, L., Brorson, S., Donner, A., Gajewski, B. J., Hróbjartsson, A., ... Streiner, D. L. (2011). Guidelines for Reporting Reliability and Agreement Studies 
(GRRAS) were proposed. Journal of Clinical Epidemiology, 64, 96-106. doi: 10.1016/j.jclinepi.2010.03.002

Lang, P. J., Bradley, M. M., \& Cuthbert, B. N. (1997). International Affective Picture System (IAPS): technical manual and affective ratings. NIMH Center for the Study of Emotion and Attention.

Lindeman, L., \& Verkasalo, M. (2005). Measuring values with the short Schwartz's value survey. Journal of Personality Assessment, 85, 170-178. doi:

10.1207/s15327752jpa8502_09

Little, T. D., Cunningham, W. A., Shahar, G., \& Widaman, K. F. (2002). To parcel or not to parcel: Exploring the question, weighing the merits. Structural Equation Modeling, 9, 151-173. doi: 10.1207/S15328007SEM0902_1

Lunney, G. H. (1970). Using analysis of variance with a dichotomous dependent variable: An empirical study. Journal of Educational Measurement, 7(4), 263-269. Retrieved from http://onlinelibrary.wiley.com/journal/10.1111/(ISSN)1745-3984

Matthews, M., \& Levin, S. (2012).Testing a dual process model of prejudice: Assessment of group threat perceptions and emotions. Motivation and Emotion, 36, 564-574. doi: 10.1007/s11031-012-9280-y

Mavor, K. I., Louis, W. R., Sibley, C. G. (2010). A bias-corrected exploratory and confirmatory factor analysis of right-wing authoritarianism: Support for a three-factor structure. Personality and Individual Differences, 48, 28-33. doi:

10.1016/j.paid.2009.08.006

McBride, D. M., \& Dosher, B. A. (2002). A comparison of conscious and automatic memory processes for picture and word stimuli: A process dissociation analysis. Consciousness and Cognition, 11, 423-460. doi: 10.1016/S1053-8100(02)00007-7

McCann, S. J. H. (1997). Threatening times, "strong" presidential vote winners, and the victory margin, 1824-1964. Journal of Personality and Social Psychology, 73, 160170. Retrieved from http://www.apa.org/pubs/journals/psp/

McCann, S. J. H. (2009). Political conservatism, authoritarianism, and societal threat: Voting for republican representatives in U.S. congressional elections from 1946 to 1992. Journal of Psychology: Interdisciplinary and Applied, 143(4), 341-358. Retrieved from http://www.tandfonline.com/toc/vjrl20/current

McCann, S. J.H., \& Stewin, L. L. (1990). Good and bad years: An index of American social, economic, and political threat (1920-1986). Journal of Psychology, 124, 601-617. doi: 10.1080/00223980.1990.10543253 
McClure, J., Johnston, D., Henrich, L., Milfont, T. L., \& Becker, J. (2015). When a hazard occurs where it is not expected: Risk judgments about different regions after the Christchurch earthquakes. Natural Hazards, 75, 635-652. doi: 10.1007/s11069-0141338-6

McFarland, S. G. (2005). On the eve of war: Authoritarianism, social dominance orientation, and American students' attitudes toward attacking Iraq. Personality and Social Psychology Bulletin, 31, 360-367. doi: 10.1177/0146167204271596

McFarland, S. G. (2010). Authoritarianism, social dominance, and other roots of generalized prejudice. Political Psychology, 31, 453-477. doi: 10.1111/j.1467-9221.2010.00765.x

McFarland, S. G., \& Adelson, S. (1996, July). An omnibus study of personality, values, and prejudice. Paper presented at the annual meeting of the International Society for Political Psychology, Vancouver, Canada.

Milfont, T. L. (2010). The psychological meaning of preservation and utilization attitudes: A study using the natural semantic network technique. Psyecology, 1(1), 123-136. http://dx.doi.org/10.1174/217119710790709559

Milfont, T. L., Richter, I., Sibley, C. G., Wilson, M. S., \& Fischer, R. (2013). Environmental consequences of the desire to dominate and be superior. Personality and Social Psychology Bulletin, 39, 1127-1138. doi: 10.1177/0146167213490805

Milfont, T. L., \& Sibley, C. G. (2014). The hierarchy enforcement hypothesis of environmental exploitation: A social dominance perspective. Journal of Experimental Social Psychology, 55, 188-193. doi: 10.1016/j.jesp.2014.07.006

Morselli, D., Pratto, F., Bou Zeineddine, F., Aranda, M., Stewart, A. L., Cidam, A., ... Sweetman, J. (2012, July). Social dominance and counter dominance orientation scales (SDO/CDO): Testing measurement invariance. Paper presented at the annual meeting of the ISPP 35th Annual Scientific Meeting, Mart Plaza, Chicago, USA.

Nagel, J. H. (1994). How many parties will New Zealand have under MMP? Political Science, 46(2), 139-160. Retrieved from http://pnz.sagepub.com/

Öhman, A. (1997). As fast as the blink of an eye: Evolutionary preparedness for preattentive processing of threat. In P. J. Lang, R. F. Simons, \& M. Balaban (Eds.), Attention and orienting sensory and motivational processes (pp. 165-184). Lawrence Erlbaum Associates Publishers: New York, NY.

Onraet, E., Dhont, K., \& Van Hiel, A. (2014). The relationships between internal and external threats and right-wing attitudes: A three-wave longitudinal study. Personality and Social Psychology Bulletin, 40, 712-725. doi: 10.1177/0146167214524256 
Onraet, E., \& Van Hiel, A. (2013).When threat to society becomes a threat to oneself: Implications for right-wing attitudes and ethnic prejudice. International Journal of Psychology, 48, 25-34. doi: 10.1080/00207594.2012.701747

Onraet, E., Van Hiel, A., Dhont, K., \& Pattyn, S. (2013). Internal and external threat in relationship with right-wing attitudes. Journal of Personality, 81, 233-248. doi: 10.1111/jopy.12011

Osborne, G. W. (2010). Improving your data transformations: Applying the Box-Cox transformation. Practical Assessment, Research \& Evaluation, 15(12), 1-9. Retrieved from http://pareonline.net/

Perrin, A. J. (2005). National threat and political culture: Authoritarianism, antiauthoritarianism, and the September 11 attacks. Political Psychology, 26(2), 167194. Retrieved from http://onlinelibrary.wiley.com/journal/10.1111/(ISSN)1467-9221

Perry, R., \& Sibley, C. G. (2010). Dangerous and competitive schemas: A new frequency estimation index of the Dual Process Model's social worldviews component. Personality and Individual Differences, 49, 983-988. doi: 10.1016/j.paid.2010.08.009

Perry, R., \& Sibley, C. G. (2012). Big-Five personality prospectively predicts Social Dominance Orientation and Right-Wing Authoritarianism. Personality and Individual Differences, 52, 3-8. doi: 10.1016/j.paid.2011.08.009

Perry, R., Sibley, C. G., \& Duckitt, J. (2013). Dangerous and competitive worldviews: A meta-analysis of their associations with social dominance orientation and right-wing authoritarianism. Journal of Research in Personality, 47, 116-127. http://dx.doi.org/10.1016/j.jrp.2012.10.004

Peterson, B. E., Doty, R. M., \& Winter, D. G. (1993). Authoritarianism and attitudes toward contemporary social issues. Personality and Social Psychology Bulletin, 19, 174-184. doi: 10.1177/0146167293192006

Peterson, B. E., \& Gerstein, E. D. (2005). Fighting and flying: Archival analysis of threat, authoritarianism, and the North American comic book. Political Psychology, 26(6), 887-904. Retrieved from http://onlinelibrary.wiley.com/journal/10.1111/(ISSN)14679221

Pratto, F., Sidanius, J., \& Levin, S. (2006). Social dominance theory and the dynamics of intergroup relations: Taking stock and looking forward. European Review of Social Psychology, 17, 271-320. doi: 10.1080/10463280601055772

Pratto, F., Sidanius, J., Stallworth, L., \& Malle, B. (1994). Social dominance orientation: A personality variable predicting social and political attitudes. Journal of Personality 
and Social Psychology, 67(4), 741-763. Retrieved from

http://www.apa.org/pubs/journals/psp/

Pyszczynski, T., Solomon, S., \& Greenberg, J. (2003). Terror in America: The day our world changed. In T. Pyszczynski, S. Solomon, \& J. Greenberg (Eds.), In the wake of 9/11: The psychology of terror (pp. 3-10). Washington, DC, US: American Psychological Association.

Reyes-Lagunes, I. (1993). Las redes semánticas naturales, su conceptualización y su utilización en la construcción de instrumentos [Natural semantic networks, its conceptualization and use in the construction of instruments]. Revista de Psícologia Social Y Personalidad, 9, 83-99.

Rosenblatt, A., Greenberg, J., Solomon, S., Pyszczynski, T., \& Lyon, D. (1989). Evidence for terror management theory: I. the effects of mortality salience on reactions to those who violate or uphold cultural values. Journal of Personality and Social Psychology, 57(4), 681-690. Retrieved from http://www.apa.org/pubs/journals/psp/

Sales, S. (1973). Threat as a factor in authoritarianism: An analysis of archival data. Journal of Personality and Social Psychology, 28(1), 44-57. Retrieved from http://www.apa.org/pubs/journals/psp/

Shepard, R. N. (1967). Recognition Memory for Words, Sentences, and Pictures. Journal of Verbal Learning and Verbal Behavior, 6, 156-163.

Sibley, C. G. (2015). An overview of the NZAVS [PowerPoint slides]. Retrieved from http://www.psych.auckland.ac.nz/en/about/our-research/research-groups/new-zealandattitudes-and-values-study/nzavs-tech-docs.html

Sibley C. G., \& Bulbulia, J. (2012). Faith after an earthquake: A longitudinal study of religion and perceived health before and after the 2011 Christchurch New Zealand earthquake. Plos One, 7, e49648. doi:10.1371/journal.pone.0049648

Sibley, C. G., \& Duckitt, J. (2008). Personality and prejudice: A meta-analysis and theoretical review. Personality and Social Psychology Review, 12, 248-279. doi: $10.1177 / 1088868308319226$

Sibley, C. G., \& Duckitt, J. (2009). Big-five personality, social worldviews, and ideological attitudes: Further tests of a dual process cognitive-motivational model. The Journal of Social Psychology, 149, 545-561. doi: 10.1080/00224540903232308

Sibley, C., \& Duckitt, J. (2010). The personality bases of ideology: A one-year longitudinal study. The Journal of Social Psychology, 150(5), 540-559. Retrieved from http://www.tandfonline.com/toc/vsoc20/current 
Sibley, C. G., \& Duckitt, J. H. (2013). The Dual Process Model of Ideology and Prejudice: A longitudinal test during a global recession. Journal of Social Psychology, 153, 448466. doi: 10.1080/00224545.2012.757544

Sibley, C. G., Duckitt, J., Bergh, R., Osborne, D., Perry, R., Asbrock, F., ... Barlow, F. K. (2013). A Dual process model of attitudes towards immigration: Person $\times$ residential area effects in a national sample. Political Psychology. 34, 553-572. doi:

10.1111/pops.12009

Sibley, C. G., \& Greaves, L. M. (2014). Item content and database keys. NZAVS Technical Documents, e03.

Sibley, C. G., Osborne, D., \& Duckitt, J. (2012). Personality and political orientation: Metaanalysis and test of a threat-constraint model. Journal of Research in Personality, 46, 664-677. doi: 10.1016/j.jrp.2012.08.002

Sibley, C. G., Wilson, M. S., \& Duckitt, J. (2007). Effects of dangerous and competitive worldviews on right-wing authoritarianism and social dominance orientation over a five-month period. Political Psychology, 28(3), 357-371. Retrieved from http://onlinelibrary.wiley.com/journal/10.1111/(ISSN)1467-9221

Sidanius, J., \& Pratto, F. (1999). Social dominance: An intergroup theory of social hierarchy and oppression. New York: Cambridge University Press.

Slovic, P. (1987). Perception of risk. Science, 236, 280-285. doi: 10.1126/science.3563507

Slovic, P., \& Peters, E. (2006). Risk perception and affect. Current Directions in Psychological Science, 15(6), 322-325. Retrieved from http://www.psychologicalscience.org/index.php/publications/journals/current_directio ns

Spencer, S. J., Zanna, M. P., \& Fong, G. T. (2005). Establishing a causal chain: Why experiments are often more effective than mediational analyses in examining psychological processes. Journal of Personality and Social Psychology, 89, 845-851. doi: 10.1037/0022-3514.89.6.845

Stephan, W. G. (2014). Intergroup anxiety: Theory, research and practice. Personality and Social Psychology Review, 18, 239-255. doi: 10.1177/1088868314530518

Stephan, W. G., Stephan, C. W., \& Gudykunst, W. B. (1999). Anxiety in intergroup relations: A comparison of anxiety/uncertainty management theory and integrated threat theory. International Journal of Intercultural Relations, 23, 613-628. doi: 10.1016/S01471767(99)00012-7 
Stephan, W. G., Ybarra, O., Martnez, C. M., Schwarzwald, J., \& Tur-Kaspa, M. (1998). Prejudice toward immigrants to Spain and Israel: An Integrated Threat Theory analysis. Journal of Cross-Cultural Psychology, 29, 559-576. doi: $10.1177 / 0022022198294004$

Tabachnick, B. G., \& Fidell, L. S. (2007). Using multivariate statistics. Boston, USA: Pearson Education.

The New Zealand Herald (2014). Asset sales. Retrieved from http://www.nzherald.co.nz/asset-sales/news/headlines.cfm?c_id=1503277

Thomsen L., Green, E. G. T., \& Sidanius, J. (2008). We will hunt them down: How social dominance orientation and right-wing authoritarianism fuel ethnic persecution of immigrants in fundamentally different ways. Journal of Experimental Social Psychology, 44, 1455-1464. doi: 10.1016/j.jesp.2008.06.011

Threat [noun]. (n.d.). In Oxford's online dictionary. Retrieved April 8, 2014, from http://www.oxforddictionaries.com/definition/english/threat

Van Den Bos, K. (2009). The social Psychology of uncertainty management and system justification. In J. T. Jost, A. C. Kay, \& H. Thorisdottir (Eds.), Social and psychological bases of ideology and system justification (pp. 185-209). New York: Oxford University Press.

Van Hiel, A., \& Mervielde, I. (2002). Explaining conservative beliefs and political preferences: A comparison of social dominance orientation and authoritarianism. Journal of Applied Social Psychology, 32, 965-976. doi: 10.1111/j.15591816.2002.tb00250.x

Van Hiel, A., Cornelis, I., \& Roets, A. (2007). The intervening role of social worldviews in the relationship between the Five-Factor model of personality and social attitudes. European Journal of Personality, 21, 131-148. doi: 10.1002/per.618

Viera, A. J., \& Garrett, J. M. (2005). Understanding interobserver agreement: the Kappa statistic. Family Medicine, 37(5), 360-363. Retrieved from http://www.ncbi.nlm.nih.gov/pubmed

Ward, C., \& Masgoret, A. M. (2008). Attitudes toward immigrants, immigration, and multiculturalism in New Zealand: A social psychological analysis. International Migration Review, 42, 227-248. doi: 10.1111/j.1747-7379.2007.00119.x

Watson, D., Clark, L. A., \& Tellegen, A. (1988). Development and validation of brief measures of positive and negative affect: The PANAS scales. Journal of Personality 
and Social Psychology, 54(6), 1063-1070. Retrieved from http://www.apa.org/pubs/journals/psp/

Wilson, M. S. (2011). Brainscan: Descriptive results from the Sunday Star Times survey of New Zealander's political beliefs. Retrieved from http://www.victoria.ac.nz/psyc/attachments/wilson-2011-sst-descriptive-summary.pdf Wilson, M. S., \& Sibley, C. G. (2013). Social dominance orientation and right-wing authoritarianism: Additive and interactive effects on political conservatism. Political Psychology, 34, 277-284. doi: 10.1111/j.1467-9221.2012.00929.x 


\section{Appendix A. Study 1 Correlation Table}

\section{Table A.1}

Descriptive statistics and correlations between measures included in Study 1

\begin{tabular}{|c|c|c|c|c|c|c|c|c|c|c|c|c|}
\hline & 1 & 2 & 3 & 4 & 5 & 6 & 7 & 8 & 9 & 10 & 11 & 12 \\
\hline 1. Agreeableness & - & $.22^{* *}$ & $.09^{* *}$ & $.16^{* *}$ & $.29^{* *}$ & $-.28^{* *}$ & .01 & $.04^{*}$ & $-.15^{* *}$ & $-.06^{* *}$ & .02 & .00 \\
\hline 2. Conscientiousness & - & - & $.06^{* *}$ & $.08^{* *}$ & $.33^{* *}$ & -.03 & $.10 * *$ & $.11^{* *}$ & .03 & $.10^{* *}$ & $.13^{* *}$ & $.11^{* *}$ \\
\hline 3. Extraversion & - & - & - & $.28^{* *}$ & $.17^{* *}$ & $.04 *$ & .01 & .01 & .02 & $.06^{* *}$ & -.01 & $.08^{* *}$ \\
\hline 4. Openness to experience & - & - & - & - & $.22^{* *}$ & $-.09 * *$ & $-.11^{* *}$ & $-.21^{* *}$ & $-.14^{* *}$ & $-.14^{* *}$ & $-.18^{* *}$ & $-.09^{* *}$ \\
\hline 5. Emotional stability & - & - & - & - & - & -.03 & -.01 & .02 & $.06^{* *}$ & $.12^{* *}$ & $.09^{* *}$ & $.12^{* *}$ \\
\hline 6. Competitive worldview & - & - & - & - & - & - & $.27^{* *}$ & $.21^{* *}$ & $.48^{* *}$ & $.35^{* *}$ & $.22^{* *}$ & $.29^{* *}$ \\
\hline 7. Dangerous worldview & - & - & - & - & - & - & - & $.43^{* *}$ & $.25^{* *}$ & $.28^{* *}$ & $.33^{* *}$ & $.28^{* *}$ \\
\hline 8. Right-wing authoritarianism & - & - & - & - & - & - & - & - & $.45^{* *}$ & $.45^{* *}$ & $.52^{* *}$ & $.42^{* *}$ \\
\hline 9. Social dominance orientation & - & - & - & - & - & - & - & - & - & $.55^{* *}$ & $.41^{* *}$ & $.47^{* *}$ \\
\hline 10. Left/right orientation & - & - & - & - & - & - & - & - & - & - & $.64^{* *}$ & $.68^{* *}$ \\
\hline 11. Liberal/conservative orientation & - & - & - & - & - & - & - & - & - & - & - & $.54^{* *}$ \\
\hline $\begin{array}{l}\text { 12. Liberal/conservative voting } \\
\text { intention }\end{array}$ & - & - & - & - & - & - & - & - & - & - & - & - \\
\hline$M$ & 5.14 & 5.59 & 4.24 & 5.23 & 5.23 & 3.26 & 4.37 & 2.85 & 2.63 & 3.83 & 3.49 & .58 \\
\hline$S D$ & 1.07 & 1.08 & 1.44 & 1.06 & 1.22 & 1.25 & 1.42 & 1.03 & 1.05 & 1.57 & 1.59 & - \\
\hline$\alpha$ & .39 & .50 & .70 & .44 & .62 & .52 & .45 & .72 & .78 & - & - & - \\
\hline Skewness & -.25 & -.69 & -.10 & -.35 & -.67 & .02 & -.16 & .33 & .33 & -.01 & .24 & -.32 \\
\hline Kurtosis & -.46 & -.05 & -.68 & -.35 & -.01 & -.49 & -.60 & -.48 & -.56 & -.74 & -.76 & -1.90 \\
\hline
\end{tabular}

Note. $* * p<.01 ; * p<.05$. Point biserial correlation coefficients are provided for analyses including liberal/conservative voting intention. 


\section{Appendix B1. Information Sheet for the Actual Survey}

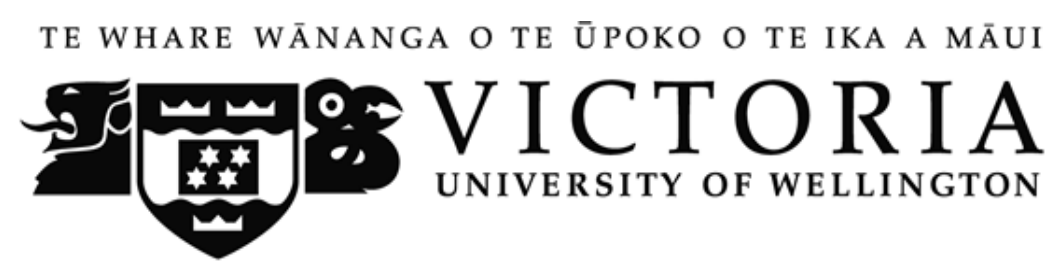

\section{SECTION 1. INFORMATION SHEET}

\section{Welcome!}

\section{What is the purpose of this research?}

You will be presented with three questions about social, economic and natural threats. The goal of this research is to understand your perceptions of these threats.

\section{Who is conducting the research?}

Clara Cantal is a PhD student in the School of Psychology of Victoria University of Wellington. Dr. Taciano Milfont and Dr. Marc Wilson are responsible for supervising this project and the other projects in the student thesis. This research has been approved by the School of Psychology Human Ethics Committee under delegated authority of the VUW Human Ethics Committee.

\section{What is involved if you agree to participate?}

If you agree to participate in this study you will be asked to complete a short survey. The survey asks you about social, economic and natural threats, and some demographic questions. We anticipate that the survey will take you no more than 10 minutes to complete. During the research you are free to withdraw at any point before your survey has been completed.

\section{Privacy and confidentiality}

This survey is anonymous. Please do not put your name anywhere on the survey. You will never be identified in my research project or in any other presentation or publication. The information you provide will be coded by number only. We will keep your survey for at least five years after publication. In accordance with the requirements of some scientific journals and organizations, your coded survey may be shared with other competent researchers. Your coded data may be used in other, related studies. A copy of the coded data will remain in the custody of Clara Cantal in the Environmental Psychology Lab.

\section{What happens to the information that you provide?}

The data you provide may be used for the following purposes: The overall findings may be submitted for publication in a scientific journal, or presented at scientific conferences. The findings will be part of a PhD thesis that will be submitted for assessment. If you would like to know the results of this study, they will be available approximately next year (2014) upon request via email to Ms. Cantal.

\section{Consent for participation}


Please note that by completing and returning the questionnaire to the researchers you agree that your survey responses will be used and analyzed. If you have any further questions regarding this study, please do not hesitate to contact the investigator listed below.

Thank you for considering participating in this research!

Clara Cantal

PhD Student

Environmental Psychology Lab.

School of Psychology, Faculty of Science

Victoria University of Wellington

Email: Clara.Cantal@vuw.ac.nz

\section{Appendix B2. Main Questionnaire for the Actual Survey}

SECTION 2. MEASURE (Please use printed letters)

On the following pages there are three open-ended questions. Please respond to them with your first, natural response. We are looking for peoples' gut-level reactions to these questions. There are no correct or incorrect answers.

Social threats are associated to the way people behave toward others "just because they can", which may lead to the creation of a dangerous and threatening place, causing harm and disruption to others' lives. Social threats can involve persons of your own society or even from other countries, as well as relationships between your country and other countries.

Please take a few minutes to ENVISION social threats that could affect you and people in your society. Visualize images, symbols, activities, groups, facts or incidents. Then list 5 words or expressions that you associate with these threats. Answer with the first words that come to mind.

Economic threats are associated to the competition for power and resources between people and by natural hierarchical relationships between both individuals and social groups. These threats can involve individuals of your own society or even from other countries, as well as relationships between your country and other countries. 
Please take a few minutes to ENVISION economic threats that could affect you and people living in your society. Visualize images, symbols, activities, groups, facts or incidents. Then list 5 words or expressions that you associate with these threats. Answer with the first words that come to mind.

Natural threats are associated to natural disasters that could impact your society and affect the way you and others live.

Please take a few minutes to ENVISION natural threats that could affect you and people in your society. Visualize images, symbols, activities, groups, facts or incidents. Then list 5 words or expressions that you associate with these threats. Answer with the first words that come to mind.

SECTION 3. BACKGROUND QUESTIONS (Please remember that your responses are confidential)

Please answer the following socio-demographic questions.

1. How old are you (in years)?

2. Are you male or female? $\square$ Male $\square$ Female $\quad$ (please $\square$ tick one)

3. Were you Born in New Zealand? $\square$ Yes $\square$ No

4. What $(\square)$ is your ethnicity?

$\square$ European/ Pakeha

Asian

$\square$ Maori

$\square$ Indian 
5. Which ( $\square)$ is your highest degree of education?

$\square$ Primary School

College or University Degree

$\square$ High School

Specialization, MBA, masters or Doctorate

\section{Appendix B3. Debriefing for the Actual Survey}

\section{SECTION 4. DEbRIEFING STATEMENT}

Thank you for taking part in this study!

The aim of this study is to examine if people can differentiate between social, economic and natural threats. These types of threats often appear mixed or not well delimitated in the literature, which makes it difficult to study whether different threats have a different impact on people' behaviors. In this study we were interested to see if people can differentiate these main types of threatening events. Results from this study will contribute to the existing literature by providing initial information to test how these differential threats impact people' behaviors.

The research project is being conducted by Clara Cantal, a PhD student, and her supervisors, Dr. Taciano L. Milfont and Dr. Marc Wilson, from the School of Psychology, Victoria University of Wellington. If you have any questions regarding your involvement in this research, or issues regarding the research in general, please do not hesitate to contact me via email at Clara.Cantal@vuw.ac.nz.

\section{Thanks again!}

Clara Cantal

Taciano Milfont

Marc Wilson 


\section{Appendix C1. Information Sheet for the Actual Survey}

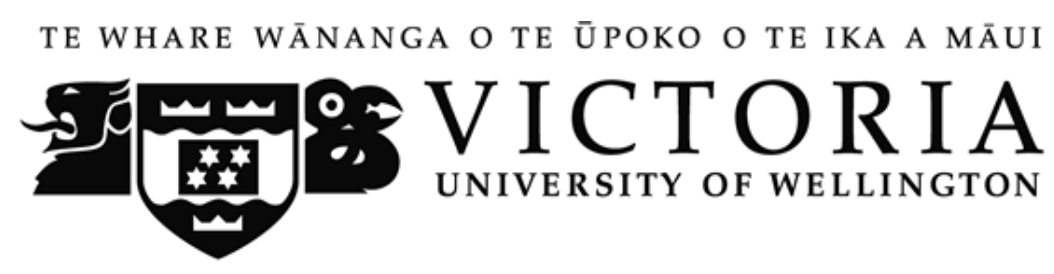

SECTION 1. INFORMATION SHEET

\section{Welcome!}

\section{What is the purpose of this research?}

You will be presented with one brief scenario. We are interested on your view of it and also on how you feel about it. The goal of this research is to understand your perceptions, evaluations and feelings towards this scenario.

\section{Who is conducting the research?}

Clara Cantal is a PhD student in the School of Psychology of Victoria University of Wellington. Dr. Taciano Milfont and Dr. Marc Wilson are responsible for supervising this project and the other projects in the student thesis.

\section{What is involved if you agree to participate?}

If you agree to participate in this study you will be asked to complete a short survey. The survey asks you about social, economic and natural threats, and some demographic questions. We anticipate that the survey will take you no more than 20 minutes to complete. During the research you are free to withdraw at any point before your survey has been completed.

\section{$\underline{\text { Privacy and confidentiality }}$}

This survey is anonymous. Please do not put your name anywhere on the survey. You will never be identified in my research project or in any other presentation or publication. The information you provide will be coded by number only. We will keep your survey for at least five years after publication. In accordance with the requirements of some scientific journals and organizations, your coded survey may be shared with other competent researchers. Your coded data may be used in other, related studies. A copy of the coded data will remain in the custody of Clara Cantal in the Environmental Psychology Lab.

\section{What happens to the information that you provide?}

The data you provide may be used for the following purposes: The overall findings may be submitted for publication in a scientific journal, or presented at scientific conferences. The findings will be part of a PhD thesis that will be submitted for assessment. If you would like to know the results of this study, they will be available approximately next year (2014) upon request via email to Ms. Cantal. 


\title{
Consent for participation
}

Please note that by completing and returning the questionnaire to the researchers online you agree that your survey responses will be used and analyzed. If you have any further questions regarding this study, please do not hesitate to contact the investigator listed below.

\author{
Thank you for considering participating in this research! \\ Clara Cantal \\ PhD Student \\ Environmental Psychology Lab. \\ School of Psychology, Faculty of Science \\ Victoria University of Wellington \\ Email: Clara.Cantal@vuw.ac.nz
}

Appendix C2. Main questionnaire for the Actual Survey

Appendix C2.1. Main questionnaire for the economic threat condition

SECTION 2. SCENARIO

Please imagine the scenario described below as real and happening right now in New Zealand. After reading the scenario, you will be asked to answer five questions related to the scenario followed by some socio-demographic questions.

\section{Scenario}

Imagine that this is happening in New Zealand right now. For you personally, the situation is basically as you expected or planned it to be. Thus, your personal affairs concerning partnering, children, marriage, jobs, career, friends, etc. have not changed unexpectedly. However, while your personal affairs are going well, there have been dramatic and far-reaching changes in New Zealand at present.

State-owned assets have been sold. New Zealand has accumulated a large debt and the economy is in recession. Some say the economy is even in depression. New Zealand is in an unprecedented economic crisis, with high inflation, job losses, unemployment and bankruptcy of various businesses. Politics is incomprehensible and corruption cases are broadcasted on the news and television almost daily. Inequality between the rich and the poor has risen. Life in New Zealand is now about greed, competition, money and capitalism. Globalization is reaching the country as never before.

\section{SECTION 3. SCEnARIO Evaluation}

Now, after imagining yourself in this scenario, please complete the following questions. Please read each question carefully. 
You will probably find that in some cases your answers to this scenario might be different to what they would be otherwise, while for other questions your answers won't be that different. It's important that you read each question and select your answers carefully, being at all times mindful of the scenario you read above.

\section{To what extent did the scenario you just read present social threats?}

(Social threats are associated with the way people behave toward others "just because they can", which may lead to the creation of a dangerous and threatening place, causing harm and disruption to others' lives.)

\begin{tabular}{|c|c|c|c|c|c|c|c|c|c|c|}
\hline \multicolumn{9}{|c|}{$\begin{array}{l}\text { Not at all } \\
\text { present }\end{array}$} & \multicolumn{2}{|c|}{$\begin{array}{r}\text { Extremely } \\
\text { present }\end{array}$} \\
\hline 0 & 1 & 2 & 3 & 4 & 5 & 6 & 7 & 8 & 9 & 10 \\
\hline
\end{tabular}

\section{To what extent did the scenario you just read present economic threats?}

(Economic threats are associated with the competition for power and resources between people and by hierarchical relationships between individuals and social groups.)

Not at all
present
\begin{tabular}{|c|c|c|c|c|c|c|c|c|c|c|}
\hline 0 & 1 & 2 & 3 & 4 & 5 & 6 & 7 & 8 & 9 & $\begin{array}{r}\text { Extremely } \\
\text { present }\end{array}$ \\
\hline
\end{tabular}

3. To what extent did the scenario you just read present natural threats?

(Natural threats are associated with natural disasters that could impact your society and affect the way you and others live.)

$\begin{array}{lr}\text { Not at all } & \text { Extremely } \\ \text { present } & \text { present }\end{array}$

\begin{tabular}{|l|l|l|l|l|l|l|l|l|l|l|}
\hline 0 & 1 & 2 & 3 & 4 & 5 & 6 & 7 & 8 & 9 & 10 \\
\hline
\end{tabular}

4. Please mark the degree to which you think that the situation presented in the scenario would impact your life and result in negative consequences. 


\begin{tabular}{|l|l|l|l|l|}
\hline 1 & 2 & 3 & 4 & 5 \\
\hline
\end{tabular}

5. Still considering the scenario you read above, imagine that there is a national election coming in a few days. Given this scenario, which party would you vote for?
$\mathrm{ACT}$
Māori
Green
National
Labour
NZ First
Mana
United Future

\section{SECTION 4. BACKGROUND QUESTIONS}

Thank you for completing the questions related to the scenario. Please answer these final background questions.

This scale consists of a number of words that describe different feelings and emotions. Indicate to what extent you feel this way right now, that is, at the present moment. Use the following scale to record your answers.

\begin{tabular}{|c|c|c|c|c|}
\hline 1 & 2 & 3 & 4 & 5 \\
$\begin{array}{c}\text { very slightly } \\
\text { or not at all }\end{array}$ & a little & moderately & quite a bit & extremely \\
\hline
\end{tabular}

\begin{tabular}{|c|c|c|c|c|c|c|c|c|c|c|c|}
\hline Interested & 1 & 2 & 3 & 4 & 5 & Irritable & 1 & 2 & 3 & 4 & 5 \\
\hline Distressed & 1 & 2 & 3 & 4 & 5 & Alert & 1 & 2 & 3 & 4 & 5 \\
\hline Excited & 1 & 2 & 3 & 4 & 5 & Ashamed & 1 & 2 & 3 & 4 & 5 \\
\hline Upset & 1 & 2 & 3 & 4 & 5 & Inspired & 1 & 2 & 3 & 4 & 5 \\
\hline Strong & 1 & 2 & 3 & 4 & 5 & Nervous & 1 & 2 & 3 & 4 & 5 \\
\hline Guilty & 1 & 2 & 3 & 4 & 5 & Determined & 1 & 2 & 3 & 4 & 5 \\
\hline
\end{tabular}




\begin{tabular}{|c|c|c|c|c|c|c|c|c|c|c|}
\hline Scared & 1 & 2 & 3 & 4 & 5 & Attentive & 1 & 2 & 3 & 4 \\
\hline Hostile & 1 & 2 & 3 & 4 & 5 & Jittery & 1 & 2 & 3 & 4 \\
\hline Enthusiastic & 1 & 2 & 3 & 4 & 5 & Active & 1 & 2 & 3 & 4 \\
\hline Proud & 1 & 2 & 3 & 4 & 5 & Afraid & 1 & 2 & 3 & 4 \\
\hline
\end{tabular}

1. How old are you (in years)?

2. Are you male or female? (please $\square$ tick one)

$\square$ Male $\square$ Female

3. Were you born in New Zealand?

$\square$ Yes $\square$ No

4. What $(\square)$ is your ethnicity?
$\square$ European/ Pakeha
Asian
Maori
Indian
$\square$ Pacific
$\square$ Other:

5. Which ( $\square)$ is your highest degree of education?

$\square$ Primary School

College or University Degree

High School

Specialization, MBA, Masters or Doctorate

6. Sometimes, people use the terms "liberal" or "conservative" to describe their political beliefs. How would you rate yourself in these terms? Select the option that best describes you.

$\square$ 1. Extremely liberal $\square$ 5. Slightly conservative

$\square$ 2. Liberal $\square$ 6. Conservative

3. Slightly liberal $\square$. Extremely conservative

$\square$ 4. Moderate 
7. Sometimes, people use the terms "left-wing" or "right-wing" to describe their political beliefs. How would you rate yourself in these terms? Select the option that best describes you.
1. Extremely left-wing
5. Slightly right-wing
2. Left-wing
6. Right-wing
3. Slightly left-wing
$\square$ 7. Extremely right-wing
4. Moderate

Appendix C2.2. Main questionnaire for the natural threat condition

\section{SECTION 2. SCENARIO}

Please imagine the scenario described below as real and happening right now in New Zealand. After reading the scenario, you will be asked to answer five questions related to the scenario followed by some socio-demographic questions.

\section{Scenario}

Imagine that this is happening in New Zealand right now. For you personally, the situation is basically as you expected or planned it to be. Thus, your personal affairs concerning partnering, children, marriage, jobs, career, friends, etc. have not changed unexpectedly. However, while your personal affairs are going well, there have been dramatic and far-reaching changes in New Zealand at present.

Strong earthquakes shook both the North and South Islands. Undersea earthquakes are also occurring, and tsunamis around the New Zealand coast are highly likely and have triggered tsunami alerts. Global warming and climate change are impacting New Zealand and a combination of diseases, drought, fires, floods, hurricanes and tornados are affecting many parts of the country. Forest fires are common, and volcanic activity is high with frequent volcanic eruptions. The possibility of a meteorite hitting New Zealand is also likely. Devastation, destruction and helplessness are consuming New Zealand citizens.

\section{SECTION 3. SCENARIO EvaluATION}

Now, after imagining yourself in this scenario, please complete the following questions. Please read each question carefully.

You will probably find that in some cases your answers to this scenario might be different to what they would be otherwise, while for other questions your answers won't be that different. It's important that you read each question and select your answers carefully, being at all times mindful of the scenario you read above.

\section{To what extent did the scenario you just read present social threats?}


(Social threats are associated with the way people behave toward others "just because they can", which may lead to the creation of a dangerous and threatening place, causing harm and disruption to others' lives.)

$\begin{array}{lr}\text { Not at all } & \text { Extremely } \\ \text { present } & \text { present }\end{array}$

\begin{tabular}{|l|l|l|l|l|l|l|l|l|l|l|}
\hline 0 & 1 & 2 & 3 & 4 & 5 & 6 & 7 & 8 & 9 & 10 \\
\hline
\end{tabular}

\section{To what extent did the scenario you just read present economic threats?}

(Economic threats are associated with the competition for power and resources between people and by hierarchical relationships between individuals and social groups.)

Not at all
present
\begin{tabular}{|c|c|c|c|c|c|c|c|c|c|c|}
\hline 0 & 1 & 2 & 3 & 4 & 5 & 6 & 7 & 8 & 9 & $\begin{array}{r}\text { Extremely } \\
\text { present }\end{array}$ \\
\hline
\end{tabular}

\section{To what extent did the scenario you just read present natural threats?}

(Natural threats are associated with natural disasters that could impact your society and affect the way you and others live.)

$\begin{aligned} & \text { Not at all } \\
& \text { present }\end{aligned}$
\begin{tabular}{|c|c|c|c|c|c|c|c|c|c|c|}
\hline 0 & 1 & 2 & 3 & 4 & 5 & 6 & 7 & 8 & 9 & 10 \\
\hline
\end{tabular}

4. Please mark the degree to which you think that the situation presented in the scenario would impact your life and result in negative consequences.

Not at all

Extremely

\begin{tabular}{|l|l|l|l|l|}
\hline 1 & 2 & 3 & 4 & 5 \\
\hline
\end{tabular}


5. Still considering the scenario you read above, imagine that there is a national election coming in a few days. Given this scenario, which party would you vote for?
$\square \mathrm{ACT}$
Māori
$\square$ Green
National
Labour
NZ First
Mana
United Future

\section{SECTION 4. BACKGROUND QUESTIONS}

Thank you for completing the questions related to the scenario. Please answer these final background questions.

This scale consists of a number of words that describe different feelings and emotions. Indicate to what extent you feel this way right now, that is, at the present moment. Use the following scale to record your answers.

\begin{tabular}{|c|c|c|c|c|}
\hline 1 & 2 & 3 & 4 \\
$\begin{array}{c}\text { very slightly } \\
\text { or not at all }\end{array}$ & a little & moderately & quite a bit & extremely \\
\hline
\end{tabular}

\begin{tabular}{|c|c|c|c|c|c|c|c|c|c|c|c|}
\hline Interested & 1 & 2 & 3 & 4 & 5 & Irritable & 1 & 2 & 3 & 4 & 5 \\
\hline Distressed & 1 & 2 & 3 & 4 & 5 & Alert & 1 & 2 & 3 & 4 & 5 \\
\hline Excited & 1 & 2 & 3 & 4 & 5 & Ashamed & 1 & 2 & 3 & 4 & 5 \\
\hline Upset & 1 & 2 & 3 & 4 & 5 & Inspired & 1 & 2 & 3 & 4 & 5 \\
\hline Strong & 1 & 2 & 3 & 4 & 5 & Nervous & 1 & 2 & 3 & 4 & 5 \\
\hline Guilty & 1 & 2 & 3 & 4 & 5 & Determined & 1 & 2 & 3 & 4 & 5 \\
\hline Scared & 1 & 2 & 3 & 4 & 5 & Attentive & 1 & 2 & 3 & 4 & 5 \\
\hline Hostile & 1 & 2 & 3 & 4 & 5 & Jittery & 1 & 2 & 3 & 4 & 5 \\
\hline Enthusiastic & 1 & 2 & 3 & 4 & 5 & Active & 1 & 2 & 3 & 4 & 5 \\
\hline Proud & 1 & 2 & 3 & 4 & 5 & Afraid & 1 & 2 & 3 & 4 & 5 \\
\hline
\end{tabular}


1. How old are you (in years)?

2. Are you male or female? (please $\square$ tick one)

Male

$\square$ Female

3. Were you born in New Zealand?

Yes

No

4. What $($ చ) is your ethnicity?
$\square$ European/ Pakeha
Asian
Maori
Indian
Pacific
$\square$ Other:

5. Which ( $\square)$ is your highest degree of education?

$\square$ Primary School $\quad \square$ College or University Degree

$\square$ High School $\quad \square$ Specialization, MBA, Masters or Doctorate

6. Sometimes, people use the terms "liberal" or "conservative" to describe their political beliefs. How would you rate yourself in these terms? Select the option that best describes you.

$\square$ 1. Extremely liberal $\square$ 5. Slightly conservative
$\square$ 2. Liberal
6. Conservative
3. Slightly liberal
7. Extremely conservative

$\square$ 4. Moderate

7. Sometimes, people use the terms "left-wing" or "right-wing" to describe their political beliefs. How would you rate yourself in these terms? Select the option that best describes you.
$\square$ 1. Extremely left-wing
5. Slightly right-wing
$\square$ 2. Left-wing
6. Right-wing 
3. Slightly left-wing $\square$ 7. Extremely right-wing

4. Moderate

Appendix C2.3. Main questionnaire for the social threat condition

SECTION 2. SCENARIO

Please imagine the scenario described below as real and happening right now in New Zealand. After reading the scenario, you will be asked to answer five questions related to the scenario followed by some socio-demographic questions.

\section{Scenario}

Imagine that this is happening in New Zealand right now. For you personally, the situation is basically as you expected or planned it to be. Thus, your personal affairs concerning partnering, children, marriage, jobs, career, friends, etc. have not changed unexpectedly. However, while your personal affairs are going well, there have been dramatic and far-reaching changes in New Zealand at present.

Gangs have taken up the streets and racism against various groups is high. Drug abuse has increased and there are drugs available everywhere. Violence, in the form of bullying, looting, intimidation, assault and rape, is taking place everywhere in New Zealand. Terrorist attacks, sometimes even with bombs, are also occurring. The possession of guns is legalized and New Zealand citizens have been buying them profusely. Religion extremism is visible across the country. People are rude and living for power. Fear is stamped on the faces of New Zealand citizens.

\section{SECTION 3. ScEnARio Evaluation}

Now, after imagining yourself in this scenario, please complete the following questions. Please read each question carefully.

You will probably find that in some cases your answers to this scenario might be different to what they would be otherwise, while for other questions your answers won't be that different. It's important that you read each question and select your answers carefully, being at all times mindful of the scenario you read above.

\section{To what extent did the scenario you just read present social threats?}

(Social threats are associated with the way people behave toward others "just because they can", which may lead to the creation of a dangerous and threatening place, causing harm and disruption to others' lives.) 
Not at all

Extremely

present

present

\begin{tabular}{|l|l|l|l|l|l|l|l|l|l|l|}
\hline 0 & 1 & 2 & 3 & 4 & 5 & 6 & 7 & 8 & 9 & 10 \\
\hline
\end{tabular}

2. To what extent did the scenario you just read present economic threats?

(Economic threats are associated with the competition for power and resources between people and by hierarchical relationships between individuals and social groups.)

$\begin{aligned} & \text { Not at all } \\
& \text { present }\end{aligned}$
\begin{tabular}{|c|c|c|c|c|c|c|c|c|c|c|}
$\begin{array}{r}\text { Extremely } \\
\text { present }\end{array}$ \\
\hline 0 & 1 & 2 & 3 & 4 & 5 & 6 & 7 & 8 & 9 & 10 \\
\hline
\end{tabular}

3. To what extent did the scenario you just read present natural threats?

(Natural threats are associated with natural disasters that could impact your society and affect the way you and others live.)

Not at all
present
\begin{tabular}{|c|c|c|c|c|c|c|c|c|c|c|}
\hline 0 & 1 & 2 & 3 & 4 & 5 & 6 & 7 & 8 & 9 & 10 \\
\hline
\end{tabular}

4. Please mark the degree to which you think that the situation presented in the scenario would impact your life and result in negative consequences.

Not at all

Extremely

\begin{tabular}{|l|l|l|l|l|}
\hline 1 & 2 & 3 & 4 & 5 \\
\hline
\end{tabular}

5. Still considering the scenario you read above, imagine that there is a national election coming in a few days. Given this scenario, which party would you vote for?
$\square \mathrm{ACT}$
Māori
Green
National
Labour
NZ First 


\section{SECTION 4. BACKGROUND QUESTIONS}

Thank you for completing the questions related to the scenario. Please answer these final background questions.

This scale consists of a number of words that describe different feelings and emotions. Indicate to what extent you feel this way right now, that is, at the present moment. Use the following scale to record your answers.

\begin{tabular}{|c|c|c|c|c|}
\hline 1 & 2 & 3 & 4 & 5 \\
$\begin{array}{c}\text { very slightly } \\
\text { or not at all }\end{array}$ & a little & moderately & quite a bit & extremely \\
\hline
\end{tabular}

\begin{tabular}{|c|c|c|c|c|c|c|c|c|c|c|c|}
\hline Interested & 1 & 2 & 3 & 4 & 5 & Irritable & 1 & 2 & 3 & 4 & 5 \\
\hline Distressed & 1 & 2 & 3 & 4 & 5 & Alert & 1 & 2 & 3 & 4 & 5 \\
\hline Excited & 1 & 2 & 3 & 4 & 5 & Ashamed & 1 & 2 & 3 & 4 & 5 \\
\hline Upset & 1 & 2 & 3 & 4 & 5 & Inspired & 1 & 2 & 3 & 4 & 5 \\
\hline Strong & 1 & 2 & 3 & 4 & 5 & Nervous & 1 & 2 & 3 & 4 & 5 \\
\hline Guilty & 1 & 2 & 3 & 4 & 5 & Determined & 1 & 2 & 3 & 4 & 5 \\
\hline Scared & 1 & 2 & 3 & 4 & 5 & Attentive & 1 & 2 & 3 & 4 & 5 \\
\hline Hostile & 1 & 2 & 3 & 4 & 5 & Jittery & 1 & 2 & 3 & 4 & 5 \\
\hline Enthusiastic & 1 & 2 & 3 & 4 & 5 & Active & 1 & 2 & 3 & 4 & 5 \\
\hline Proud & 1 & 2 & 3 & 4 & 5 & Afraid & 1 & 2 & 3 & 4 & 5 \\
\hline
\end{tabular}

1. How old are you (in years)?

2. Are you male or female? (please $\square$ tick one)

Male

Female 
3. Were you born in New Zealand?

Yes

No

4. What $(\square)$ is your ethnicity?

$\square$ European/ Pakeha

Asian

Maori

Indian

Pacific

$\square$ Other:

5. Which ( $\square)$ is your highest degree of education?

Primary School

High School
College or University Degree

Specialization, MBA, Masters or Doctorate

6. Sometimes, people use the terms "liberal" or "conservative" to describe their political beliefs. How would you rate yourself in these terms? Select the option that best describes you.

$\square$ 1. Extremely liberal

2. Liberal

3. Slightly liberal

4. Moderate
5. Slightly conservative

6. Conservative

7. Extremely conservative

7. Sometimes, people use the terms "left-wing" or "right-wing" to describe their political beliefs. How would you rate yourself in these terms? Select the option that best describes you.
$\square$ 1. Extremely left-wing
5. Slightly right-wing
2. Left-wing
6. Right-wing
$\square$ 3. Slightly left-wing
$\square$ 7. Extremely right-wing
4. Moderate

Appendix C2.4. Main questionnaire for the control condition

\section{SECTION 2. SCENARIO}


Please imagine the scenario described below as real and happening right now in New Zealand. The scenario will be presented along with some real facts about New Zealand. After reading the scenario and the facts, you will be asked to answer five questions related to the scenario followed by some socio-demographic questions.

\section{Scenario and facts}

Imagine that this is happening in New Zealand right now. For you personally, the situation is basically as you expected or planned it to be. Thus, your personal affairs concerning partnering, children, marriage, jobs, career, friends, etc. have not changed unexpectedly. Your personal affairs are going well, and there have been no dramatic or far-reaching changes in New Zealand at present.

New Zealand's location protects the country from unexpected changes. The country is made up of two main islands and some smaller islands, located near the centre of the water hemisphere (largest area of water of the Earth's surface), and far away from other big land masses. The country is situated some 1,500 kilometres east of Australia across the Tasman Sea, and roughly 1,000 kilometres south of some Pacific islands. New Zealand is long (over 1,600 kilometres) and narrow (with a maximum of 400 kilometres) if considered the main islands.

\section{SeCTION 3. ScEnARio Evaluation}

Now, after imagining yourself in the scenario and reading real facts about New Zealand, please complete the following questions. Please read each item carefully.

You will probably find that in some cases your answers to this scenario might be different to what they would be otherwise, while for other questions your answers won't be that different. It's important that you read each question and select your answers carefully, being at all times mindful of the scenario you read above.

\section{To what extent did the scenario and the facts you just read present social threats?}

(Social threats are associated with the way people behave toward others "just because they can", which may lead to the creation of a dangerous and threatening place, causing harm and disruption to others' lives.)

$\begin{array}{lr}\text { Not at all } & \text { Extremely } \\ \text { present } & \text { present }\end{array}$

\begin{tabular}{|l|l|l|l|l|l|l|l|l|l|l|}
\hline 0 & 1 & 2 & 3 & 4 & 5 & 6 & 7 & 8 & 9 & 10 \\
\hline
\end{tabular}

2. To what extent did the scenario and the facts you just read present economic threats? 
(Economic threats are associated with the competition for power and resources between people and by hierarchical relationships between individuals and social groups.)

$\begin{aligned} & \text { Not at all } \\
& \text { present }\end{aligned}$
\begin{tabular}{|c|c|c|c|c|c|c|c|c|c|c|}
\hline 0 & 1 & 2 & 3 & 4 & 5 & 6 & 7 & 8 & 9 & 10 \\
\hline
\end{tabular}

\section{To what extent did the scenario and the facts you just read present natural threats?}

(Natural threats are associated with natural disasters that could impact your society and affect the way you and others live.)

$\begin{aligned} & \text { Not at all } \\
& \text { present }\end{aligned}$
\begin{tabular}{|c|c|c|c|c|c|c|c|c|c|c|}
\hline 0 & 1 & 2 & 3 & 4 & 5 & 6 & 7 & 8 & 9 & $\begin{array}{r}\text { Extremely } \\
\text { present }\end{array}$ \\
\hline
\end{tabular}

4. Please mark the degree to which you think that the situation and the facts presented in the text would impact your life and result in negative consequences.

Not at all

Extremely

\begin{tabular}{|l|l|l|l|l|}
\hline 1 & 2 & 3 & 4 & 5 \\
\hline
\end{tabular}

5. Still considering the scenario and the facts you read above, imagine that there is a national election coming in a few days. Given this scenario and the facts, which party would you vote for?

$\begin{array}{ll}\square \text { ACT } & \square \text { Māori } \\ \square \text { Green } & \square \text { National } \\ \square \text { Labour } & \square \text { NZ First } \\ \square \text { Mana } & \square \text { United Future }\end{array}$


Thank you for completing the questions related to the scenario and the facts. Please answer these final background questions.

This scale consists of a number of words that describe different feelings and emotions. Indicate to what extent you feel this way right now, that is, at the present moment. Use the following scale to record your answers.

\begin{tabular}{|c|c|c|c|c|}
\hline 1 & 2 & 3 & 4 & 5 \\
$\begin{array}{c}\text { very slightly } \\
\text { or not at all }\end{array}$ & a little & moderately & quite a bit & extremely \\
\hline
\end{tabular}

\begin{tabular}{|c|c|c|c|c|c|c|c|c|c|c|c|}
\hline Interested & 1 & 2 & 3 & 4 & 5 & Irritable & 1 & 2 & 3 & 4 & 5 \\
\hline Distressed & 1 & 2 & 3 & 4 & 5 & Alert & 1 & 2 & 3 & 4 & 5 \\
\hline Excited & 1 & 2 & 3 & 4 & 5 & Ashamed & 1 & 2 & 3 & 4 & 5 \\
\hline Upset & 1 & 2 & 3 & 4 & 5 & Inspired & 1 & 2 & 3 & 4 & 5 \\
\hline Strong & 1 & 2 & 3 & 4 & 5 & Nervous & 1 & 2 & 3 & 4 & 5 \\
\hline Guilty & 1 & 2 & 3 & 4 & 5 & Determined & 1 & 2 & 3 & 4 & 5 \\
\hline Scared & 1 & 2 & 3 & 4 & 5 & Attentive & 1 & 2 & 3 & 4 & 5 \\
\hline Hostile & 1 & 2 & 3 & 4 & 5 & Jittery & 1 & 2 & 3 & 4 & 5 \\
\hline Enthusiastic & 1 & 2 & 3 & 4 & 5 & Active & 1 & 2 & 3 & 4 & 5 \\
\hline Proud & 1 & 2 & 3 & 4 & 5 & Afraid & 1 & 2 & 3 & 4 & 5 \\
\hline
\end{tabular}

1. How old are you (in years)?

2. Are you male or female? (please $\square$ tick one)

$\square$ Male $\square$ Female

3. Were you born in New Zealand?

Yes

$\square$ No

4. What $(\square)$ is your ethnicity? 


$\begin{array}{ll}\square \text { European/ Pakeha } & \square \text { Asian } \\ \square \text { Maori } & \square \text { Indian } \\ \square \text { Pacific } & \square \text { Other: }\end{array}$

5. Which ( $\square)$ is your highest degree of education?

Primary School

College or University Degree

$\square$ High School

Specialization, MBA, Masters or Doctorate

6. Sometimes, people use the terms "liberal" or "conservative" to describe their political beliefs. How would you rate yourself in these terms? Select the option that best describes you.
1. Extremely liberal
5. Slightly conservative
2. Liberal
6. Conservative
3. Slightly liberal
7. Extremely conservative
4. Moderate

7. Sometimes, people use the terms "left-wing" or "right-wing" to describe their political beliefs. How would you rate yourself in these terms? Select the option that best describes you.

$\square$ 1. Extremely left-wing $\square$ 5. Slightly right-wing
$\square$ 2. Left-wing
$\square$ 6. Right-wing
3. Slightly left-wing
$\square 7$. Extremely right-wing

4. Moderate

Appendix C3. Debriefing for the Actual Survey

\section{SECTION 5. DEbriefing Statement}

Thank you for participating in this study!

The aim of this study is to evaluate if people can differentiate between social, economic and natural threat. These types of threat often appear mixed or are not well delimited in the literature, which makes it difficult to study whether different threats have a different impact on 
people' behaviors. Different participants in this study read different kinds of scenarios, evaluating their link to social, economic and natural threat. The results of the various participants will be evaluated together in order to evaluate if different scenarios are linked to different kinds of threat. Results from this study will contribute to the existing literature by providing initial information to test how these differential threats impact people' behaviors.

The research project is being conducted by Clara Cantal, a $\mathrm{PhD}$ student, and her supervisors, Dr. Taciano L. Milfont and Dr. Marc Wilson, from the School of Psychology, Victoria University of Wellington. If you have any questions regarding your involvement in this research, or issues regarding the research in general, please do not hesitate to contact me via email at Clara.Cantal@vuw.ac.nz.

\section{Thanks again!}

Clara Cantal

Taciano Milfont

Marc Wilson

Thank you for participating in our study! 


\section{Appendix D1. Information Sheet for the Actual Survey}

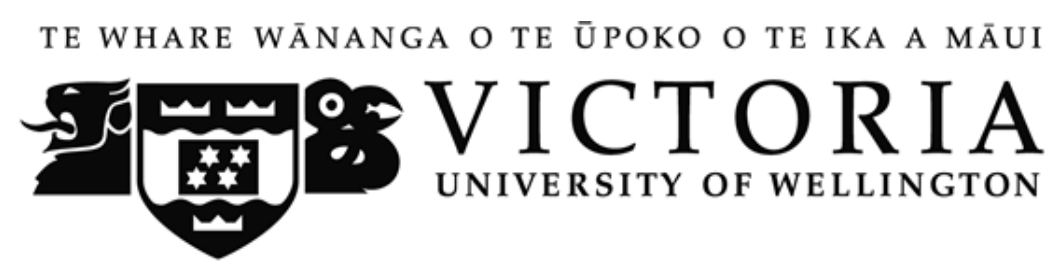

\section{SECTION 1. INFORMATION SHEET}

\section{Welcome!}

\section{What is the purpose of this research?}

- You will be presented with 85 images and 4 Party proposals.

- We are interested on your views of them. The goal of this research is to understand your perceptions of these images and of the political discourses.

\section{Who is conducting the research?}

- Clara Cantal is a PhD student in the School of Psychology of Victoria University of Wellington. Dr. Taciano Milfont and Dr. Marc Wilson are responsible for supervising this project and the other projects in the student thesis.

- This research has been approved by the School of Psychology Human Ethics Committee under delegated authority of the VUW Human Ethics Committee (Approved 12/02/2013; Reference number: RM019658).

\section{What is involved if you agree to participate?}

- If you agree to participate in this study you will be asked to complete a short survey.

- The survey asks you about social, economic and natural threats, and some demographic questions.

- We anticipate that the survey will take you no more than 30 minutes to complete.

- During the research you are free to withdraw at any point before your survey has been completed.

\section{$\underline{\text { Privacy and confidentiality }}$}

- This survey is anonymous. Please do not put your name anywhere on the survey.

- You will never be identified in my research project or in any other presentation or publication. The information you provide will be coded by number only. We will keep your survey for at least five years after publication.

- In accordance with the requirements of some scientific journals and organizations, your coded survey may be shared with other competent researchers.

- Your coded data may be used in other, related studies. A copy of the coded data will remain in the custody of Clara Cantal in the Environmental Psychology Lab.

- Provided ID will only be used to award IPRP credits for taking part in the study and will not be stored.

\section{What happens to the information that you provide?}


- The data you provide may be used for the following purposes: The overall findings may be submitted for publication in a scientific journal, or presented at scientific conferences. The findings will be part of a $\mathrm{PhD}$ thesis that will be submitted for assessment.

- If you would like to know the results of this study, they will be available approximately next year (2014) upon request via email to Ms. Cantal.

\title{
Consent for participation
}

- Please note that by completing and returning the questionnaire to the researchers online you agree that your survey responses will be used and analyzed. If you have any further questions regarding this study, please do not hesitate to contact the investigator listed below.

\section{Thank you for considering participating in this research!}

\author{
Clara Cantal \\ PhD Student \\ Environmental Psychology Lab \\ School of Psychology, Faculty of Science \\ Victoria University of Wellington \\ Email: Clara.Cantal@ vuw.ac.nz
}

\section{Do you consent your participation? \\ $\mathrm{O}$ Yes \\ O No}

This study has five parts. On the first part you will be presented with 85 images and asked three questions about each image. On the second part you will be asked to read short Political Party proposals and asked to identify to which New Zealand Party it belongs to. On the third part you will be asked some background questions. On the fourth part you will be given the study debrief. Finally, on the fifth part you will answer a brief post-experimental questionnaire and your student ID will be required.

\section{Appendix D2. Main Questionnaire for the Actual Survey \\ Part 1: Image Validation}

In this part of the questionnaire you will be presented with 85 images and asked whether the image depicts one of the following: economic threat, natural threat, social threat, or New Zealand natural territory. A definition of these categories is presented below:

- Economic threat -- associated with the competition for power and resources between people and by hierarchical relationships between individuals and social groups

- Natural threat -- associated with natural disasters that could impact your society and affect the way you and others live

- Social threat -- associated with the way people behave toward others "just because they can", which may lead to a dangerous and threatening place, causing harm and disruption to others 
- New Zealand natural territory -- landscapes or characteristics of New Zealand territory (questions presented after each of the 85 images)

- Economic threat -- associated with the competition for power and resources between people and by hierarchical relationships between individuals and social groups

- Natural threat -- associated with natural disasters that could impact your society and affect the way you and others live

- Social threat -- associated with the way people behave toward others "just because they can", which may lead to a dangerous and threatening place, causing harm and disruption to others

- New Zealand natural territory -- landscapes or characteristics of New Zealand territory

1. This image more strongly illustrates...

O Economic threat

O Natural threat

O Social threat

New Zealand natural territory

2. How well does this image illustrate the category you selected?

Illustrates the category

$$
\begin{array}{lllllllllll}
0=N o t \text { at all } & 1 & 2 & 3 & 4 & 5 & 6 & 7 & 8 & 9 & 10=\text { Very well }
\end{array}
$$

3. In which extent this image evokes positive and negative emotion?

Negative emotion

$$
\begin{array}{lllllllllll}
0=\text { Not at all } & 1 & 2 & 3 & 4 & 5 & 6 & 7 & 8 & 9 & 10=\text { Extremely }
\end{array}
$$

Positive emotion

$$
\begin{array}{lllllllllll}
0=\text { Not at all } & 1 & 2 & 3 & 4 & 5 & 6 & 7 & 8 & 9 & 10=\text { Extremely }
\end{array}
$$

Thank you for completing the first part of this study. In the second part that follows you will be asked to read four Political Party proposals and indicate to which party it belongs to.

Part 2: Party proposals validation

Please read the following Political Party proposals and indicate to which New Zealand party you think it belongs to.

\section{(options presented after each of the four political discourses)}



ACT
Green
O Labour
O Mana
O Māori
O National
O New Zealand First
O United Future
O I don't know

Thank you for completing the second part of this study. In this section you will be asked some background questions.

Part 3: background data

Please answer the following socio-demographic questions.

1. How old are you (in years)?

2. Are you male or female?

O male

O female

3. Were you born in New Zealand?
O Yes
O No

4. Which is your ethnicity?
$\square$ European
口 Māori
$\square$ Pacific Islander
a Asian
Indian

$\square$ Other

Thank you for participating in this study! You will be presented with the debriefing below. Please read it carefully to be able to complete the post-experimental questionnaire. You will also be asked for your student ID. This is necessary to award you course credit.

\section{Appendix D3. Debriefing for the Actual Survey}

\section{Part 4: debriefing}

Thank you for participating in this study!

The aim of this study is to examine if people can differentiate between social, economic and natural threats and if they can differentiate some of New Zealand's Parties proposals. Results from this study will contribute to the existing literature by providing initial information on how to test how these differential threats impact people' voting intention. 
The research project is being conducted by Clara Cantal, a PhD student, and her supervisors, Dr. Taciano L. Milfont and Dr. Marc Wilson, from the School of Psychology, Victoria University of Wellington. If you have any questions regarding your involvement in this research, or issues regarding the research in general, please do not hesitate to contact me via email at Clara.Cantal@vuw.ac.nz.

Thanks again!

Clara Cantal

Taciano Milfont

Marc Wilson

Thank you for reading the debriefing. In the last part of the survey you will answer some questions about this study.

\section{Appendix D4. Post-Experimental Questionnaire for the Actual Survey}

Part 5: post-experimental questionnaire

Please tell us a bit about the study in which you just participated. We want to be able to get a sense of what you learned now that you have been debriefed:

1. Every research project tries to answer at least one question. What question was this project trying to answer?

2. Research projects usually have one major hypothesis. What was the hypothesis in this project?

3. If you were to predict what the data will look like when the study is completed, do you think the data will support the hypothesis? Please briefly explain your answer.

4. Do you have any other comments about this project? We are always looking for helpful feedback.

5. Student ID:

6. Surname:

Thank you for completing all the survey! 


\section{Appendix E. Study 2C Image Evaluation Table}

Table E.1

Image evaluation scores for images selected according to the first and second criteria

\begin{tabular}{|c|c|c|c|c|c|c|c|c|}
\hline Image & Correct category & $\begin{array}{c}\% \text { of } \\
\text { participants } \\
\text { who } \\
\text { pointed out } \\
\text { the correct } \\
\text { category }\end{array}$ & $\begin{array}{l}M \text { extent to } \\
\text { which the } \\
\text { image } \\
\text { represents the } \\
\text { correct } \\
\text { category }\end{array}$ & $\begin{array}{l}S D \text { extent to } \\
\text { which the } \\
\text { image } \\
\text { represents the } \\
\text { correct } \\
\text { category }\end{array}$ & $\begin{array}{l}M \text { difference } \\
\text { between } \\
\text { negative and } \\
\text { positive } \\
\text { sentiments }\end{array}$ & $\begin{array}{c}S D \text { difference } \\
\text { between } \\
\text { negative and } \\
\text { positive } \\
\text { sentiments }\end{array}$ & $\begin{array}{c}\text { Number of } \\
\text { participants } \\
\text { who pointed } \\
\text { out the correct } \\
\text { category }\end{array}$ & $\begin{array}{l}\text { Total number } \\
\text { of participants }\end{array}$ \\
\hline
\end{tabular}

\begin{tabular}{|c|c|c|c|c|c|c|c|c|}
\hline assetsales2 & Economic threat & 100.00 & 7.91 & 1.76 & 5.36 & 4.18 & 11 & 11 \\
\hline assetsales 3 & Economic threat & 100.00 & 3.30 & 2.00 & 1.60 & 2.76 & 10 & 10 \\
\hline assetsales 4 & Economic threat & 100.00 & 6.50 & 1.51 & 4.33 & 3.94 & 12 & 12 \\
\hline assetsales 5 & Economic threat & 90.90 & 6.80 & 2.30 & 5.70 & 3.06 & 10 & 11 \\
\hline bankruptcy 2 & Economic threat & 100.00 & 8.00 & 1.83 & 7.00 & 2.45 & 9 & 9 \\
\hline bankruptcy 4 & Economic threat & 100.00 & 7.10 & 0.99 & 6.30 & 2.91 & 10 & 10 \\
\hline bankruptcy1 & Economic threat & 100.00 & 7.25 & 1.66 & 7.50 & 2.28 & 12 & 12 \\
\hline bankruptcy5 & Economic threat & 100.00 & 6.30 & 2.26 & 6.30 & 2.54 & 10 & 10 \\
\hline bankruptcynew & Economic threat & 100.00 & 7.30 & 1.77 & 7.60 & 2.22 & 10 & 10 \\
\hline capitalism4 & Economic threat & 92.30 & 7.92 & 1.98 & 4.25 & 4.03 & 12 & 13 \\
\hline
\end{tabular}




\begin{tabular}{|c|c|c|c|c|c|c|c|}
\hline competition2 & Economic threat & 100.00 & 5.45 & 2.46 & 1.00 & 2.61 & 11 \\
\hline competition4 & Economic threat & 80.00 & 6.13 & 2.80 & 2.38 & 3.66 & 8 \\
\hline corruption3 & Economic threat & 91.70 & 6.00 & 1.55 & 3.09 & 4.32 & 11 \\
\hline corruption5 & Economic threat & 100.00 & 6.00 & 2.00 & 3.92 & 3.40 & 13 \\
\hline corruptionnew1 & Economic threat & 83.30 & 6.60 & 2.55 & 2.10 & 4.09 & 10 \\
\hline corruptionnew2 & Economic threat & 91.70 & 7.09 & 2.07 & 4.36 & 4.23 & 11 \\
\hline corruptionnew3 & Economic threat & 91.70 & 7.27 & 2.15 & 6.00 & 3.13 & 11 \\
\hline debt2 & Economic threat & 100.0 & 8.00 & 1.41 & 6.88 & 1.96 & 8 \\
\hline debt3 & Economic threat & 90.90 & 6.20 & 2.78 & 4.30 & 3.37 & 10 \\
\hline debt4 & Economic threat & 100.00 & 7.40 & 1.07 & 4.90 & 3.75 & 10 \\
\hline debt5 & Economic threat & 93.30 & 6.00 & 2.15 & 4.00 & 3.37 & 14 \\
\hline debtnew & Economic threat & 100.00 & 7.38 & 1.41 & 5.75 & 3.06 & 8 \\
\hline depression1 & Economic threat & 100.00 & 7.18 & 2.18 & 6.36 & 3.29 & 11 \\
\hline depression 3 & Economic threat & 91.70 & 8.00 & 1.34 & 5.64 & 2.50 & 11 \\
\hline depression 4 & Economic threat & 100.00 & 7.30 & 2.26 & 5.90 & 3.35 & 10 \\
\hline depression5 & Economic threat & 100.00 & 5.70 & 2.36 & 4.10 & 3.31 & 10 \\
\hline economiccrisis1 & Economic threat & 100.00 & 8.13 & 2.36 & 7.13 & 2.90 & 8 \\
\hline economiccrisis2 & Economic threat & 90.90 & 7.20 & 1.75 & 5.00 & 3.27 & 10 \\
\hline economiccrisis4 & Economic threat & 88.90 & 4.63 & 1.85 & 3.88 & 3.18 & 8 \\
\hline
\end{tabular}




\begin{tabular}{|c|c|c|c|c|c|c|c|c|}
\hline economiccrisis5 & Economic threat & 90.90 & 6.00 & 2.16 & 4.60 & 3.50 & 10 & 11 \\
\hline economiccrisisnew & Economic threat & 100.00 & 7.50 & 1.58 & 5.00 & 3.02 & 10 & 10 \\
\hline globalisation1 & Economic threat & 90.90 & 6.70 & 2.16 & 6.20 & 3.22 & 10 & 11 \\
\hline globalisation4 & Economic threat & 92.90 & 7.62 & 1.61 & 5.08 & 3.40 & 13 & 14 \\
\hline globalisationnew & Economic threat & 91.70 & 8.55 & 1.57 & 4.09 & 3.73 & 11 & 12 \\
\hline greed1 & Economic threat & 100.00 & 4.40 & 1.58 & 2.40 & 4.17 & 10 & 10 \\
\hline greed3 & Economic threat & 100.00 & 7.67 & 1.97 & 4.92 & 4.85 & 12 & 12 \\
\hline greed4 & Economic threat & 100.00 & 8.56 & 1.42 & 5.44 & 3.21 & 9 & 9 \\
\hline greed5 & Economic threat & 88.90 & 6.88 & 2.80 & 5.13 & 3.72 & 8 & 9 \\
\hline inequality 2 & Economic threat & 72.70 & 7.00 & 1.51 & 5.75 & 3.37 & 8 & 11 \\
\hline inflation1 & Economic threat & 100.00 & 6.00 & 2.83 & 3.75 & 3.39 & 12 & 12 \\
\hline inflation2 & Economic threat & 100.00 & 7.60 & 1.80 & 6.27 & 3.31 & 15 & 15 \\
\hline inflation3 & Economic threat & 100.00 & 7.40 & 2.88 & 5.40 & 3.10 & 10 & 10 \\
\hline inflation4 & Economic threat & 100.00 & 8.63 & 1.51 & 6.25 & 3.11 & 8 & 8 \\
\hline jobloss1 & Economic threat & 92.30 & 5.50 & 2.20 & 5.58 & 3.48 & 12 & 13 \\
\hline jobloss5 & Economic threat & 100.00 & 6.25 & 1.39 & 5.88 & 3.09 & 8 & 8 \\
\hline money1 & Economic threat & 86.70 & 5.92 & 2.50 & -1.69 & 2.84 & 13 & 15 \\
\hline money2 & Economic threat & 100.00 & 4.80 & 2.10 & -3.40 & 3.37 & 10 & 10 \\
\hline money4 & Economic threat & 90.90 & 5.40 & 2.67 & -2.40 & 4.45 & 10 & 11 \\
\hline
\end{tabular}




\begin{tabular}{|c|c|c|c|c|c|c|c|c|}
\hline money5 & Economic threat & 91.70 & 4.27 & 2.15 & -3.45 & 4.23 & 11 & 12 \\
\hline moneynewzealand1 & Economic threat & 100.00 & 4.30 & 3.20 & -2.50 & 3.92 & 10 & 10 \\
\hline politics2 & Economic threat & 70.00 & 6.14 & 2.97 & 1.29 & 2.43 & 7 & 10 \\
\hline politics3 & Economic threat & 91.70 & 3.91 & 1.87 & 2.45 & 3.47 & 11 & 12 \\
\hline politics4 & Economic threat & 75.00 & 5.56 & 2.88 & .78 & 3.67 & 9 & 12 \\
\hline politics5 & Economic threat & 73.30 & 4.82 & 3.57 & .09 & 4.68 & 11 & 15 \\
\hline recession1 & Economic threat & 100.00 & 7.73 & 1.79 & 5.45 & 2.91 & 11 & 11 \\
\hline recession3 & Economic threat & 100.00 & 7.00 & 4.24 & 6.00 & 5.66 & 10 & 10 \\
\hline recessionnew & Economic threat & 90.90 & 5.80 & 2.35 & 1.10 & 3.51 & 10 & 11 \\
\hline unemployment3 & Economic threat & 91.70 & 6.09 & 2.34 & 4.73 & 2.28 & 11 & 12 \\
\hline unemployment4 & Economic threat & 100.00 & 7.30 & 2.16 & 6.40 & 2.84 & 10 & 10 \\
\hline climatechange1 & Natural threat & 100.00 & 6.82 & 1.60 & 6.18 & 3.60 & 11 & 11 \\
\hline climatechange2 & Natural threat & 80.00 & 7.13 & 2.53 & 5.13 & 3.36 & 8 & 10 \\
\hline climatechange4 & Natural threat & 88.90 & 6.25 & 2.66 & 5.88 & 3.52 & 8 & 9 \\
\hline climatechange5 & Natural threat & 100.00 & 6.80 & 3.08 & 5.30 & 3.40 & 10 & 10 \\
\hline destruction1 & Natural threat & 81.80 & 8.00 & 1.73 & 7.56 & 2.60 & 9 & 11 \\
\hline destruction2 & Natural threat & 90.00 & 8.78 & 1.20 & 8.00 & 2.69 & 9 & 10 \\
\hline destruction4 & Natural threat & 100.00 & 6.27 & 2.61 & 6.18 & 2.48 & 11 & 11 \\
\hline destruction5 & Natural threat & 100.00 & 8.10 & 1.29 & 6.90 & 2.47 & 10 & 10 \\
\hline
\end{tabular}




\begin{tabular}{|c|c|c|c|c|c|c|c|}
\hline devastation2 & Natural threat & 85.70 & 7.17 & 1.70 & 6.83 & 2.59 & 12 \\
\hline devastation4 & Natural threat & 100.00 & 7.30 & 2.58 & 7.60 & 2.72 & 10 \\
\hline devastation5 & Natural threat & 90.90 & 8.30 & 1.77 & 5.80 & 3.08 & 10 \\
\hline devastationnewzealandnew & Natural threat & 76.90 & 7.70 & 1.57 & 7.70 & 2.54 & 10 \\
\hline disease3 & Natural threat & 76.90 & 6.10 & 1.79 & 7.50 & 2.64 & 10 \\
\hline drought2 & Natural threat & 90.00 & 5.89 & 2.76 & 3.22 & 3.46 & 9 \\
\hline drought5 & Natural threat & 100.00 & 6.91 & 2.30 & 5.27 & 3.80 & 11 \\
\hline earthquakes1 & Natural threat & 100.00 & 7.62 & 2.40 & 7.08 & 2.84 & 13 \\
\hline fires2 & Natural threat & 100.00 & 8.18 & 1.72 & 7.36 & 2.29 & 11 \\
\hline fires4 & Natural threat & 100.00 & 8.13 & 1.73 & 7.25 & 2.87 & 8 \\
\hline fires5 & Natural threat & 100.00 & 7.82 & 1.99 & 6.73 & 2.83 & 11 \\
\hline floods1 & Natural threat & 100.00 & 8.30 & 1.64 & 7.30 & 2.11 & 10 \\
\hline floods2 & Natural threat & 100.00 & 8.80 & 1.75 & 7.70 & 2.50 & 10 \\
\hline floods 5 & Natural threat & 100.00 & 9.00 & 1.47 & 7.23 & 2.83 & 13 \\
\hline forestfires1 & Natural threat & 100.00 & 8.00 & 2.05 & 6.80 & 3.29 & 10 \\
\hline forestfires3 & Natural threat & 100.00 & 8.60 & 1.35 & 8.00 & 2.17 & 15 \\
\hline forestfires 4 & Natural threat & 100.00 & 8.63 & 1.69 & 7.75 & 1.91 & 8 \\
\hline globalwarming2 & Natural threat & 81.80 & 6.44 & 1.94 & 5.22 & 3.83 & 9 \\
\hline hurricanes1 & Natural threat & 100.00 & 8.70 & 1.57 & 7.60 & 2.80 & 10 \\
\hline
\end{tabular}




\begin{tabular}{|c|c|c|c|c|c|c|c|c|}
\hline hurricanes4 & Natural threat & 100.00 & 8.82 & 2.09 & 7.64 & 3.04 & 11 & 11 \\
\hline hurricanes5 & Natural threat & 100.00 & 8.10 & 1.79 & 6.70 & 2.21 & 10 & 10 \\
\hline meteorites1 & Natural threat & 100.00 & 8.89 & 1.96 & 7.44 & 2.83 & 9 & 9 \\
\hline meteorites2 & Natural threat & 100.00 & 8.75 & 1.22 & 5.92 & 4.01 & 12 & 12 \\
\hline meteorites3 & Natural threat & 100.00 & 7.67 & 2.99 & 6.83 & 3.74 & 12 & 12 \\
\hline meteorites4 & Natural threat & 100.00 & 7.83 & 2.29 & 6.83 & 2.98 & 12 & 12 \\
\hline meteorites5 & Natural threat & 100.00 & 7.60 & 2.12 & 5.80 & 4.16 & 10 & 10 \\
\hline tornados 1 & Natural threat & 100.00 & 8.50 & 2.02 & 6.50 & 3.12 & 12 & 12 \\
\hline tornados 2 & Natural threat & 100.00 & 8.88 & 1.13 & 6.50 & 4.07 & 8 & 8 \\
\hline tornados3 & Natural threat & 100.00 & 9.13 & 1.25 & 6.75 & 4.03 & 8 & 8 \\
\hline tornados 4 & Natural threat & 100.00 & 8.89 & 1.76 & 7.33 & 2.65 & 9 & 9 \\
\hline tornados5 & Natural threat & 100.00 & 8.56 & 1.42 & 6.89 & 3.79 & 9 & 9 \\
\hline tsunamis4 & Natural threat & 100.00 & 9.00 & 1.51 & 7.63 & 2.97 & 8 & 8 \\
\hline tsunamis5 & Natural threat & 88.90 & 7.75 & 2.05 & 4.50 & 4.00 & 8 & 9 \\
\hline volcanicactivity 1 & Natural threat & 100.00 & 7.75 & 2.26 & 4.92 & 4.32 & 12 & 12 \\
\hline volcanicactivity 2 & Natural threat & 90.00 & 8.56 & 1.59 & 3.78 & 4.74 & 9 & 10 \\
\hline volcanicactivity 3 & Natural threat & 88.90 & 7.63 & 1.69 & 6.75 & 1.67 & 8 & 9 \\
\hline volcanicactivity 5 & Natural threat & 100.00 & 7.13 & 0.99 & 3.75 & 2.66 & 8 & 8 \\
\hline volcaniceruption 1 & Natural threat & 100.00 & 8.00 & 2.08 & 4.92 & 4.17 & 13 & 13 \\
\hline
\end{tabular}




\begin{tabular}{|c|c|c|c|c|c|c|c|c|}
\hline volcaniceruption2 & Natural threat & 100.00 & 7.85 & 2.12 & 3.31 & 5.34 & 13 & 13 \\
\hline volcaniceruption3 & Natural threat & 100.00 & 8.09 & 1.64 & 4.55 & 3.56 & 11 & 11 \\
\hline volcaniceruption4 & Natural threat & 90.90 & 7.80 & 1.75 & 3.90 & 4.41 & 10 & 11 \\
\hline newzealandnaturalterritory 1 & $\begin{array}{l}\text { New Zealand } \\
\text { natural territory }\end{array}$ & 100.00 & 8.00 & 2.75 & -2.30 & 6.02 & 10 & 10 \\
\hline newzealandnaturalterritory 12 & $\begin{array}{l}\text { New Zealand } \\
\text { natural territory }\end{array}$ & 90.00 & 8.00 & 2.24 & -4.22 & 4.44 & 9 & 10 \\
\hline newzealandnaturalterritory 14 & $\begin{array}{l}\text { New Zealand } \\
\text { natural territory }\end{array}$ & 100.00 & 8.80 & 1.14 & -7.80 & 2.39 & 10 & 10 \\
\hline newzealandnaturalterritory 16 & $\begin{array}{l}\text { New Zealand } \\
\text { natural territory }\end{array}$ & 90.00 & 5.22 & 2.44 & -3.22 & 4.32 & 9 & 10 \\
\hline newzealandnaturalterritory17 & $\begin{array}{l}\text { New Zealand } \\
\text { natural territory }\end{array}$ & 100.00 & 7.56 & 1.94 & -5.22 & 3.19 & 9 & 9 \\
\hline newzealandnaturalterritory 18 & $\begin{array}{l}\text { New Zealand } \\
\text { natural territory }\end{array}$ & 80.00 & 6.50 & 2.33 & -6.88 & 3.09 & 8 & 10 \\
\hline newzealandnaturalterritory19 & $\begin{array}{l}\text { New Zealand } \\
\text { natural territory }\end{array}$ & 100.00 & 8.10 & 2.28 & -7.50 & 3.17 & 10 & 10 \\
\hline newzealandnaturalterritory 2 & $\begin{array}{l}\text { New Zealand } \\
\text { natural territory }\end{array}$ & 100.00 & 8.30 & 1.49 & -3.40 & 3.86 & 10 & 10 \\
\hline newzealandnaturalterritory 21 & $\begin{array}{l}\text { New Zealand } \\
\text { natural territory }\end{array}$ & 100.00 & 8.00 & 1.73 & -5.82 & 2.99 & 11 & 11 \\
\hline newzealandnaturalterritory 22 & $\begin{array}{l}\text { New Zealand } \\
\text { natural territory }\end{array}$ & 100.00 & 6.67 & 2.74 & -1.58 & 3.68 & 12 & 12 \\
\hline newzealandnaturalterritory 27 & $\begin{array}{l}\text { New Zealand } \\
\text { natural territory }\end{array}$ & 92.90 & 7.15 & 2.30 & -5.38 & 3.64 & 13 & 14 \\
\hline newzealandnaturalterritory 28 & $\begin{array}{l}\text { New Zealand } \\
\text { natural territory }\end{array}$ & 81.80 & 6.44 & 2.07 & -3.00 & 4.24 & 9 & 11 \\
\hline newzealandnaturalterritory3 & $\begin{array}{l}\text { New Zealand } \\
\text { natural territory }\end{array}$ & 100.00 & 8.67 & 1.78 & -7.67 & 3.28 & 12 & 12 \\
\hline
\end{tabular}




\begin{tabular}{|c|c|c|c|c|c|c|c|c|}
\hline newzealandnaturalterritory 30 & $\begin{array}{l}\text { New Zealand } \\
\text { natural territory }\end{array}$ & 100.00 & 8.13 & 1.89 & -2.75 & 3.88 & 8 & 8 \\
\hline newzealandnaturalterritory31 & $\begin{array}{c}\text { New Zealand } \\
\text { natural territory }\end{array}$ & 100.00 & 9.30 & 1.34 & -5.40 & 5.85 & 10 & 10 \\
\hline newzealandnaturalterritory 33 & $\begin{array}{c}\text { New Zealand } \\
\text { natural territory }\end{array}$ & 100.00 & 8.75 & 1.04 & -7.88 & 2.23 & 8 & 8 \\
\hline newzealandnaturalterritory 35 & $\begin{array}{l}\text { New Zealand } \\
\text { natural territory }\end{array}$ & 90.90 & 7.00 & 2.75 & -5.80 & 4.54 & 10 & 11 \\
\hline newzealandnaturalterritory37 & $\begin{array}{c}\text { New Zealand } \\
\text { natural territory }\end{array}$ & 100.00 & 8.88 & 1.25 & -5.38 & 6.57 & 8 & 8 \\
\hline newzealandnaturalterritory 38 & $\begin{array}{c}\text { New Zealand } \\
\text { natural territory }\end{array}$ & 100.00 & 8.00 & 3.10 & -6.33 & 2.77 & 12 & 12 \\
\hline newzealandnaturalterritory39 & $\begin{array}{c}\text { New Zealand } \\
\text { natural territory }\end{array}$ & 100.00 & 9.33 & .87 & -7.33 & 3.35 & 9 & 9 \\
\hline newzealandnaturalterritory4 & $\begin{array}{l}\text { New Zealand } \\
\text { natural territory }\end{array}$ & 100.00 & 9.00 & 2.00 & -6.22 & 3.56 & 9 & 9 \\
\hline newzealandnaturalterritory 42 & $\begin{array}{l}\text { New Zealand } \\
\text { natural territory }\end{array}$ & 100.00 & 7.63 & 2.20 & -6.00 & 2.00 & 8 & 8 \\
\hline newzealandnaturalterritory 43 & $\begin{array}{c}\text { New Zealand } \\
\text { natural territory }\end{array}$ & 100.00 & 8.50 & 1.18 & -7.10 & 2.08 & 10 & 10 \\
\hline newzealandnaturalterritory 45 & $\begin{array}{c}\text { New Zealand } \\
\text { natural territory }\end{array}$ & 100.00 & 8.88 & 0.99 & -7.75 & 1.98 & 8 & 8 \\
\hline newzealandnaturalterritory 46 & $\begin{array}{l}\text { New Zealand } \\
\text { natural territory }\end{array}$ & 100.00 & 7.67 & 2.18 & -6.56 & 3.00 & 9 & 9 \\
\hline newzealandnaturalterritory47 & $\begin{array}{l}\text { New Zealand } \\
\text { natural territory }\end{array}$ & 100.00 & 7.29 & 1.86 & -6.12 & 3.46 & 17 & 17 \\
\hline newzealandnaturalterritory50 & $\begin{array}{l}\text { New Zealand } \\
\text { natural territory }\end{array}$ & 100.00 & 6.82 & 2.09 & -5.55 & 2.91 & 11 & 11 \\
\hline newzealandnaturalterritory51 & $\begin{array}{c}\text { New Zealand } \\
\text { natural territory }\end{array}$ & 100.00 & 8.50 & 1.65 & -6.70 & 3.09 & 10 & 10 \\
\hline
\end{tabular}




\begin{tabular}{|c|c|c|c|c|c|c|c|c|}
\hline newzealandnaturalterritory 52 & $\begin{array}{l}\text { New Zealand } \\
\text { natural territory }\end{array}$ & 90.00 & 7.33 & 2.50 & -4.67 & 4.61 & 9 & 10 \\
\hline newzealandnaturalterritory 53 & $\begin{array}{l}\text { New Zealand } \\
\text { natural territory }\end{array}$ & 100.00 & 6.17 & 2.69 & -6.17 & 3.24 & 12 & 12 \\
\hline newzealandnaturalterritory 55 & $\begin{array}{l}\text { New Zealand } \\
\text { natural territory }\end{array}$ & 100.00 & 8.27 & 2.15 & -6.00 & 4.07 & 11 & 11 \\
\hline newzealandnaturalterritory 58 & $\begin{array}{l}\text { New Zealand } \\
\text { natural territory }\end{array}$ & 100.00 & 7.27 & 2.53 & -6.91 & 2.59 & 11 & 11 \\
\hline newzealandnaturalterritory59 & $\begin{array}{l}\text { New Zealand } \\
\text { natural territory }\end{array}$ & 88.90 & 8.00 & 1.51 & -7.00 & 2.20 & 8 & 9 \\
\hline newzealandnaturalterritory 60 & $\begin{array}{l}\text { New Zealand } \\
\text { natural territory }\end{array}$ & 100.00 & 7.80 & 1.99 & -6.60 & 2.72 & 10 & 10 \\
\hline newzealandnaturalterritory 62 & $\begin{array}{l}\text { New Zealand } \\
\text { natural territory }\end{array}$ & 100.00 & 8.38 & 1.66 & -7.38 & 2.06 & 13 & 13 \\
\hline newzealandnaturalterritory66 & $\begin{array}{l}\text { New Zealand } \\
\text { natural territory }\end{array}$ & 100.00 & 6.27 & 2.25 & -5.80 & 3.26 & 15 & 15 \\
\hline newzealandnaturalterritory 67 & $\begin{array}{l}\text { New Zealand } \\
\text { natural territory }\end{array}$ & 66.70 & 6.00 & 2.33 & -1.88 & 5.49 & 8 & 12 \\
\hline newzealandnaturalterritory 69 & $\begin{array}{l}\text { New Zealand } \\
\text { natural territory }\end{array}$ & 91.70 & 8.36 & 1.80 & -7.18 & 2.99 & 11 & 12 \\
\hline newzealandnaturalterritory7 & $\begin{array}{c}\text { New Zealand } \\
\text { natural territory }\end{array}$ & 90.90 & 8.70 & 1.42 & -7.40 & 2.95 & 10 & 11 \\
\hline newzealandnaturalterritory 70 & $\begin{array}{l}\text { New Zealand } \\
\text { natural territory }\end{array}$ & 100.00 & 8.00 & 2.00 & -5.73 & 4.80 & 11 & 11 \\
\hline newzealandnaturalterritory71 & $\begin{array}{c}\text { New Zealand } \\
\text { natural territory }\end{array}$ & 100.00 & 8.63 & 1.19 & -8.00 & 1.51 & 8 & 8 \\
\hline newzealandnaturalterritory 72 & $\begin{array}{l}\text { New Zealand } \\
\text { natural territory }\end{array}$ & 100.00 & 9.00 & 1.07 & -3.88 & 3.64 & 8 & 8 \\
\hline newzealandnaturalterritory 73 & $\begin{array}{l}\text { New Zealand } \\
\text { natural territory }\end{array}$ & 91.70 & 5.36 & 2.29 & -3.36 & 2.77 & 11 & 12 \\
\hline
\end{tabular}




\begin{tabular}{|c|c|c|c|c|c|c|c|c|}
\hline newzealandnaturalterritory74 & $\begin{array}{c}\text { New Zealand } \\
\text { natural territory }\end{array}$ & 100.00 & 8.50 & 1.31 & -7.00 & 1.41 & 8 & 8 \\
\hline newzealandnaturalterritory76 & $\begin{array}{c}\text { New Zealand } \\
\text { natural territory }\end{array}$ & 100.00 & 8.44 & 1.67 & -6.00 & 2.35 & 9 & 9 \\
\hline newzealandnaturalterritory 77 & $\begin{array}{l}\text { New Zealand } \\
\text { natural territory }\end{array}$ & 100.00 & 7.78 & 1.09 & -6.33 & 2.74 & 9 & 9 \\
\hline newzealandnaturalterritory 78 & $\begin{array}{l}\text { New Zealand } \\
\text { natural territory }\end{array}$ & 100.00 & 7.50 & 2.20 & -3.75 & 3.19 & 12 & 12 \\
\hline newzealandnaturalterritory81 & $\begin{array}{c}\text { New Zealand } \\
\text { natural territory }\end{array}$ & 100.00 & 9.08 & 1.16 & -7.17 & 4.93 & 12 & 12 \\
\hline newzealandnaturalterritory 82 & $\begin{array}{l}\text { New Zealand } \\
\text { natural territory }\end{array}$ & 100.00 & 7.56 & 1.24 & -5.33 & 2.74 & 9 & 9 \\
\hline newzealandnaturalterritory 83 & $\begin{array}{l}\text { New Zealand } \\
\text { natural territory }\end{array}$ & 100.00 & 6.67 & 2.45 & -5.78 & 3.96 & 9 & 9 \\
\hline newzealandnaturalterritorynew1 & $\begin{array}{l}\text { New Zealand } \\
\text { natural territory }\end{array}$ & 88.90 & 5.25 & 2.49 & -1.75 & 3.41 & 8 & 9 \\
\hline newzealandnaturalterritorynew2 & $\begin{array}{l}\text { New Zealand } \\
\text { natural territory }\end{array}$ & 100.00 & 8.45 & 1.44 & -5.91 & 5.19 & 11 & 11 \\
\hline newzealandnaturalterritorynew3 & $\begin{array}{c}\text { New Zealand } \\
\text { natural territory }\end{array}$ & 100.00 & 9.54 & .66 & -7.62 & 3.36 & 13 & 13 \\
\hline newzealandnaturalterritorynew5 & $\begin{array}{l}\text { New Zealand } \\
\text { natural territory }\end{array}$ & 100.00 & 5.60 & 2.59 & -5.90 & 2.92 & 10 & 10 \\
\hline newzealandnaturalterritorynew6 & $\begin{array}{l}\text { New Zealand } \\
\text { natural territory }\end{array}$ & 91.70 & 7.91 & 2.55 & -6.73 & 2.97 & 11 & 12 \\
\hline newzealandnaturalterritorynew7 & $\begin{array}{l}\text { New Zealand } \\
\text { natural territory }\end{array}$ & 90.90 & 6.60 & 1.84 & -2.60 & 4.90 & 10 & 11 \\
\hline newzealandnaturalterritorynew8 & $\begin{array}{l}\text { New Zealand } \\
\text { natural territory }\end{array}$ & 100.00 & 8.00 & 2.00 & -6.36 & 2.84 & 11 & 11 \\
\hline newzealandnaturalterritorynew9 & $\begin{array}{l}\text { New Zealand } \\
\text { natural territory }\end{array}$ & 100.00 & 8.67 & 1.50 & -6.89 & 2.71 & 9 & 9 \\
\hline assault2 & Social threat & 100.00 & 7.62 & 1.12 & 6.85 & 1.95 & 13 & 13 \\
\hline
\end{tabular}




\begin{tabular}{|c|c|c|c|c|c|c|c|c|}
\hline assault3 & Social threat & 100.00 & 7.23 & 1.83 & 6.23 & 3.06 & 13 & 13 \\
\hline assault4 & Social threat & 100.00 & 7.45 & 2.16 & 6.64 & 2.87 & 11 & 11 \\
\hline assault5 & Social threat & 100.00 & 7.40 & 2.17 & 7.50 & 2.32 & 10 & 10 \\
\hline bomb2 & Social threat & 88.90 & 6.25 & 1.98 & 7.63 & 2.67 & 8 & 9 \\
\hline bullying1 & Social threat & 100.00 & 7.90 & 1.45 & 7.30 & 2.71 & 10 & 10 \\
\hline bullying3 & Social threat & 100.00 & 8.50 & 1.51 & 7.38 & 2.67 & 8 & 8 \\
\hline bullying4 & Social threat & 100.00 & 8.11 & 1.90 & 7.33 & 3.24 & 9 & 9 \\
\hline bullying5 & Social threat & 100.00 & 7.75 & 1.58 & 6.75 & 2.82 & 8 & 8 \\
\hline drugabuse 2 & Social threat & 81.80 & 7.67 & 2.96 & 4.56 & 5.83 & 9 & 11 \\
\hline drugabuse 3 & Social threat & 100.00 & 6.67 & 2.69 & 5.56 & 3.13 & 9 & 9 \\
\hline drugabuse 5 & Social threat & 100.00 & 6.36 & 2.66 & 6.73 & 3.07 & 11 & 11 \\
\hline drugs1 & Social threat & 100.00 & 6.73 & 1.79 & 6.18 & 2.56 & 11 & 11 \\
\hline drugs2 & Social threat & 90.00 & 6.89 & 2.67 & 5.78 & 4.06 & 9 & 10 \\
\hline drugs3 & Social threat & 90.90 & 6.40 & 2.46 & 6.30 & 4.52 & 10 & 11 \\
\hline drugs5 & Social threat & 100.00 & 7.07 & 2.30 & 7.07 & 2.87 & 14 & 14 \\
\hline fear1 & Social threat & 100.00 & 4.38 & 3.36 & 3.08 & 3.50 & 13 & 13 \\
\hline fear 2 & Social threat & 100.00 & 3.11 & 2.26 & 1.22 & 1.92 & 9 & 9 \\
\hline fear3 & Social threat & 100.00 & 4.33 & 2.45 & 3.11 & 3.10 & 9 & 9 \\
\hline fear5 & Social threat & 92.30 & 4.83 & 2.25 & 5.00 & 2.89 & 12 & 13 \\
\hline
\end{tabular}




\begin{tabular}{|c|c|c|c|c|c|c|c|c|}
\hline gang1 & Social threat & 81.80 & 5.67 & 1.41 & 3.33 & 3.08 & 9 & 11 \\
\hline gang2 & Social threat & 100.00 & 7.88 & 1.25 & 8.00 & 1.60 & 8 & 8 \\
\hline gang3 & Social threat & 100.00 & 6.80 & 2.49 & 5.40 & 3.53 & 10 & 10 \\
\hline gang4 & Social threat & 81.80 & 5.67 & 3.04 & 4.33 & 2.50 & 9 & 11 \\
\hline guns1 & Social threat & 90.00 & 4.89 & 2.52 & 5.67 & 3.61 & 9 & 10 \\
\hline gunsnew & Social threat & 90.00 & 6.56 & 1.59 & 6.78 & 2.68 & 9 & 10 \\
\hline intimidation3 & Social threat & 90.00 & 6.11 & 3.30 & 5.00 & 3.04 & 9 & 10 \\
\hline intimidation4 & Social threat & 88.90 & 6.00 & 2.27 & 3.38 & 4.07 & 8 & 9 \\
\hline intimidation5 & Social threat & 90.00 & 6.56 & 2.24 & 5.56 & 2.70 & 9 & 10 \\
\hline intimidationnew & Social threat & 66.70 & 6.38 & 2.62 & 6.00 & 2.56 & 8 & 12 \\
\hline looting4 & Social threat & 80.00 & 7.13 & 1.89 & 6.13 & 3.68 & 8 & 10 \\
\hline looting5 & Social threat & 72.70 & 7.63 & 2.00 & 5.75 & 3.62 & 8 & 11 \\
\hline powerful & Social threat & 57.10 & 6.38 & 2.00 & 3.50 & 3.46 & 8 & 14 \\
\hline powerhungry1 & Social threat & 90.00 & 5.78 & 2.99 & 5.44 & 4.19 & 9 & 10 \\
\hline racism4 & Social threat & 100.00 & 7.45 & 1.69 & 8.00 & 2.41 & 11 & 11 \\
\hline racism6 & Social threat & 91.70 & 7.27 & 2.28 & 5.27 & 3.29 & 11 & 12 \\
\hline rape2 & Social threat & 88.90 & 5.63 & 2.92 & 6.63 & 3.34 & 8 & 9 \\
\hline religionextremism2 & Social threat & 100.00 & 5.38 & 2.22 & 3.38 & 3.18 & 13 & 13 \\
\hline religionextremism3 & Social threat & 100.00 & 6.78 & 2.17 & 5.78 & 2.44 & 9 & 9 \\
\hline
\end{tabular}




\begin{tabular}{|c|c|c|c|c|c|c|c|c|}
\hline religionextremism6 & Social threat & 100.00 & 8.22 & 1.56 & 7.44 & 3.17 & 9 & 9 \\
\hline rudeness 1 & Social threat & 100.00 & 6.10 & 2.08 & 6.40 & 2.80 & 10 & 10 \\
\hline rudeness 2 & Social threat & 100.00 & 4.50 & 2.83 & 3.50 & 2.93 & 8 & 8 \\
\hline rudeness 3 & Social threat & 100.00 & 4.44 & 1.94 & 4.00 & 2.96 & 9 & 9 \\
\hline rudeness 4 & Social threat & 100.00 & 5.27 & 2.69 & 5.00 & 4.05 & 11 & 11 \\
\hline terrorism5 & Social threat & 80.00 & 6.88 & 2.17 & 7.38 & 1.92 & 8 & 10 \\
\hline violence2 & Social threat & 100.00 & 7.25 & 1.04 & 7.50 & 2.93 & 8 & 8 \\
\hline violence4 & Social threat & 90.90 & 7.60 & 1.43 & 7.90 & 1.52 & 10 & 11 \\
\hline violence5 & Social threat & 92.90 & 8.23 & 1.83 & 7.69 & 2.14 & 13 & 14 \\
\hline
\end{tabular}

Note. $M=$ Mean; $S D=$ Standard Deviation. Images included in the experimental stimuli are presented in boldface. 
Appendix F. Examples of Images Selected for Study 3C per Type of Condition Appendix F1. Economic Threat

These images have been removed for copyright reasons.

\section{Appendix F2. Natural Threat}

These images have been removed for copyright reasons.

\section{Appendix F3. Social Threat}

These images have been removed for copyright reasons.

\section{Appendix F4. Control}

These images have been removed for copyright reasons. 
Appendix G. Description of the Control Measures Initially Included in Study 3 Appendix G1. Measures Included in Studies 3A, 3B and 3C

Impact of the scenario. Participants were asked about the extent to which the scenario would impact their life and result in negative consequences. Participants' answers could vary from 1 (not at all) to 5 (extremely).

Positive and negative affect. The positive and negative affect schedule (PANAS) was used to measure affect (Watson et al., 1988). This measure includes two factors that enclose positive (e.g. "proud") and negative (e.g. "guilty") affect. The measure was answered on a 5point scale, varying from 1 (very slightly or not at all) to 5 (extremely). The number of factors, as well as their high internal reliability, has been confirmed by previous research (Crawford \& Henry, 2004).

Values. The short form of the Schwartz Value Survey (SSVS) was used to measure values (Lindeman \& Verkasalo, 2005). This measure maintains the circumplex relationship between values. The SSVS includes 10 items rated on a 9-point scale ranging from 0 (opposed to my principles) to 8 (of supreme importance). An additional environmental item ("UNIVERSALISM - NATURE/ENVIRONMENTAL - beauty of nature, unity with nature, environmental protection”) was included in Studies 3A, 3B and 3C to provide a finer distinction between the social and environmental universalism dimensions.

\section{Appendix G2. Measure Included in Studies 3B and 3C}

Impact of the scenario. Three items measured the level of pleasure, arousal and control that participants felt after reading the scenario (Bradley \& Lang, 1994). Answers were given in a 5-point semantic differential scale with images attached to each of the points. The items varied from Happy/Pleased to Unhappy/Unsatisfied, from Excited/Aroused to Calm/Relaxed, and from Submissive/Controlled to Dominant/In control. 
Appendix H. Study 3A Actual Survey

\title{
Appendix H1. Information Sheet for the Actual Survey
}

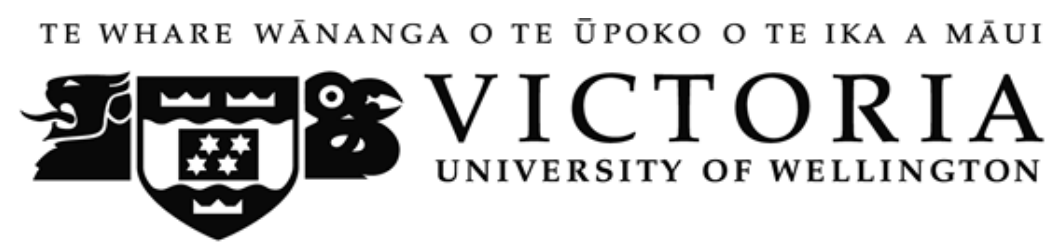

\section{Welcome!}

\section{What is the purpose of this research?}

You will be presented with one brief scenario. We are interested on your view of it and also on how you feel about it. The goal of this research is to understand your perceptions, evaluations and feelings towards this scenario.

\section{Who is conducting the research?}

Clara Cantal is a PhD student in the School of Psychology of Victoria University of Wellington. Dr. Taciano Milfont and Dr. Marc Wilson are responsible for supervising this project and the other projects in the student thesis. This research has been approved by the School of Psychology Human Ethics Committee under delegated authority of the VUW Human Ethics Committee (Approved 29/07/2013; Reference number: RM019658).

\section{What is involved if you agree to participate?}

If you agree to participate in this study you will be asked to complete a short survey. The survey asks you about social, economic and natural threats, and some demographic questions. We anticipate that the survey will take you no more than 30 minutes to complete. During the research you are free to withdraw at any point before your survey has been completed.

\section{Privacy and confidentiality}

This survey is anonymous. Please do not put your name anywhere on the survey. You will never be identified in my research project or in any other presentation or publication. The information you provide will be coded by number only. We will keep your survey for at least five years after publication. In accordance with the requirements of some scientific journals and organizations, your coded survey may be shared with other competent researchers. Your coded data may be used in other, related studies. A copy of the coded data will remain in the custody of Clara Cantal in the Environmental Psychology Lab. Provided ID will only be used to award IPRP credits for taking part in the study and will not be stored.

\section{What happens to the information that you provide?}

The data you provide may be used for the following purposes: The overall findings may be submitted for publication in a scientific journal, or presented at scientific conferences. The findings will be part of a $\mathrm{PhD}$ thesis that will be submitted for assessment. If you would like to know the results of this study, they will be available approximately next year (2014) upon request via email to Ms. Cantal.

\section{Consent for participation}

Please note that by completing and returning the questionnaire to the researchers online you agree that your survey responses will be used and analyzed. If you have any further questions regarding this study, please do not hesitate to contact the investigator listed below.

\author{
Thank you for considering participating in this research! \\ Clara Cantal \\ PhD Student \\ Environmental Psychology Lab. \\ School of Psychology, Faculty of Science \\ Victoria University of Wellington
}


Email: $\underline{\text { Clara.Cantal@ vuw.ac.nz }}$

Do you consent your participation?

$\mathrm{O}$ Yes

$\mathrm{ONo}$

Thank you for taking the time to complete our study! This study has three parts. In the first part you will be presented with a scenario and asked to think about it. The second part asks you several questions related to the scenario. After these sections related to the scenario, you will be presented with the third and final part with socio-demographic questions. Please click 'next' to proceed to the first part.

\section{Appendix H2. Main Questionnaire for the Actual Survey}

\section{Appendix H2.1. Main questionnaire for the threat conditions}

Please imagine the scenario described below as real and happening right now in New Zealand. After reading the scenario, you will be asked to answer five questions related to the scenario.

\section{[Threat scenario]}

Please take two minutes to ENVISION this scenario. After two minutes, the survey will give you the option to progress to the next page.

Now, after imagining yourself in this scenario, please complete the following questions. Please read each question carefully. You will probably find that in some cases your answers to this scenario might be different to what they would be otherwise, while for other questions your answers won't be that different. It's important that you read each question and select your answers carefully, being at all times mindful of the scenario you read before.

1. To what extent did the scenario you just read present social threats?

(Social threats are associated with the way people behave toward others "just because they can", which may lead to the creation of a dangerous and threatening place, causing harm and disruption to others' lives.)

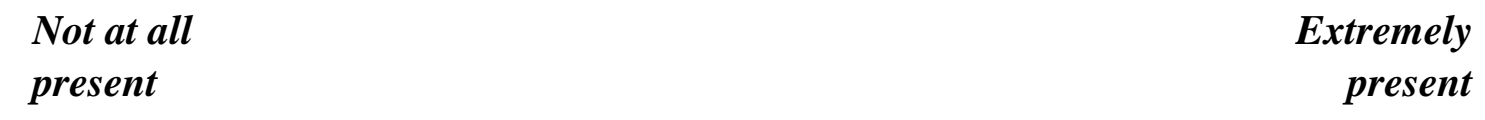

\begin{tabular}{|l|l|l|l|l|l|l|l|l|l|l|}
\hline 0 & 1 & 2 & 3 & 4 & 5 & 6 & 7 & 8 & 9 & 10 \\
\hline
\end{tabular}

2. To what extent did the scenario you just read present economic threats? 
(Economic threats are associated with the competition for power and resources between people and by hierarchical relationships between individuals and social groups.)

$\begin{aligned} & \text { Not at all } \\
& \text { present }\end{aligned}$
\begin{tabular}{|c|c|c|c|c|c|c|c|c|c|c|}
\hline 0 & 1 & 2 & 3 & 4 & 5 & 6 & 7 & 8 & 9 & 10 \\
\hline
\end{tabular}

3. To what extent did the scenario you just read present natural threats?

(Natural threats are associated with natural disasters that could impact your society and affect the way you and others live.)

$\begin{aligned} & \text { Not at all } \\
& \text { present }\end{aligned}$
\begin{tabular}{|c|c|c|c|c|c|c|c|c|c|c|}
\hline 0 & 1 & 2 & 3 & 4 & 5 & 6 & 7 & 8 & 9 & $\begin{array}{r}\text { Extremely } \\
\text { present }\end{array}$ \\
\hline
\end{tabular}

4. Please mark the degree to which you think that the situation presented in the scenario would impact your life and result in negative consequences.

Not at all

\begin{tabular}{|l|l|l|l|l|}
\hline 1 & 2 & 3 & 4 & 5 \\
\hline
\end{tabular}

Thank you for completing the first part of this study. Please click 'next' to move to the second part. In the second part of this study you will be asked to answer the questions thinking about the scenario you just read. After answering these questions, you will be asked for some sociodemographic data in the third part.

Part 2

1. STILL THINKING ABOUT THE SCENARIO... We would like you to give your best guess about the percentage of people in New Zealand that would do each of the following things provided there were no apparent personal gains or losses as a result of their action. That is, the percentage of people in New Zealand that would do these things just because they could. Please note this research is designed to measure people's best guesses about the percentage of New Zealanders that would do each of these things in a hypothetical, consequence-free situation. It does not matter if you have no idea of the actual or official number; we are interested in your best guess or estimation. Please try to give your best guess for every item. 
a. Rob someone.

b. Mug someone.

$\%$

c. Break into someone's house.

d. Commit a violent crime. $\%$

e. Attack someone for no reason at all.

$\%$

f. Attack someone purely out of meanness. $\%$

g. Terrorize other people.

h. Abuse their children.

i. Deal drugs. $\%$

2. STILL THINKING ABOUT THE SCENARIO... We would like you to give your best guess about the percentage of people in New Zealand that would do each of the following things provided there were no apparent personal gains or losses as a result of their action. That is, the percentage of people in New Zealand that would do these things just because they could. Please note this research is designed to measure people's best guesses about the percentage of New Zealanders that would do each of these things in a hypothetical, consequence-free situation. It does not matter if you have no idea of the actual or official number; we are interested in your best guess or estimation. Please try to give your best guess for every item.

a. Charm someone to manipulate them.

$\%$

b. Take advantage of people that play by the rules. $\%$

c. Intimidate someone to get what they want. $\%$

d. Put money, wealth and luxury before other important concerns. $\%$

e. Trick their friends out of an important opportunity. $\%$

f. Intimidate someone with their social position to get what they want. $\%$

g. Be cruel to another person to impress their friends. $\%$

h. Deliberately make a mess someone else had to clean up. $\%$

i. Treat poor people as if they were scum. $\%$

3. STILL THINKING ABOUT THE SCENARIO... Please indicate to what extent you disagree or agree with each of the following statements of opinion by marking the number (ranging from -4 to +4 ) that best reflects your degree of disagreement or agreement given the scenario you just read.

$-4=$ Very strongly disagree

$-3=$ Strongly disagree

$-2=$ Somewhat disagree

$-1=$ Slightly disagree

$0=$ Unsure/neutral

$+1=$ Slightly agree

$+2=$ Somewhat agree

$+3=$ Strongly agree

$+4=$ Very strongly agree

a. Being kind to loafers or criminals will only encourage them to take advantage of your weakness, so it's best to use a firm, tough hand when dealing with them.

$$
\begin{array}{lllllllll}
-4 & -3 & -2 & -1 & 0 & +1 & +2 & +3 & +4
\end{array}
$$


b. Obedience and respect for authority are the most important virtues children should learn.

$$
\begin{array}{lllllllll}
-4 & -3 & -2 & -1 & 0 & +1 & +2 & +3 & +4
\end{array}
$$

c. Our society does NOT need tougher government and stricter laws.

$$
\begin{array}{lllllllll}
-4 & -3 & -2 & -1 & 0 & +1 & +2 & +3 & +4
\end{array}
$$

d. The facts on crime and the recent public disorders show we have to crack down harder on troublemakers, if we are going preserve law and order.

$$
\begin{array}{lllllllll}
-4 & -3 & -2 & -1 & 0 & +1 & +2 & +3 & +4
\end{array}
$$

e. Our country will be great if we show respect for authority and obey our leaders

$$
\begin{array}{lllllllll}
-4 & -3 & -2 & -1 & 0 & +1 & +2 & +3 & +4
\end{array}
$$

f. There is nothing wrong with premarital sexual intercourse.

$$
\begin{array}{lllllllll}
-4 & -3 & -2 & -1 & 0 & +1 & +2 & +3 & +4
\end{array}
$$

g. It's great that many young people today are prepared to defy authority.

$$
\begin{array}{lllllllll}
-4 & -3 & -2 & -1 & 0 & +1 & +2 & +3 & +4
\end{array}
$$

h. Strong, tough government will harm not help our country

$$
\begin{array}{lllllllll}
-4 & -3 & -2 & -1 & 0 & +1 & +2 & +3 & +4
\end{array}
$$

i. There is absolutely nothing wrong with nudist camps.

$$
\begin{array}{lllllllll}
-4 & -3 & -2 & -1 & 0 & +1 & +2 & +3 & +4
\end{array}
$$

j. The way things are going in this country, it's going to take a lot of "strong medicine" to straighten out the troublemakers, criminals, and perverts.

$$
\begin{array}{lllllllll}
-4 & -3 & -2 & -1 & 0 & +1 & +2 & +3 & +4
\end{array}
$$

$\mathrm{k}$. What our country needs most is discipline, with everyone following our leaders in unity

$$
\begin{array}{lllllllll}
-4 & -3 & -2 & -1 & 0 & +1 & +2 & +3 & +4
\end{array}
$$

1. Our prisons are a shocking disgrace. Criminals are unfortunate people who deserve much better care, instead of so much punishment.

$$
\begin{array}{lllllllll}
-4 & -3 & -2 & -1 & 0 & +1 & +2 & +3 & +4
\end{array}
$$

$\mathrm{m}$. This country will flourish if young people stop experimenting with drugs, alcohol, and sex, and pay more attention to family values.

$$
\begin{array}{lllllllll}
-4 & -3 & -2 & -1 & 0 & +1 & +2 & +3 & +4
\end{array}
$$

n. People should be ready to protest against and challenge laws that they don't agree with.

$$
\begin{array}{lllllllll}
-4 & -3 & -2 & -1 & 0 & +1 & +2 & +3 & +4
\end{array}
$$

o. God's laws about abortion, pornography, and marriage must be strictly followed before it is too late.

$$
\begin{array}{lllllllll}
-4 & -3 & -2 & -1 & 0 & +1 & +2 & +3 & +4
\end{array}
$$


p. Nobody should stick to the "straight and narrow". Instead people should break loose and try out lots of different ideas and experiences.

$$
\begin{array}{lllllllll}
-4 & -3 & -2 & -1 & 0 & +1 & +2 & +3 & +4
\end{array}
$$

q. Students at high schools and at university must be encouraged to challenge, criticize, and confront established authorities.

$$
\begin{array}{lllllllll}
-4 & -3 & -2 & -1 & 0 & +1 & +2 & +3 & +4
\end{array}
$$

r. The "old-fashioned ways" and "old-fashioned values" still show the best way to live.

$$
\begin{array}{lllllllll}
-4 & -3 & -2 & -1 & 0 & +1 & +2 & +3 & +4
\end{array}
$$

4. STILL THINKING ABOUT THE SCENARIO... Indicate how much you oppose or favour each idea below by selecting a number from 1 to 7 on the scale below. You can work quickly; your first feeling is generally best. Consider the scenario you read previously.

$1=$ Strongly disagree

$2=$ Somewhat disagree

$3=$ Slightly disagree

$4=$ Neutral

$5=$ Slightly agree

$6=$ Somewhat agree

$7=$ Strongly agree

a. Having some groups on top really benefits everybody.

$$
\begin{array}{lllllll}
1 & 2 & 3 & 4 & 5 & 6 & 7
\end{array}
$$

b. It's probably a good thing that certain groups are at the top and other groups are at the bottom.

$$
\begin{array}{lllllll}
1 & 2 & 3 & 4 & 5 & 6 & 7
\end{array}
$$

c. An ideal society requires some groups to be on top and others to be on the bottom.

$$
\begin{array}{lllllll}
1 & 2 & 3 & 4 & 5 & 6 & 7
\end{array}
$$

d. Some groups of people are simply inferior to other groups.

$$
\begin{array}{lllllll}
1 & 2 & 3 & 4 & 5 & 6 & 7
\end{array}
$$

e. Groups at the bottom are just as deserving as groups at the top.

$$
\begin{array}{lllllll}
1 & 2 & 3 & 4 & 5 & 6 & 7
\end{array}
$$

f. No one group should dominate in society.

$$
\begin{array}{lllllll}
1 & 2 & 3 & 4 & 5 & 6 & 7
\end{array}
$$

g. Groups at the bottom should not have to stay in their place.

$$
\begin{array}{lllllll}
1 & 2 & 3 & 4 & 5 & 6 & 7
\end{array}
$$

h. Group dominance is a poor principle.

$$
\begin{array}{lllllll}
1 & 2 & 3 & 4 & 5 & 6 & 7
\end{array}
$$

i. We should not push for group equality.

$$
\begin{array}{lllllll}
1 & 2 & 3 & 4 & 5 & 6 & 7
\end{array}
$$


j. We shouldn't try to guarantee that every group has the same quality of life.

$$
\begin{array}{llllllll}
1 & 2 & 3 & 4 & 5 & 6 & 7
\end{array}
$$

$\mathrm{k}$. It is unjust to try to make groups equal.

$$
\begin{array}{lllllll}
1 & 2 & 3 & 4 & 5 & 6 & 7
\end{array}
$$

1. Group equality should not be our primary goal.

$$
\begin{array}{lllllll}
1 & 2 & 3 & 4 & 5 & 6 & 7
\end{array}
$$

m. We should work to give all groups an equal chance to succeed.

$$
\begin{array}{lllllll}
1 & 2 & 3 & 4 & 5 & 6 & 7
\end{array}
$$

n. We should do what we can to equalize conditions for different groups.

$$
\begin{array}{lllllll}
1 & 2 & 3 & 4 & 5 & 6 & 7
\end{array}
$$

o. No matter how much effort it takes, we ought to strive to ensure that all groups have the same chance in life.

$$
\begin{array}{lllllll}
1 & 2 & 3 & 4 & 5 & 6 & 7
\end{array}
$$

p. Group equality should be our ideal.

$$
\begin{array}{lllllll}
1 & 2 & 3 & 4 & 5 & 6 & 7
\end{array}
$$

5. STILL THINKING ABOUT THE SCENARIO... Sometimes, people use the terms "leftwing" or "right-wing" to describe their political beliefs. How would you rate yourself in these terms? Select the option that best describes you.
$\square$ 1. Extremely left-wing
5. Slightly right-wing
$\square$ 2. Left-wing
$\square$ 6. Right-wing
3. Slightly left-wing
$\square 7$. Extremely right-wing
$\square$ 4. Moderate

6. STILL THINKING ABOUT THE SCENARIO... Imagine that there is a national election coming in a few days. Given this scenario, which political party would you vote for? 

O ACT
O Green
O Labour
O Mana
O Māori
O National
O NZ First
O United Future

7. STILL THINKING ABOUT THE SCENARIO... Sometimes, people use the terms "liberal" or "conservative" to describe their political beliefs. How would you rate yourself in these terms? Select the option that best describes you.
1. Extremely liberal
5. Slightly conservative
$\square$ 2. Liberal
6. Conservative
3. Slightly liberal
7. Extremely conservative

$\square$ 4. Moderate

\section{Part 3}

1. This scale consists of a number of words that describe different feelings and emotions. Indicate to what extent you feel this way right now, that is, at the present moment, after answering the questions displayed on this study. Use the following scale to record your answers.

\begin{tabular}{|c|c|}
\hline $\begin{array}{l}1=\text { Very slightly } \\
2=\text { A little } \\
3=\text { Moderately } \\
4=\text { Quite } \text { a bit } \\
5=\text { Extremely }\end{array}$ & \\
\hline $\begin{array}{l}\text { interested } \\
\text { distressed } \\
\text { excited } \\
\text { upset } \\
\text { strong } \\
\text { guilty } \\
\text { scared } \\
\text { hostile } \\
\text { enthusiastic } \\
\text { proud }\end{array}$ & $\begin{array}{l}\text { irritable } \\
\text { alert } \\
\text { ashamed } \\
\text { inspired } \\
\text { nervous } \\
\text { determined } \\
\text { attentive } \\
\text { jittery } \\
\text { active } \\
\text { afraid }\end{array}$ \\
\hline
\end{tabular}

2. Please rate the importance of the following values as a life-guiding principle for you. Use the following scale to rate each value: 012345678 . Remember that: 


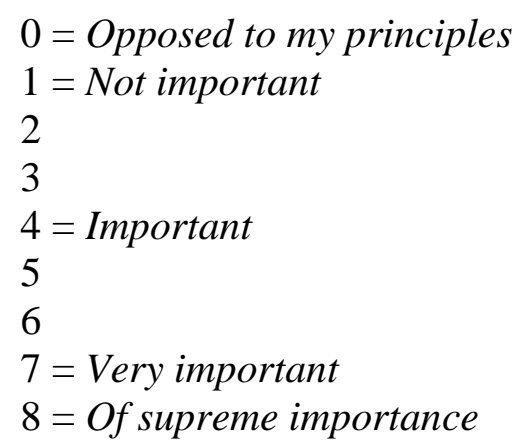

a. POWER (social power, authority, wealth)

$$
\begin{array}{lllllllll}
0 & 1 & 2 & 3 & 4 & 5 & 6 & 7 & 8
\end{array}
$$

b. ACHIEVEMENT (success, capability, ambition, influence on people and events)

$\begin{array}{lllllllll}0 & 1 & 2 & 3 & 4 & 5 & 6 & 7 & 8\end{array}$

c. HEDONISM (gratification of desires, enjoyment in life, self-indulgence)

$\begin{array}{llllllllll}0 & 1 & 2 & 3 & 4 & 5 & 6 & 7 & 8\end{array}$

d. STIMULATION (daring, a varied and challenging life, an exciting life)

$\begin{array}{llllllllll}0 & 1 & 2 & 3 & 4 & 5 & 6 & 7 & 8\end{array}$

e. SELF-DIRECTION (creativity, freedom, curiosity, independence, choosing one's own goals)

$$
\begin{array}{lllllllll}
0 & 1 & 2 & 3 & 4 & 5 & 6 & 7 & 8
\end{array}
$$

f. UNIVERSALISM - SOCIAL (broad-mindedness, beauty of arts, social justice, a world at peace, equality, wisdom)

$$
0 \begin{array}{llllllll}
0 & 1 & 3 & 4 & 5 & 6 & 7 & 8
\end{array}
$$

g. UNIVERSALISM - NATURE/ENVIRONMENTAL (beauty of nature, unity with nature, environmental protection)

$$
\begin{array}{llllllllll}
0 & 1 & 2 & 3 & 4 & 5 & 6 & 7 & 8
\end{array}
$$

h. BENEVOLENCE (helpfulness, honesty, forgiveness, loyalty, responsibility)

$\begin{array}{lllllllll}0 & 1 & 2 & 3 & 4 & 5 & 6 & 7 & 8\end{array}$

i. TRADITION (respect for tradition, humbleness, accepting one's portion in life, devotion, modesty)

$$
\begin{array}{llllllllll}
0 & 1 & 2 & 3 & 4 & 5 & 6 & 7 & 8
\end{array}
$$

j. CONFORMITY (obedience, honoring parents and elders, self-discipline, politeness)

$\begin{array}{lllllllll}0 & 1 & 2 & 3 & 4 & 5 & 6 & 7 & 8\end{array}$

k. SECURITY (national security, family security, social order, cleanliness, reciprocation of favors) 
3. Please, read the following questions and mark the alternative that best describes how you feel about New Zealand and New Zealanders.

a. I often think about the fact that I am a New Zealander.

_ Strongly disagree

_ Moderately disagree

_ Neither agree or disagree

_ Moderately agree

_ Strongly agree

b. The fact that I am a member of New Zealand society is an important part of my identity.

_ Strongly disagree

_ Moderately disagree

_ Neither agree or disagree

_ Moderately agree

_ Strongly agree

c. Being a New Zealander is an important part of how I see myself.

_ Strongly disagree

- Moderately disagree

_ Neither agree or disagree

_ Moderately agree

_ Strongly agree

4. How old are you (in years)?

5. Are you male or female? $\square$ Male $\square$ Female

6. Were you Born in New Zealand? $\square$ Yes $\square$ No

7. Which is your ethnicity?
$\square$ European
$\square$ Asian
$\square$ Maori
$\square$ Other:

$\square$ Pacific Islander

8. Which ( $\square)$ is your highest degree of education?
$\square$ Primary School
$\square$ College or University Degree
$\square$ High school
$\square$ Specialization, MBA, Masters or Doctorate

9. Do you have kids? $\square$ Yes $\square$ No

10. How many?

11. Do you usually vote in New Zealand? $\square$ Yes $\square$ No 
12. Please rate how strongly you oppose or support each of the following political parties.

a. ACT

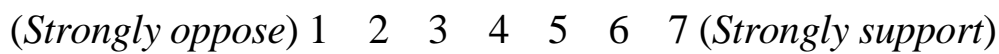

b. Green

(Strongly oppose) $1 \quad 2 \quad \begin{array}{llllll} & 3 & 4 & 5 & 6 & 7 \text { (Strongly support) }\end{array}$

c. Labour

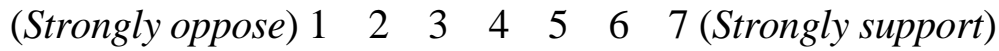

d. Mana

(Strongly oppose) $1 \quad 2 \quad 2 \quad 3 \quad 4 \quad 5 \quad 6 \quad 7$ (Strongly support)

e. Māori

(Strongly oppose) $1 \quad 2 \quad 3 \quad 3 \quad 4 \quad 5 \quad 6 \quad 7$ (Strongly support)

f. National

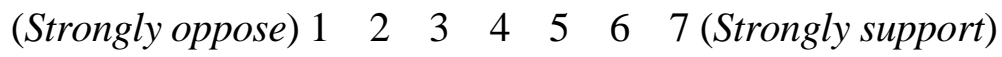

g. NZ First

(Strongly oppose) $1 \quad 2 \quad 2 \quad 3 \quad 4 \quad 5 \quad 5 \quad 6 \quad 7$ (Strongly support)

h. United Future

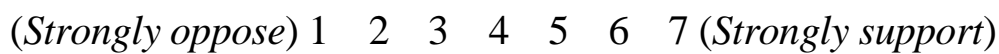

13. Please type your surname and student ID below. (Remember that this information will only be used for awarding of credit, and that it will be removed from the dataset.)

Surname:

Student ID:

\section{Appendix H2.2. Main questionnaire for the control condition}

Please imagine the personal scenario described below as real and happening right now in New Zealand. The personal scenario will be presented along with some real facts about New Zealand. After reading the personal scenario and the facts, you will be asked to answer five questions related to the scenario and the facts.

\section{[Control scenario]}

Please take two minutes to ENVISION this personal scenario and the facts about New Zealand. After two minutes, the survey will give you the option to progress to the next page. Please type the first few words that come to mind when thinking about this scenario. 
Now, after imagining yourself in the personal scenario and reading real facts about New Zealand, please complete the following questions. Please read each item carefully. You will probably find that in some cases your answers to this personal scenario might be different to what they would be otherwise, while for other questions your answers won't be that different. It's important that you read each question and select your answers carefully, being at all times mindful of the scenario you read before.

1. To what extent did the personal scenario and the facts you just read present social threats?

(Social threats are associated with the way people behave toward others "just because they can", which may lead to the creation of a dangerous and threatening place, causing harm and disruption to others' lives.)

Not at all

Extremely

present

present

\begin{tabular}{|l|l|l|l|l|l|l|l|l|l|l|}
\hline 0 & 1 & 2 & 3 & 4 & 5 & 6 & 7 & 8 & 9 & 10 \\
\hline
\end{tabular}

2. To what extent did the personal scenario and the facts you just read present economic threats?

(Economic threats are associated with the competition for power and resources between people and by hierarchical relationships between individuals and social groups.)

Not at all
present
\begin{tabular}{|c|c|c|c|c|c|c|c|c|c|c|}
\hline 0 & 1 & 2 & 3 & 4 & 5 & 6 & 7 & 8 & 9 & 10 \\
\hline
\end{tabular}

3. To what extent did the personal scenario and the facts you just read present natural threats?

(Natural threats are associated with natural disasters that could impact your society and affect the way you and others live.)

Not at all

Extremely

present

present

\begin{tabular}{|l|l|l|l|l|l|l|l|l|l|l|}
\hline 0 & 1 & 2 & 3 & 4 & 5 & 6 & 7 & 8 & 9 & 10 \\
\hline
\end{tabular}


4. Please mark the degree to which you think that the situation presented in the personal scenario and the facts presented in the text would impact your life and result in negative consequences.

Not at all

\begin{tabular}{|l|l|l|l|l|}
\hline 1 & 2 & 3 & 4 & 5 \\
\hline
\end{tabular}

Thank you for completing the first part of this study. Please click 'next' to move to the second part. In the second part of this study you will be asked to answer the questions thinking about the personal scenario and the real facts about New Zealand you just read. After answering these questions, you will be asked for some socio-demographic data in the third part.

\section{Part 2}

1. STILL THINKING ABOUT THE PERSONAL SCENARIO AND THE REAL FACTS ABOUT NEW ZEALAND... We would like you to give your best guess about the percentage of people in New Zealand that would do each of the following things provided there were no apparent personal gains or losses as a result of their action. That is, the percentage of people in New Zealand that would do these things just because they could. Please note this research is designed to measure people's best guesses about the percentage of New Zealanders that would do each of these things in a hypothetical, consequence-free situation. It does not matter if you have no idea of the actual or official number; we are interested in your best guess or estimation. Please try to give your best guess for every item.
a. Rob someone. $\%$
b. Mug someone. $\%$
c. Break into someone's house.
d. Commit a violent crime. $\%$
e. Attack someone for no reason at all.
f. Attack someone purely out of meanness. $\%$
g. Terrorize other people.
h. Abuse their children.
i. Deal drugs. $\%$

\section{STILL THINKING ABOUT THE PERSONAL SCENARIO AND THE REAL FACTS} ABOUT NEW ZEALAND... We would like you to give your best guess about the percentage of people in New Zealand that would do each of the following things provided there were no apparent personal gains or losses as a result of their action. That is, the percentage of people in New Zealand that would do these things just because they could. Please note this research is designed to measure people's best guesses about the percentage of New Zealanders that would do each of these things in a hypothetical, consequence-free situation. It does not matter if you have no idea of the actual or official number; we are interested in your best guess or estimation. Please try to give your best guess for every item.

a. Charm someone to manipulate them. $\%$

b. Take advantage of people that play by the rules. $\%$

c. Intimidate someone to get what they want. $\%$ 
d. Put money, wealth and luxury before other important concerns. $\%$

e. Trick their friends out of an important opportunity. $\%$

f. Intimidate someone with their social position to get what they want. $\%$

g. Be cruel to another person to impress their friends. $\%$

h. Deliberately make a mess someone else had to clean up. $\%$

i. Treat poor people as if they were scum. $\%$

3. STILL THINKING ABOUT THE PERSONAL SCENARIO AND THE REAL FACTS ABOUT NEW ZEALAND... Please indicate to what extent you disagree or agree with each of the following statements of opinion by marking the number (ranging from -4 to +4 ) that best reflects your degree of disagreement or agreement given the scenario and the facts you just read.

$-4=$ Very strongly disagree

$-3=$ Strongly disagree

$-2=$ Somewhat disagree

$-1=$ Slightly disagree

$0=$ Unsure/neutral

$+1=$ Slightly agree

$+2=$ Somewhat agree

$+3=$ Strongly agree

$+4=$ Very strongly agree

a. Being kind to loafers or criminals will only encourage them to take advantage of your weakness, so it's best to use a firm, tough hand when dealing with them.

$$
\begin{array}{lllllllll}
-4 & -3 & -2 & -1 & 0 & +1 & +2 & +3 & +4
\end{array}
$$

b. Obedience and respect for authority are the most important virtues children should learn.

$$
\begin{array}{lllllllll}
-4 & -3 & -2 & -1 & 0 & +1 & +2 & +3 & +4
\end{array}
$$

c. Our society does NOT need tougher government and stricter laws.

$$
\begin{array}{lllllllll}
-4 & -3 & -2 & -1 & 0 & +1 & +2 & +3 & +4
\end{array}
$$

d. The facts on crime and the recent public disorders show we have to crack down harder on troublemakers, if we are going preserve law and order.

$$
\begin{array}{lllllllll}
-4 & -3 & -2 & -1 & 0 & +1 & +2 & +3 & +4
\end{array}
$$

e. Our country will be great if we show respect for authority and obey our leaders

$$
\begin{array}{lllllllll}
-4 & -3 & -2 & -1 & 0 & +1 & +2 & +3 & +4
\end{array}
$$

f. There is nothing wrong with premarital sexual intercourse.

$$
\begin{array}{lllllllll}
-4 & -3 & -2 & -1 & 0 & +1 & +2 & +3 & +4
\end{array}
$$

g. It's great that many young people today are prepared to defy authority.

$$
\begin{array}{lllllllll}
-4 & -3 & -2 & -1 & 0 & +1 & +2 & +3 & +4
\end{array}
$$

h. Strong, tough government will harm not help our country 


$$
\begin{array}{lllllllll}
-4 & -3 & -2 & -1 & 0 & +1 & +2 & +3 & +4
\end{array}
$$

i. There is absolutely nothing wrong with nudist camps.

$$
\begin{array}{lllllllll}
-4 & -3 & -2 & -1 & 0 & +1 & +2 & +3 & +4
\end{array}
$$

j. The way things are going in this country, it's going to take a lot of "strong medicine" to straighten out the troublemakers, criminals, and perverts.

$$
\begin{array}{lllllllll}
-4 & -3 & -2 & -1 & 0 & +1 & +2 & +3 & +4
\end{array}
$$

$\mathrm{k}$. What our country needs most is discipline, with everyone following our leaders in unity

$$
\begin{array}{lllllllll}
-4 & -3 & -2 & -1 & 0 & +1 & +2 & +3 & +4
\end{array}
$$

1. Our prisons are a shocking disgrace. Criminals are unfortunate people who deserve much better care, instead of so much punishment.

$$
\begin{array}{lllllllll}
-4 & -3 & -2 & -1 & 0 & +1 & +2 & +3 & +4
\end{array}
$$

$\mathrm{m}$. This country will flourish if young people stop experimenting with drugs, alcohol, and sex, and pay more attention to family values.

$$
\begin{array}{lllllllll}
-4 & -3 & -2 & -1 & 0 & +1 & +2 & +3 & +4
\end{array}
$$

n. People should be ready to protest against and challenge laws that they don't agree with.

$$
\begin{array}{llllllllll}
-4 & -3 & -2 & -1 & 0 & +1 & +2 & +3 & +4
\end{array}
$$

o. God's laws about abortion, pornography, and marriage must be strictly followed before it is too late.

$$
\begin{array}{lllllllll}
-4 & -3 & -2 & -1 & 0 & +1 & +2 & +3 & +4
\end{array}
$$

p. Nobody should stick to the "straight and narrow". Instead people should break loose and try out lots of different ideas and experiences.

$$
\begin{array}{lllllllll}
-4 & -3 & -2 & -1 & 0 & +1 & +2 & +3 & +4
\end{array}
$$

q. Students at high schools and at university must be encouraged to challenge, criticize, and confront established authorities.

$$
\begin{array}{lllllllll}
-4 & -3 & -2 & -1 & 0 & +1 & +2 & +3 & +4
\end{array}
$$

r. The "old-fashioned ways" and "old-fashioned values" still show the best way to live.

$$
\begin{array}{lllllllll}
-4 & -3 & -2 & -1 & 0 & +1 & +2 & +3 & +4
\end{array}
$$

4. STILL THINKING ABOUT THE PERSONAL SCENARIO AND THE REAL FACTS ABOUT NEW ZEALAND... Indicate how much you oppose or favour each idea below by selecting a number from 1 to 7 on the scale below. You can work quickly; your first feeling is generally best. Consider the scenario and the facts you read previously.

$1=$ Strongly disagree

$2=$ Somewhat disagree

$3=$ Slightly disagree

$4=$ Neutral

$5=$ Slightly agree

$6=$ Somewhat agree 
$7=$ Strongly agree

a. Having some groups on top really benefits everybody.

$$
\begin{array}{lllllll}
1 & 2 & 3 & 4 & 5 & 6 & 7
\end{array}
$$

b. It's probably a good thing that certain groups are at the top and other groups are at the bottom.

$$
\begin{array}{lllllll}
1 & 2 & 3 & 4 & 5 & 6 & 7
\end{array}
$$

c. An ideal society requires some groups to be on top and others to be on the bottom.

$$
\begin{array}{lllllll}
1 & 2 & 3 & 4 & 5 & 6 & 7
\end{array}
$$

d. Some groups of people are simply inferior to other groups.

$$
\begin{array}{lllllll}
1 & 2 & 3 & 4 & 5 & 6 & 7
\end{array}
$$

e. Groups at the bottom are just as deserving as groups at the top.

$$
\begin{array}{lllllll}
1 & 2 & 3 & 4 & 5 & 6 & 7
\end{array}
$$

f. No one group should dominate in society.

$$
\begin{array}{lllllll}
1 & 2 & 3 & 4 & 5 & 6 & 7
\end{array}
$$

g. Groups at the bottom should not have to stay in their place.

$$
\begin{array}{lllllll}
1 & 2 & 3 & 4 & 5 & 6 & 7
\end{array}
$$

h. Group dominance is a poor principle.

$$
\begin{array}{lllllll}
1 & 2 & 3 & 4 & 5 & 6 & 7
\end{array}
$$

i. We should not push for group equality.

$$
\begin{array}{lllllll}
1 & 2 & 3 & 4 & 5 & 6 & 7
\end{array}
$$

j. We shouldn't try to guarantee that every group has the same quality of life.

$$
\begin{array}{lllllll}
1 & 2 & 3 & 4 & 5 & 6 & 7
\end{array}
$$

$\mathrm{k}$. It is unjust to try to make groups equal.

$$
\begin{array}{lllllll}
1 & 2 & 3 & 4 & 5 & 6 & 7
\end{array}
$$

1. Group equality should not be our primary goal.

$$
\begin{array}{lllllll}
1 & 2 & 3 & 4 & 5 & 6 & 7
\end{array}
$$

m. We should work to give all groups an equal chance to succeed.

$$
\begin{array}{lllllll}
1 & 2 & 3 & 4 & 5 & 6 & 7
\end{array}
$$

n. We should do what we can to equalize conditions for different groups.

$$
\begin{array}{lllllll}
1 & 2 & 3 & 4 & 5 & 6 & 7
\end{array}
$$

o. No matter how much effort it takes, we ought to strive to ensure that all groups have the same chance in life.

$$
\begin{array}{lllllll}
1 & 2 & 3 & 4 & 5 & 6 & 7
\end{array}
$$

p. Group equality should be our ideal.

$$
\begin{array}{lllllll}
1 & 2 & 3 & 4 & 5 & 6 & 7
\end{array}
$$


5. STILL THINKING ABOUT THE PERSONAL SCENARIO AND THE REAL FACTS ABOUT NEW ZEALAND... Sometimes, people use the terms "left-wing" or "right-wing" to describe their political beliefs. How would you rate yourself in these terms? Select the option that best describes you.

$\square$ 1. Extremely left-wing $\square$ 5. Slightly right-wing
$\square$ 2. Left-wing
6. Right-wing
3. Slightly left-wing
$\square 7$. Extremely right-wing
$\square$ 4. Moderate

\section{STILL THINKING ABOUT THE PERSONAL SCENARIO AND THE REAL FACTS} ABOUT NEW ZEALAND... Imagine that there is a national election coming in a few days. Given this scenario, which political party would you vote for?
ACT
O Green
Labour
O Mana
O Māori
O National
O NZ First
O United Future

7. STILL THINKING ABOUT THE PERSONAL SCENARIO AND THE REAL FACTS ABOUT NEW ZEALAND... Sometimes, people use the terms "liberal" or "conservative" to describe their political beliefs. How would you rate yourself in these terms? Select the option that best describes you.
$\square$ 1. Extremely liberal
5. Slightly conservative
2. Liberal
6. Conservative
$\square$ 3. Slightly liberal
$\square$ 7. Extremely conservative
$\square$ 4. Moderate

Part 3

1. This scale consists of a number of words that describe different feelings and emotions. Indicate to what extent you feel this way right now, that is, at the present moment, after answering the questions displayed on this study. Use the following scale to record your answers.

$1=$ Very slightly or not at all

$2=$ A little 
$3=$ Moderately

$4=$ Quite $a$ bit

$5=$ Extremely

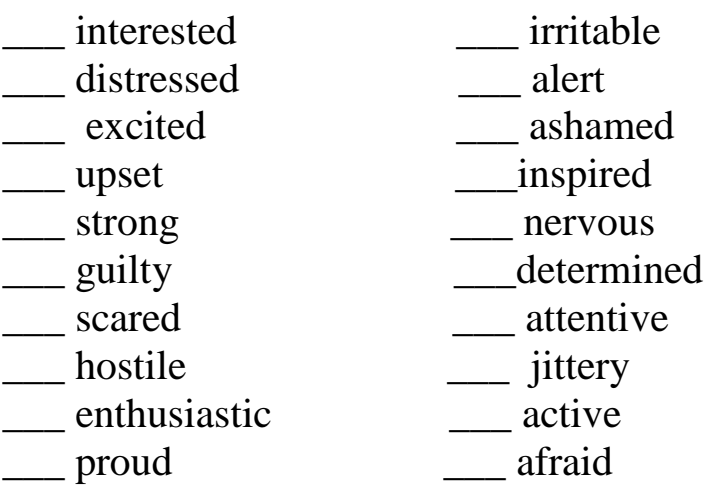

2. Please rate the importance of the following values as a life-guiding principle for you. Use the following scale to rate each value: 012345678 . Remember that:

$0=$ Opposed to my principles

$1=$ Not important

2

3

$4=$ Important

5

6

$7=$ Very important

$8=$ Of supreme importance

a. POWER (social power, authority, wealth)

$\begin{array}{lllllllll}0 & 1 & 2 & 3 & 4 & 5 & 6 & 7 & 8\end{array}$

b. ACHIEVEMENT (success, capability, ambition, influence on people and events)

$\begin{array}{llllllllll}0 & 1 & 2 & 3 & 4 & 5 & 6 & 7 & 8\end{array}$

c. HEDONISM (gratification of desires, enjoyment in life, self-indulgence)

$\begin{array}{llllllllll}0 & 1 & 2 & 3 & 4 & 5 & 6 & 7 & 8\end{array}$

d. STIMULATION (daring, a varied and challenging life, an exciting life)

$\begin{array}{llllllllll}0 & 1 & 2 & 3 & 4 & 5 & 6 & 7 & 8\end{array}$

e. SELF-DIRECTION (creativity, freedom, curiosity, independence, choosing one's own goals)

$\begin{array}{lllllllll}0 & 1 & 2 & 3 & 4 & 5 & 6 & 7 & 8\end{array}$ 
f. UNIVERSALISM - SOCIAL (broad-mindedness, beauty of arts, social justice, a world at peace, equality, wisdom)

$$
\begin{array}{llllllllll}
0 & 1 & 2 & 3 & 4 & 5 & 6 & 7 & 8
\end{array}
$$

g. UNIVERSALISM - NATURE/ENVIRONMENTAL (beauty of nature, unity with nature, environmental protection)

$$
\begin{array}{llllllllll}
0 & 1 & 2 & 3 & 4 & 5 & 6 & 7 & 8
\end{array}
$$

h. BENEVOLENCE (helpfulness, honesty, forgiveness, loyalty, responsibility)

$\begin{array}{lllllllll}0 & 1 & 2 & 3 & 4 & 5 & 6 & 7 & 8\end{array}$

i. TRADITION (respect for tradition, humbleness, accepting one's portion in life, devotion, modesty)

$$
\begin{array}{llllllllll}
0 & 1 & 2 & 3 & 4 & 5 & 6 & 7 & 8
\end{array}
$$

j. CONFORMITY (obedience, honoring parents and elders, self-discipline, politeness)

$$
\begin{array}{lllllllll}
0 & 1 & 2 & 3 & 4 & 5 & 6 & 7 & 8
\end{array}
$$

k. SECURITY (national security, family security, social order, cleanliness, reciprocation of favors)

$\begin{array}{llllllllll}0 & 1 & 2 & 3 & 4 & 5 & 6 & 7 & 8\end{array}$

3. Please, read the following questions and mark the alternative that best describes how you feel about New Zeland and New Zealanders.

a. I often think about the fact that I am a New Zealander.

_ Strongly disagree

_ Moderately disagree

- Neither agree or disagree

_ Moderately agree

_ Strongly agree

b. The fact that I am a member of New Zealand society is an important part of my identity.

_ Strongly disagree

_ Moderately disagree

_ Neither agree or disagree

_ Moderately agree

_ Strongly agree

c. Being a New Zealander is an important part of how I see myself.

_ Strongly disagree

_ Moderately disagree

_ Neither agree or disagree

_ Moderately agree

_ Strongly agree

4. How old are you (in years)? 
5. Are you male or female? $\square$ Male $\square$ Female

6. Were you Born in New Zealand? $\square$ Yes $\square$ No

7. Which is your ethnicity?
$\square$ European
Asian
$\square$ Maori
$\square$ Other:

$\square$ Pacific Islander

8. Which $(\square)$ is your highest degree of education?
$\square$ Primary School
$\square$ College or University Degree
$\square$ High school
$\square$ Specialization, MBA, Masters or Doctorate

9. Do you have kids? $\square$ Yes $\square$ No

10. How many?

11. Do you usually vote in New Zealand? $\square$ Yes $\square$ No

12. Please rate how strongly you oppose or support each of the following political parties.

a. ACT

(Strongly oppose) $1 \quad 2 \quad 2 \quad 3 \quad 4 \quad 5 \quad 6 \quad 7$ (Strongly support)

b. Green

(Strongly oppose) $1 \quad 2 \quad 3 \quad 3 \quad 4 \quad 5 \quad 6 \quad 7$ (Strongly support)

c. Labour

(Strongly oppose) $1 \quad 2 \quad 2 \quad 3 \quad 4 \quad 5 \quad 6 \quad 7$ (Strongly support)

d. Mana

(Strongly oppose) $1 \quad 2 \quad 2 \quad 3 \quad 4 \quad 5 \quad 6 \quad 7$ (Strongly support)

e. Māori

(Strongly oppose) $1 \quad 2 \quad 2 \quad 3 \quad 4 \quad 5 \quad 6 \quad 7$ (Strongly support)

f. National

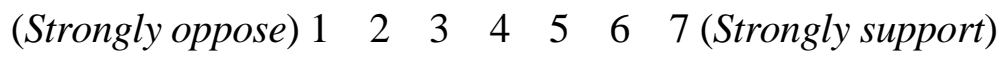

g. NZ First

(Strongly oppose) $1 \quad 2 \quad 2 \quad 3 \quad 4 \quad 5 \quad 6 \quad 7$ (Strongly support)

h. United Future

(Strongly oppose) $1 \quad 2 \quad 2 \quad 3 \quad 4 \quad 5 \quad 6 \quad 7$ (Strongly support)

13. Please type your surname and student ID below. (Remember that this information will only be used for awarding of credit, and that it will be removed from the dataset.) 
Surname:

Student ID:

\section{Appendix H3. Debriefing for the Actual Survey}

The aim of this study is to evaluate if people can differentiate between social, economic and natural threat. These types of threat often appear mixed or are not well delimited in the literature, which makes it difficult to study whether different threats have a different impact on people' behaviors. Different participants in this study read different kinds of scenarios, evaluating their link to social, economic and natural threat, and answering questions about attitudes related to them. The results of the various participants will be evaluated together in order to evaluate if different scenarios are linked to different kinds of threat and attitudes. Results from this study will contribute to the existing literature by providing initial information to test how these differential threats impact people' behaviors.

The research project is being conducted by Clara Cantal, a PhD student, and her supervisors, Dr. Taciano L. Milfont and Dr. Marc Wilson, from the School of Psychology, Victoria University of Wellington. If you have any questions regarding your involvement in this research, or issues regarding the research in general, please do not hesitate to contact me via email at Clara.Cantal@vuw.ac.nz

\section{Thanks again!}

Clara Cantal

Taciano Milfont

Marc Wilson

Thank you for participating in our study! 


\section{Appendix I. Study 3A Correlation Table}

Table I.1

Descriptive statistics and correlations between measures in Study $3 \mathrm{~A}$

\begin{tabular}{|c|c|c|c|c|c|c|c|c|c|c|c|c|}
\hline & 1 & 2 & 3 & 4 & 5 & 6 & 7 & 8 & 9 & 10 & 11 & 12 \\
\hline $\begin{array}{l}\text { 1. Right-wing } \\
\text { authoritarianism (pre-test) }\end{array}$ & - & $.68^{* *}$ & $.44^{* *}$ & $.47^{* *}$ & $.41^{* *}$ & .14 & .05 & $.72^{* *}$ & $.41^{* *}$ & $.54^{* *}$ & $.55^{* *}$ & $.31^{* *}$ \\
\hline $\begin{array}{l}\text { 2. Social dominance } \\
\text { orientation (pre-test) }\end{array}$ & - & - & $.31^{* *}$ & $.28^{* *}$ & $.34^{* *}$ & .02 & .00 & $.40^{* *}$ & $.55^{* *}$ & $.38^{* *}$ & $.38^{* *}$ & $.22 *$ \\
\hline $\begin{array}{l}\text { 3. Left/right orientation } \\
\text { (pre-test) }\end{array}$ & - & - & - & $.64^{* *}$ & $.49^{* *}$ & $.18^{*}$ & $.20^{*}$ & $.46^{* *}$ & $.27^{* *}$ & $.52^{* *}$ & $.46^{* *}$ & $.35^{* *}$ \\
\hline $\begin{array}{l}\text { 4. Liberal/conservative } \\
\text { orientation (pre-test) }\end{array}$ & - & - & - & - & $.30^{* *}$ & .09 & .13 & $.43^{* *}$ & .16 & $.47^{* *}$ & $.56^{* *}$ & .13 \\
\hline $\begin{array}{l}\text { 5. Liberal/conservative } \\
\text { voting intention (pre-test) }\end{array}$ & - & - & - & - & - & .18 & .17 & $.43^{* *}$ & .12 & $.45^{* *}$ & $.32^{* *}$ & $.76^{* * *}$ \\
\hline 6. Competitive worldview & - & - & - & - & - & - & $.67^{* *}$ & $.15^{*}$ & .09 & .09 & .08 & .10 \\
\hline 7. Dangerous worldview & - & - & - & - & - & - & - & .12 & .03 & .06 & .09 & .05 \\
\hline $\begin{array}{l}\text { 8. Right-wing } \\
\text { authoritarianism (post- } \\
\text { test) }\end{array}$ & - & - & - & - & - & - & - & - & $.39^{* *}$ & $.51^{* *}$ & $.45^{* *}$ & $.42^{* *}$ \\
\hline $\begin{array}{l}\text { 9. Social dominance } \\
\text { orientation (post-test) }\end{array}$ & - & - & - & - & - & - & - & - & - & $.30^{* *}$ & $.29^{* *}$ & $.24^{* *}$ \\
\hline $\begin{array}{l}\text { 10. Left/right orientation } \\
\text { (post-test) }\end{array}$ & - & - & - & - & - & - & - & - & - & - & $.60^{* *}$ & $.36^{* *}$ \\
\hline $\begin{array}{l}\text { 11. Liberal/conservative } \\
\text { orientation (post-test) } \\
\text { 12. Liberal/conservative }\end{array}$ & - & - & - & - & - & - & - & - & - & - & - & $.28^{* * *}$ \\
\hline $\begin{array}{l}\text { voting intention (post- } \\
\text { test) }\end{array}$ & - & - & - & - & - & - & - & - & - & - & - & - \\
\hline
\end{tabular}




\begin{tabular}{lcccccccccccc}
$M$ & 2.81 & 2.32 & 3.34 & 3.24 & .42 & 38.68 & 23.92 & -.66 & 2.92 & 3.46 & 3.34 & .35 \\
$S D$ & .80 & .95 & 1.20 & 1.28 & - & 20.15 & 16.83 & 1.02 & .88 & 1.18 & 1.22 & - \\
$\alpha$ & .92 & .74 & - & - & - & .93 & .93 & .86 & .87 & - & - & - \\
Skewness & -.05 & .41 & -.18 & -.02 & .31 & .34 & .77 & -.50 & -.03 & .14 & .21 & .64 \\
Kurtosis & -.67 & -.65 & -.15 & -.50 & -1.94 & -.76 & -.25 & .75 & -.69 & -.02 & -.20 & -1.60 \\
\hline
\end{tabular}

Note. ${ }^{*} p<.05 ; * * p .01$. Point biserial correlation coefficients are provided for analyses including liberal/conservative voting intention. 


\section{Appendix J. Study 3A Correlations between Sentiments toward Political Parties}

Table J.1

Correlations between sentiments toward five of New Zealand's political parties in Study $3 \mathrm{~A}$

\begin{tabular}{|c|c|c|c|c|c|}
\hline & 1 & 2 & 3 & 4 & 5 \\
\hline 1. $\mathrm{ACT}^{\mathrm{a}}$ & - & $-.19^{* *}$ & -.09 & $.25^{* *}$ & $.63^{* *}$ \\
\hline 2. Green & - & - & $.54^{* *}$ & $-.39^{* *}$ & -.11 \\
\hline 3. Labour & - & - & - & $-.41^{* *}$ & -.02 \\
\hline 4. National & - & - & - & - & $.14^{*}$ \\
\hline 5. NZ First & - & - & - & - & - \\
\hline
\end{tabular}

Note. $n=215 . * p<.05 ; * * p<.01{ }^{\mathrm{a}}$ No participant reported intention to vote for the ACT political party in the pre-experimental dataset and only one participant reported intention to vote for this political party in the postexperimental dataset. 


\section{Appendix K. Study 3B Correlation Table}

\section{Table K.1}

Descriptive statistics and correlations between measures in Study $3 B$

\begin{tabular}{|c|c|c|c|c|c|c|c|c|c|c|c|c|c|c|c|}
\hline & 1 & 2 & 3 & 4 & 5 & 6 & 7 & 8 & 9 & 10 & 11 & 12 & 13 & 14 & 15 \\
\hline $\begin{array}{l}\text { 1. Right-wing } \\
\text { authoritarianism (pre- } \\
\text { test) }\end{array}$ & - & $.58^{* *}$ & $.45^{* *}$ & $.44^{* *}$ & $.32^{* *}$ & $.24^{* *}$ & $.22^{*}$ & .16 & .15 & $.68^{* *}$ & $.52^{* *}$ & $.51^{* *}$ & $.61^{* *}$ & $.35^{* *}$ & .18 \\
\hline $\begin{array}{l}\text { 2. Social dominance } \\
\text { orientation (pre-test) }\end{array}$ & - & - & $.39^{* *}$ & $.26^{* *}$ & .17 & $.44^{* * *}$ & .16 & .11 & .11 & $.46^{* *}$ & $.76^{* *}$ & $.48^{* *}$ & $.39^{* *}$ & $.23^{*}$ & $.28^{* *}$ \\
\hline $\begin{array}{l}\text { 3. Left/right orientation } \\
\text { (pre-test) }\end{array}$ & - & - & - & $.70^{* *}$ & $.50^{* *}$ & $.20^{*}$ & .12 & -.01 & .09 & $.49^{* *}$ & $.31^{* *}$ & $.68^{* *}$ & $.62^{* *}$ & $.51^{* *}$ & $.41^{* *}$ \\
\hline $\begin{array}{l}\text { 4. Liberal/conservative } \\
\text { orientation (pre-test) }\end{array}$ & - & - & - & - & $.34^{* *}$ & .08 & .05 & -.01 & .00 & $.51^{* *}$ & $.28^{* *}$ & $.54^{* *}$ & $.71^{* *}$ & $.42^{* *}$ & $.31^{* *}$ \\
\hline $\begin{array}{l}\text { 5. Liberal/conservative } \\
\text { voting intention (pre-test) }\end{array}$ & - & - & - & - & - & .18 & .21 & .10 & .05 & $.30^{* *}$ & .14 & $.49^{* *}$ & $.42^{* *}$ & $.79^{* *}$ & $.37^{* *}$ \\
\hline $\begin{array}{l}\text { 6. Competitive } \\
\text { worldview (Duckitt et al., } \\
\text { 2002) }\end{array}$ & - & - & - & - & - & - & .11 & $.26^{* *}$ & .15 & $.29^{* *}$ & $.40^{* *}$ & $.32^{* *}$ & .16 & .14 & $.26^{* *}$ \\
\hline $\begin{array}{l}\text { 7. Competitive } \\
\text { worldview (Perry \& } \\
\text { Sibley, 2010) }\end{array}$ & - & - & - & - & - & - & - & $.37^{* *}$ & $.78^{* *}$ & .10 & .12 & $.24^{* *}$ & .15 & .10 & .01 \\
\hline $\begin{array}{l}\text { 8. Dangerous worldview } \\
\text { (Duckitt et al., 2002) }\end{array}$ & - & - & - & - & - & - & - & - & $.26^{* *}$ & $.18^{*}$ & .11 & $.19^{*}$ & .03 & .09 & -.02 \\
\hline $\begin{array}{l}\text { 9. Dangerous worldview } \\
\text { (Perry \& Sibley, 2010) }\end{array}$ & - & - & - & - & - & - & - & - & - & .07 & .11 & .14 & .07 & .07 & -.03 \\
\hline
\end{tabular}


10. Right-wing

authoritarianism (post-

test)

11. Social dominance

orientation (post-test)

12. Left/right orientation (post-test)

13. Liberal/conservative orientation (post-test)

14. Liberal/conservative voting intention (posttest)

15. Liberal/conservative

political discourse

preference

\begin{tabular}{|c|c|c|c|c|c|c|c|c|c|c|c|c|c|c|c|}
\hline$M$ & 2.59 & 2.78 & 3.23 & 3.08 & .53 & 2.58 & 36.39 & 3.90 & 22.70 & -1.04 & 2.78 & 3.38 & 3.00 & .41 & .59 \\
\hline$S D$ & .85 & 1.01 & 1.22 & 1.29 & - & .84 & 20.09 & .89 & 16.73 & 1.16 & .99 & 1.04 & 1.01 & - & - \\
\hline$\alpha$ & .94 & .91 & - & - & - & .78 & .94 & .72 & .93 & .89 & .90 & - & - & - & - \\
\hline Skewness & .21 & -.09 & .10 & .52 & -.13 & 1.02 & .41 & -.18 & 1.04 & .08 & .21 & -.02 & .25 & .39 & -.36 \\
\hline Kurtosis & $\begin{array}{c}- \\
1.00\end{array}$ & -1.14 & -.09 & .25 & -2.04 & 2.26 & -.50 & -.17 & .79 & .29 & -.72 & .36 & -.83 & -1.88 & -1.90 \\
\hline
\end{tabular}

Note. ${ }^{*} p<.05 ; * *<.01$. Point biserial correlation coefficients are provided for analyses including liberal/conservative voting intention and political discourse preference. 


\section{Appendix L. Validation of the Political Discourses}

\section{Appendix L1. Brief Description of Method, Results and Conclusion}

The political discourses were based on available information on the political parties' websites and on speeches delivered in the opening parliamentary session after the 2011 general election. After being proof-read by a native English speaker, each of the political discourses included 165 words. The discourses were then presented to participants along with the images and related questions described in Study 2C. Data were collected through the Qualtrics online platform during November and December of 2013. Participants were asked to read the political discourses and select the political party they thought the discourse belonged to. The political parties presented were the eight political parties with seats in New Zealand's Parliament: ACT, Green, Labour, Mana, Māori, National, New Zealand First and United Future. The participants could also select the option "I don't know". The study was approved by the School of Psychology Human Ethics Committee under delegated authority of the Victoria University of Wellington Human Ethics Committee (Reference number: RM019658).

Overall, 77 participants took part in the study. Of those, 40 participants who were New Zealand-born with at least 18 years old and described themselves as European New Zealanders (Pākehā) were considered in the final analyses. In total, 52.5\% of the participants were female, the mean age of the sample was 20.73 years $(S D=3.33)$, and $17.5 \%$ of the participants also described themselves as Asian, Māori and/or Pacific Islander.

Siegel and Castellan's Kappa statistic was used to evaluate the reliability for these multi-rater categorical variables (1988, as cited in Eugenio \& Glass, 2004). This type of Kappa is preferable than Cohen's Kappa because it is less affected by skewed distribution of answers and how much coders disagree (Eugenio \& Glass, 2004). Siegel and Castellan's Kappa can vary from -1 to +1 with values suggesting less-than-chance agreement $(<0)$, slight agreement (.01 to .20), fair agreement (.21 to .40), moderate agreement (.41 to .60), substantial agreement (.61 to .80) and almost perfect agreement (.81 to .99) (Kottner et al., 2011; Viera \& Garrett, 2005). Small Kappas can become statistically significant in large samples given that this statistic is sensitive to the sample size. Besides the Kappa statistic, the percentage of agreement between raters was also calculated and used to evaluate the appropriateness of the political discourses.

Overall, $80.0 \%$ of the participants paired correctly the Green party with its discourse, $77.5 \%$ paired correctly the National party with its discourse, and $35.0 \%$ paired correctly the Labour and the ACT parties with their discourses. Kappas for interrater agreement between 
each pair of political discourses ranged from .04 to .45. Overall, slight-to-moderate agreement was achieved for all pair of discourses being compared, with great agreement observed between Green and National $\left(K_{S C}=.45, p<.001\right)$, and Green and ACT $\left(K_{S C}=.24, p<.001\right)$. The Kappa for the four political discourses was .29 (fair agreement). Given the overall poor level of raters' agreement, the political discourses were evaluated for a second time among experts. It was hypothesized that the student sample used to validate the discourses could be uninformed regarding political parties and their discourses.

Fifteen political science/political psychology academics working at Victoria University of Wellington or University of Auckland were invited to take part in the study during February of 2014. The academics were contacted through their university email addresses. Data was collected through Qualtrics online platform and data analysis procedures were the same reported for the first political discourses validation study. Five academics completed the survey. The four academics that studied political issues, lived in New Zealand for more than one year, and had not gone abroad for more than six months at a time were included in the analyses. Two of the participants were male, and two were born in New Zealand. From those born in New Zealand, all were European New Zealanders. All had lived in New Zealand for more than five years.

Overall, all four experts correctly paired the political discourse designed for the Green party $(100.0 \%)$, three correctly paired the political discourses designed for the National and the Labour parties (75.0\%) and two correctly paired the political discourse designed for the ACT party (50.0\%). The political discourses designed for ACT and National were only paired with one of these two parties. The only participant, who did not correctly pair the Labour party with its discourse, chose the option "I don't know".

Kappas for interrater agreement between each pair of political discourses ranged from -.24 to .58. The Kappa for the four political discourses was .46 (moderate agreement). Moderate agreement was also reached when considered the comparisons between the pairs Green and ACT, Green and National, and Green and Labour. The comparison between Labour and National suggested only fair agreement $\left(K_{S C}=.27, p=.204\right)$, while the comparison between Labour and ACT suggested only slight agreement $\left(K_{S C}=.19, p=.327\right)$. The comparison between National and ACT was negative, indicating less-than-chance agreement $\left(K_{S C}=-.24, p=.474\right)$.

Overall, the results were better for the second validation study than for the first validation study, which seems to confirm that maybe the student sample was uninformed about the political parties and their discourses. The results also showed that the Green party 
discourse was more correctly identified. Given that participants assigned political discourses designed for ACT and National only to one of these two conservative parties and that the lack of agreement might be due to a small sample size, the unchanged discourses remained as a dependent variable in studies $3 \mathrm{~B}$ and $3 \mathrm{C}$. The political discourses are presented in Appendix L2.

\section{Appendix L2. Political Discourses per Political Party They Were Designed for}

ACT party. We believe that: individuals are the rightful owners of their lives and therefore have rights and responsibilities; the proper purpose of government is to protect such rights and not to assume such responsibilities. We take our principles into action by: encouraging individual choice and responsibility and the pursuit of excellence; enhancing living standards for all New Zealanders through sustainable economic growth and international competitiveness; ensuring that all New Zealanders have access to quality health care and have security in retirement; providing for the nation's security and the protection of individual lives and property; exploring and implementing practical and innovative ways to protect the natural environment; maintaining sound economic management, including a balanced government budget, price stability and a free and open market economy; and limiting the involvement of central and local government to those areas where collective action is a practical necessity. Most of all, we believe that education should be improved and that welfare should be remodelled, limiting the continuity of benefits through generations.

Green party. Our main purposes are: seek political change through fostering and developing community-based green action; engage individuals and communities in lively and constructive civic discussion and decision-making; and work constructively with all those who want to contribute to achieving green goals. We believe that: each of us should be aware of the land, water, air, energy and materials we use, using them sustainably, and taking responsibility for doing so; a thriving new economy, rich in creativity and meaningful work, results from business and the community sector embracing their social and environmental responsibilities; the Treaty of Waitangi should be the base for our local and national relationships; power imbalance should be reduced and resources should be shared more equally; and we protect our sovereignty and enhance sustainability by controlling corporate power in the public interest, limiting foreign control of our land and becoming more selfreliant. Most of all, we believe that work is not the only requirement to eradicate poverty, nor is the termination of social benefits. 
Labour party. We act according to the following democratic socialist principles: The natural resources of New Zealand belong to all the people and should benefit all, including future generations; all people should have equal access to all social, economic, cultural, political and legal spheres, regardless of wealth or social position; co-operation, rather than competition, should be the governing factor in economic relations; all people are entitled to dignity, self-respect and the opportunity to work; all people, either individually or in groups, may own wealth or property for their own use, but in any conflict of interest people are always more important than property and the state must ensure a just distribution of wealth; and the Treaty of Waitangi is the founding document of New Zealand and should be honoured by the government. Our guiding principles are: Freedom; equality; opportunity; solidarity; and sustainability. Most of all, we believe that poverty and inequality should be addressed and that New Zealand should grow in a clean, green and innovative way.

National party. We seek a safe, prosperous and successful New Zealand that creates opportunities for all New Zealanders to reach their personal goals and dreams. We believe that this will only be achieved with: Loyalty to our country, its democratic principles and our Sovereign as Head of State; national and personal security; equal citizenship and equal opportunity; individual freedom and choice; personal responsibility; competitive enterprise and rewards for achievement; limited government; strong families and caring communities; and sustainable development of our environment. Our main policies are: selling of around $49 \%$ of New Zealand's public companies assets in order to enable the country's development and the economy to recover; developing schools in order to allow graduates to gain easier access to the market; welfare reform, limiting the continuity of benefits through generations; limiting immigration to the numbers needed in our workforce; decreasing the spending in the public sector, fostering productivity; and not burdening struggling companies with more taxes. Most of all, we believe in working hard and willpower. 
Appendix M. Measures Added to Studies 3B and 3C

\section{Appendix M1. Items Measuring Emotion (Bradley \& Lang, 1994)}

Now, after imagining yourself in this scenario, please complete the following questions. Please read each question carefully.

You will probably find that in some cases your answers to this scenario might be different to what they would be otherwise, while for other questions your answers won't be that different. It's important that you read each question and select your answers carefully, being at all times mindful of the scenario you read before.

How do you feel after the scenario just presented?
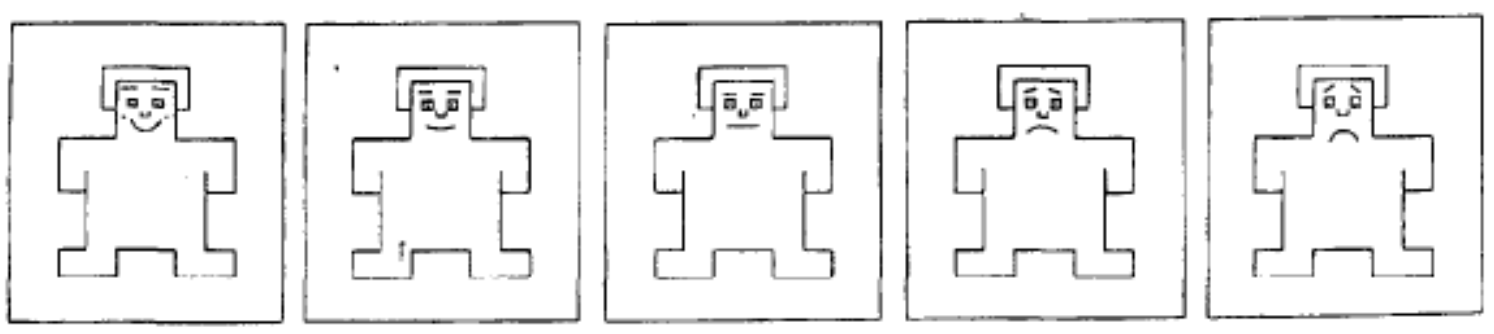

How do you feel after the scenario just presented?

\section{Excited/ Aroused}

Calm/ Relaxed
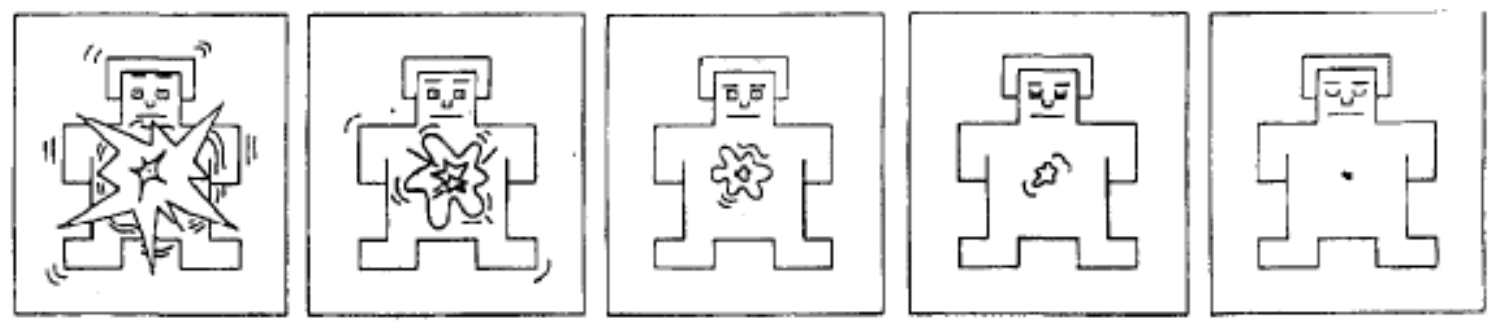

How do you feel after the scenario just presented?

Submissive/ Controlled
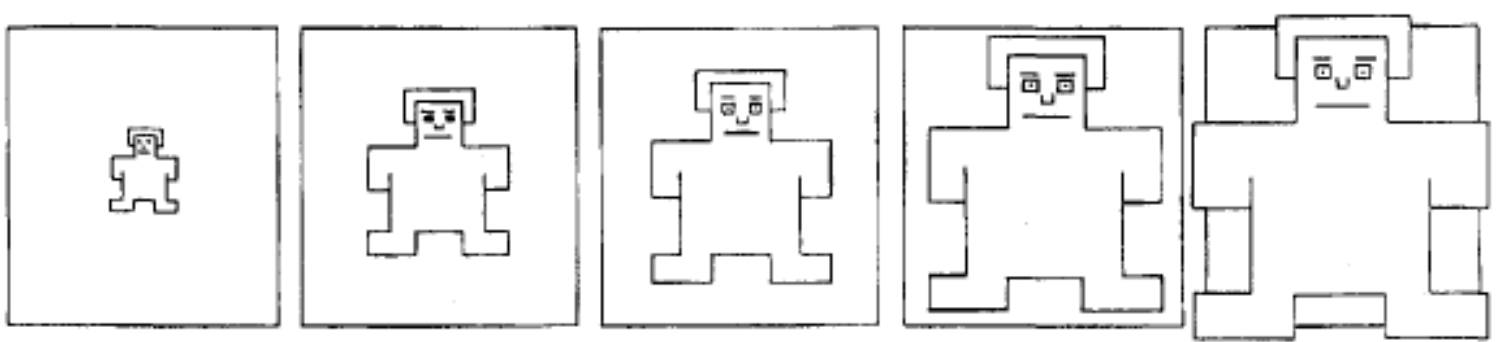

Appendix M2. Competitive and Dangerous World Beliefs Scale Based on Work of

Duckitt et al. (2002) and Sibley et al. (2007) 


\section{STILL THINKING ABOUT THE SCENARIO (STILL THINKING ABOUT THE} PERSONAL SCENARIO AND THE TEXT ABOUT NEW ZEALAND)...

Please indicate the extent to which you agree or disagree with each of the following statements using the 7-point scale below.

$1=$ Strongly disagree

$2=$ Somewhat disagree

$3=$ Slightly disagree

$4=$ Neutral

$5=$ Slightly agree

$6=$ Somewhat agree

$7=$ Strongly agree

a. There are many dangerous people in our society who will attack someone out of pure meanness, for no reason at all.

$$
\begin{array}{lllllll}
1 & 2 & 3 & 4 & 5 & 6 & 7
\end{array}
$$

b. Despite what one hears about "crime in the street," there probably isn't any more now than there ever has been.

$$
\begin{array}{lllllll}
1 & 2 & 3 & 4 & 5 & 6 & 7
\end{array}
$$

c. If a person takes a few sensible precautions, nothing bad is likely to happen to him or her; we do not live in a dangerous world.

$$
\begin{array}{lllllll}
1 & 2 & 3 & 4 & 5 & 6 & 7
\end{array}
$$

d. Every day as society become more lawless and bestial, a person's chances of being robbed, assaulted, and even murdered go up and up.

$$
\begin{array}{lllllll}
1 & 2 & 3 & 4 & 5 & 6 & 7
\end{array}
$$

e. My knowledge and experience tells me that the social world we live in is basically a safe, stable and secure place in which most people are fundamentally good.

$$
\begin{array}{lllllll}
1 & 2 & 3 & 4 & 5 & 6 & 7
\end{array}
$$

f. It seems that every year there are fewer and fewer truly respectable people, and more and more persons with no morals at all who threaten everyone else.

$$
\begin{array}{lllllll}
1 & 2 & 3 & 4 & 5 & 6 & 7
\end{array}
$$

g. The "end" is not near. People who think that earthquakes, wars, and famines mean God might be about to destroy the world are being foolish.

$$
\begin{array}{lllllll}
1 & 2 & 3 & 4 & 5 & 6 & 7
\end{array}
$$

h. My knowledge and experience tells me that the social world we live in is basically a dangerous and unpredictable place, in which good, decent and moral people's values and way of life are threatened and disrupted by bad people. 
i. Winning is not the first thing; it's the only thing.

$$
\begin{array}{lllllll}
1 & 2 & 3 & 4 & 5 & 6 & 7
\end{array}
$$

$\mathrm{j}$. The best way to lead a group under one's supervision is to show them kindness, consideration, and treat them as fellow workers, not as inferiors.

$$
\begin{array}{lllllll}
1 & 2 & 3 & 4 & 5 & 6 & 7
\end{array}
$$

k. If it's necessary to be cold blooded and vengeful to reach one's goals, then one should do it.

$$
\begin{array}{lllllll}
1 & 2 & 3 & 4 & 5 & 6 & 7
\end{array}
$$

1. Life is not governed by the "survival of the fittest." We should let compassion and moral laws be our guide.

$$
\begin{array}{lllllll}
1 & 2 & 3 & 4 & 5 & 6 & 7
\end{array}
$$

m. It is much more important in life to have integrity in your dealings with others than to have money and power.

$$
\begin{array}{lllllll}
1 & 2 & 3 & 4 & 5 & 6 & 7
\end{array}
$$

n. It's a dog-eat-dog world where you have to be ruthless at times.

$$
\begin{array}{lllllll}
1 & 2 & 3 & 4 & 5 & 6 & 7
\end{array}
$$

o. Charity (i.e., giving somebody something for nothing) is admirable not stupid.

$$
\begin{array}{lllllll}
1 & 2 & 3 & 4 & 5 & 6 & 7
\end{array}
$$

p. You know that most people are out to "screw" you, so you have to get them first when you get the chance.

$$
\begin{array}{lllllll}
1 & 2 & 3 & 4 & 5 & 6 & 7
\end{array}
$$




\section{Appendix N. Study 3B Correlations between Sentiments toward Political Parties}

\section{Table N.1}

Correlations between sentiments toward five of New Zealand's political parties in Study $3 B$

\begin{tabular}{lccccc}
\hline & 1 & 2 & 3 & 4 & 5 \\
\hline 1. $\mathrm{ACT}^{\mathrm{a}}$ & - & -.05 & -.05 & $.31^{* *}$ & $.63^{* *}$ \\
2. Green & - & - & $.37^{* *}$ & $-.31^{* *}$ & -.10 \\
3. Labour & - & - & - & $-.37^{* *}$ & -.03 \\
4. National & - & - & - & - & .15 \\
5. NZ First & - & - & - & - & - \\
\hline
\end{tabular}

Note. $n=136 . * * p<.01$. ${ }^{\text {a }}$ No participant reported intention to vote for the ACT political party in the pre-experimental dataset and only one participant reported intention to vote for this political party in the post-experimental dataset. 


\section{Appendix O. Study 3C Correlation Table}

\section{Table O.1}

Descriptive statistics and correlations between measures in Study $3 C$

\begin{tabular}{|c|c|c|c|c|c|c|c|c|c|c|c|c|c|c|c|}
\hline & 1 & 2 & 3 & 4 & 5 & 6 & 7 & 8 & 9 & 10 & 11 & 12 & 13 & 14 & 15 \\
\hline $\begin{array}{l}\text { 1. Right-wing } \\
\text { authoritarianism (pre- } \\
\text { test) }\end{array}$ & - & $.58^{* *}$ & $.36^{* *}$ & $.36^{* *}$ & $.38^{* * *}$ & $.29^{* *}$ & .05 & .15 & .09 & $.69^{* * *}$ & $.30^{* *}$ & $.45^{* *}$ & $.37^{* *}$ & $.35^{* *}$ & .16 \\
\hline $\begin{array}{l}\text { 2. Social dominance } \\
\text { orientation (pre-test) }\end{array}$ & - & - & .19 & $.33^{* *}$ & $.39^{* *}$ & $.42^{* *}$ & .01 & .18 & .02 & $.42^{* * *}$ & $.76^{* *}$ & $.31^{* *}$ & $.33^{* *}$ & $.40^{* *}$ & $.22^{*}$ \\
\hline $\begin{array}{l}\text { 3. Left/right orientation } \\
\text { (pre-test) }\end{array}$ & - & - & - & $.64^{* *}$ & $.54^{* *}$ & $.28^{* *}$ & .00 & .12 & .05 & $.40^{* * *}$ & $.23^{*}$ & $.68^{* *}$ & $.62^{* *}$ & $.39^{* *}$ & .09 \\
\hline $\begin{array}{l}\text { 4. Liberal/conservative } \\
\text { orientation (pre-test) }\end{array}$ & - & - & - & - & $.47^{* *}$ & $.28^{* *}$ & .06 & .19 & .14 & $.41^{* *}$ & $.20^{*}$ & $.57^{* *}$ & $.67^{* *}$ & $.43^{* *}$ & .06 \\
\hline $\begin{array}{l}\text { 5. Liberal/conservative } \\
\text { voting intention (pre- } \\
\text { test) }\end{array}$ & - & - & - & - & - & $.35^{* *}$ & .04 & .11 & .17 & $.45^{* * *}$ & $.47^{* *}$ & $.51^{* *}$ & $.65^{* *}$ & $.91^{* *}$ & $.32^{* * *}$ \\
\hline $\begin{array}{l}\text { 6. Competitive } \\
\text { worldview (Duckitt et } \\
\text { al., 2002) }\end{array}$ & - & - & - & - & - & - & .14 & $.23^{*}$ & .05 & .17 & $.44^{* *}$ & $.24^{* *}$ & $.32^{* *}$ & $.21^{*}$ & .13 \\
\hline $\begin{array}{l}\text { 7. Competitive } \\
\text { worldview (Perry \& } \\
\text { Sibley, 2010) }\end{array}$ & - & - & - & - & - & - & - & $.32^{* *}$ & $.57^{* *}$ & .00 & .00 & .00 & -.01 & .04 & .06 \\
\hline $\begin{array}{l}\text { 8. Dangerous worldview } \\
\text { (Duckitt et al., 2002) }\end{array}$ & - & - & - & - & - & - & - & - & $.28^{* *}$ & $.21^{*}$ & .12 & .16 & $.20^{*}$ & .09 & .07 \\
\hline $\begin{array}{l}\text { 9. Dangerous worldview } \\
\text { (Perry \& Sibley, 2010) }\end{array}$ & - & - & - & - & - & - & - & - & - & .12 & .02 & -.02 & .03 & .18 & -.07 \\
\hline
\end{tabular}


10. Right-wing

authoritarianism (post-
test)

11. Social dominance

orientation (post-test)

12. Left/right orientation (post-test)

13. Liberal/conservative orientation (post-test)

14. Liberal/conservative voting intention (post-

test)

15. Liberal/conservative

political discourse

preference

M

$S D$

$\alpha$

Skewness

Kurtosis

$\begin{array}{cccccccccccccccc}2.70 & 3.01 & 3.32 & 2.96 & .52 & 2.49 & 37.27 & 4.06 & 18.88 & -.96 & 2.97 & 3.37 & 3.13 & .46 & .54 \\ .81 & .97 & 1.35 & 1.31 & - & .74 & 17.99 & .90 & 13.1 & 1.11 & .93 & 1.01 & 1.14 & - \\ .93 & .91 & - & - & - & .73 & .92 & .73 & .92 & .89 & .90 & - & - \\ .21 & -.19 & .10 & .08 & -.09 & .70 & .14 & .05 & 1.11 & -.33 & .19 & -.63 & .03 & .16 & -.16 \\ -.67 & -.69 & .38 & -.34 & -2.06 & .87 & -.63 & -.39 & .88 & -.30 & .20 & -.65 & -.88 & -2.01 & -2.01\end{array}$

Note. $* p<.05 ; * *<.01$. Point biserial correlation coefficients are provided for analyses including liberal/conservative voting intention and political discourse preference. 


\section{Appendix P. Study 3C Correlations between Sentiments toward Political Parties}

Table P.1

Correlations between sentiments toward five of New Zealand's political parties in Study 3 C

\begin{tabular}{lccccc}
\hline & 1 & 2 & 3 & 4 & 5 \\
\hline 1. ACT & - & $-.21^{*}$ & -.02 & $.25^{* *}$ & $.48^{* *}$ \\
2. Green & - & - & $.35^{* *}$ & $-.52^{* *}$ & .13 \\
3. Labour & - & - & - & $-.37^{* *}$ & -.01 \\
4. National & - & - & - & - & -.11 \\
5. NZ First & - & - & - & - & -
\end{tabular}

Note. $n=112 . * p<.05 ; * * p<.01$. ${ }^{\text {a }}$ No participant reported intention to vote for the ACT political party in the pre-experimental dataset and only one participant reported intention to vote for this political party in the postexperimental dataset. 